\title{
XENOBIOTIC MONOOXYGENASE ACTIVITY AND THE RESPONSE \\ TO INDUCERS OF CYTOCHROME P-450 DURING \\ EMBRYONIC AND LARVAL DEVELOPMENT IN FISH
}

by

ROBERT L. BINDER

A.B. University of Pennsylvania 1972

Submitted to the Massachusetts Institute of Technology/

Woods Hole Oceanographic Institution

Joint Program in Biological Oceanography

August, 1981

in partial fulfillment of the requirements for the degree of Doctor of Philosophy

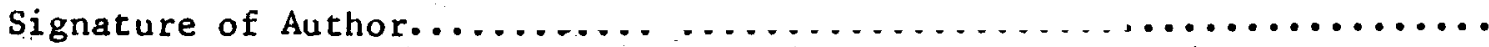

Massachusetts Institute of Technology/ Woods Hole

Qfeanographic Institution, August 1981

Certified by $\ldots \ldots \ldots \ldots \ldots \ldots \ldots, \ldots \ldots \ldots \ldots \ldots \ldots \ldots \ldots \ldots \ldots \ldots \ldots \ldots \ldots \ldots \ldots$

Thesis Suptedvisor

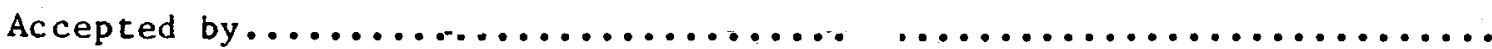

Chairman, Joint Program in Biological Oceanography, Massachusetts Institute of Technology/Woods Hole Oceanographic Institution 
This thesis is dedicated to Dorothy 
Page 3 .

\author{
XENOBIOTIC MONOOXYGENASE ACTIVITY AND THE \\ RESPONSE TO INDUCERS OF CYTOCHROME P-450 DURING \\ EMB RYONIC AND LARVAL DEVELOPMENT IN FISH \\ by \\ ROBERT L BINDER
}

\begin{abstract}
Submitted to the Massachusetts Institute of Technonogy/
Woods Hole Oceanographic Institution Joint Program in

Biological Oceanography in August, 1981, in partial fulfillment of the requirements for the degree of Doctor of Philosophy.
\end{abstract}

\title{
AB STRACT
}

Data demonstrating the presence and inducibility of the xenobiotic monooxygenase system in $\mathrm{f}$ ish embryos and larvae are described. The ontogeny of benzo(a)pyrene monooxygenase (BPM) activity, and NADPH- and $\mathrm{NADH}-\mathrm{cytoch}$ rome $\mathrm{c}$ reductase activities, were followed in microsomes prepared from whole embryos of the estuarine killifish Fundulus heteroclitus. BPM activity was detectable as early as 4 days from fertilization, prior to the appearance of the liver rudiment, which indicates a substantial role for the extrahepatic tissues in xenobiotic metabolism in Fundulus embryos. At all stages assayed before hatching, BPM activity was uniformly low, but within 24 hours of hatching there was a 10-fold increase in specific activity. This increase was shown not to be age-dependent but required hatching, and was not an artifact of the presence of endogenous inhibitors in embryos.

Both $\mathrm{NADPH}-$ and $\mathrm{NADH}-\mathrm{cytoch}$ rome $\mathrm{c}$ reductase activities were measurable at all stages assayed. The developmental patterns of these two reductases were distinct from each other and did not closely correlate with that of BPM activity. However, the functional involvement of the NADPH-cytochrome $c$ reductase in monooxygenase activity was indicated by the inhibition of BPM activity by cytochrome $c$. The metabolism of benzo(a)pyrene by fractions prepared from whole Fundulus embryos and eleutheroembryos appears to be catalyzed by a typical cytochrome $\mathrm{P}-450$ dependent monooxygenase. This activity is localized in the microsomal fraction, requires $0_{2}, \mathrm{NADPH}$ and native enzyme, and is inhibited by $C O$. NADPH supports much higher activity than NADH.

BPM activity was detectable in the livers of Fundulus eleutheroembryos, larvae and juveniles. The level of activity in Fundulus eleutheroembryo livers was about $1 / 4$ the average adult activity. Specific activity rose continuously from the end of the embryonic period into the juvenile period when adult levels were approached.

BPM activity was also measurable in the livers of brook trout (Salvelinus fontinalis) embryos and eleutheroembryos. The ontogenic pattern contrasted with that seen in Fundulus. At 6 and 1 days before hatching $B P M$ specific activity in embryonic liver was close to the adult 
level. After hatching there was a 3 -fold increase in activity, thus the livers of eleutheroembryos were considerably more active in metabolizing BP than those of adult brook trout.

BPM activity was inducible in Fundulus embryos by both Aroclor 1254 and No. 2 Fuel oil. Embryos were competent to respond to induction as early as 4 days from fertilization. In Fundulus eleutheroembryos, Aroclor 1254 induced BPM activity in both the liver and extrahepatic tissues. Aminopyrine $\mathrm{N}$-demethylase activity was detectable in microsomes prepared from whole eleutheroembryos, but was not induced by Aroclor 1254. Neither NADPH- nor $\mathrm{NADH}-\mathrm{cytoch}$ rome c reductase activities were induced by Aroclor 1254 before hatching, but after hatching both activities were induced.

A striking developmental change in the sensitivty of the induction response was observed in Fundulus. The tissue levels of PCBs necessary to produce a maximal induction of BPM activity were at least 5 times lower in post-hatching stages compared to prehatching stages. The relative insensitivity of the induction response prior to hatching may serve to protect embryos from damage from activated metabolites during organogenesis.

Aroclor 1254 was also shown to induce BPM activity in brook trout embryonic liver. The data obtained with both Fundulus and brook trout indicate that levels of PCBs occurring in $\mathrm{fish}$ in contaminated environments are likely to induce the monooxygenase system during embryonic deve lopment.

Metabolites of benzo(a)pyrene produced by microsomes prepared from adult Fundulus liver, and untreated and $P C B$ exposed eleutheroembryos were analyzed by HPLC. Similar metabolite profiles were obtained in all cases, with a high proportion of benzo-ring dihydrodiols. The dihydrodiol peaks produced by eleutheroembryo microsomes were abolished by TCPO, indicating the presence of epoxide hydrolase. These results suggest that Fundulus embryos and eleutheroembryos can activate BP to the highly mutagenic trans $-7,8$-dihydrodiol-9,10-epoxides. Fish embryonic monooxygenase activity may play a role in pollutant-induced lesions, including teratogenic effects, by producing reactive and mutagenic metabolites during organodifferentiation.

Thesis advisor: John J. Stegeman

Position: Associate Scientist 
First and foremost I must acknowledge my wife Dorothy, without whose love, support and patience I probably would never have completed this work. I could not ask for a better friend or wife. Towards the end, she was a great help in proofreading and tracking down references in the library. Next I owe great thanks to John Stegeman, my thesis advisor and friend. John supported my efforts in every way possible, more than I even could have reasonably expected, and was always available when needed. I hope we can collaborate fruitfully in the future.

Heidi Kaplan was a true friend who never hesitated to help. Nick Staresinic deserves special thanks for providing me with a place to live during my last days in the program, as well as friendship, help, and much good advice, which I generally did not follow. I thank Dan Repeta for his generous hospitality. Bruce Woodin was a good friend and all around pleasant person to work with, although he tells bad jokes. I thank Bruce for performing HPLC analysis on metabolites.

I want to thank Dale Goehringer for her excellent secretarial assistance, amazing energy and enthusiasm. Lloyd Raymond of the Sandwich Fish Hatchery kindly provided the trout used, as well as good natured assistance. Dr. Cuhel made late nights more pleasant with company and rock ' $n$ roll. I also wish to thank Richard Woelke for histology and EM, John Farrington for encouragement and interest; $A \perp$ Davis for PCB analysis, Jane Peterson for encouragement and secretarial help and Peggy Dimmock for secretarial help. Bill Thilly and John Teal deserve credit for their interest and help. I sincerely thank all of the members of the Joint Committee for Biological Oceanography for continued tuition support. Lastly I must thank my parents for their continuous help and support, and for prodding me when I needed it.

This work was supported by National Science Foundation grants OCE7724517 and OCE80-18569. 


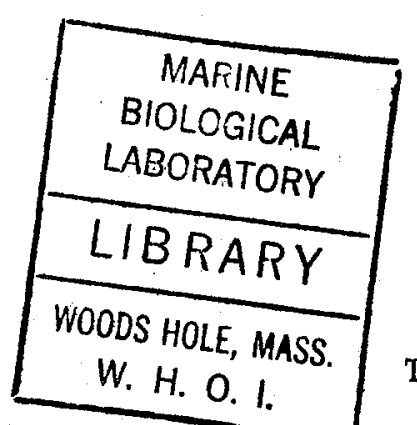

Page No.
Page 6.

TABLE OF CONTENTS

DE DICATION

AB STRACT

ACK NOWLEDGEME NTS

TABLE OF CONTENTS $\ldots \ldots \ldots \ldots \ldots \ldots \ldots \ldots \ldots \ldots \ldots \ldots \ldots \ldots \ldots \ldots \ldots \ldots \ldots \ldots . \ldots \ldots$

LIST OF FIGURES

LIST OF TABLES.

ABBREVIATIONS USED.

CHAPTER 1. Introductory material..................... 15 .

MAMMALIAN CYTOCHROME P-450 DEPENDENT MONOOXYGENASES ............ 18 . Induction of microsomal monooxygenases $\ldots \ldots \ldots \ldots \ldots \ldots \ldots \ldots \ldots \ldots . \ldots \ldots$. Induction of the monooxygenase system by polychlorinated biphenyls:........................ 29 .

THE CYTOCHROME P-450 DEPENDENT MONOOXYGENASE SYSTEM IN FISH...... 31 . Responses of fish to inducers of cytoch rome $P-450 . \ldots \ldots \ldots \ldots \ldots . . . . . . . .$. Induction in the environment ......................... 40. Evidence for multiple forms of cytochrome $P-450$ in fish ....... 42 .

DEVELOPMENTAL CHANGES IN THE CYTOCHROME P-450

MONOOXYGENASE SYSTEM............................ 44 .

Regulation of the perinatal development of the

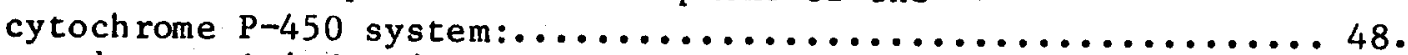

Transplacental induction of monooxygenase activity ........... 51 .

B IOACTIVAT ION BY THE CYTOCHROME P-450 SYSTEM............... 58 .

THE RESEARCH PROBLEM AND EXPERIMENTAL APPROACH..............63.

AN IMPORTANT NOTE ON NOMENCLATURE.................... 67 .

CHAPTER 2. Induction of benzo(a)pyrene monooxygenase activity in embryos and eleutheroembryos of the estuarine killifish,

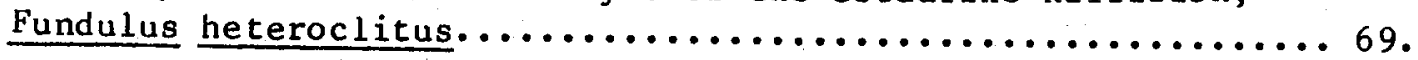

MATERIALS AND METHODS............................. 69 .

RESULTS AND DISCUSSION........................... 71 . 
CHAPTER 3. The xenobiotic monooxygenase system in early developmental stages of Fundulus heteroclitus.........77.

MATERIALS AND METHODS

Chemicals:.................................... 78.

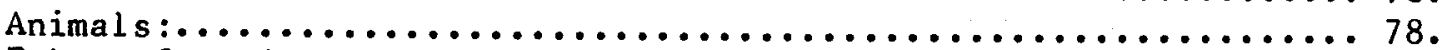

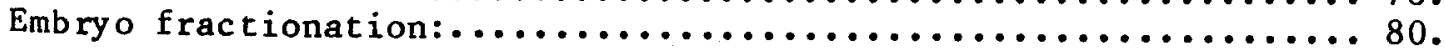

Livers from eleutheroembryos, larvae, and juveniles:......... 81 .

Livers from adults:............................... 82 .

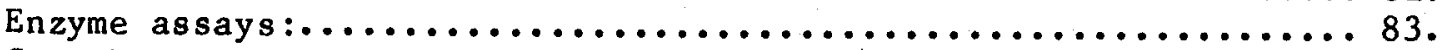

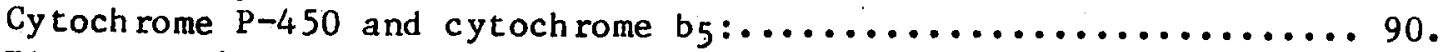

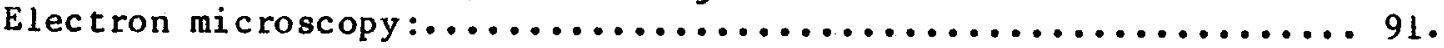

RESULTS........................................ 92.

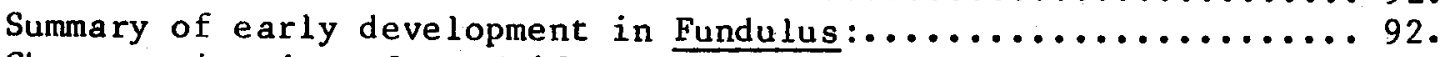

Characterization of centrifugal fractions of whole

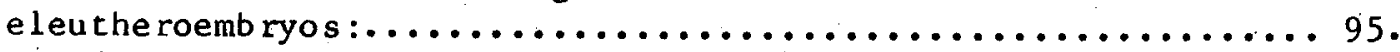

Detection of BPM activity in untreated embryos before

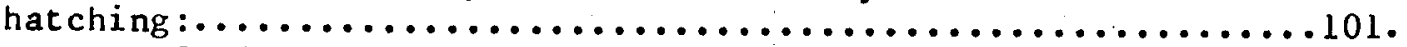

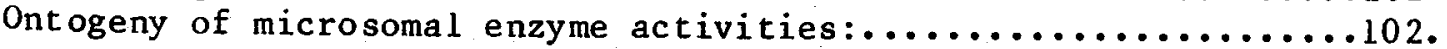

Test for the presence of endogenous inhibitors before

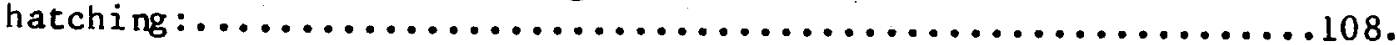

Time-dependent changes in BPM and NADPHcytoch rome $c$ reductase activities after hatching:...........110.

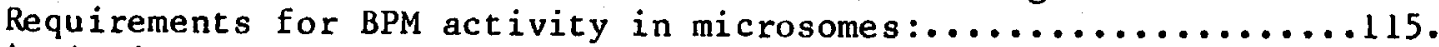

Analysis of eleutheroembryo fractions by difference

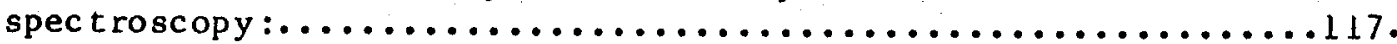

Compilation of data on the monooxygenase system in microsomes prepared from whole eleutheroembryos $\ldots \ldots \ldots \ldots \ldots \ldots \ldots \ldots \ldots \ldots . \ldots \ldots$.

BPM activity in livers of Fundulus larvae and

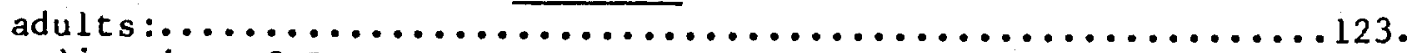

Localization of $B P$ monooxygenase activity in the microsomal fraction of Fundulus larval liver, and a comparison of enzymatic activities and cytochrome content of larval, juvenile and adult hepatic microsomes :......................

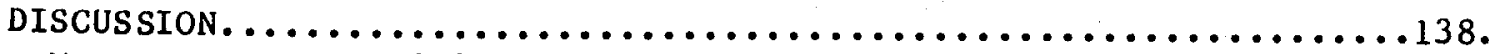
Monooxygenase activity and components of the monooxygenase

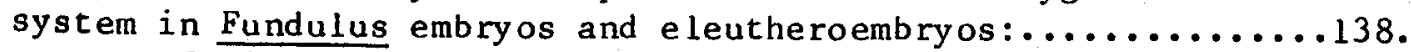

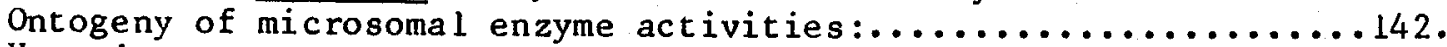

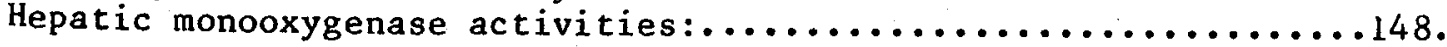
Comparative aspects of the development of the monooxygenase system, and a rationale for the developmental

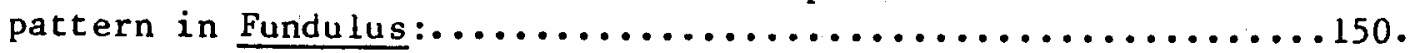

CHAPTER 4. The responses of the monooxygenase systems of Fundulus embryos and eleutheroembryos to Aroclor $1254 \ldots \ldots \ldots \ldots 155$. 


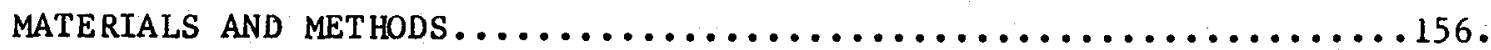

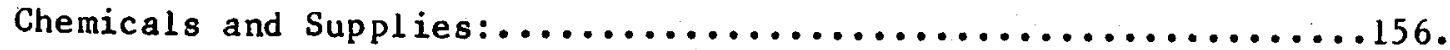

Embryos: PCB Exposure and Quantitation of PCB Uptake:..........156.

Fractionation of Embryos and Enzyme Assays:....................

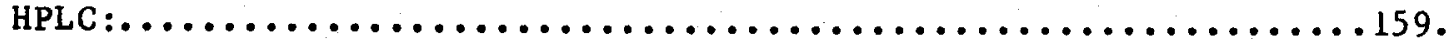

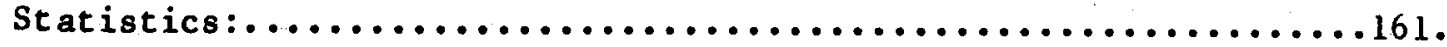

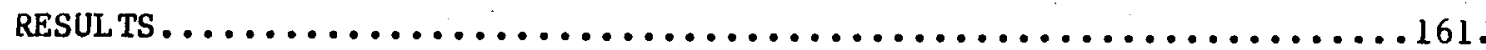

Experiment 1. Responses of the monooxygenase system of embryos and eleutheroembryos to Aroclor $1254: \ldots \ldots \ldots \ldots \ldots 161$.

Experiment 2. A comparison of the response of 4 and

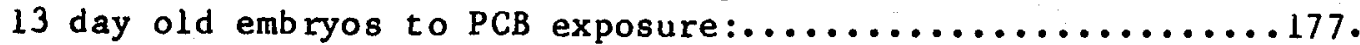

Experiment 3. Additional Observations on the Induction

of Benzola]pyrene Monooxygenase Activity in

El eu the roembryos : .................................. 183 .

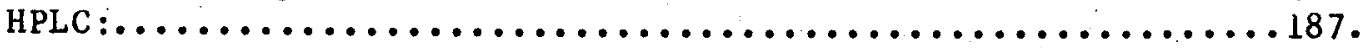

DISCUSSION...............................................

Induction competence in embryos prior to the appearance of the liver

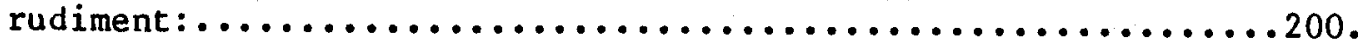

Factors affecting the induction of BPM activity in embryos and

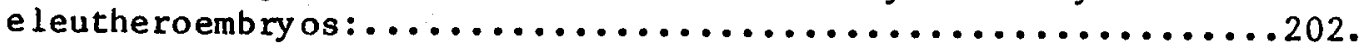

Comparison of the induction response to other species:.........204.

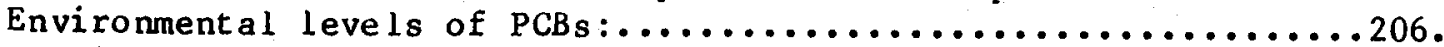

Possible significance of the presence and inducibility of xenobiotic monooxygenase activity in Fundulus embryos

and eleutheroembryos :..............................

CHAPTER 5..Hepatic Benzo(a)pyrene monooxygenase activity in brook trout (Salvelinus fontinalis) embryos:

constitutive levels and induction by PCBs..............214.

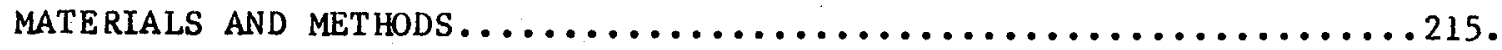

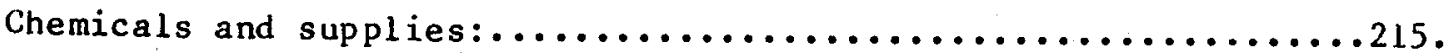

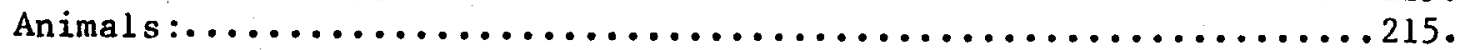

Exposure of embryos to PCBs and quantitation of PCB levels

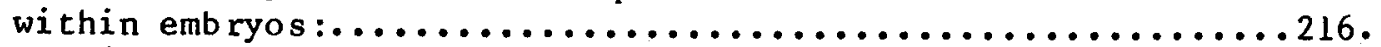

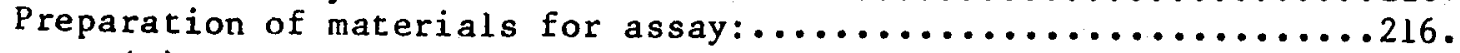

Benzo(a)pyrene monooxygenase activity:.....................

RESULTS ............................................

Comparison of Fundulus and brook trout embryonic

deve lopment :....................................... 


\section{Page 9.}

Hepatic BP monooxygenase activity in brook trout embryos

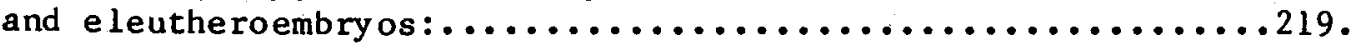
Lack of detection of BPM activity in fractions of whole

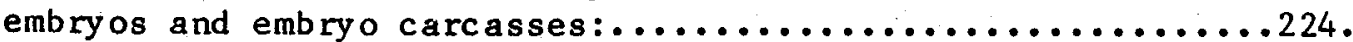
Induction of $\mathrm{BP}$ monooxygenase activity in brook trout

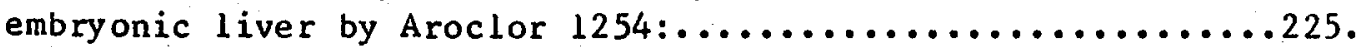

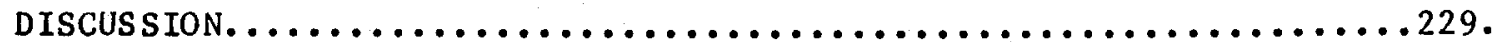

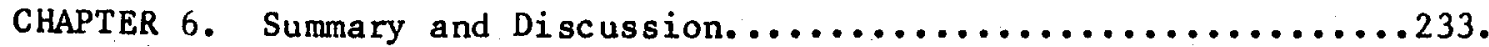

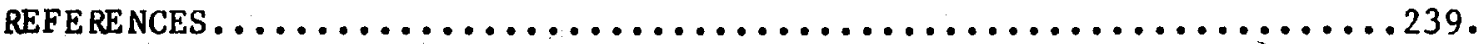

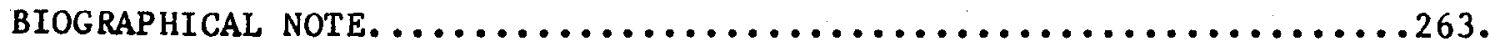




\section{LIST OF FIGURES}

CHAPTER 1.

Page No.

Figure 1-1. Pathways of microsomal electron flow............ 21 .

Figure 1-2. Pathways of benzo(a)pyrene metabolism........... 60 .

Figure 1-3. Oxidative $\mathrm{N}$-demethylation of aminopyrine by the cytoch rome $\mathrm{P}-450$ dependent monooxygenase system............66.

CHAPTER 3

Figure 3-1. Distribution of benzo(a)pyrene monooxygenase activity and various cytochrome $c$ reductase activities in centrifugal fractions of whole eleutheroembryos........... 97 .

Figure 3-2. Electron micrograph of a $40 \mathrm{~K}$ or microsomal pellet prepared from a homogenate of whole Fundulus embryos

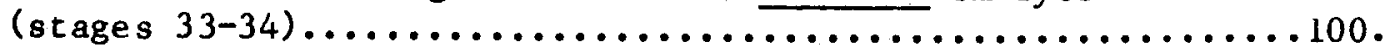

Figure 3-3. Ontogeny of BPM activity and NADPH- and NADH-cytochrome $c$ reductase activities in microsomes prepared from whole Fundulus embryos and eleutheroembryos...................... 04 .

Figure 3-4. Levels of BPM activity and NADPH cytochrome c reductase activity in microsomes prepared from 19 day old e leuthe roemb ryos.......................................

Figure 3-5. Difference spectra obtained with whole Fundulus eleutheroembryo fractions and adult liver microsomes.........119.

Figure 3-6. Cytoch rome $b_{5}$ difference spectra obtained with whole Fundulus eleutheroembryo microsomes and adult liver

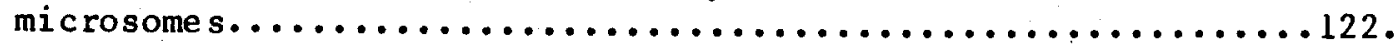

Figure 3-7. Difference spectra obtained with hepatic microsomes from Fundulus juveniles 48 days from hatching..................

\section{CHAPTER 4}

Figure 4-1. Levels of $\mathrm{PCB}$ s in whole embryos during the

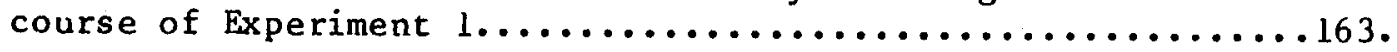

Figure 4-2. Microsomal BPM, APD and NADPH-cytochrome $c$ reductase activities in fractions prepared from Experiment 1 embryos and eleutheroembryos....................

Figure 4-3. BPM activities for Experiment 1 embryos and eleutheroembryos normalized to embryo body weight, and plotted versus ppm PCBs in embryo bodies.................. 
Figure 4-4. The distribution of BPM activity in centrifugal fractions of $\mathrm{PCB}$ exposed embryos

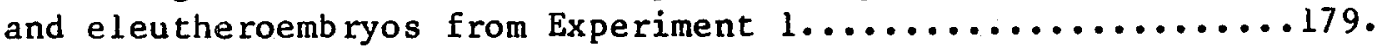

Figure 4-5. A) Levels of PCBs in Experiment 2 embryos during the course of exposure. B) BPM activity in fractions from control and PCB exposed embryos.............181.

Figure 4-6. Levels of PCBs in whole embryos during

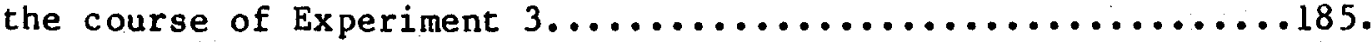

Figure 4-7. Experiment 3 results; microsomal BPM activity in fractions prepared from whole eleutheroembryos exposed to varying levels of PCBs...........189.

Figure 4-8. HPLC elution profile of benzo(a)pyrene metabolites produced by microsomes from PCB

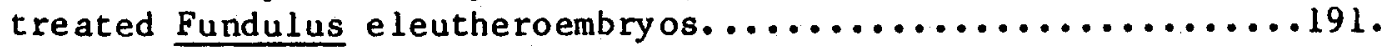

CHAPTER 5

Figure 5-1. BP monooxygenase activity in whole homogenates of livers of brook trout embryos and eleutheroembryos..........221.

Figure 5-2.Figure 5-2. Levels of $\mathrm{PCBs}$ in dechorionated brook trout embryos during the course of exposure...............227. 
CHAPTER 2.

Table 2-I. Benzo(a)pyrene monooxygenase activity in the $10,000 \times g$ fraction of homogenates of Fundulus heteroclitus embryos exposed to Aroclor 1254 and No. 2 fuel oil........... 72.

Table 2-II. BPM activity in fractions of homogenates of control and Aroclor-exposed Fundulus embryos and eleutheroembryos...... 74 .

CHAPTER 3.

Table 3-I. A synopsis of Fundulus heteroclitus embryonic

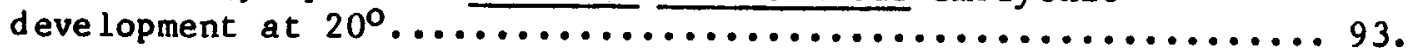

Table 3-II. Whole embryo weights, microsomal protein, and microsomal benzo(a)pyrene monooxygenase activity at

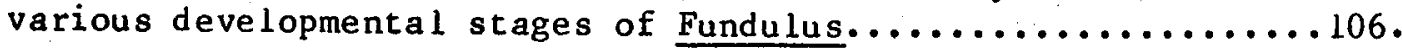

Table 3-III. BP monooxygenase activity in microsomes prepared from whole embryos, eleutheroembryos, and a mixture of the two

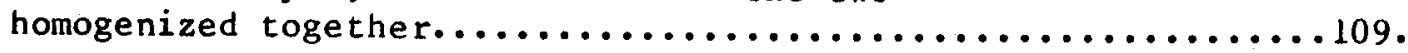

Table 3-IV. Requirements for benzo(a)pyrene monooxygenase activity with microsomes prepared from homogenates of whole Fundulus embryos and eleutheroembryos, and

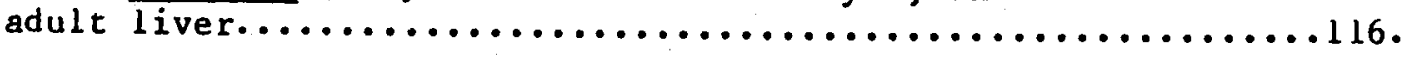

Table 3-V. Monooxygenase activities, NADPH- and NADHcytochrome $c$ reductase activities and content of cytoch romes $\mathrm{P}-450$ and $\mathrm{b}_{5}$ in microsomes prepared from whole Fundulus eleutheroembryos..................... 24 .

Table 3-VI. BPM activity in liver whole homogenates

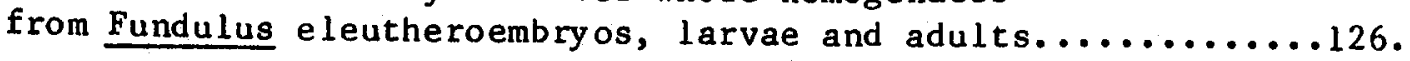

Table 3-VII. A comparison of Fundulus adult liver microsomes prepared by the micro- and standard fractionation

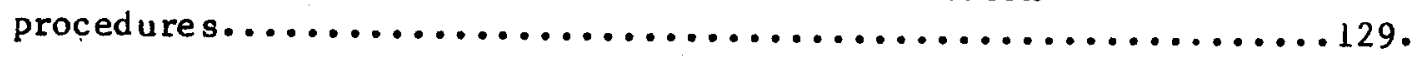

Table 3-VIII. BP monoxygenase activity in centrifugal

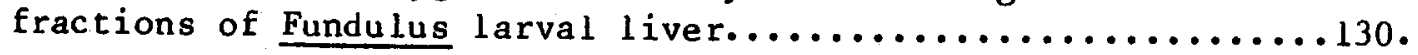

Table 3-IX. A comparison of hepatic microsomal enzyme activities and cytoch rome content in fractions prepared from Fundulus larvae, juveniles and adults..........132. 
Table 3-X. Inhibition of Fundulus larval, juvenile and adult hepatic microsomal BPM activity by $\alpha$-napthoflavone and

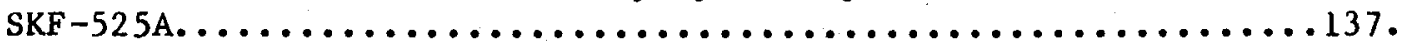

CHAPTER 4.

Table 4-I. Levels of PCB's in Experiment 1 embryos and

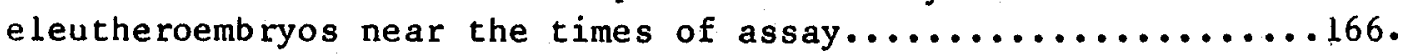

Table 4-II. Compiled statistics for PCB exposed experiment 1 embryos and eleutheroembryos near the times of assay..........167.

Table 4-III. Leve 1 s of PCBs in intact eleutheroembryos and eleutheroembryo tissues at the time of assay in Experiment 3.......................................

Table 4-IV. Relative amounts of benzo(a)pyrene metabolites produced by microsomes prepared from adult Fundulus liver

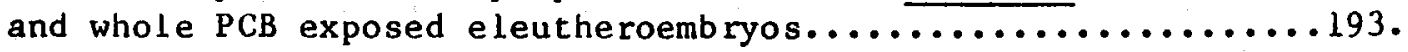

Table 4-V. A compilation of data on the sensitivity of Fundulus embryos and eleutheroembryos to Aroclor 1254

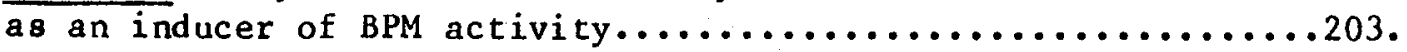

Table 4-VI. Levels of $P C B$ reported in the literature for fish species collected at various locations................208.

CHAPTER 5.

Table 5-I. BP monooxygenase activities in whole homogenates of 1 ivers from brook trout embryos, eleutheroembryos

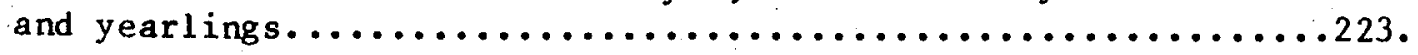

Table 5-II. BP monooxygenase activities in whole homogenates of Livers from control and Aroclor 1254 exposed brook

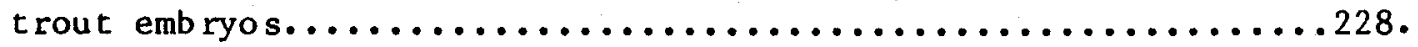


ABB REVIAT IONS USED

$\mathrm{AP}$

APD

ANF

BeND

BP

BPM

BSA

DMSO

$\mathrm{ED}_{50}$

EDTA

HCB

3-MC

NADH

$\mathrm{NADP}{ }^{+}$

NADPH

PAH

PB

PCB

SKF $-525 A$

SDS

TCPO

TES

TS

TRIS aminopyrine

aminopyrine demethylase

$\alpha$-naphthoflavone

benzphetamine $\mathrm{N}$-demethy lase

benzo(a)pyrene

benzo(a) pyrene monooxygenase

bovine serum albumin

dimethyl sulfoxide

dose necessary to produce a $50 \%$ maximal response

ethylenediaminetetraacetic acid, disodium salt

hexach Lo robiphenyl

3-methy Ichol anth re ne

nicotinamide adenine dinucleotide, reduced form

nicotinamide adenine dinucleotide phosphate

nicotinamide adenine dinucleotide phosphate, reduced form

polycyclic aromatic hydrocarbon

phenobarbital

polychlorinated bipheny 1

$\beta$-diethyl aminoethyl dipheny 1 valerate

sodium dodecyl sulfate

trichl ropropylene oxide

$0.05 \mathrm{M} \mathrm{pH} 7.2 \mathrm{Tris} \mathrm{HCl,} \mathrm{ImM} \mathrm{EDTA,} 0.25 \mathrm{M}$ sucrose

as described above without EDTA

tris (hydroxymethyl) aminomethane 
Page 15.

CHAPTER 1

INTRODUCTORY MATERIAL 
The oceans are subject to a continuous input of organic chemical pollutants (Duce and Duursma, 1977; Goldberg, 1976; National Academy of Sciences, 1975; Neff, 1979). Sources include the intentional dumping of industrial wastes and municipal sewerage sludge, pollutant loads of rivers, spillage during petroleum production and transport, terrestrial runoff of agricultural chemicals, and dry and wet deposition of air pollutants. Concern about the effects of this contamination of the marine environment, and the pollution of freshwater systems, has led to the study of the capacity of fish to chemically transform and detoxify foreign compounds (xenobiotics). Particular attention has focused on a widely occurring system of enzymes known as the cytochrome $\mathrm{P}-450$ dependent monooxygenases or mixed function oxidases. These enzymes oxidatively metabolize a variety of lipophilic xenobiotics, including pesticides, hydrocarbons and carcinogens (reviewed by Lu et al., 1976; Sato and Omura, 1978). One of the most striking properties of the cytochrome P-450 dependent monooxygenases is their versatility, as they are active in metabolizing several different classes of organic chemicals. The structurally diverse substrates of these enzymes share the common property of lipid solubility.

Many of the reactions catalyzed by the cytochrome P-450 system involve the introduction of hydroxyl groups into substrates, or the exposure of functional groups by oxidative dealkylation. These reactions serve to put "handles" on hydrophobic molecules which can be used for conjugation with polar cellular constituents such as glucuronic acid or sulfate (Goldstein et al., 1974). This two step 
Page 17 .

process greatly facilitates the elimination of lipophilic foreign compounds, which might otherwise accumulate in tissues to very high levels. The consequences of the metabolism of a xenobiotic by cytochrome P-450 will depend upon the structure of the compound. In some cases metabolism may destroy the pharmacological activities of a substance and result in overall detoxification (Conney, 1967). However, certain substances which are relatively inert under physiological conditions, are activated by cytochrome $\mathrm{P}-450$ to highly reactive metabolites that can produce necrotic lesions, mutations and cancer (Gillette, 1974; Weisburger, 1978). Thus the cytochrome P-450 system can be involved in determining both the fate and effects of xenobiotics in fish.

Generally, the early developmental stages of $f$ ish have been found to be more sensitive to environmental stresses and pollution than adults (Kuhnhold et al.., 1978; McKim, 1977; Rosenthal and Alderdice, 1976). It should be noted that the rapidly proliferating tissues of embryos may be particularly sensitive to damage from activated metabolites generated by cytochrome P-450 (Harbison, 1978). Since the cytochrome $\mathrm{P}-450$ system can potentially play a critical role in determining the susceptibility of fish embryos and larvae to the toxicity of a wide range of pollutants, knowledge of the occurrence and properties of these enzymes during the early development of fish is important. The research described in this thesis approaches this problem, and is a study of the ontogeny of the cytochrome $\mathrm{P}-450$ monooxygenase system in fish embryos and larvae. In the following 
sections of this chapter relevant literature is reviewed, and the research problem is defined. In Chapters 2-5 experimental results are presented. Each of these chapters is written as a unit resembling a manuscript for publication, with methods, results and discussion sections. A brief summary and discussion of results is presented in Chapter 6.

\section{MAMMALIAN CYTOCHROME P-450 DEPENDENT MONOOXYGENASES}

The cytoch rome P-450 dependent monooxygenases occur widely among plants, animals and bacteria (Kulkarni et al., 1976; Sato and Omura, 1978). Of the animal systems, those of the common laboratory mammals (rats, rabbits and mice) have been characterized in greatest detail. As such they serve as a point of reference for work with other groups of animals, especially the lower vertebrates. Relevant aspects of the mammalian cytochrome $\mathrm{P}-450$ systems will be briefly discussed in this section.

In mammals, the liver is the major site of foreign compound metabolism (Goldstein et al., 1974). The hepatic cytochrome P-450 dependent monooxygenases are versatile enzymes that catalyze the oxidation of a wide range of lipophilic foreign compounds, as well as endogenous substances such as hormones and fatty acids (for reviews see: Gillette et al., 1972; Lu et al., 1976; Sato and Omura, 1978). The reactions catalyzed include: aromatic and aliphatic hydroxylation, $\mathrm{N}^{-}, \mathrm{S}-$, and $\mathrm{O}-\mathrm{dea}$ kylation, $\mathrm{N}-$ and $\mathrm{S}-$ oxidation, and dehalogenation. 
These reactions require $\mathrm{NADPH}$ and oxygen, and in many cases can initially be considered hydroxylations. The following equation, in which $\mathrm{AH}$ is the substrate, is generally used to describe the reactions mediated by this system:

$$
\mathrm{AH}+\mathrm{NADPH}+\mathrm{H}^{+}+\mathrm{O}_{2} \longrightarrow \mathrm{AOH}+\mathrm{NADP}^{+}+\mathrm{H}_{2} \mathrm{O}
$$

The liver cytochrome $\mathrm{P}-450$ dependent monooxygenase system is primarily localized in the endoplasmic reticulum of hepatocytes, or the microsomal fraction of tissue homogenates (DePierre and Dallner, 1975). The major protein components of this system are the flavoprotein $\mathrm{NADPH}-\mathrm{cyt}$ toch rome $\mathrm{P}-450$ reductase, and the family of hemeproteins known collectively as cytochrome P-450 (Lu and Levin, 1974a). These b-type cytochromes were given the designation $\mathrm{P}-450$ because of their atypical spectral property of exhibiting a Soret band around $450 \mathrm{~nm}$ in the reduced and carbon monoxide ligated state (Omura and Sato, 1964). Cytochrome P-450 functions as the terminal oxygenase and binds both substrates and oxygen (Cooper et a1., 1965). Both the specificity for different substrates and positional specificity for oxygenation of a given substrate, are determined primarily by the cytoch rome components of the system ( $\mathrm{Lu}$ and West, 1980). Multiple forms of cytochrome $\mathrm{P}-450$, with differing but overlapping substrate specificities, have been purified from hepatic microsomes of rats, rabbits, mice and guinea pigs (reviewed by: Johnson, 1979; Lu and West, 1980). The extent of the diversity of cytochrome P-450 types 
within a given species has yet to be established. The term cytochrome $\mathrm{P}-450$ will be used here to indicate this whole class of proteins rather than a single entity. Electrons, originating from NADPH, and donated to cytochrome $\mathrm{P}-450$ by the reductase, are used to activate molecular oxygen, and ultimately to reduce one atom of oxygen to water while the other atom is inserted into the substrate (Dus, 1976).

In addition to the above pathway from NADPH to cytochrome P-450, hepatic microsomes contain an electron transport chain responsible for the $\Delta 9$ desaturation of fatty acids (Schenkman et al., 1976). The components of this system and their interactions with cytochrome $\mathrm{P}-450$ and NADPH-cytochrome $\mathrm{P}-450$ reductase are shown in Figure 1-1 (Lu et al., 1976; Schenkman et al., 1976). For NADH-dependent fatty acid desaturation, electrons from NADH are donated to the flavoprotein NADH-cytochrome $b_{5}$ reductase, then to the hemeprotein cytochrome $b_{5}$, and finally to the cyanide sensitive factor, a nonheme iron protein which serves as the desaturase. Fatty acid desaturation can also be supported by $\mathrm{NADPH}$, with $\mathrm{NADPH}-\mathrm{cy}$ toch rome $\mathrm{P}-450$ reductase transferring electrons to cytoch rome $b_{5}$. NADPH-cytochrome $\mathrm{P}-450$ reductase can transfer electrons to a number of nonphysiological electron acceptors, including cytochrome c (Sato and Omura, 1978). This enzyme is routinely assayed by measuring cytochrome c reduction, and is then referred to as NADPH-cytochrome $c$ reductase. Early evidence for the involvement of the $\mathrm{NADPH}-\mathrm{cyt}$ tochrome $c$ reductase in microsomal monooxygenase activity, was the observation that in vitro monooxygenase activity is strongly inhibited by cytochrome c (Gillette 

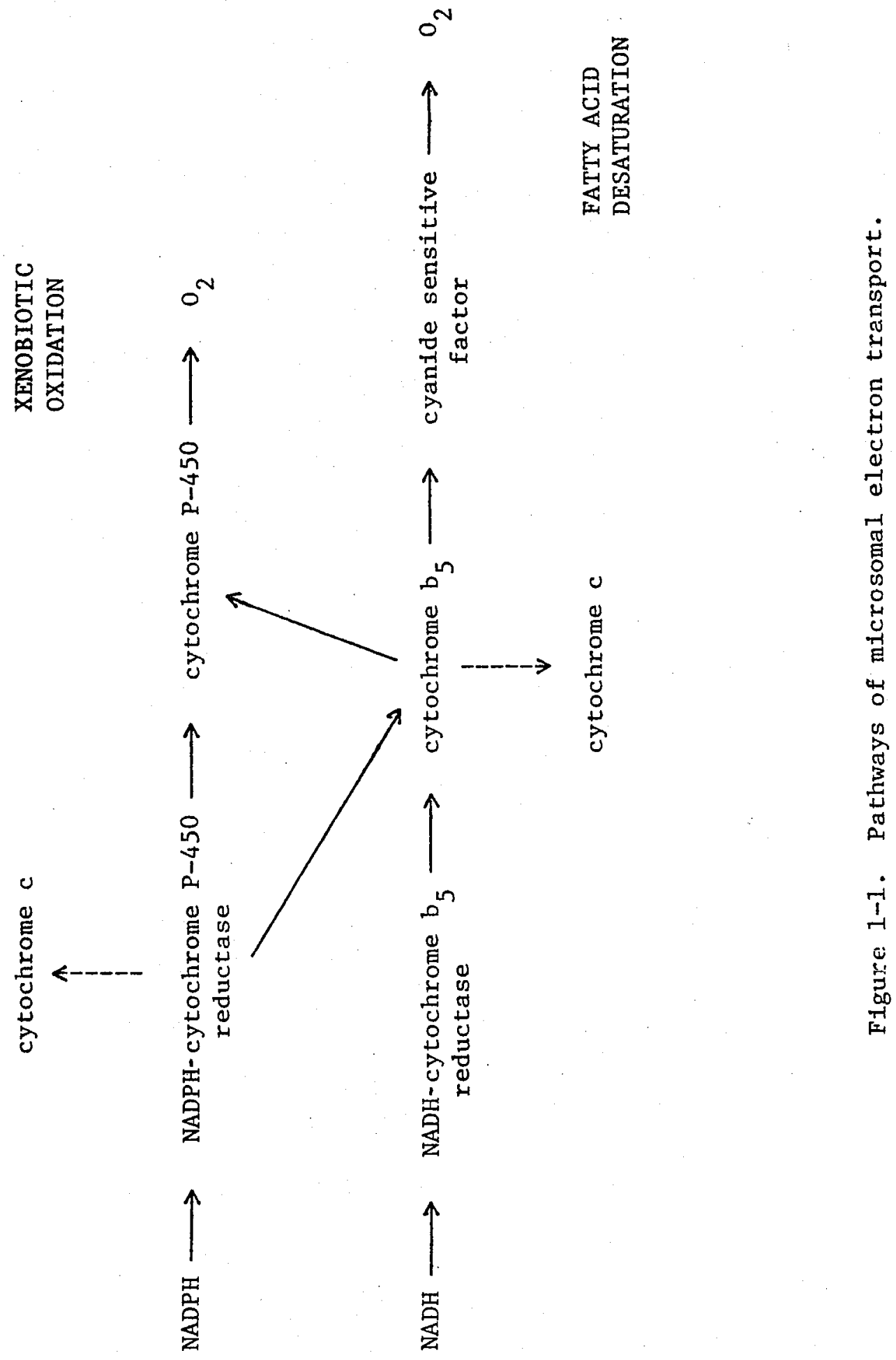
et al., 1957; Phillips and Langdon, 1962). Apparently, cytochrome c effectively competes with cytochrome $\mathrm{P}-450$ for electrons from NADPH. Microsomal $\mathrm{NADH}-\mathrm{cyt}$ toch rome c reductase activity is mediated by both NADH-cytoch rome $b_{5}$ reductase and cytochrome $b_{5}$, as cytoch rome $b_{5}$ reductase cannot transfer electrons directly to cytochrome $c$ (Schenkman et al., 1976).

Electrons from NADH can reduce cytochrome P-450, with cytochrome $\mathrm{b}_{5}$ and its reductase serving as electron transfer components (Omura and Sato, 1964; Fujita and Peisach, 1977; Hrycay and Prough, 1974). An NADH-dependent pathway of benzo(a)pyrene hydroxylation has been reported which requires $\mathrm{NADH}-\mathrm{cytoch}$ rome $\mathrm{b}_{5}$ reductase, cytoch rome $\mathrm{b}_{5}$, phospholipid, and cytoch rome $\mathrm{P}-450$, but quantitatively, the NADH dependent hydroxylation of this substrate is probably of minor significance (West and $L u, 1977$ ). Since cytochrome $b_{5}$ can be reduced by electrons from NADPH and can transfer electrons to cytochrome $\mathrm{P}-450$, it apparently can also play a role in NADPH-dependent cytoch rome $\mathrm{P}-450$ mediated reactions (Estabrook, 1971; Lu and Levin, 1974b). The involvement of cytochrome $b_{5}$ in the NADPH-dependent pathway seems to depend on the type of substrate and the particular species of cytochrome $\mathrm{P}-450$ catalyzing the reaction; for many substrates, cytochrome $b_{5}$ is not an obligatory component of this pathway (Jansson and Schenkman, 1973; Lu and Levin, 1974b; Lu et a1., 1974; Sugiyama et al. , 1979).

The microsomal cytochrome P-450 monooxygenase system is widely distributed in extrahepatic tissues, including lung, kidney, skin 
and gonads (Sato and Omura, 1978). Generally, the cytochrome P-450 levels and xenobiotic metabolizing capacities of extrahepatic tissues are much lower than those of the liver, and substrate specificities are found to vary from tissue to tissue probably due to qualitative differences in the cytochrome components.

\section{Induction of microsomal monooxygenases:}

The microsomal monooxygenase system is inducible by both substrates and certain compounds which are not readily metabolized. Two major classes of inducers have been recognized which are typified by the barbiturate, phenobarbital (PB), and the polycyclic aromatic hydrocarbon, 3-methylcholanth rene (Conney, 1967). The terms PB-type and 3-MC-type will be used here to indicate these two classes of inducers. A number of drugs and pesticides, such as DDT and chlordane, and certain halogenated bipheny 1 isomers behave as $\mathrm{PB}$ type inducers (Conney, 1967; Goldstein et al., 1977). Among the 3-MC-class of inducers are other polycyclic aromatic hydrocarbons, chlorinated dibenzodioxin and dibenzofurans, and certain halogenated biphenyls (Conney, 1967; Poland and Glover, 1973; Goldstein et al., 1977). Apparently the synthetic steroid pregnenolone-16 $\alpha$-carbonitrile and isosafrole represent classes of inducers distinct from either PB or 3-MC (Lu et al., 1972; Dickens et al., 1978).

$\mathrm{PB}$ and $3-\mathrm{MC}$ produce characteristic responses in the tissues of treated animals (Conney, 1967). PB type inducers appear to be most active in the liver, while 3-MC type inducers are active in a number of 
extrahepatic tissues, as well as the liver (Alvares and Kappas, 1977; Conney, 1967). PB stimulates the hepatic metabolism of a large number of foreign compounds, including drugs, pesticides and carcinogens. Associated with the enhanced xenobiotic metabolism is a dramatic proliferation of the smooth endoplasmic reticulum (SER), and thus an increase in the yield of microsomal protein per gram liver (Orrenius et al., 1965). PB also induces increases in the total content of hepatic microsomal cytochrome $\mathrm{P}-450$, NADPH-cytoch rome c reductase activity, cytoch rome $b_{5}$ and $\mathrm{NADH}-\mathrm{cytoch}$ rome $c$ reductase activity (Conney, 1967; Orrenius et al., 1965; de Barros et al., 1978). In contrast to PB, 3-MC enhances the biotransformation of fewer substances, and treatment with 3-MC of ten leads to a depression of the monooxygenase activities which are not stimulated (Conney, 1967; Lu et al., 1976). 3-MC causes only slight changes in the SER, and does not substantially affect the Levels of NADPH-cytochrome c reductase activity, but does induce an increase in the total content of cytochrome $\mathrm{P}-450$ (Alvares et al., 1967; Conney et al., 1967; Kuntzman et al., 1968; Parkinson et al., 1980a; Thorgeirsson et al., 1979). Generally associated with the induction of cytochrome $P-450$ by $3-M C$ is a blue shift of about $2 \mathrm{~nm}$ in the absorption maximum of the co difference spectrum of reduced hepatic microsomes. Hepatic microsomes from PB treated animals do not show such a spectral shift. The differential induction of monooxygenase activities by the $P B$ and 3-MC classes of inducers, and the differences in the spectral properties of hepatic microsomes from animals treated with these two types of inducers are due to the fact that they induce 
different forms of cytochrome P-450 (Botelho et al., 1979; Haugen and Coon, 1976; Lu and West, 1980). Induction has been shown to require de novo synthesis of cytochrome $\mathrm{P}-450$, rather than modification of existing peptides or decreases in the rate of turnover (Haugen et al., 1976). The major forms of cytochrome $P-450$ induced by $3-M C$ in livers of rats and rabbits absorb maximally at 447-448 $\mathrm{nm}$ in the co-ligated state; this accounts for the spectral shifts observed with microsomes from treated animals (Haugen and Coon, 1976; Ryan et al., 1979). Because the cytochrome $\mathrm{P}-450$ isozymes induced by $3-\mathrm{MC}$ are spectrally and catalytically distinct from those of control animals, they are sometimes referred to as cytoch rome $\mathrm{P}-448$ or cytochrome $\mathrm{P}_{1}-450$. These designations are clearly inadequate, but a systematic nomenclature for cytochrome $\mathrm{P}-450$ isozymes has not been established. The substrate specificities of the induced forms of hepatic cytochrome $\mathrm{P}-450$ vary between species, and different forms may be induced at different stages of development in the same species (Norman et al., 1978; Thorgeirsson et al., 1979). Phenobarbital usually induces the $\mathrm{N}$-demethylation of certain drugs such as aminopyrine and benzphetamine, while these activities are little affected by $3-M C$ type inducers (Conney, 1967; Lu et al., 1976; Alvares and Kappas, 1977). In adult rats, guinea pigs and responsive strains of mice, the polycyclic aromatic hydrocarbon, 3-MC, stimulates the metabolism of its own class of compounds (Alvares and Levin, 1970; Nebert and Gelboin, 1969). The model substrate for studying $\mathrm{PAH}$ metabolism is the carcinogenic hydrocarbon benzo(a)pyrene. The monooxygenase activity associated with 
BP metabolism is known by various names, and will be referred to here as benzo(a)pyrene monooxygenase (BPM). Phenobarbital also induces hepatic $B P M$ activity; the relative induction produced by $P B$ and $3-M C$ varies from species to species, and between inbred strains of the same species (Alvares and Levin, 1970; Nebert and Gelboin, 1969).

In rats the major cytochrome $\mathrm{P}-450$ isozyme induced by $3-\mathrm{MC}$ is greater than 100 times more active in metabolizing BP than the major isozyme induced by PB (Ryan et al., 1979). In rabbit liver the isozyme of cytochrome $\mathrm{P}-450$ most active in $\mathrm{BP}$ metabolism is also induced by the 3-MC-type inducers, but substantial induction of this isozyme occurs only during the late fetal and neonatal periods (Norman et al., 1978). In adult rabbits the major form of cytochrome $P-450$ induced by $P B$ is more active in metabolizing benzo(a)pyrene than the major 3-MC inducible form (Coon and Vatsis, 1978). Various cytochrome P-450 isozymes not only differ in the rate at which they metabolize BP; they also show differing regiospecificity (Deutsch et al., 1978; Thakker et al., 1977; Yang et al., 1976). In other words they preferentially oxygenate different sites on the molecule. Varying regiospecificity is also observed with other substrates such as testosterone (Ryan et al., 1979; Thorgeirsson and Nebert, 1977). In the case of benzo(a)pyrene the various metabolites produced by cytochrome $\mathrm{P}-450$ may differ substantially in their mutagenicity and carcinogenecity (Nebert and Jensen, 1979). Thus qualitative and quantitative changes in cytochrome P-450 isozymes associated with induction can substantially affect the susceptibility of an animal to the deleterious properties of a 
toxicant. The role of cytochrome $\mathrm{P}-450$ in chemical carcinogenesis and toxicity will be discussed later.

Certain inhibitors of cytochrome P-450 dependent monooxygenase activities are useful tools for characterizing the forms of cytochrome p -450 present in intact microsomes. Two inhibitors which were used in the work presented here are $\alpha$-napthoflavone (ANF) and SKF-525A ${ }^{\perp}$. These compounds differentially inhibit monooxygenase activities induced by $\mathrm{PB}$ and 3-MC (Lu et al., 1972; Thorgeirsson et a1., 1979; Goujon et al., 1972; Wiebel et al., 1971). In rats and responsive strains of mice, hepatic microsomal BPM activity induced by $3-M C$ is very sensitive to inhibition by ANF and little affected by SKF-525A. The opposite is true in control or $\mathrm{PB}$ treated rats and mice, in which hepatic BPM activity is more strongly inhibited by SKF-525A. In fact BPM activity in microsomes from control animals is actually stimulated by certain concentrations of ANF. The effects of these inhibitors on microsomal monooxygenase activities can be diagnostic for changes in the complement of cytochrome $\mathrm{P}-450$ isozymes upon induction.

In tissues that respond to 3-MC type inducers, specific cytosolic receptors are believed to play a role in the induction response, analogous to the steroid receptors of steroidogenic tissues (Carlstedt-Duke et al., 1980; Greenlee and Poland, 1979; Okey et al., 1979; Poland and Glover, 1975; Poland et a 1., 1976). Evidence for the

1 SKF-525A is $\beta$-diethy 1 aminoethy $l$ dipheny 1 valerate. 
Page 28.

existence of such receptors has been obtained using the extremely toxic compound $2,3,7,8$-tetrachlorodibenzo-p-dioxin (TCDD). TCDD is the most potent known inducer of the 3-MC class, and is more than 30,000 times as potent as 3-MC in inducing BPM activity (Poland and Glover, 1973). Specific, saturatable, high affinity binding sites for TCDD have been detected in the hepatic cytosol of rats, rabbits, cotton rats (Sigmoden hispedis) and responsive strains of mice (Kahl et al., 1980; Poland et al., 1976; Okey et al., 1979). These binding sites apparently are proteins, and are not detectable in strains of mice genetically nonresponsive to 3-MC (Greenlee and Poland, 1979; Okey et al., 1979). A large number of substances have been tested for their capacity to compete with TCDD for binding to the cytosolic receptors (Greenlee and Poland, 1979; Okey et al, 1979; Poland and Glover, 1977). Generally the affinity of various substances for the receptors correlates well with their potency as 3-MC type inducers. Phenobarbital, pregnenolone-16$\propto$-carbonitrile, and steroid hormones show no specific binding. Generally, planar molecules are the most potent 3-MC type inducers; apparently there are geometric constraints on the interaction of the inducer and receptor molecules. Specific TCDD receptors have also been detected in several extrahepatic tissues, but there is no strict correlation between the levels of receptor and the levels of enzyme activities induced (Carlstedt-Duke, 1979; Okey et al., 1979). After binding TCDD, the TCDD-receptor complexes have been shown to migrate to the nucleus (Greenlee and Poland, 1979; Okey et al., 1979). In vitro, the TCDD-receptor complexes bind to DNA, while the empty receptors do not 
bind (Carlstedt-Duke et al., 1980). Presumably upon binding inducer, there is a conformational change in the receptor which results in its nuclear translocation, and ultimately the derepression of genes coding for induced proteins. At present there is no experimental evidence for a receptor which binds phenobarbital.

Induction of the monooxygenase system by polychlorinated biphenyls:

Polychlorinated biphenyls (PCBs) are industrial chemicals that are ubiquitous and persistent environmental contaminants, and are also potent inducers of xenobiotic monooxygenase activity (Risebrough et al., 1968; Nisbet and Sarofim, 1972; Wassermann et al., 1979; Alvares et al., 1973). Commercial PCB mixtures are complex assemblages of chlorinated bipheny 1 congeners which act as "mixed inducers" in rats, having properties of both the $\mathrm{PB}-$ and 3-MC-classes of inducers (Alvares et al., 1973; Vainio, 1974). Commercial preparations with higher degrees of chlorination have been found to be more potent inducers of monooxygenase activity than those of lower chlorination (Bickers et al., 1972; Chen and DuBois, 1973). Aroclor 1254 is the trade name for a commercial PCB mixture produced by the Monsanto Company which contains $54 \%$ chlorine by weight, and is primarily composed of tetra-, penta-, and hexach Lorobiphenyls (Webb and McCall, 1972). Residues of PCBs in animal tissues often resemble the composition of this $P C B$ mixture or the related Aroclor 1260, which contains $60 \%$ chlorine by weight (e.g. Norstrom et al., 1978; Risebrough and delappe, 1972; Zitko et al., 1972). Aroclor 1254 is of particular interest in the present context, because it was 
Page 30 .

used as a model inducing substance in experiments described in this thesis.

Alvares and Kappas (1977) have clearly shown that Aroclor 1254 has the inducing properties of both $\mathrm{PB}$ and 3-MC. More recently Levin's group has purified the major isozymes of cytochrome $\mathrm{P}-450$ induced in rat liver by PB, 3-MC and Aroclor 1254 (Botelho et al., 1979; Ryan et al., 1979; Thomas et al., 1981). On the basis of mobility on electrophoretic gels, substrate specificity, spectral properties, immunochemical properties, peptide mapping, and $\mathrm{N}-$ and $\mathrm{C}$ - terminal aminoacid sequences, the major isozymes of cytochrome $\mathrm{P}-450$ induced by $\mathrm{PB}$ and 3-MC are indistinguishable from those induced by Aroclor 1254 .

Of the 209 possible PCB isomers, a number of pure isomers have been examined for their properties as inducers of cytochrome $P-450$. The results of separate studies by Goldstein et al. (1977) and Poland and Glover (1977) suggested that individual PCB isomers behave either as inducers of the $\mathrm{PB}$ or 3-MC type, and that the inducing properties of Aroclor 1254 and other commercial PCB preparations result from their being mixtures of these two classes of inducers. However, PCB isomers shown to be active 3-MC type inducers, such as $3,3^{\prime}, 4^{\prime}, 4^{\prime}$-tetrachlorobipheny 1 are only minor components of commercial $\mathrm{PCB}$ mixtures (Sissons and Welti, 1971; Jensen and Sundstrom, 1974). Commercial PCB preparations are contaminated with chlorinated dibenzofurans, some of which are among the most potent known inducers of the 3-MC type (Vos et al., 1970; Bowes et al., 1975; Poland et al., 1973). However, the levels of these compounds in the Monsanto Aroclors 
(1-2ppm) are not high enough to account for the potency of the Aroclors as 3-MC type inducers. Recently Parkinson et al. (1980a and b) have shown that several individual, highly purified $P C B$ congeners can act as mixed type inducers, producing effects in rat liver similar to the coadminstration of $\mathrm{PB}$ and 3-MC. Some of these compounds are major components of commercial PCB mixtures and presumably contribute to their properties as 3-MC type inducers. These compounds are of particular theoretical interest since they can presumably bind to both the putative 3-MC and $\mathrm{PB}$ induction receptors.

THE CYTOCHROME P-450 DEPENDENT MONOOXYGENASE SYSTEM IN FISH

The overall pathways of biotransformation of foreign compounds in fish are like those in mammals (reviewed by Bend and James, 1978). More specifically, the hepatic cytochrome $P-450$ monooxygenases of $\mathrm{fish}$ are similar in many respects to the mammalian systems. These enzymes are localized in the microsomal fraction of homogenates and require $\mathrm{O}_{2}$, and generally NADPH for activity (Ahokas et al., 1977a; Bend et al., 1977; Buhler and Rasmusson, 1968; Statham et al.., 1977; Stegeman et al., 1979). All of the electron transfer components known to play a functional role in mammalian microsomal monooxygenase activity have been detected in fish hepatic microsomes (e.g. Ahokas et al., 1976; Bend and James, 1978; Stegeman and Binder, 1979). Cytoch rome P-450, NADPH cytochrome $\mathrm{p}-450$ reductase, and cytochrome $\mathrm{b}_{5}$ have been partially purified from hepatic microsomes prepared from little skate, Raja erinacea (Bend et al.., 1977; Philpot et al.., 1977). The absolute 
spectrum of the skate cytochrome was similar to that of mammalian cytochrome $\mathrm{P}-450$, and the cytochrome $b_{5}$ preparation appeared spectrally identical to the hemeprotein of mammalian hepatic microsomes. A reconstituted system composed of skate $\mathrm{NADPH}-\mathrm{cytoch}$ rome $\mathrm{P}-450$ reductase, cytochrome $\mathrm{P}-450$, and microsomal lipid was active in the 0 -deethylation of 7-ethoxycoumarin. Thus the minimal components necessary for NADPH-supported monooxygenase activity in this species of fish are the same as in mammals ( Lu and Levin, 1974a). Furthermore, monooxygenase activity could be reconstituted with skate cytochrome $\mathrm{P}-450$ and NADPH-cytoch rome $\mathrm{P}-450$ reductase purified from rabbit, indicating the similarity of piscine and mammalian cytochromes $\mathrm{P}-450$ (Ball et al., 1979). Studies of fish hepatic microsomes by electron paramagnetic resonance spectroscopy, and by difference spectroscopy in the presence of substrates and 1 igands of cytochrome $\mathrm{P}-450$, have provided further evidence of the similarity of the mammalian and piscine microsomal cytochromes (Ahokas et al., 1979; Chevion et al., 1977; Stegeman and Chevion, 1980). Little is known about fish NADPH-cytochrome P-450 reductase per se, but microsomal NADPH-cytochrome $c$ reductase has been measured in several species, and presumably these activities are catalyzed by the same enzyme (e.g., Ahokas, 1977a; Bend and James, 1978; Forlin and Lidman, 1978; Lipsky et al., 1978; Stegeman et al., 1979; Yarbrough and Chambers, 1977). With hepatic microsomes from the marine teleost Stenotomus chrysops, the porgy or scup, the optima of $\mathrm{pH}$ and ionic strength for NADPH-cytochrome $c$ reductase activity are similar to those seen in mammals (Stegeman et al., 1979). NADH-cytoch rome c 
reductase activity is also measurable in fish hepatic microsomes (Stegeman, 1979; Stegeman and Chevion, 1980; Stegeman et al., 1979; Yarbrough and Chambers, 1977). Generally, NADH has been found to support fish microsomal monooxygenase activities at substantially lower rates than NADPH (Buhler and Rasmusson, 1968; Stegeman et al., 1979). However, with scup hepatic microsomes $\mathrm{NADH}$ supports aminopyrine demethylation to at least the same extent as NADPH, suggesting a functional role of cytoch rome $b_{5}$ in the hepatic monooxygenase system of this species (Stegeman et al., 1979).

Hepatic microsomes from $f$ ish catalyze a variety of monooxygenase reactions with xenobiotic substrates, such as aldrin epoxidation, aniline hydroxylation, phenacetin 0-dealkylation, aminopyrine $\mathrm{N}$-demethylation, and parathion desulfuration and also hydroxylate steroid hormones, important endogenous substrates (Buhler and Rasmusson, 1968; Burns, 1976; Hanson et a1., 1979; Iano et a1., 1976; Murphy, 1966). A number of factors can potentially affect the levels of hepatic monooxygenase activity in fish including diet, temperature, season, reproductive status, and previous exposure to xenobiotic compounds $(\mathrm{e} \cdot \mathrm{g} \cdot$, Bend and James, 1978; Hanson et al., 1980; Stegeman, 1979; Stegeman and Chevion, 1980; Stegeman et al., 1978; Walton et al., 1978). One difference between the piscine and mammalian enzymes is that the optimal temperatures for in vitro monooxygenase activities are generally lower for fish than mammals (e.g., Buhler and Rasmusson, 1968; Burns, 1976; Dewaide and Henderson, 1968; Stegeman et al., 1979). This is consistent with the fact that fish are poikilotherms, and most of the species 
studied inhabit waters which are much cooler than mammalian physiological temperatures. Generally, hepatic microsomes prepared from fish have a lower capacity to catalyze monooxygenations under optimal conditions than similar preparations from mammalian livers (reviewed in: Chambers and Yarbrough, 1976; James and Bend, 1978). However, microsomal preparations from untreated individuals of certain species of fish are considerably more active in metabolizing benzo(a)pyrene than hepatic microsomes from rodents (Ahokas, 1975; Pederson et al., 1974; Stegeman and Binder, 1979). Reasons why this may be the case will be discussed later.

Most work on the cytochrome P-450 monooxygenases of fish has focused on the liver enzymes, because the highest levels of activity are usually found in this organ, and it probably serves as the primary site of xenobiotic metabolism. However, monooxygenase activity has been reported in several extrahepatic tissues including blood, kidney, lens, gill, alimentary tract, red muscle, testis, heart, spleen, and pancreas (Bend et al., 1973; Buhler and Rasmusson, 1968; James et al., 1979; Payne and Penrose, 1975; Pederson et al., 1974; Stegeman et al., 1979). With most substrates the activities in the extrahepatic tissues are much lower than in the liver, and usually the kidney is second to the liver in activity. Interesting exceptions are two teleost $\mathrm{fish}$, the sheepshead (Archosargus probatocephalus) and black drum (Pogonias cromix), whose gill microsomal benzphetamine $\mathrm{N}$-demethylase activities approach the respective liver activities (James et $21 ., 1979$ ). With benzo(a)pyrene as a substrate, gill microsomes from these $f$ ish are much less active than liver microsomes. Another interesting case is scup, whose heart microsomes 
have a relatively high specific content of cytochrome $\mathrm{P}-450$, second only to the liver, yet have low monooxygenase activity with either aminopyrine or benzo(a)pyrene (Stegeman, 1980; Stegeman et al., 1979). The physiological function of this heart cytochrome $\mathrm{P}-450$ is unknown.

While the extrahepatic monooxygenase may not be quantitatively as important as the liver enzymes in the metabolism of xenobiotics, they may play a critical role in target organ toxicity. The target organs of xenobiotics requiring metabolic activation are not necessarily those most active in xenobiotic metabolism. As an example, benzo(a)pyrene, which is actively metabolized by mammalian liver, produces lung and skin tumors, and is generally not a hepatocarcinogen in the species examined (Thorgeirsson and Nebert, 1977).

Responses of fish to inducers of cytochrome $\mathrm{P}-450$ :

Experimental exposure of fish to petroleum hydrocarbons, polyhalogenated bipheny is or polycyclic aromatic hydrocarbons has been shown to induce increased levels of hepatic monooxygenase activities in several different species (e.g., Bend et al., 1973; Gruger, 1976; James and Bend, 1978; Lidman et a 1., 1976; Payne and Penrose, 1975; Pederson et a 1., 1976). In some cases induction has also been observed in extrahepatic tissues such as gill, kidney and ovary (James and Bend, 1980; Payne and Penrose, 1975; Pohl et al., 1975). The response of fish to inducers can be affected by a number of factors including age, sex, route of administration, and temperature (Hansson et al., 1980; James and Bend, 1980; Stegeman, 1979). 
A major difference between fish and mammals is that several species of $\mathrm{f}$ ish have been found not to respond to $P B$ type inducers such as phenobarbital, DDT, 2,2',4,4'-tetrachlorobiphenyl, and $2,2^{\prime}, 4,4^{\prime}, 5,5^{\prime}$-hexabromobiphenyl (Addison et al., 1977; Balk et al. , 1980; Bend et al., 1973; Forlin, 1980; Elcombe and Lech, 1979a; Hannson et al., 1980; James and Bend, 1978). Burns (1976) reported that phenylbutazone, an inducer of the PB-type, induced dieldrin epoxidase activity in liver of the killifish Fundulus heteroclitus. However, the levels of cytochrome $\mathrm{P}-450$ in the control animals in this study were much lower than normally seen in this species, and were very low even when compared to other untreated animals described in the same report. The levels of cytochrome $P-450$ in the "induced" fish were also low; thus the results of this study must be considered equivocal. Forlin and Lidman (1978) reported that $2,2^{\prime}, 4,4^{\prime}, 5,5^{\prime}$-hexachlorobipheny 1 (HCB) induced a 2-fold increase in hepatic p-nitroanisole 0 -demethylase activity in rainbow trout. Highly purified $2,2^{\prime}, 4,4^{\prime}, 5,5^{\prime}-\mathrm{HCB}$ has been shown to be a PB-type inducer in rats (Goldstein et al., 1978; Parkinson et al., 1980). However, Goldstein et al. (1978) also reported that a $99 \%$ pure commercial preparation of $2,2^{\prime}, 4,4^{\prime}, 5,5^{\prime}-\mathrm{HCB}$ was contaminated with 44 ppm of chlorinated dibenzofurans, some of which are extremely potent inducers of the 3-MC type (Poland et al., 1976). Because of this contamination, the commercial HCB behaved as a mixed type inducer. Forlin and Lidman did not indicate the purity of their $\mathrm{HCB}$, and quite possibly the response they observed in trout was due to similar contamination. The report of Goldstein et al. (1978) indicates that individual chlorinated biphenyl 
isomers used for induction studies must be rigorously purified, and that commercial preparations intended to be used as gas chromatography standards are not adequate for this purpose. Thus, there are no convincing reports in the literature of the response of $f$ ish to $P B-t y p e$ inducers.

Inducers of the 3-MC type are quite active in $\mathrm{fish}$ as indicated by the responses elicited by $3-M C$ itself, related polycyclic aromatic hydrocarbons, chlorinated biphenyl isomers and $\operatorname{TCDD}(\mathrm{e} . \mathrm{g} ., \mathrm{Elcombe}$ et al., 1979b; James and Bend, 1978; Pohl et al., 1975; Stegeman, 1979). Commercial PCBs, which are complex mixtures known to contain congeners which are $\mathrm{PB}, 3-\mathrm{MC}$ or mixed type inducers, generally produce a response in fish similar to pure compounds of the 3-MC type (Elcombe et al., 1979b; James and Bend, 1978; Hinton et al; 1978). Rainbow trout (Salmo gairdneri) have been shown to respond to the novel inducer isosafrole, but the response was like that to $\operatorname{TCDD}(E l c o m b e$ et al., 1980). Hannson et al. (1980) found that pregnenolone-16- $\alpha$-carbonitrile (PCN) did not affect hepatic levels of cytochrome $\mathrm{P}-450$ or steroid hydroxylase activity in rainbow trout. Similarly, Forlin (1980) reported that injection of rainbow trout with $P C N$ did not affect the levels of hepatic BPM activity or p-nitroanisole 0-demethylase activity, but did significantly alter the apparent $\mathrm{K}_{\mathrm{m}}$ for $\mathrm{p}-\mathrm{nit}$ roanisole. This result suggests that PCN may have produced a change in the complement of cytochrome $\mathrm{P}-450$ isozymes present in the livers of treated $\mathrm{fish}$, and thus this species may be competent to respond to this class of inducers.

The responses of different species of fish to 3-MC type inducers are varied. In some species a response similar to that of rats has been seen 
Page 38.

with an induction of BP monooxygenase activity or other cytoch rome $\mathrm{P}-448$ associated monooxygenases, an increase in the content of cytochrome $\mathrm{P}-450$, and a blue shift in its $\lambda_{\max }$ in the reduced co bound state (James and Bend, 1980; Stegeman, 1981b). With species such as sheepshead and scup, variable results have been reported, with increases in cytochrome $\mathrm{P}-450$ and spectral shifts observed in only certain experiments, although in all cases monooxygenase activities were induced (Chevion et al., 1977; James et al., 1977; James and Bend, 1980; Stegeman and Woodin, 1980). Rainbow trout are somewhat different, in that PCBs and polycyclic aromatic hydrocarbons induce increases in a number of hepatic monooxygenase activities as well as significant increases in cytochrome $P-450$, but there is no spectral shift in the $\lambda_{\max }$ of cytochrome P-450 (Elcombe et a1., 1979a; Gerhart and Carlson, 1978; Lidman et al., 1976). However, Elcombe and Lech (1979a) have observed an association between induction of hepatic microsomal monooxygenase activity in trout, and the appearance of a new protein band of 57,000 molecular weight using SDS-polyacrylamide gel electrophoresis. The band stains for heme and may be a novel form of cytochrome $P-450$.

Treatment of little skate with 1,2,3,4-dibenzanthracene (DBA) induced hepatic BPM activity 35-fold, with no apparent changes in cytochrome P-450 (Bend et al., 1976). However, the BPM activity in control microsomes was stimulated by $10^{-4} \mathrm{M} \alpha$-napthoflavone (ANF), while the activity in microsomes from untreated animals was strongly inhibited by this concentration of ANF, suggesting the induction of a different form of cytochrome $\mathrm{P}-450$. This was verified by the partial purification of 
cytochrome P-450 from control and DBA treated little skate (Ball et al., 1979). The control cytochrome $P-450$ has a $\lambda_{\max }$ at $450 \mathrm{~nm}$, and is relatively inefficient in metabolizing BP. DBA induces a form of cytochrome $\mathrm{P}-450$ that is very active in $B P$ metabolism, sensitive to inhibition by $\mathrm{ANF}$, and with a $\lambda_{\max }$ at $448 \mathrm{~nm}$, much like the cytochrome $\mathrm{P}-448$ induced in rats by $3-\mathrm{MC}$. The spectral shift is masked by the induction of another cytoch rome $P-450$ species with a $\lambda_{\max }$ at $451 \mathrm{~nm}$. Similar effects in other species might explain induction of monooxygenase activities without increases in cytochrome $\mathrm{P}-450$, or without spectral shifts.

In rodents, administration of $3-M C$ has little effect on hepatic microsomal $\mathrm{NADPH}-\mathrm{cyt}$ toch rome $\mathrm{c}$ reductase, while monooxygenase activities associated with cytoch rome P-448 are induced, such as BPM (Parkinson et al., 1980a; Lu et al., 1976). Inducers of the 3-MC-class produce little change in the $\mathrm{N}$-demethylation of aminopyrine and benzphetamine. Increases in these demethylase activities and NADPH-cytochrome $c$ reductase are part of the characteristic response to phenobarbital. As mentioned above, a number of species of fish have been shown not to respond to $\mathrm{PB}$ and related inducers. However, some responses of $\mathrm{fish}$ to inducers resemble those elicited by $\mathrm{PB}$ in mammals. Benzo(a)pyrene has been shown to induce hepatic NADPH-cytochrome c reductase in Fundulus, although aminopyrine demethylase (APD) activity was unchanged (Stegeman, 1979). Similarly, Hinton et al. (1978) found that 3-MC more than doubled hepatic NADPH-cytochrome c reductase activity in rainbow trout, although Forlin and Lidman (1978) observed that a commercial PCB mixture (Clophen 
A-50) had no significant effect on this activity in the same species. Exposure of channel catfish, Ictalurus punctatus, to PCBs and mullet, Mugil cephalus, to crude oil have been reported to induce hepatic NADPH-cytochrome $c$ reductase activity (Lipsky and Klaunig, 1978; Yarbrough and Chambers, 1977). Additionally, PCBs have been reported to induce aminopyrine $\mathrm{N}$-demethylase in channel catfish and mullet, Chelon labrosus (Hill and Camp, 1976; Hinton et al., 1978; Narbonne and Gallis, 1979). Whether these species can respond to $\mathrm{PB}-t y p e$ inducers has not been examined. In contrast to the above results, James and Bend (1980) found that treatment of sheepshead, stingray (Dasyatis sabina), and southern flounder (Paralichthyes lethostigma) with 3-MC did not affect hepatic NADPH-cytochrome c reductase activity. It should be evident that the induction responses in $\mathrm{f}$ ish are varied, and differ in certain ways from those seen in mammals.

Induction in the environment:

Correlations have been observed between exposure of fish to environmental pollution and the levels of hepatic microsomal monooxygenase activity (Burns, 1976; Dunn, 1979; Kurelec et al., 1977; Payne, 1976; Stegeman, 1978). Apparently these enzymes are induced in fish inhabiting heavily polluted environments, but it should be noted that exposure to various pollutants does not necessarily lead to induction. Ahokas et al. (1976) observed that fish inhabiting a grossly polluted lake had decreased levels of hepatic monooxygenase activity, possibly as a result of toxic injury. 
Generally hepatic BP monooxygenase activity induced in fish by experimental exposure to xenobiotics is sensitive to inhibition by $\alpha$-napthoflavone (Elcombe and Lech, 1979a; James and Bend, 1978; Stegeman, 1979; Stegeman, 1980). Among different species, and in some cases among individuals of the same species, considerable variability is seen in the sensitivity of constitutive BPM activity to ANF. In the case of little skate, Bend et al. (1978) reported that all untreated individuals examined had hepatic BPM activity that was stimulated by ANF. These same investigators found that hepatic BPM in some sheepshead and the majority of winter flounder (Pseudopleuronectes americanus) examined were inhibited by ANF, suggesting that some members of these species have monooxygenase systems that are induced. Scup and European lake trout, Salmo trutta lacustrus, are interesting because the BPM activity in all individuals sampled is strongly inhibited by ANF (Ahokas et al., 1977a; Stegeman and Binder, 1979). Additionally, hepatic microsomes from these species are much more active than those from untreated rats or mice in metabolizing benzo(a)pyrene, although the levels of cytochrome $\mathrm{P}-450$ are lower than in rodents. Possibly these species of fish are particularly sensitive to ambient levels of ubiquitous pollutants, such as PCBs, and the monooxygenase systems of all individuals are induced. Alternately the constitutive cytochromes of these species may resemble rat cytochrome P-448. BPM activity in untreated brook trout and rainbow trout is also 
sensitive to ANF inhibition, even when constitutive activities are very Low (Elcombe and Lech, 1979a; Stegeman and Chevion, 1980). These observations lend support to the notion that the constitutive cytochromes of some species of $\mathrm{f}$ ish may be like cytochrome P-448. However the induction of very low levels of a cytochrome active in BP metabolism and sensitive to ANF could also explain these results. Whether some species of fish are sensitive enough to be induced by ambient levels of ubiquitous contaminants, even in relatively clean environments, is an interesting question deserving of further investigation.

Evidence for multiple forms of cytoch rome $\mathrm{P}-450$ in fish:

Over the past few years considerable evidence has been obtained indicating the presence of multiple forms of cytochrome $\mathrm{p}-450$ in $\mathrm{fish}$. Much of this evidence has already been described (references cited above). Substantial inductions of monooxygenase activity without increases in the total content of cytochrome $\mathrm{P}-450$, or with changes in $\lambda_{\max }$ and sensitivity to ANF, all suggest changes in the isozymes of cytoch rome $P-450$ present. Differential sensitivity of monooxygenase activity to ANF among different individuals of the same species also is evidence for multiple forms of this heme protein. The induction of specific monooxygenase activities such as BPM with little change in other activities, such as benzphetamine $\mathrm{N}$-demethylase, indicate changes in the catalytic entities present before and after induction. The appearance of a novel heme-staining band in the electrophoretic pattern of microsomes from induced compared to that from control rainbow trout, suggests the synthesis of a new form of cytochrome $P-450$. Perhaps the clearest 
Page 43.

evidence is the resolution of different forms of cytochrome $P-450$ from little skate, with differing substrate specificities, spectral properties and sensitivities to ANF. Whether these proteins are the products of different genes, or the result of post-translational modification is not known.

Additional evidence for multiple forms of cytochrome $\mathrm{P}-450$ in $\mathrm{fish}$, not previously mentioned, includes the fact that the absorption maximum of hepatic cytochrome $\mathrm{P}-450$ in spawning winter flounder males is at 448 $\mathrm{nm}$, while that of the gravid females is at $450 \mathrm{~nm}$ (Stegeman et al., 1978). During the rest of the year, the $\lambda_{\max }$ of the male cytochrome is at $450 \mathrm{~nm}$. James and Bend (1980) observed that in 3-MC treated sheepshead, the time course of change in BPM activity was distinct from that of total cytochrome $\mathrm{P}-450$ and two other monooxygenase activities. Administration of $3-M C$ induced an increase in the specific content of cytochrome $P-450$, and a blue shift in its $\lambda_{\max }$; however BPM activity rose before the increase in cytochrome or spectral shift were evident. The other monooxygenase activities measured more closely followed changes in cytochrome content. These results suggest that $3-\mathrm{MC}$ may induce more than one form of cytochrome $\mathrm{P}-450$ in sheepshead, possibly including a minor form very active in BP metabolism. Based on the sum of evidence described above, and the more rigorous evidence obtained with mammalian species, it seems safe to conclude that multiple forms of cytochrome $\mathrm{P}-450$ do exist within individuals of various species of $\mathrm{f}$ ish. 
Page 44.

DEVELOPMENTAL CHANGES IN THE CYTOCHROME P-450 MONOOXYGENASE SYSTEM

The ontogeny of the hepatic microsomal monooxygenase system has been studied in several mammalian species including rat, mouse, rabbit, guinea pig and swine (reviewed by Gillette and Stripp, 1975; Neims et al., 1976; Short et a1., 1976). Generally, monooxygenase activities become detectable in fetal liver of nonprimate mammals during the second or third trimester of pregnancy, remain low during the fetal development, and rise to adult levels over a period of days to weeks after birth. While the details of the developmental patterns of monooxygenase activities and the components of the monooxygenase system may vary from species to species, substantial increases in hepatic monooxygenase activities have consistently been observed shortly after birth in all of the placental mammals studied (e.g. Cresteil et al., 1974; Dallner et al., 1966b; Ecobichon et al., 1972; Rane et al., 1973; Short and Davis, 1970). Generally in mammalian species, the postnatal development of monooxygenase activity roughly parallels that of the various components of the monooxygenase system (Short et al., 1976). Levels of hepatic cytoch romes $\mathrm{P}-450$ and $\mathrm{b}_{5}$, and $\mathrm{NADPH}$-and $\mathrm{NADH}-\mathrm{cytoch}$ rome $c$ reductase activities increase substantially during postnatal development (e.g. Cresteil et al., 1979; Dallner et al., 1966b; Kahl et al., 1980; Kuenzig et al., 1974; Rane et al., 1973; Short and Stith, 1973). However, the developmental sequences of particular monooxygenase activities may not correlate well with the total content of cytochrome $\mathrm{P}-450$ or the levels 
Page 45 .

of other components of microsomal electron transport (e.g. At las et $\underline{\text { a }}$., 1977; Basu et al., 1971; Guenthner and Nebert, 1978; Kahl et al., 1980). Within a species distinct developmental patterns of monooxygenase activity have been observed for different substrates and for positional specificity with the same substrate (e.g. At las et al., 1977; Basu et al., 1971; Gram et al., 1969; Kahl et al., 1980; McCormack et al., 1979; Norman et al., 1978). The following results from Atlas et al. (1977) are presented as an example. In rabbit liver microsomes, 2-acetylaminofluorene $\mathrm{N}$-hydroxylase activity rises steadily from birth and reaches a plateau after 25 days, at a specific activity approximately five times higher than in the near term fetus. The total content of cytochrome $\mathrm{P}-450$ in hepatic microsomes shows a similar pattern of development. Bipheny 1 4-hydroxylase activity increases from birth to a peak at 50 days, at a specific activity more than 30 times higher than in the near term fetus. In contrast, biphenyl 2-hydroxylase activity changes little postnatally and becomes undetectable by 16 days post partum. When liver microsomes from rabbits of different ages were analyzed by SDS-polyacrylamide gel electrophoresis, correlations were observed between the intensity of certain protein staining bands, within the molecular weight range of cytoch rome $\mathrm{P}-450$, and the various monooxygenase activities. These results strongly suggest ontogenic changes in the compliment of liver cytochrome $\mathrm{P}-450$ isozymes.

The postnatal period is characterized not only by changes in the levels of the various components of the monooxygenase system, but also dramatic changes in the hepatic endoplasmic reticulum (e.g. Dallner et 
Page 46.

a1., 1966a; Chedid and Nair, 1974). A close association has been observed between hepatocyte ultrastructure and developmental changes in monooxygenase activity (e.g. Dallner et al., 1966b; Ecobichon et al., 1978; Kuenzig et al., 1974; Short et al., 1976). In fetal hepatocytes of nonprimate mammals, the endoplasmic reticulum (ER) is sparse in the early stages of liver development, and gradually becomes more prominent as parturition is approached. Before parturition the ER is predominantly of the rough type ( $R E R$ ), whereas the smooth ER ( $S E R$ ) does not increase substantially until after birth. Low levels of monooxygenase activity become detectable during the development of the RER prenatally and increase in parallel with the proliferation of the SER postnatally.

Developmental changes in the physical properties of the ER have also been observed. In rats, Kapitulnik et al. (1979) reported that the fluidity of hepatic microsomal membranes was 2 -fold higher on the first day after birth, compared with the last day of fetal life. This change in membrane fluidity was attributed to an increase in the ratio of membrane phospholipid to cholesterol. Fuer (1978) reported a trend towards increasing unsaturation in the fatty acyl groups of rat hepatic microsomal phospholipids, with development after birth. Such a change in membrane fatty acids would also be expected to increase fluidity. Changes in membrane fluidity might affect the functional associations of the components of the monooxygenase system, and may be partially responsible for increases in activity after birth.

The majority of developmental studies on the cytochrome P-450 system have been concerned with the enzymes of the liver, and relatively little 
Page 47.

work has been done with the extrahepatic tissues. Generally the levels of extrahepatic monooxygenase activities are lower in fetuses and neonates than in adults (Berry et al., 1977; Fouts and Devereux, 1972; Kahl et al., 1980; Tredger et al., 1980; Short and Davis, 1970). However, the extrahepatic tissues may play a quantitatively more important role in xenobiotic metabolism in the fetus than during later stages of development. Berry et a 1 . (1977) reported that in untreated fetal rats, the specific activities of BPM in lung, kidney and liver homogenates were comparable, while in adult rats the liver was 3 times as active as the kidney, and 13 times as active as the lung in metabolizing BP. In the human fetus BPM specific activity is highest in the adrenals, and considerable activity is also present in other extrahepatic $t$ issues (Juchau et a1., 1972; Rifkind et al., 1979). Since the adrenals are relatively large during fetal development, they may play a significant role in xenobiotic metabolism (Short et al., 1976).

Apparently the only nonmammalian species in which the ontogeny of the microsomal monooxygenase system has been examined is the chicken (Drummond et al., 1972; Powis et al., 1976; Rifkind et al., 1979). At comparable stages of development, chick embryo livers are much more active in metabolizing xenobiotics than mammalian fetal livers (Rifkind et al., 1979). Powis et al. (1976) examined changes in the oxidative metabolism of aminopyrine, aniline and napthalene by chicken liver microsomes from 1 day before hatching until 7 days after. Monooxygenase activities with each of these substrates showed the same developmental pattern. Prior to hatching activities were about $50 \%$ of the adult 
Page 48.

values; within one day of hatching they peaked at 3 -fold higher levels, then gradually fell off to the adult levels within 7 days. Cytochrome $\mathrm{P}-450$, cytochrome $\mathrm{b}_{5}$, and NADPH-cytoch rome $c$ reductase activity changed relatively little over the period examined. The liver monooxygenase activities more closely correlated with NADPH cytochrome P-450 reductase activity, which also peaked at one day after hatching. This suggests that around the time of hatching, monooxygenase activity in chicken liver is Limited by the functional association of cytochrome $P-450$ and reductase, rather than the actual levels of these proteins.

Regulation of the perinatal development of the cytoch rome P-450 system:

The factors regulating the postnatal increases in the components of the monooxygenase system and monooxygenase activities in mammals have not been clearly established. Negishi and Kreibich (1978) reported electrophoretic and immunochemical evidence that the increase in cytochrome $\mathrm{P}-450$ content in rat liver after birth results from de novo synthesis of the hemeprotein, rather than activation of a pool of apoprotein by insertion of heme. Manchester and Neims (1977) followed changes in hepatic monooxygenases in guinea pigs delivered naturally and 5 days before term by Caesarian section. Within 72 hours after birth, in both premature and full-term guinea pigs, the monooxygenase activities examined increased 3-fold. Similarly, Leakey and Fouts (1979) showed that premature delivery of rats produced a precocious surge in the level of hepatic cytochrome $\mathrm{P}-450$. These results indicate that physiological changes associated with the event of birth trigger the increase in 
Page 49.

cytochrome $\mathrm{P}-450$ and associated monooxygenase activities.

The developmental changes in a number of enzymes have been shown to be under hormonal control, especially during the perinatal period (Greengard, 1971; Oliver, 1974). Wilson (1970) has proposed that growth hormone $(\mathrm{GH})$ is a physiological repressor of hepatic monooxygenase activity in the rat fetus. Serum levels of growth hormone are high in the fetus and fall rapidly after birth, and there is a strong correlation between the levels of circulating $\mathrm{GH}$ and the levels of hepatic cytochrome P-450 and xenobiotic metabolism (Wilson and Frohman, 1974). Furthermore, injection of growth hormone was found to slow the postnatal maturation of hepatic monooxygenase activity in male rats, and to diminish the hepatic xenobiotic metabolizing capacity of adult males (Wilson, 1970). However, $\mathrm{GH}$ does not affect hepatic monooxygenase activity in adult female rats, and its inhibitory effects on the postnatal development of monooxygenase activity in males only become evident beyond 20 days from birth (Wilson, 1970; Leakey et al., 1979). Kramer et al. (1978) reported the results of experiments with gonadectomized and hormone treated rats, which indicate that the effects of $\mathrm{GH}$ on the monooxygenase system are due in part to an antagonism of the effects of androgens. In adult rats there are sex differences in cytochrome $\mathrm{P}-450$ dependent monooxygenase activities that are controlled by gonadal steroids (Kato, 1974). Hepatic microsomes from males are more active than those of females in metabolizing a variety of substrates. Sex related differences in xenobiotic metabolism become apparent around the time of puberty, beginning about 3 weeks from birth (Macleod et al., 1972). The fact that GH does not affect the 
monooxygenase system of female rats, and that its effects on males are not apparent until puberty ( 20 days from birth) are further evidence that it acts as an antagonist of androgens. Whether $\mathrm{GH}$ is a prenatal repressor of the cytochrome $P-450$ system in both male and female fetuses is uncertain.

Leakey and Fouts (1979) have shown that adrenalectomy of prematurely delivered rats blocks the early increase in cytochrome $\mathrm{P}-450$, indicating the role of adrenal hormones in this process. Administration of glucocorticoids to neonatal rats produces a precocious stimulation of the development of cytochrome $\mathrm{P}-450$ and associated monooxygenase activities that is not blocked by growth hormone (Leakey et al., 1979; Leakey and Fouts, 1979; Mukhtar et al., 1974). Glucocorticoids have little effect on the monooxygenase system of adult rats, indicating that their effect on neonates is not simply a xenobiotic type induction (Leakey and Fouts, 1979). However, the administration of glucocorticoids to pregnant rats does not stimulate an early increase in fetal hepatic cytochrome $\mathrm{P}-450$, although the hormones can be detected in the fetal plasma and liver (Leakey and Fouts, 1978; 1979). Thus competence to respond to glucocorticoids does not appear until after birth, and changes in the levels of these hormones are probably not the physiological trigger which results in postnatal increase in hepatic cytochrome $P-450$. Once competence to respond to glucocorticoids appears, the content of cytochrome P-450 may increase under their influence. The "trigger" mechanism has yet to be established. The genetic regulation of the development of mammalian cytochrome $\mathrm{P}-450$ is likely to be complex, as 
multiple forms may have distinct developmental patterns that are tissue specific.

Chick embryos are a useful model system for studying the regulation of the cytochrome $\mathrm{P}-450$ system during development, because they are free of maternal influences. Wishart and Dutton (1975) showed that grafting chicken pituitary tissue on the chorioallontoic membrane of chick embryos precociously stimulated aniline hydroxylase activity in the embryonic liver. Later work indicated that the factor released from the grafted pituitaries was probably adrenocorticotrophic hormone (ACTH), as ACTH and glucocorticoids stimulated precocious development of aniline hydroxylase, while a number of other hormonal substances were inactive (Leakey and Dutton, 1975; Leakey and Wishart, 1976). Chick embryos differ from rat fetuses in that they are competent to respond to glucocorticoid stimulation of monooxygenase activity. In chicken, ACTH is released upon the onset of hatching, and thus may mediate the post hatching surge in monooxygenase activity through its effects on the adrenals and circulating levels of glucocorticoids (Leakey and Dutton, 1975).

\section{Transplacental induction of monooxygenase activity:}

Treatment of pregnant animals with 3-MC-type inducers has been shown to produce large increases in hepatic monooxygenase activities in fetuses of rat, rabbit, hamsters and responsive strains of mice (e.g. Alvares and Kappas, 1975; At las et al., 1977; Cresteil et al., 1979; Gielen et al., 1972; Guenthner and Mannering, 1977a; Guenthner and Nebert, 1978; Lucier et al., 1975; Nebert and Gelboin, 1969; Welch et al., 1972). These 
inducers also stimulate monooxygenase activity in fetal extrahepatic tissues such as lung, kidney, small intestine, and spleen (Atlas et al., 1977; Berry et a1., 1977; Nebert and Gelboin, 1969). Induction of fetal liver monooxygenase activities by $3-M C$ type inducers is generally accompanied by elevated levels of cytochrome $\mathrm{P}-450$ and a blue shift in the co difference spectrum as seen in adult animals. While the constitutive levels of fetal monooxygenase activities generally are very low, induced activities can exceed those of untreated adults. For example, Berry et al. (1977) reported that in fetal rats TCDD induced BPM activity about 60-fold in the liver and about 22-fold in the kidney. The induced levels of activity in both these fetal tissues were about 4-fold higher than the activities of the respective tissues of control pregnant rats. These results indicate that the low levels of monooxygenase activities in fetal tissues are not the result of a lack of competence to respond to induction:

In the majority of transplacental induction studies with 3-MC-type inducers, induction of monooxygenase activity has only been demonstrated during the last third of gestation. However some studies have examined the induction of monooxygenase activity in fetuses during earlier development. Welch et al. (1972) reported that in rats, which have a gestation period of about 22 days, BPM activity was not detectable in fetal liver on gestation day 15 but was inducible by 3-MC at that $t$ ime. The majority of inbred strains of mice can respond to 3-MC type inducers, but a number of strains have been found to be genetically non responsive (Nebert et al., 1975). Gielen et al. (1972) have shown that in 
responsive strains of mice, which have a gestation period of about 21 days, hepatic BP monooxygenase activity is inducible by 3-MC on gestation day 12. Apparently, induction of monooxygenase activity by 3-MC type inducers has not been directly demonstrated in mammals during earlier periods of embryonic development.

On the basis of an increased incidence of sister chromatid exchanges $(S C E)^{2}$ in embryos of responsive strains of mice cultured in the presence of benzo(a)pyrene, Galloway et al. (1980) have concluded that mouse embryos are competent to respond to inducers of cytochrome $\mathrm{P}-450$ on day $71 / 2$ of gestation. No increase in SCE was observed in the embryos of nonresponsive strains of mice cultured in the presence of $\mathrm{BP}$. However, an increase in SCE in embryos of non responsive strains was produced by the inclusion of rat liver enzymes in the culture medium, thus indicating that the nonresponsive strains of mice do not have some defect which prevents the formation of SCE. Using the same system, preliminary data was obtained, suggesting that mouse embryos as early as the third day of gestation have inducible BPM activity ${ }^{3}$. This indirect approach to examining induction competence during embryonic development was required because monooxygenase activity is not directly measurable in the embryos. These data do not conclusively demonstrate induction but do indicate that the responsive strain embryos have the capacity to activate

2. Damage to DNA results in exchanges between sister chromatids during DNA synthesis. BP requires metabolic activation to produce such effects.

3. The third day of gestation is before implantation and mouse embryos are in the blastula stage. Day $71 / 2$ of gestation is characterized by the appearance of the somites; the major organ systems have yet to form (Rugh, 1974). 
BP.

Kahl et al. (1980) studied the orcugeny of hepatic cytosolic TCDD receptors in rats, rabbits, mice and cotton rat. Although the detailed developmental patterns vary between species, TCDD binding sites become detectable in liver cytosol during the second half of gestation, reach a peak of concentration between the neonatal and weanling periods, and are considerably decreased in adults. Carlstedt-Duke et al. (1979) observed a similar postnatal developmental pattern for TCDD receptors in rat liver cytosol. The ontogeny of receptor concentration roughly parallels developmental changes in maximum inducible monooxygenase activity (Carlstedt-Duke et al., 1979; Kahl et al., 1980).

Relatively. few transplacental induction studies have been done with phenobarbital and the results have been variable. Induction of monooxygenase activity in fetal liver by maternal pretreatment with PB has been reported in rat, rabbit, guinea pig and hamster (Alvares and Kappa s, 1975; Kuenzig et al., 1974; Nebert and Gelboin, 1969; Rane et al., 1973). However, Welch et al. (1972) and Guenthner and Mannering (1977a) found that fetal rat liver was refractive to induction by $P B$. Cresteil et al. (1979) attributed an increase in the specific content of cytoch rome $\mathrm{P}-450$ in fetal rat hepatic microsomes following $\mathrm{PB}$ treatment, to a decrease in the amount of bound ribosomes, rather than a net synthesis of cytochrome P-450. PB apparently stimulated the conversion of rough ER to smooth ER, without affecting cytochrome P-450. The results of this study cast some doubt on earlier reports of induction of fetal liver monooxygenase activity by $\mathrm{PB}$. However, while other studies 
only reported moderate increases in fetal monooxygenase activities after PB treatment, Nebert and Gelboin (1969) observed that pretreatment of pregnant hamsters with $P B$ resulted in a 21 -fold induction of BPM activity in fetal liver. Such an extensive induction is not likely to be artifactual. $\mathrm{PB}$ is clearly active in inducing hepatic monooxygenase activities and cytochrome $\mathrm{P}-450$ in various species shortly after parturition (Alvares and Kappas, 1975; Cresteil et al., 1979; Guenthner and Mannering, 1977a; Hart et al., 1962; Schwab et al., 1980). Results of various studies are in agreement concerning the cransplacental effects of PB on fetal hepatic NADPH-cytoch rome c reductase and NADPH-cytoch rome p-450 reductase activities. PB apparently has little effect on either of these activities in fetal liver until near parturition, while both activities are inducible by $\mathrm{PB}$ in neonates and adults (Cresteil et al., 1979; Guenthner and Mannering, 1977a; Kuenzig et al., 1974; Rane et al., 1973).

Chick embryonic livers are competent to respond to inducers of cytochrome P-450. Rifkind et a1. (1979) examined the response of chick embryos to $\beta$-naphthoflavone. This 3-MC-type inducer was injected into yolk sacs at 4 days before hatching. Within 24 hours of injection, hepatic BPM activity was induced 6-fold, ethoxycoumarin 0-deethylase was induced 2-fold, and the total content of cytochrome P-450 was induced about 2.5-fold. Associated with the induction of cytochrome $\mathrm{P}-450$ was a $2 \mathrm{~nm}$ blue shift in the characteristic $\lambda_{\max }$ of this microsomal cytochrome. Various chlorinated dibenzodioxins, dibenzofurans, and bipheny 1 congeners are also active in inducing cytochrome $\mathrm{P}-448$ and BPM 
activity in chick embryonic liver (Poland and Glover, 1977 and 1973). Chick embryonic livers may also be competent to respond to $\mathrm{PB}$-type inducers, as Rifkind et $\underline{\text { al. }}$. (1973) reported that PB produced a modest induction of cytochrome $\mathrm{P}-450$ and aminopyrine demethylase activity 3 days before hatching.

Just as the constitutive forms of cytochrome $P-450$ present during the course of development may vary, distinct forms of cytochrome P-450 may be induced in various tissues at different stages of development. At las et al. (1977) followed the developmental patterns of a number of monooxygenase activities in the livers of control and 3-MC treated rabbits from the late fetal period until adulthood, and correlated changes in activity with changes in intensity of protein staining bands on SDS-polyacrylamide gels. Some of the observations on control animals were described above. BPM activity was found to be inducible in rabbit liver by $3-M C$ only from the late fetal and neonatal periods. The induced activity was associated with a polypeptide of 57,000 molecular weight and was sensitive to inhibition by $\alpha$-naphthoflavone. Developmental changes in response to $3-M C$ were shown to be $t$ issue dependent, as BPM activity was inducible in kidney at all ages. The induction of 2-acetylaminofluorene $\mathrm{N}$-hydroxylase activity was associated with a band of 54,000 molecular weight and was inducible beginning 10 days from parturition through adulthood.

More definitive evidence for temporal control of inducible forms of cytochrome P-450 have been reported by Norman et al. (1978). They purified the major form of cytoch rome $P-450$ induced by TCDD in neonatal 
Page 57.

rabbit. Like Atlas et $\underline{\text { al}}$., they found this cytochrome to have a molecular weight of 57,000 , to be sensitive to inhibition by ANF, and to be very active in $B P$ metabolism in a reconstituted system with reductase and phospholipid. On the basis of peptide fingerprinting and immunochemical analysis, this protein was found to be distinct from the major form of cytoch rome $\mathrm{P}-450$ induced by TCDD in adult rabbit liver. In contrast to 3-MC, TCDD was also found to induce a small amount of the "neonatal" form of cytochrome P-450 in adult liver. Schwab et al. (1980) have purified the major form of cytochrome $P-450$ induced in neonatal rabbit liver by $\mathrm{PB}$, and have shown on the basis of immunochemical characterization, peptide mapping, and kinetic properties, that it is the 8 ame as the major form of cytoch rome $P-450$ induced by $P B$ in adult liver. Thus, in contrast to $3-M C$ and $T C D D, P B$ induces the same form of cytoch rome $P-450$ in neonatal and adult rabbits.

Negishi and Nebert (1979) and Guenthner and Nebert (1978) have reported electrophoretic and immunochemical evidence indicating that TCDD induces two different forms of cytochrome $\mathrm{P}-450$ in fetuses of both rats and mice. Apparently, the form of cytochrome $P-450$ most active in $B P$ metabolism is inducible a few days earlier than the other form of cytoch rome $\mathrm{P}-450$, which is active in the hydroxylation of acetanilide. Both forms of cytochrome $\mathrm{P}-450$ remain inducible in rodent liver during later deve lopment. 
Page 58.

B IOACTIVATION BY THE CYTOCHROME P-450 SYSTEM

The role of the cytoch rome $\mathrm{P}-450$ monooxygenase system in mediating the cytotoxicity, carcinogenicity and mutagenicity of certain classes of compounds in mammals is well established (reviews: Gillette et al., 1974; Thorgeirsson and Nebert, 1977; Weisburger, 1978). Metabolism by cytoch rome $\mathrm{P}-450$ can convert relatively inert substances into reactive electrophiles, which can combine with nucleophilic sites on cellular macromolecules leading to tissue damage, mutations, and in some cases neoplastic disease. Presumably similar mechanisms operate in lower vertebrates; a number of studies have shown that $f$ ish are susceptible to chemical carcinogenesis (e.g., Grieco et al., 1978; Hendricks et al., 1980; Pliss and Khudoley, 1975; Sinnhuber et al., 1968). A point worth emphasizing is that early developmental stages may be particularly sensitive to damage from activated metabolites, because cells undergoing division generally are more sensitive to such damage than nondividing cells (Harbison, 1978). A number of studies have shown that fetuses and neonates are more susceptible to chemical carcinogenesis than weanlings or adults (reviewed by: Schoental, 1974). Possibly many of the cancers occurring in later life are initiated during early development. Additionally, early developmental stages are uniquely sensitive to teratogenic effects. While there are likely to be many different mechanisms of teratogenesis, cytochrome $\mathrm{P}-450$ appears to play a role in the activation of certain proteratogens (Fantel et, 1979; Kitchin et al., 1981; Martz et al., 1977; Shum et al., 1979). 
The susceptibility of a tissue to the toxicity of a compound requiring metabolic activation by cytochrome $\mathrm{P}-450$ is 1 ikely to depend, in part, on the temporary steady state levels of activated metabolites (Thorgeirsson and Nebert, 1977). This in turn will depend on the catalytic properties and levels of cytochrome P-450 isozymes present, as well as the activities of other enzymes and nonenzymatic factors involved in either activation or detoxification. Any factor which affects the balance between production and detoxification of activated metabolites will influence the likelihood that critical lesions will be produced. Thus, the qualitative and quantitative changes in the cytochrome $P-450$ system, which occur during the course of development, or after induction, may significantly affect the sensitivity of individuals to the toxicity of a given substance.

Several polycyclic aromatic hydrocarbons are procarcinogens that are activated by the cytochrome $\mathrm{P}-450$ system; of these benzo(a)pyrene probably has been most extensively studied (Thorgeirsson and Nebert, 1977; Weisburger, 1978). BP is a widespread environmental contaminant that is found in coastal marine sediments and animals, possibly as a result of the aerial fallout of combustion products (Laflamme and Hites, 1978; Pancirov and Brown, 1977; Neff, 1979). BP is of particular interest in the present context, because it was used as a model monooxygenase substrate in the research described in this thesis. Metabolism of BP by the cytoch rome $\mathrm{P}-450$ system yields a variety of hydroxylated products and quinones, shown in Figure 1-2. The relative proportions of various metabolites vary with species, tissue and 

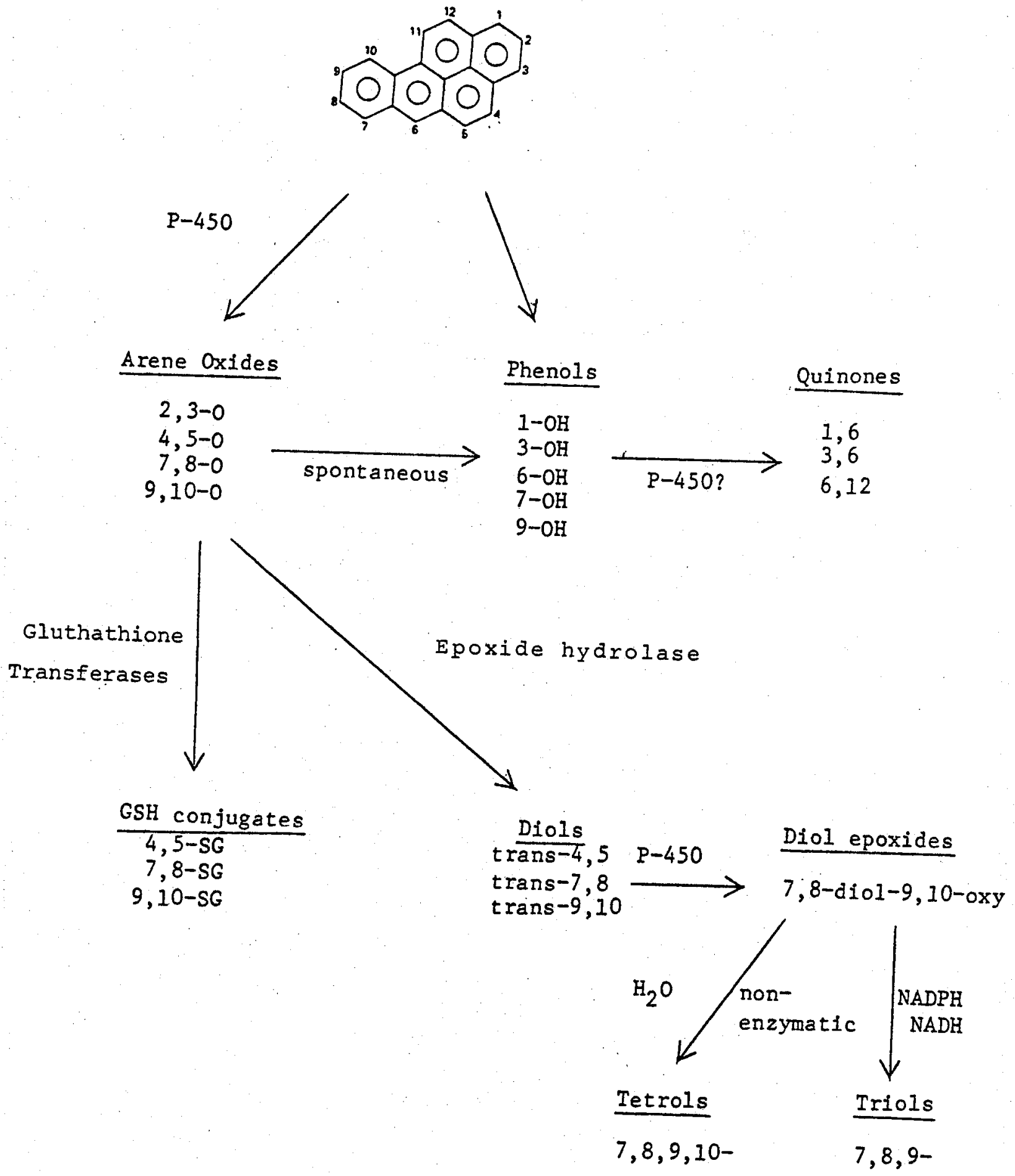

Figure 1-2. PATHWAYS OF BENZO(A)PYRENE METABOLISM (After Yang et al.,
1998). 
pretreatment of animals (Berry et a et al., 1979). Arene oxides, activated molecules that react with cellular nucleophiles in vitro, have been implicated as metabolic intermediates in the formation of most of these products (Jerina and Daly, 1974). Arene oxides isomerize spontaneously to yield phenols, and can be inactivated by hydration to dihydrodiols by the microsomal enzyme, epoxide hydrolase, or by addition of glutathione, catalyzed by the cytosolic glutathione transferases (Yang et al., 1978). While many of the metabolites of $\mathrm{BP}$ are toxic and mutagenic, the diastereomeric 7,8-dihydrodiol-9, 10-epoxides are among the most potent mutagens known (Newbold and Brookes, 1976; Wislocki et al., 1976). These are the metabolites of $\mathrm{BP}$ responsible for most of the binding to nucleic acids in vivo, and are likely to be the ultimate carcinogenic forms of $B P$ (Kapitulnik et al., 1978; King et al. , 1976; Weinstein et al., 1976). The formation of the 7,8-dihydrodiol, the precursor of the extremely reactive diol epoxides, requires epoxide hydrolase. Thus this enzyme, which is normally involved in the inactivation of reactive electrophilic metabolites, catalyzes one of the steps leading to proximate carcinogenic form of $B P$.

The mammalian liver cytochrome $\mathrm{P}-450$ isozymes induced by $\mathrm{PB}$ and $3-\mathrm{MC}$ show different positional and stereospecificity in metabolizing $B P$ (Holder et al., 1974; Pezzuto et al., 1978; Rasmussen and Wang, 1974; Yang et al., 1975; Yang et al., 1978). The major isozymes induced by 3-MC in rats and rabbits produce more benzo-ring metabolites than the isozymes induced by $\mathrm{PB}$. The benzo-ring metabolites include the highly mutagenic 7,8-dihydrodiol-9,10-epoxides; thus changes in metabolite 
Page 62.

profiles upon induction by 3-MC type inducers may be associated with an increased risk of BP initiated cancer (Thorgeirsson and Nebert, 1977).

The pathways of BP metabolism in fish appear to be quite similar to those in mammals (reviewed by Stegeman, 1981b). Liver preparations from a number of different species of fish have been shown to metabolize BP to a spectrum of diols, quinones and phenols like those produced by mammalian cytochromes $\mathrm{P}-450$, but there is considerable species variability in the relative proportions of different metabolites (Ahokas et al., 1979; Bend et a1., 1979; Stegeman, 1981; Varanasi et al., 1980). Epoxide hydrolase and glutathione S-transferase activities with benzo(a)pyrene 4,5-oxide have been shown to be present in the livers and extrahepatic tissues of a number of different species of $\mathrm{fish}$ ( $\mathrm{James}$ et al., 1979). It is of interest to note that hepatic microsomes or postmitochondrial supernatants (PMS) from several different teleost species, produce profiles of BP metabolites like those of liver microsomes from 3-MC induced mammals, with a high proportion of metabolism on the benzo-ring (Ahokas et al., 1979; Stegeman, 1981; Varanasi and Gmur, 1980). These results are consistent with the $\alpha$-napthoflavone inhibition data presented above, suggesting that the cytochrome $\mathrm{P}-450$ systems of certain species of $\mathrm{f}$ ish have been induced by ambient levels of environmental contaminants, or that their constitutive cytoch romes are like rat cytoch rome $\mathrm{P}-448$.

The activation of BP can be studied in vitro using mutation assays with bacterial or eukaryotic cells, and by measuring covalent binding of BP metabolites to DNA (Yang et al., 1979). Hepatic microsomes from 
several species of $\mathrm{f}$ ish have been shown to metabolize BP to products that are mutagenic to bacteria (Ahokas et al., 1977; Hinton et al., 1978;

Kurelec et al., 1979; Payne et a1., 1979; Stegeman et al., 1978). In fact, hepatic microsomes from untreated European lake trout, scup and winter flounder activate BP to about the same extent as hepatic microsomes from $\mathrm{PCB}$-induced rats. Similarly fish liver microsomes or PMS can activate BP to products that covalently bind to DNA (Ahokas et al., 1979; Varanasi et al., 1980; Varanasi and Gmur, 1980). There is considerable species variability in the degree of activation of BP. For example, Ahokas et al. (1979) observed that hepatic microsomes from European lake trout catalyzed more than 30 times as much covalent binding of BP to.DNA as similar preparations from roach, Rutilus rutilis. Induction of the monooxygenase activity in fish results in changes in $B P$ metabolite profiles, but no consistent pattern of change is apparent among different species (Bend et al., 1979; Stegeman, 1981b; Varanasi and Gmur, 1980). In some species, but not all, induction results in greatly enhanced capacity to activate BP (Kurelec et al, 1977; Varanasi and Gmur, 1980; Varanasi et al., 1980). Quite possibly, species differences in the capacity to activate environmental carcinogens may result in differences in their sensitivity to carcinogenesis.

THE RESEARCH PROBLEM AND EXPERIMENTAL APPROACH

The cytochrome P-450 dependent monooxygenases may play an important role in determining the fate and effects of organic pollutants in fish. 
Page 64.

Fish probably are most sensitive to toxic injury during embryonic and larval development, yet the occurrence and properties of the monooxygenase systems during these periods are entirely unknown. The research described in this thesis was undertaken to answer the following questions :

1) Do fish embryos have the capacity to catalyze xenobiotic monooxygenase reactions, and if so, how does this capacity change during the course of development?

2) When do the components of the microsomal electron transport system become detectable, and how do their levels change during the course of development?

3) Can fish embryos respond to inducers of cytochrome P-450? If so, how does their response change during the course of development, and can environmentally realistic levels of inducers produce a response?

Setting out to answer these questions involved a number of practical considerations including the selection of experimental species, monooxygenase substrates and inducers. The estuarine killifish Fundulus heteroclitus and brook trout Salvelinus fontinalis were selected for this study primarily because their embryos are convenient experimental material, and because considerable background information exists on the monooxygenase systems of the adults of these species (Addison et al., 1978; Stegeman, 1981; Stegeman, 1978; Stegeman and Chevion, 1980).

A necessary prerequisite for a study of this kind is the capacity to measure monooxygenase activities with great sensitivity, since only small 
amounts of tissue are available, and activities are likely to be low. When this research was undertaken, the necessary methods were not available, and considerable effort was spent modifying existing procedures for use on an ultramicro-scale. That work is not described in the thesis.

The two substrates selected for this study were benzo(a)pyrene and the analgesic drug, aminopyrine (AP); both of these compounds are model substrates of cytochrome $\mathrm{P}-450$. Radiometric assays for these two substrates have been described in the literature (DePierre, 1977; Poland and Nebert, 1974). Modification of these assays for use on an ultramicro-scale resulted in about 40-fold increases in sensitivity. Aminopyrine is $\mathrm{N}$-demethylated by cytoch rome $\mathrm{P}-450$ as shown in Figure 1-3. The aminopyrine $\mathrm{N}$-demethylase assay measures the production of formaldehyde. The radiometric benzo(a)pyrene monooxygenase assay measures all of the known oxygenated metabolites of $\mathrm{BP}$.

Polychlorinated biphenyls were selected as model inducing substances for most of the work presented here because they are environmentally relevant chemicals whose inducing properties have been extensively examined. Aroclor 1254 was specifically selected because it is about equipotent as both a PB and 3-MC type inducer (Goldstein et al., 1977). Also a commercial preparation of $\left[{ }^{14} \mathrm{C}\right]-$ labelled PCBs of similar isomer composition is available. This material allowed the simple and sensitive quantitation of $\mathrm{PCB}$ uptake by embryos.

A point worth emphasizing is that the cytochrome $\mathrm{P}-450$ system is active in metabolizing a great variety of xenobiotics, and is induced by 
Page 66
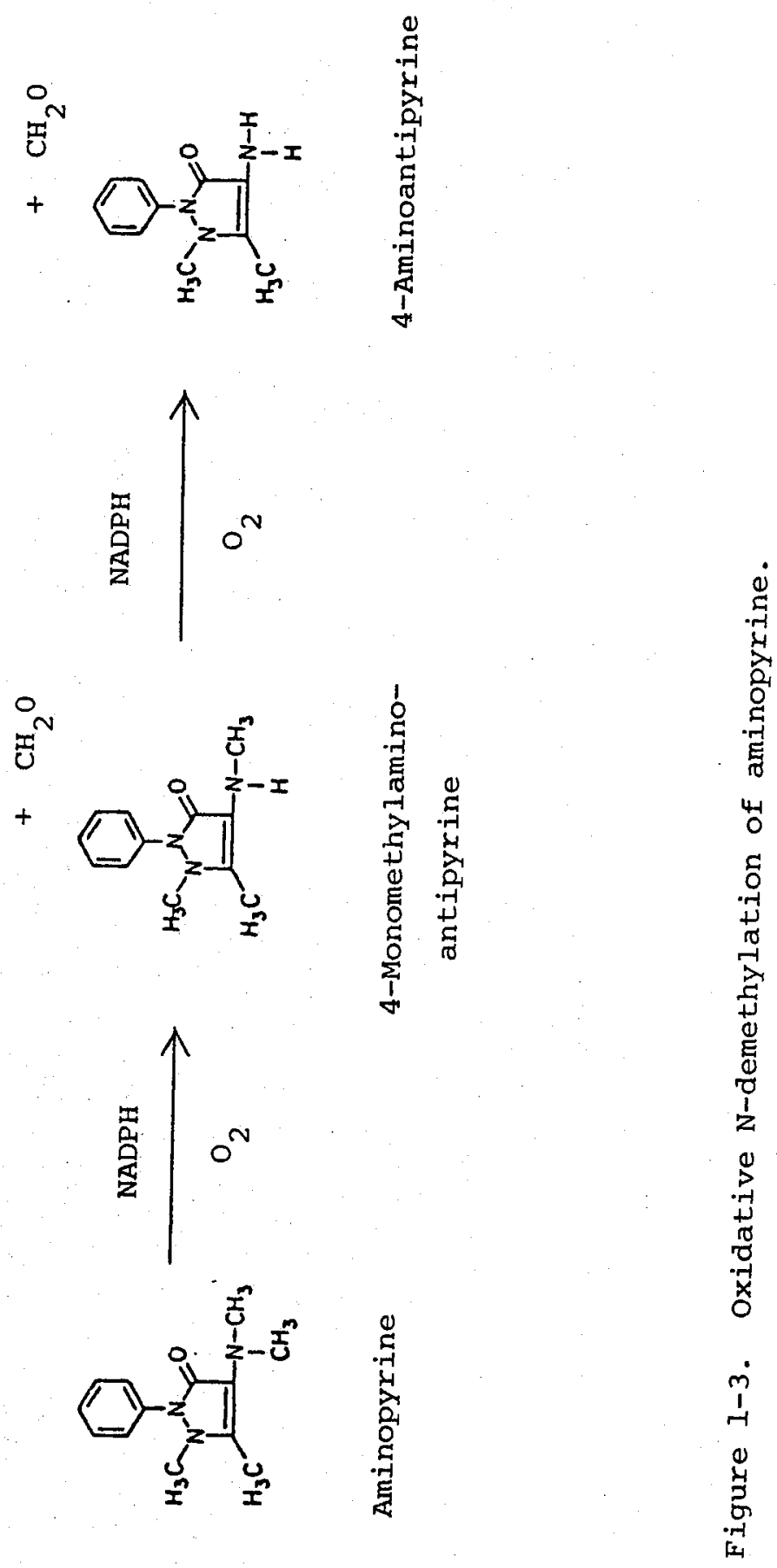
a similarly large number of compounds. While any given study may examine the metabolism of a limited range of substrates, or a response to certain inducers, the results are likely to apply to a whole range of foreign compound s.

AN IMPORTANT NOTE ON NOME NCLATURE

The developmental terminology of Balon (1975) will be used in this thesis. According to Balon (1975), the embryonic period of fish development extends from fertilization until feeding begins. In other words, the embryonic period is characterized by "endogenous nutrition from the yolk." The embryonic period is arbitrarily divided into three phases: cleavage, embryonic, and eleutheroembryonic. The latter two are of interest here. The embryonic phase extends from the end of cleavage until hatching, and is characterized by active organogenesis. The eleutheroembryonic phase extends from hatching until feeding begins, marking the transition to the period of larval development. In this thesis, the term "embryo" will refer to all prehatching developmental stages examined; the term "eleutheroembryo" will refer to the hatched embryo. Other workers have referred to eleutheroembryos as yolk sac larvae, sac fry or prolarvae.

Another term which will be used throughout the thesis without further definition is "chorion." The chorion is the shell surrounding the fish embryo, and is composed largely of fibrous protein (Kaighn, 1964). In most of the work described in this thesis chorions were removed from 
Page 68 .

embryos before they were fractionated or assayed for PCB content. In the early experiments described in Chapter 2 embryos were homogenized whole with chorions intact. "Age" will be measured from the time of fertilization. It is important that the reader become familiar with the terms defined here, because they are used throughout the thesis, and are necessary for an understanding of the material presented. 
INDUCTION OF BENZO(A) PYRENE MONOOXYGENASE ACTIVITY IN EMBRYOS AND ELEUTHEROEMBRYOS OF THE ESTUARINE KILLIFISH, FUNDULUS HETEROCLITUS

The data presented in this chapter were the first observations on the presence and inducibility of xenobiotic monooxygenase activity in fish embryos and eleutheroembryos (Binder and Stegeman, 1980). A separate presentation of these early findings allows a logical development of experimental results, and serves to indicate the rationale for some of the later work. Also, methodological improvements were made during the course of this research, so the results presented here are not directly comparable to subsequent data.

MATERIALS AND METHODS

Methods are described only when they differ from those used later. Assay procedures will be described in detail in Chapter 3. All chemicals and supplies were as described in Chapters 3 and 4, and No. 2 fuel oil was an American Petroleum Institute reference standard. Ripe fish were collected at Herring Brook (H.B.) and Wild Harbor (W.H.) marshes (N. Falmouth, MA) during the spawning season of Fundulus in the spring and 
summer of 1978. Fertilization was accomplished in the laboratory by stripping eggs from ripe females and fertilizing with minced testis. The embryos described in Table 2-I were from H.B. and those described in Table 2-II from W.H.; adults were from H.B. After determining the developmental stage according to Armstrong and Child (1965), eggs were washed twice with filtered seawater, and twice with $0.1 \mathrm{M}$ Tris-HCL pH $7.4,0.25 \mathrm{M}$ sucrose, then homogenized whole with chorions intact in this buffer, $(20 \% \mathrm{w} / \mathrm{v})$ using a Potter-Elvehjem tissue grinder. The homogenates were fractioned by centrifugation: $5 \mathrm{~min}$. at $120 \times \mathrm{g}, 10$ min. at $10,000 \times \mathrm{g}(10 \mathrm{~K})$, and $90 \mathrm{~min}$. at $40,000 \times \mathrm{g}(40 \mathrm{~K})$. The first fraction containing much large debris was discarded, and the $10 \mathrm{~K}$ and $40 \mathrm{~K}$ pellets were resuspended in $0.1 \mathrm{MTris}-\mathrm{HCl} \mathrm{pH} 7.0(0.5-3.0 \mu \mathrm{l} / \mathrm{embryo})$. This fractionation procedure roughly corresponds to one that yields mitochondrial ( $10 \mathrm{~K}$ ) and microsomal (40K) fractions from adult fish liver (Stegeman et al., 1979). Eleutheroembryos were dissected and the livers, carefully separated from gall bladders, were assayed as dilute whole homogenates in the embryo homogenization buffer. The remaining eleutheroembryo carcasses were fractionated and assayed like the embryos.

Benzo(a)pyrene monooxygenase was assayed by the sensitive radiometric procedure of Van Cantfort et $\underline{\text { al. }}$ (1977) modified for use on an ultramicro-scale. The reaction mixture was reduced to $25 \mu \mathrm{L}$ and consisted of $0.1 \mathrm{M}$ Tris- $\mathrm{HCl} \mathrm{pH} 7.0,0.40 \mathrm{mM} \mathrm{NADPH}, 0.060 \mathrm{mM}$ $\left({ }^{3} \mathrm{H}\right.$ )-benzo( a) pyrene (about $300 \mu \mathrm{Ci} /$ umole), $2 \mathrm{mg} / \mathrm{mL}$ bovine serum albumin (BSA), and from 5 to $170 \mu \mathrm{g}$ of embryonic protein depending on the fraction assayed. Blanks consisted of the complece reaction mixture 
without NADPH. The reaction was initiated by adding BP in $1 \mu 1$ of acetone, incubated at $25^{\circ}$ for 30 minutes, stopped with $50 \mu \mathrm{l}$ of 0.15 $\mathrm{M} \mathrm{KOH} \mathrm{in} 85 \%$ dimethyl sulfoxide, then extracted three times with 0.375 $\mathrm{ml}$ of hexane. Polar metabolites were quantitiated by counting $30 \mu \mathrm{l}$ of the aqueous phase acidified with $10 \mu 1$ of $0.6 \mathrm{~N} \mathrm{HCl}$, in $3 \mathrm{ml}$ of scintillation cocktail. The liquid scintillation couting efficiency was determined by internal standardization. Under these conditions the reaction with adult Fundulus microsomes was linear for 35 minutes.

BPM activity was considered detectable when the mean dpm of complete reaction mixtures differed from the mean of the blanks at the 0.05 level of significance by the Student t-test. Based on the average variance of 10 triplicate blanks, it is estimated that for the power of the $t$-test to be 0.95 with $P<0.05$, the sample assayed must have the capacity to produce 2.0 picomoles of polar metabolites during the incubation (Winer, 1971). The Limits of detection indicated in the tables were calculated by dividing this value by the number of embryos per reaction mixture and the incubation time.

RESULTS AND DISCUSSION

BPM activity was not reproducibly detectable in untreated embryos assayed at stages from zygote to shortly before hatching. As shown in Table 2-I, exposure to the PCB mixture Aroclor 1254 or to No. 2 fuel oil over the course of development resulted in an induction of BPM 
Table 2-I. Benzo(a)pyrene monooxygenase activity in the $10,000 \times \mathrm{g}$ fraction of homogenates of Fundulus heteroclitus embryos exposed to Aroclor 1254 and No. 2 fuel oil.**

\begin{tabular}{lc}
\hline Treatment & $\begin{array}{c}\text { Activity } \\
\text { (Femtomole/min/embryo)** }\end{array}$ \\
\hline DMSO control & N.D. ${ }^{+}$ \\
$20 \mathrm{ppb}$ Aroclor 1254 & N.D. \\
$100 \mathrm{ppb}$ Aroclor 1254 & $30 \pm 3$ \\
$200 \mathrm{ppb}$ Aroclor 1254 & $62 \pm 7$ \\
$1000 \mathrm{ppb}$ No. 2 fuel oil & $39 \pm 8$ \\
\hline
\end{tabular}

*Eggs stripped from 11 females were pooled and fertilized with minced testes from 4 males. For each treatment approximately 90 embryos were placed in a glass dish with $50 \mathrm{ml}$ of $0.22 \mu$ filtered seawater and incubated at $20^{\circ}$. The exposure was initiated 8.5 hours after fertilization by the addition of the inducing substance dissolved in 50 $\mu \mathrm{l}$ of dimethylsulfoxide (DMSO). DMSO alone was added to the control embryos. Water was changed and additional inducer was added 6 times before assay at day 12 (stages 33-34). $\mathrm{ppb}=\mu \mathrm{g} / \mathrm{liter}$.

$* *$ femtomole $=10^{-15}$ mole, mean of three replicates $\pm S D$.

${ }^{+}$N.D. $=$not detectable. Limit of detection: 11 femtomole/min/embryo. 
activity in embryos near hatching (stages $33-34)^{1}$. The induction of BPM by Aroclor 1254 was dose dependent. The induced activity appeared in the $10 \mathrm{~K}$ fraction while no activity was detectable in the $40 \mathrm{~K}$ fraction. In a separate experiment, Fundulus embryos exposed to $200 \mathrm{ppb}$ Aroclor 1254 were assayed at stages $32-33$ and shortly after hatching (stages 34-35). As before, there was no detectable BPM activity in the control eggs (Table 2-II) and substantial activity was present in the 10K fraction of embryos treated with Aroclor 1254. BPM activity was higher in the $10 \mathrm{~K}$ fraction of these embryos than in those in Table 2-I exposed to $200 \mathrm{ppb}$ Aroclor 1254 and activity was also detectable in the $40 \mathrm{~K}$ fraction, perhaps because there were four more water changes with addition of inducer in this experiment.

Unlike control embryos, control eleutheroembryos had detectable BPM activity in all fractions assayed. Comparing the total activity in the two groups of eleutheroembryos reveals that Aroclor stimulated a greater than three-fold induction of BPM activity. Induction in eleutheroembryos apparently occurred to a greater extent in the extrahepatic tissues compared to liver, as liver accounted for more than half of total activity in the controls but less than half in the treated group. In

1 The embryos used in the experiments described here began hatching at stage 34. However, based on observations of several different pools of eggs, hatching generally does not begin until stage 35. A synopsis of Fundulus embryonic development is presented in Table 3-I. 
Table 2-II. BPM activity in fractions of homogenates of control and Aroclor-exposed Fundulus embryos and eleutheroembryos*.

\begin{tabular}{|c|c|c|c|}
\hline \multirow{2}{*}{ Embryonic material } & \multirow{2}{*}{ Fraction } & \multicolumn{2}{|c|}{ Activity (femtomole/min/ind } \\
\hline & & Control & 200 ppb Aroc \\
\hline \multirow[t]{2}{*}{ Whole embryos } & $10 \mathrm{~K}$ & N.D. ${ }^{++}$ & $100 \pm$ \\
\hline & $40 \mathrm{~K}$ & N.D. & $12 \pm$ \\
\hline Dissected & carcass, $10 \mathrm{~K}$ & $22 \pm 2$ & $133 \pm$ \\
\hline eleutheroembryos & carcass, $40 \mathrm{~K}$ & $17 \pm 3$ & $76 \pm$ \\
\hline & $\begin{array}{l}\text { liver, whole } \\
\text { homogenate }\end{array}$ & $52 \pm 6$ & $117 \pm 1$ \\
\hline
\end{tabular}

*Eggs stripped from six females and fertilized with minced testes from four males were treated under conditions similar to those described in Table 2-I. At the time of assay, 11 days of development, control embryos were in stage $33(N=121)$. Aroclor exposed embryos $(N=34)$ were assayed in the same stages after 16 days of development. Median hatching times for control and Aroclor treated embryos were 14 and 16 days, respectively. Approximately $90 \%$ hatching of the control embryos occurred by day 15 after fertilization, whereas about 19 days were required for $90 \%$ hatching of the Aroclor exposed embryos. Hatching success in the two groups was similar: $95 \%$ for the controls and 93\% for the Aroclor treated embryos. Water was changed and additional inducer added ten times before embryos were assayed, and 14 times before treated eleutheroembryos were assayed.

twhole embryos: Mean of three replicates \pm SD. Data for eleutheroembryos represent means of two replicates \pm range.

${ }^{++}$N.D. = not detectable. Limits of detection: 10K fraction, 11 femtomole/min/embryo; $40 \mathrm{~K}$ fraction, 7 femtomole/min/embryo. 
either case the data suggest that extrahepatic tissues of fish embryos may play a significant role in the metabolism of foreign compounds.

The distribution of monooxygenase activity in centrifugal fractions of Fundulus embryos was atypical. In adult fish and higher vertebrates the majority of xenobiotic monooxygenase activity in various active tissues is associated with the microsomal fractions of homogenates. In Fundulus embryos, the majority of induced BPM activity was associated with the lOK fraction, which was sedimented under conditions approximating those used for preparing mitochondrial fractions from adult fish liver. After hatching a larger portion of the activity was associated with the high speed or $40 \mathrm{~K}$ fraction. Chatterjee et al. (1965) reported a similar difference between the sedimentation properties of liver microsomal enzymes from fetal and neonatal rats which may have been the result of the formation of vesicles from the fetal hepatic endoplasmic reticulum (ER) that were larger than the microsomes produced Erom neonatal or adult hepatic ER. Considering the unusual distribution of BPM activity in the centrifugal fractions of embryos, it is important to know whether the $10 \mathrm{~K}$ and $40 \mathrm{~K}$ fractions prepared from whole embryos, as described here, correspond to mitochondrial and microsomal fractions. Another question which arises from these results is whether the metabolism of BP by Fundulus embryos is catalyzed by a typical cytochrome P-450 dependent monooxygenase or some other enzyme.

The data presented clearly demonstrate the induction of BPM activity in $f$ ish embryos and eleutheroembryos by common environmental contaminants. Since the levels of these substances accumulated by 
embryos during the course of exposure were not monitored, the question remains whether environmentally realistic levels are likely to produce a response. Another important question is whether fish embryos are competent to respond to inducers of monooxygenase activity at earlier stages in development.

BPM activity was readily measurable in control eleutheroembryos but could not be detected in fractions from untreated or control embryos. Although the limits of detection were fairly high, the data suggest that there is a substantial increase in the capacity of Fundulus embryos to metabolize BP after hatching. Questions which remain are whether Fundulus embryos have the capacity to metabolize xenobiotics before hatching, and whether the appearance of activity during later embryonic development is associated with hatching or is simply a function of age. All of the above questions are addressed in the next two chapters. The possible significance of the presence and inducibility of monooxygenase activity in fish embryos and eleutheroembryos will be discussed later. 


\section{CHAPTER 3}

\section{THE XENOBIOT IC MONOOXYGENASE SYSTEM IN EARLY DEVELOPMENTAL STAGES OF FUNDULUS HETEROCLITUS}

In the previous chapter data demonstrating the presence and inducibility of benzo[a]pyrene monooxygenase activity in Fundulus heteroclitus embryos and eleutheroembryos were described. In these early experiments monooxygenase activity was not detectable in fractions prepared from untreated embryos, but could be induced in embryos by exposure to oil and PCBs. In contrast to the results with embryos, BPM activity was measurable in both the livers and extrahepatic tissues of control eleutheroembryos, and was also inducible in these tissues. These data suggest that in Fundulus there is a substantial increase in the capacity to metabolize foreign compounds after hatching.

The results of further experimental work on the ontogeny of the monooxygenase system in untreated Fundulus embryos are presented in this chapter. Using improved methods, levels of BPM activity were measured in fractions prepared from whole embryos. Changes associated with hatching were examined, and some basic properties of embryonic monooxygenase activity were characterized, including its subcellular localization and evidence for the involvement of cytochrome P-450. Additionally, levels of monooxygenase activity and components of the monooxygenase system were measured in livers of Fundulus larvae and juveniles. 
MATERIALS AND METHODS

\section{Chemicals:}

Generally labelled [ ${ }^{3} \mathrm{H}$ ]-benzo[a]pyrene was purchased from Amersham Searle, Arlington Heights, IL. Aquasol, [dimethylamine- ${ }^{14} \mathrm{C}$ ]aminopyrine, $\left[{ }^{14} \mathrm{C}\right]$-formaldehyde, $\left[{ }^{14} \mathrm{C}\right]$-toluene and $\left[{ }^{3} \mathrm{H}\right]$-toluene were purchased from New. England Nuclear, Boston, MA. NADPH, NADH, bovine serum albumin, HEPES, ${ }^{1}$ and horse heart cytochrome $c$ were from Sigma Chemical Co., St. Louis, MO. Aminopyrine (AP), benzola]pyrene, $\alpha$-naphthoflavone (ANF) and dimethylsulfoxide (DMSO) were from Aldrich Chemical Co., Milwaukee, WI., and SKF-525A was a gift of Smith KIine and French Laboratories, Philadelphia, PA. All other chemicals, solvents and gases were standard reagent grade or higher quality and were purchased from various suppliers. Microsurgical instruments were purchased from Roboz Surgical Instrument Co., Inc., Washington, D. C., and Fluropore filters from the Millipore Corp., Bedford, MA.

\section{Animals:}

Adult Fundulus heteroclitus were collected by seining or trapping at Herring Brook Marsh, North Falmouth, $\mathrm{MA}^{2}$, and were maintained in flow-through aquaria in a mixture of natural seawater and dechlorinated

1 HEPES is $\mathrm{N}-2$-Hydroxethylpiperazine-Nl-2-ethanesulfonic acid. Other abbreviations are. listed at the beginning of the thesis. 2For a photograph of the collection site and the author's back see (Rose, 1980). 
tap water at a salinity of about $20 \%$. Fish were fed chopped quahogs, smelt, and scup as well as the following commercial fish foods distributed by Tetra Products, NY: Tetra SM, SM80, and conditioning food.

Eggs were obtained either from ripe fish collected during the natural spawning season or fish in which gametogenesis was induced by appropriate conditions of light and temperature (14-16 hour light period at $22-23^{\circ}$ ) as described by Boyd and Simmonds (1974). Eggs were stripped from ripe fish, fertilized with minced testis, and incubated at $20^{\circ}$ in glass dishes with daily water changes. The incubation medium was $0.22 \mu$ filtered natural seawater, adjusted to a salinity of 25 or $30^{\circ} \%$ with deionized water. Generally, within 24 hours of fertilization embryos were gently rolled on filter paper to remove chorionic fibrils and thus prevent clumping. Methods for handling Fundulus embryos have been discussed in detail by Trinkais (1967). The standard Fundulus embryonic stages described by Armstrong and Child (1965) will be used here.

In experiments in which Fundulus larvae and juveniles were examined, feeding of fry was begun within 4 to 5 days of hatching, when some yolk was still present. The fry were provided with a continuous supply of freshly hatched brine shrimp, which was supplemented with Tetra SM after about 2 weeks. Fry were maintained in glass aquaria in static, aerated, filtered natural seawater at the same temperature and salinity as during the embryonic period. Water was changed every other day, and the lightdark cycle was controlled with a 14 hour 1 ight period. 
Page 80

\section{Embryo fractionation:}

Assays were performed on centrifugal fractions of whole embryo homogenates. In preparation for homogenization, embryos were dechorionated with microsurgical scissors, washed in $0.05 \mathrm{M}$ Tris-HCl pH 7.2, $1 \mathrm{mM}$ EDTA, $0.25 \mathrm{M}$ sucrose $(\mathrm{TES})^{3}$, and then gently trumpetted in and out of a Pasteur pipette tip to rupture yolk sacs and release a substantial portion of the fluid yolk. After trumpetting, embryos were washed twice by swirling in TES, and then homogenized in this buffer (15-25 $\mu 1 /$ embryo) in a Potter-Elvehjem tissue grinder with a teflon pestle, 8 strokes at about $2500 \mathrm{rpm}$. Eleutheroembryos were simply washed with TES and then similarly homogenized. All operations were carried out at ice temperature. The numbers of embryos and eleutheroembryos used varied, but generally was greater than 50 . Embryos were weighed using the method described in Chapter 4 for PCB quantitation.

Centrifugal fractions of embryos were prepared in either 7 or $10 \mathrm{ml}$ tubes in a Sorvall ss-34 rotor. The standard conditions were equivalent to 5 minutes at a maximum of $200 \mathrm{xg}$ (low speed), $15 \mathrm{~min}$. at a maximum of $10,000 \mathrm{xg}(10 \mathrm{~K})$, and $180 \mathrm{~min}$. at a maximum of $40,000 \mathrm{xg}(40 \mathrm{~K}$ or microsomal) for full tubes. However, in all cases tubes were spun with substantially less than full volumes and sedimentation conditions were adjusted using the " $K$ " factor method (Du Pont Instrument, Centrifuge Applications Bulletin No.1). The time of microsomal spins did not exceed 90 minutes. Pellets were resuspended in the BP monooxygenase assay

\footnotetext{
${ }^{3}$ The $\mathrm{pH}$ of Tris buffers is temperature sensitive; all Tris buffers were $\mathrm{pH}$ adjusted at $30^{\circ}$.
} 
Page 81

buffer, $0.05 \mathrm{M}$ Tris-HCL, $\mathrm{pH} 7.2(0.2-3.0 \mu \mathrm{l} / \mathrm{embryo})$. In some cases when just the microsomal fraction was assayed, the low speed and $10 \mathrm{~K}$ fractions were sedimented in the same tube without decantation of supernatant fluid; this resulted in a higher yield of microsomal protein per embryo. When the distribution of enzymatic activity in the various fractions was examined, each pellet was washed by resuspension in buffer by hand homogenization and then resedimented. The wash and the original supernatant fluids were combined at each step in the fractionation.

\section{Livers from eleutheroembryos, larvae, and juveniles:}

Livers were dissected from Fundulus eleutheroembryos in ice cold Tris-sucrose (TS) buffer ${ }^{4}$ using microsurgical instruments. Livers were carefully separated from gall bladders, transferred with a drawn out Pasteur pipette to a $1 \mathrm{ml}$ Potter-Elvehjem tissue grinder, washed once with TS, then homogenized in this buffer $(1-3 \mu l / 1$ iver $)$ with a teflon pestle, 8 strokes at about $2500 \mathrm{rpm}$. The resulting dilute whole homogenates (about $0.5 \mu \mathrm{g}$ protein $/ \mu 1$ ) were assayed immediately without further fractionation. Homogenates were prepared from pools of livers dissected from 30-60 individuals. Eleutheroembryo carcasses remaining after dissection were fractionated like whole embryos.

Larvae and juveniles were immobilized by placing in ice cold seawater, killed by pithing then washed with and dissected in ice cold TS buffer. Livers carefully separated from gall bladders were homogenized like those from eleutheroembryos. The concentration of protein in the

\footnotetext{
${ }^{4}$ Tris-sucrose buffer is $0.05 \mathrm{M}$ Tris-HCl, $\mathrm{pH} 7.2,0.25 \mathrm{M}$ sucrose.
} 
liver homogenates ranged from $0.5-4.0 \mu \mathrm{g} / \mu \mathrm{l}$. In some cases, whole homogenates were assayed for monooxygenase activity immediately. The following procedure was established for the preparation of microsomes from larval and juvenile livers. Homogenates were centrifuged in $0.4 \mathrm{ml}$ conical bottom polypropylene tubes using a Sorvall ss-34 rotor with Sorvall no. 365 rubber adaptors. A postmitochondrial supernatant was prepared by spinning $300 \mu \mathrm{l}$ of homogenate for $10 \mathrm{~min}$. at $5000 \mathrm{rpm}$; microsomes were then spun down at 18,000 rpm for $60 \mathrm{~min}$. These speeds are approximately equivalent to a maximum of $2100 \mathrm{xg}$ and $27,500 \mathrm{xg}$, respectively. Centrifugation times and speeds were corrected when volumes other than $300 \mu \mathrm{l}$ were used. Microsomes were resuspended in $0.05 \mathrm{M} \mathrm{Tris}-\mathrm{HCl}, \mathrm{pH} 7.2$ to a protein concentration of $0.4-0.6 \mu \mathrm{g} / \mu \mathrm{l}$. Microsomes were stored in liquid nitrogen until used. A comparison of adult microsomes prepared by this microprocedure and the standard liver fractionation procedure used in this laboratory is presented in the Results section.

\section{Livers from adults:}

The adult Fundulus used here were collected in November 1980. Three pools of livers were prepared, each with livers from 3 males and 3 females. Fish were killed by severance of the spinal column; livers were immediately excised, washed with ice cold Ts buffer, minced with scissors and homogenized $1 / 20(\mathrm{~W} / \mathrm{V})$ in the buffer like the livers of embryos. During dissection care was taken to avoid rupturing gall bladders, and no livers contaminated with bile were used. Aliquots of the dilute whole 
homogenates were assayed immediately for monooxygenase activity for comparison with whole homogenates of livers from eleutheroembryos and. larvae. The remainder of the homogenates were fractionated in a Sorvall SS-34 rotor in $15 \mathrm{ml}$ Corex tubes. A postmitochondrial supernatant (PMS) was prepared by spinning $12 \mathrm{ml}$ of homogenate per tube at a maximum of $10,000 \mathrm{xg}$ for 10 minutes. Microsomes were spun down from the PMS at a maximum of $40,000 \mathrm{xg}$ for 90 minutes and were resuspended in $0.05 \mathrm{M}$ Tris-HCl $\mathrm{pH} 7.2,3 \mathrm{ml}$ of buffer per gram wet weight of liver. Microsomes were stored in liquid nitrogen until they were assayed.

\section{Enzyme assays:}

Benzola]pyrene monooxygenase (BPM) was assayed by a modification of the method of Van Cantfort et al. (1977) as described in Chapter 2, but with several changes in the procedure. The overall procedure is more fully described here. The substrate, benzo(a)pyrene, was prepared for use in the following way. Generally labelled $\left[{ }^{3} \mathrm{H}\right]-\mathrm{BP}$ ( $5 \mathrm{mCi}$ ) was mixed with unlabelled BP to a specific activity of about $300 \mu \mathrm{Ci} /$ umole and dissolved in $6 \mathrm{ml}$ of hexane, then extracted 5 times with $3 \mathrm{ml}$ of aqueous IM KOH/DMSO $(65 / 85 ; \mathrm{v} / \mathrm{v})$, washed twice with $3 \mathrm{~mL}$ of deionized water, dried with anhydrous $\mathrm{MgSO}_{4}$, filtered through a hexane washed $0.2 \mu$ Fluoropore filter and dried under a stream of nitrogen. The purified $\left[{ }^{3} \mathrm{H}\right]-\mathrm{BP}$ solid was stored at $-20^{\circ}$ under nitrogen. All

glassware used in the purification procedure was washed with chromic acid cleaning solution and hexane, and the entire procedure was done under red light. The actual specific activity of each preparation was determined by counting aliquots of dilutions of 3-4 individual stock solutions of 
the $\left[{ }^{3} \mathrm{H}\right]-\mathrm{BP}$.

The BPM assay was carried out in $10 \times 75 \mathrm{~mm}$ disposable glass tubes with a reaction volume of $25 \mu \mathrm{L}$. Reaction mixtures consisted of $0.05 \mathrm{M}$ Tris-HCl, $\mathrm{pH} 7.2$ at $30^{\circ}, 0.40 \mathrm{mM} \mathrm{NADPH}, 0.070 \mathrm{mM}\left[{ }^{3} \mathrm{H}\right]-\mathrm{BP}, 0.8 \mathrm{mg} / \mathrm{ml}$ bovine serum albumin (BSA), and varying amounts of embryonic protein depending on the fraction assayed. Between 15-100 $\mu$ of whole embryo microsomal protein, 4-10 $\mu$ of whole liver protein, and $1-5 \mu \mathrm{gg}$ of liver microsomal protein were added per reaction mixture. Blanks consisted of the complete reaction mixture without NADPH. The reaction was initiated on ice by adding BP in $1 \mu 1$ of acetone ${ }^{5}$. When the influence of ANF or SKF-525A on the reaction was examined, these inhibitors were added with the $\mathrm{BP}$ in $1 \mu \mathrm{l}$ of acetone. Incubation was for 25 minutes at $30^{\circ}$, then reactions were stopped by placing on ice and adding $50 \mu \mathrm{l}$ of $0.15 \mathrm{M} \mathrm{KOH}$ in $85 \%$ dimethylsulfoxide. The stopped reaction mixtures were extracted three times, by vortexing for 15 seconds with $0.25 \mathrm{ml}$ of hexane, centrifuging for 5 minutes at $5000 \mathrm{rpm}$, and then aspirating of $f$ the organic phase. Polar metabolites were quantitated by counting $30-50 \mu 1$ of the remaining aqueous phase in $3 \mathrm{ml}$ of Aquasol acidified with $10 \mu \mathrm{l}$ of $0.6 \mathrm{~N} \mathrm{HCl}$. Counting was done in a Beckman LS-100C liquid scintillation counter, and efficiency was determined by internal standardization with $\left[{ }^{3} \mathrm{H}\right]$-toluene. All micropipetting devices used in the procedure were calibrated gravimetrically using water with correction for evaporation.

${ }^{5}$ There was no difference in the total activity measured with adult Fundulus hepatic microsomes, when the enzyme was pre-incubated with BP at the reaction temperature and then initiated by the addition of cofactor, as compared to initiation on ice by the addition of $B P$. 
The assay was carried out under red light from the addition of $\left[{ }^{3} \mathrm{H}\right]-\mathrm{BP}$ through the first extraction with hexane. Although Van Cantfort et a1. (1977) indicate that the activity measured in the assay is little affected by exposure to light, the sensitivity of the assay is decreased when the procedure is carried out under white light. The limit of detection of the assay is determined by the sample to blank ratio. Exposure of $\mathrm{BP}$ solutions and reaction mixtures to white light results in elevated blanks, presumably due to photooxidation. The blank was minimized in the procedure described here by reducing the assay volume and using great care to protect the $\left[{ }^{3} \mathrm{H}\right]-\mathrm{BP}$ from light. The assay as described can detect about 1 pmole of metabolites in the final stopped reaction mixture.

In experiments in which the gas phase above BPM reaction mixtures was controlled, assays were performed in $10 \times 50 \mathrm{~mm}$ tubes. Enzyme and cofactor or enzyme and buffer were added to the tubes and they were then sealed with serum stoppers and kept at ice temperature. Mixtures of $\mathrm{N}_{2}: \mathrm{O}_{2}$ and $\mathrm{CO}: \mathrm{O}_{2}(80: 20)$ were prepared in the sealed tubes in the following way. The sealed volume of each tube was connected to a manifold with capillary tubing and also the needle of a $20 \mathrm{ml}$ syringe was passed through the serum stopper. The tube-syringe units were sequentially evacuated and then gassed with either $\mathrm{N}_{2}$ or $\mathrm{CO}$. After several cycles, the total volume of gas in each tube-syringe unit was adjusted to $8 \mathrm{ml}$ by moving the syringe plunger. Each tube was disconnected from the manifold and $2 \mathrm{ml}$ of $\mathrm{O}_{2}$ was injected through the stopper with a second syringe. Mixing was accomplished by pumping gas 
back and forth between the two syringes, then they were removed, leaving the sealed tube with the desired gas mixture. When just a nitrogen atmosphere was desired, sealed tubes were simply connected to the manifold and alternately evacuated and gassed several times. Reactions were initiated by injection of $\left[{ }^{3} \mathrm{H}\right]-\mathrm{BP}$ through the serum stoppers with a microsyringe. The rest of the procedure was standard as described above.

The BPM assay conditions were optimized for the activity in adult Fundulus hepatic microsomes. The conditions used here differ in a number of ways from those described in Chapter 2; changes generally were made to optimize activity and thus increase the sensitivity of the assay. The concentrations of $\mathrm{BP}$ and NADPH used were saturating. At a constant ionic strength of 0.14 , the adult BPM activity was insensitive to pH from 6.8 to 7.5 and fell off at higher or lower $\mathrm{pH}^{\prime} \mathrm{s} ; \mathrm{pH} 7.2$ was chosen as standard for the assay. At equivalent ionic strengths, activity was about $25 \%$ higher when Tris was used for buffering rather than potassium phosphate. Activity fell off continuously with increasing Tris concentration; the selection of the standard concentration for the assay $(0.05 \mathrm{M})$ was based on the need to maintain adequate buffering capacity. Maximal activity was observed at a temperature of $35^{\circ}$, then fell off sharply at higher temperatures. The activity at $35^{\circ}$ was only marginally higher than at $30^{\circ}$, so $30^{\circ}$ was selected as the standard temperature. Acetone was found to be superior to methanol as a solvent for the addition of BP; BPM activity with acetone was $17 \%$ higher than with methanol. The adult BPM activity showed no dependence on magnesium, 
and in fact was inhibited by its presence. BSA was included in reaction mixtures to maintain linearity with enzyme concentration at low protein concentrations; variations in the concentration of BSA had little effect on the adult activity. In the original reference, the stopped reaction mixtures were extracted 2 times with hexane, while 3 extractions were used here. The additional extraction was found to reduce replicate variability, although the activity measured is somewhat lower than with 2 extractions. Under the standard conditions, the BPM activity in adult liver microsomes is linear with time for 30-35 minutes and with protein from 1 to at least $10 \mu \mathrm{g}$.

Aminopyrine $\mathrm{N}$-demethylase (APD) was assayed by the radiometric procedure of Poland and Nebert (1973) modified for use on a microscale. The substrate used was prepared in the following way. Unlabelled aminopyrine (AP), recrystallized twice from methanol, was mixed with an aqueous solution of $\left[{ }^{14} \mathrm{C}\right]-\mathrm{AP}$ to a specific activity of $1.5 \mu \mathrm{Ci} /$ umole. The AP was extracted from this solution into chloroform, then was washed three times with deionized water to remove any soluble impurities, dried with anhydrous $\mathrm{MgSO}_{4}$, filtered through a chloroform washed $0.2 \mu$ fluoropore filter, and dried under a stream of nitrogen, then under vacuum. The labelled AP was stored as a dry powder, desiccated at $-20^{\circ}$. The specific activity of each preparation was checked by counting aliquots of dilutions of 3-4 individual stock solutions. The assay was carried out in $6 \times 50 \mathrm{~mm}$ tubes with the total reaction volume reduced to $15 \mathrm{\mu l}$. The reaction mixture consisted of $7.5 \mathrm{mM}$ $\left[{ }^{14} \mathrm{C}\right]-\mathrm{AP}, 7.5 \mathrm{mM} \mathrm{NADPH}, 10 \mathrm{mM}$ semicarbazide- $\mathrm{HCl}, 1 \mathrm{mM} \mathrm{MgCl}, 0.15 \mathrm{M}$ 
Tris- $\mathrm{HCl}, \mathrm{pH} 7.2$ at $30^{\circ}$, and varying amounts of protein depending on the sample assayed. About $100 \mu \mathrm{g}$ of whole eleutheroembryo microsomal protein, $10 \mu \mathrm{g}$ of juvenile liver microsomal protein, and $20 \mu \mathrm{g}$ of adult liver microsomal protein were added per reaction mixture. Blanks consisted of the complete reaction mixture without NADPH. Reactions were initiated on ice by the addition of $\left[{ }^{14} \mathrm{C}\right]-\mathrm{AP}$ in $2 \mu 1$ of $\mathrm{H}_{2} \mathrm{O}$, incubated at $30^{\circ}$ for 35 minutes, then stopped by placing on ice and adding $50 \mu \mathrm{l}$ of ice cold $0.1 \mathrm{~N} \mathrm{NaOH}$ and $0.38 \mathrm{ml}$ of chloroform. After addition of chloroform, tubes were vortexed for 10 seconds to extract the unmetabolized parent compound, then the phases were separated by centrifugation for 5 minutes at $5000 \mathrm{rpm}$. A $60 \mu \mathrm{l}$ aliquot of the aqueous phase of each tube was transferred to a new tube containing $0.38 \mathrm{ml}$ of fresh chloroform, then vortexed and centrifuged again. To quantitate the production of formaldehyde $40 \mu \mathrm{l}$ of the final aqueous phase was counted in $3 \mathrm{ml}$ of Aquasol acidified with $10 \mu \mathrm{l}$ of $0.6 \mathrm{~N} \mathrm{HCl}$. The scintillation counting efficiency was determined using $\left[{ }^{14} \mathrm{C}\right]-$ toluene as an internal standard. The efficiency of recovery of formaldehyde was measured by adding 200 picomoles of $\left[{ }^{14} \mathrm{C}\right]-\mathrm{CH}_{2} \mathrm{O}(10 \mu \mathrm{Ci} / \mu \mathrm{mol})$ in place of $\left[{ }^{14} \mathrm{C}\right]-\mathrm{AP}$; typically, the recovery was a round $80-85 \%$. The recovery of formaldehyde was considered when activity was calculated.

The conditions of the APD assay were optimized for the activity in adult Fundulus hepatic microsomes. The concentrations of substrates used were saturating. Activities measured were equivalent with HEPES, Tris and phosphate buffers. The adult APD activity was insensitive to $\mathrm{pH}$ from 7.0 to 8.2 at a constant ionic strength of 0.1 . The activity fell off at 
$\mathrm{pH}$ 's below 7.0, and $\mathrm{pH} 7.2$ was chosen as the standard condition for the assay. A Tris buffer concentration of $0.15 \mathrm{M}$ was optimal, as the activity declined at either higher or lower buffer concentrations. Activity increased sharply with temperature between $25^{\circ}$ and $30^{\circ}$; but then rose only moderately at higher temperatures; $30^{\circ}$ was chosen as the st andard temperature. In contrast to BPM activity, APD activity was enhanced by $\mathrm{Mg}^{++}$; the optimal concentration was $1 \mathrm{mM}$. Under the standard conditions, the reaction with adult liver microsomes was linear with time for 40 minutes, and with protein up to $40 \mu \mathrm{g}$.

NADPH-cytoch rome $c$ reductase was assayed by a modification of the method of Phillips and Langdon (1962) using a reaction mixture containing $0.40 \mathrm{mM} \mathrm{NADPH}, 100 \mu \mathrm{M}$ horse heart cytochrome $c, 1 \mathrm{mM} \mathrm{KCN}$, and $0.2 \mathrm{M}$ phosphate buffer, $\mathrm{pH} 7.7$, and varying amounts of protein depending on the fractions assayed in a final volume of $0.45 \mathrm{ml}$. Between $5-25 \mu \mathrm{g}$ of whole embryo microsomal protein and about $2 \mu g$ of liver microsomal protein were added per reaction mixture. The reaction was initiated by the addition of $\mathrm{NADPH}$ and was incubated at $25^{\circ}$. The reduction of cytochrome $c$ was followed at $550 \mathrm{~nm}$ using a Cary $118-\mathrm{C}$ dual beam recording spectrophotometer with water-jacketed cuvette holders. Reference cuvettes contained reaction mixtures without enzyme. Reduced cytochrome $c$ was determined using an extinction coefficient of $21 \mathrm{~cm}^{-1} \mathrm{mM}^{-1}$. NADH-cytochrome $c$ reductase was assayed under identical conditions with $0.40 \mathrm{mM}$ NADH substituted for NADPH. Succinate-cytochrome c reductase was assayed according to Green et al. (1955) as previously described (Stegeman et al., 1979), except the reaction volume was reduced to 0.45 ml. Reaction mixtures contained from 4-20 $\mathrm{gg}$ protein depending on the 
fraction assayed and the incubation temperature was $25^{\circ}$.

The conditions of the NADPH-cytochrome $c$ reductase assay were optimized for the activity in Fundulus adult hepatic microsomes. At a constant ionic strength of 0.5 , the reaction was fairly insensitive to pH from 6.9 to 8.1 , however the optimal $\mathrm{pH}$ was around 7.7 . The reaction was insensitive to ionic strength from values of 0.4 to 0.9 , but dropped off sharply beyond this range. The ionic strength of the buffer used is 0.58. The temperature of the assay is optimal and the concentrations of substrates are saturating. Activities were measured within the range of time and protein in which linearity was observed.

Protein was assayed by the method of Lowry et al. (1951) using crystalline BSA as a standard.

Cytochrome $\mathrm{P}-450$ and cytoch rome $\mathrm{b}_{5}$ :

For difference spectrocopy, fractions were prepared from whole homogenates of eleutheroembryos essentially as described above, except microsomes were washed by resuspension in TES buffer and then resedimented. In some cases the $10 \mathrm{~K}$ fraction was sedimented for 3 times longer than the standard time, and in all cases great care was taken to. avoid contamination of the microsomal fraction with material from the $10 \mathrm{~K}$ or "mitochondrial" pellet. Microsomes were either resuspended in TES buffer or $0.05 \mathrm{M} \mathrm{pH} 7.2 \mathrm{Tris}-\mathrm{HCl}$. Difference spectra were recorded in a Cary 118 dual beam spectrophotometer using self masking microcuvettes with about $0.6 \mathrm{ml}$ of sample per cuvette. Cytoch rome P-450 content was estimated using the $C O$ reduced versus $C O$ oxidized method Matsubara et al., 1974). A suspension of microsomes, at about $0.5 \mathrm{mg}$ protein/ml, was 
bubbled with $\mathrm{CO}$, then divided equally into 2 cuvettes, and a baseline was recorded. Sodium dithionite was then added to the sample cuvette and the spectrum recorded. To measure cytochrome $b_{5}$, a suspension of microsomes was divided between two cuvettes and a baseline was recorded. $\mathrm{NADH}$ was added to the sample cuvette in a small volume of buffer to a final concentration of $0.034 \mathrm{mg} / \mathrm{ml}$; an equal volume of buffer was added to the reference cuvettes, and the spectrum was recorded (Stegeman et a.., 1979).

Since only a limited volume of juvenile hepatic microsomes was available for spectrophotometric analysis, the same microsomal suspension was assayed for both cytochrome $b_{5}$ and cytochrome P-450. Cytochrome $b_{5}$ was assayed as above, then the microsomal suspensions in the sample and reference cuvettes were recombined and additional NADH added to make the suspension $0.034 \mathrm{mg} / \mathrm{ml}$ with $\mathrm{NADH}$. The microsomal suspension was then bubbled with $\mathrm{CO}$ and cytochrome $\mathrm{P}-450$ was quantitated as above. Adult hepatic microsomes were similarly assayed for cytochromes $\mathrm{P}-450$ and $b_{5}$. With adult microsomes, co reduced versus co oxidized difference spectra were also recorded in the absence of NADH. An extinction coefficient of $91 \mathrm{mM}^{-1} \mathrm{~cm}^{-1}\left(\mathrm{OD}_{490-450}\right)$ was used for cytochrome $\mathrm{P}-450$ and $185 \mathrm{mM}^{-1} \mathrm{~cm}^{-1}\left(\mathrm{OD}_{424-410}\right)$ for cytochrome $\mathrm{b}_{5}$ (Omura and Sato, 1964).

\section{Electron microscopy:}

Stage 33-34 embryos (200) were homogenized and fractionated as described above. Freshly prepared $10 \mathrm{~K}$ and $40 \mathrm{~K}$ pellets were fixed 
for 3 hours at room temperature in $3 \%$ glutaraldehyde, $1.5 \%$ formaldehyde (generated from paraformaldehyde), $0.05 \% \mathrm{CaCl}_{2}$ and $5 \%$ sucrose in $0.1 \mathrm{M}$ cacodylate buffer, $\mathrm{pH} 7.4$, then were stored at $5^{\circ}$ in a solution of $1 \%$ glutaraldehyde in cacodylate buffer. Pellets were post fixed with osmium tetroxide, embedded in Spurrs resin, and thin sections were examined with a Hitachi HS-9 electron microscope.

\section{RESULTS}

Summary of early development in Fundulus:

Standard stages for Fundulus heteroclitus embryonic development have been described by Oppenheimer (1937) and by Armstrong and Child (1965); the latter are used here. A brief summary of events during the course of Fundulus embryonic development is given in Table 3-I. The developmental events listed in the table were described by Armstrong and Child (1965), but the schedule of development shown is based on original observations. It should be noted that age in days is measured from the time of fertilization. The developmental sequence was found to closely follow the schedule given by Armstrong and Child up to around stage 30 , after which development was observed to proceed more slowly. This difference in developmental rate may be due to genetic differences in the populations sampled, or possibly some difference in incubation conditions other than temperature.

The overall mean hatching time for 5 pools of embryos in which hatching was closely monitored was $19.9 \pm 1.8$ days from fertilization 
Table 3-I. A Synopsia of Fundulus heceroclicus Enbryonic Development at $20^{\circ}$.

\begin{tabular}{|c|c|c|}
\hline Age in Days ${ }^{+}$ & $\begin{array}{c}\text { Deve lopment a } 1 \\
\text { Stages }\end{array}$ & Developmental Events \\
\hline $0-2$ & $1-20$ & $\begin{array}{l}\text { Early development, } \\
\text { gastrulacion, neuralation. }\end{array}$ \\
\hline $2-3$ & $21-24$ & $\begin{array}{l}\text { Further differenciation of } \\
\text { brain; differentiation of } \\
\text { sensory organs, pericardium, } \\
\text { heart, trunk mugculature, and } \\
\text { blood cells, first cardiec } \\
\text { contractions. }\end{array}$ \\
\hline $3-4$ & $25-26$ & $\begin{array}{l}\text { Onset of circulation, } \\
\text { ocoliths appear, first } \\
\text { body motility. }\end{array}$ \\
\hline $4-7$ & $27-30$ & $\begin{array}{l}\text { Appearance of urinary } \\
\text { bladder, retinal }\end{array}$ \\
\hline & & $\begin{array}{l}\text { pigmentacion, liver and } \\
\text { pectoral fin rudiments, body } \\
\text { cavity forming, pronephros } \\
\text { can eliminate dyes. }\end{array}$ \\
\hline $7-14$ & $31-34$ & $\begin{array}{l}\text { Swimbladder and rays in } \\
\text { caudal fin appear; lower jaw } \\
\text { foms and mouth opens; first } \\
\text { fin motilicy; increased. } \\
\text { retinal pignentation. }\end{array}$ \\
\hline & $35-37$ & $\begin{array}{l}\text { llatching, head lifted of } \\
\text { yolk, decrease in yolk }\end{array}$ \\
\hline $\begin{array}{l}\text { Variable } \\
\text { depending or } \\
\text { time of } \\
\text { hatching }\end{array}$ & $38-39$ & $\begin{array}{l}\text { size, medial fins form. } \\
\text { Increased swimning capacity, } \\
\text { onser of feeding, conspicuous } \\
\text { yolk disappears, end of } \\
\text { enbryonic period. }\end{array}$ \\
\hline
\end{tabular}

* The developmental evencs liaced in this table were described by Anngtrong and Child ( 1965$)$, but the schedule of development is based on original observations on 5 pools of egga frum a total of 55 females.

+ Age in days is measured from the time of fertilization. 
( \pm S.D. of mean). Hatching occurs over a period of about a week; the mean time from the onset of hatching to $90 \%$ hatching was $5.9 \pm 1.7$ days. Generally the first embryos to hatch were in stage 35, while latest hatching embryos were in stages 36 or 37 . Prior to hatching the development of embryos of the same age is closely parallel, while embryos that have hatched (eleutheroembryos) develop more rapidly than those that have not hatched. Since hatching occurs over several days, more than one developmental stage will be present after the onset of hatching although all embryos are of the same age.

Fundulus eleutheroembryos were observed to begin feeding in stage 38 , when conspicuous yolk is still present. Those that were not fed did not develop beyond stage 39, the stage described by Armstrong and Child (1965) as transitional between the embryonic and larval periods. Larval development in Fundulus is characterized by extremely rapid growth and attainment of the adult body form. During the larval period the dorsal and ventral fins develop, the scales appear, and the overall body proportions approach those of the adult. For the purpose of this study the larval period is defined as beginning at the end of stage 39 with the appearance of rays in the dorsal fin, and is considered to end when all of the fins have the adult form. When raised at $20^{\circ} \mathrm{C}$, Fundulus begins feeding about 4 days after hatching. The larval period begins at about 6 days and lasts until about 24 days after hatching. The juvenile period which follows is also characterized by rapid growth. 
Characterization of centrifugal fractions of whole eleutheroembryos:

Shown in Figure $3-1$ are the distributions of BPM activity and various cytochrome $c$ reductase activities in centrifugal fractions prepared from whole eleutheroembryos as described in Materials and Methods. The data are plotted as the relative specific activity in a given fraction versus the percent total protein in that fraction. Relative specific activity is the ratio of the percent total activity, and the percent total protein. Thus, the area under each bar in the plots is equal to the percent total activity in that particular fraction. Succinate cytochrome c reductase (SCR), a mitochondrial marker (Fleischer and Kervina, 1974), clearly sedimented in the 10K fraction. Both NADPH cytochrome c reductase and BPM activities were clearly enriched in the $40 \mathrm{~K}$ fraction as indicated by their high relative specific activities in this fraction. However, considerable NADPH cytochrome $c$ reductase activity was present in all fractions. The presence of NADPH-cytochrome c reductase activity in the supernatant may be due to proteolysis, physical disruption or incomplete sedimentation of all particulate material.

The Localization of monooxygenase activity and NADPH cytochrome c reductase activity in the $40 \mathrm{~K}$ fraction, and the fact that this preparation is post-mitochondrial, indicate that it corresponds to a whole eleutheroembryo microsomal fraction. This fraction does contain mitochondrial contamination as indicated by the presence of SCR activity. Reduction of the mitochondrial contamination of the microsomal fraction by more intense sedimentation of the $10 \mathrm{~K}$ "mitochondrial" fraction, could only be achieved at a substantial loss of microsomal BPM activity. The SCR activity in the microsomal fraction may be associated with fragments of mitochondrial membrane rather than intact mitochondria. 
Figure 3-1. Distribution of benzo(a)pyrene monooxygenase activity and various cytochrome $c$ reductase activities in centrifugal fractions of whole eleutheroembryos. A total of 52 eleutheroembryos in stages 36-39 were homogenized and fractionated as described in Materials and Methods. The fractions are: I, low speed; II, 10K; III, 40K or microsomal; IV, supernatant. Relative specific activity is the percent total activity divided by the percent total protein. 


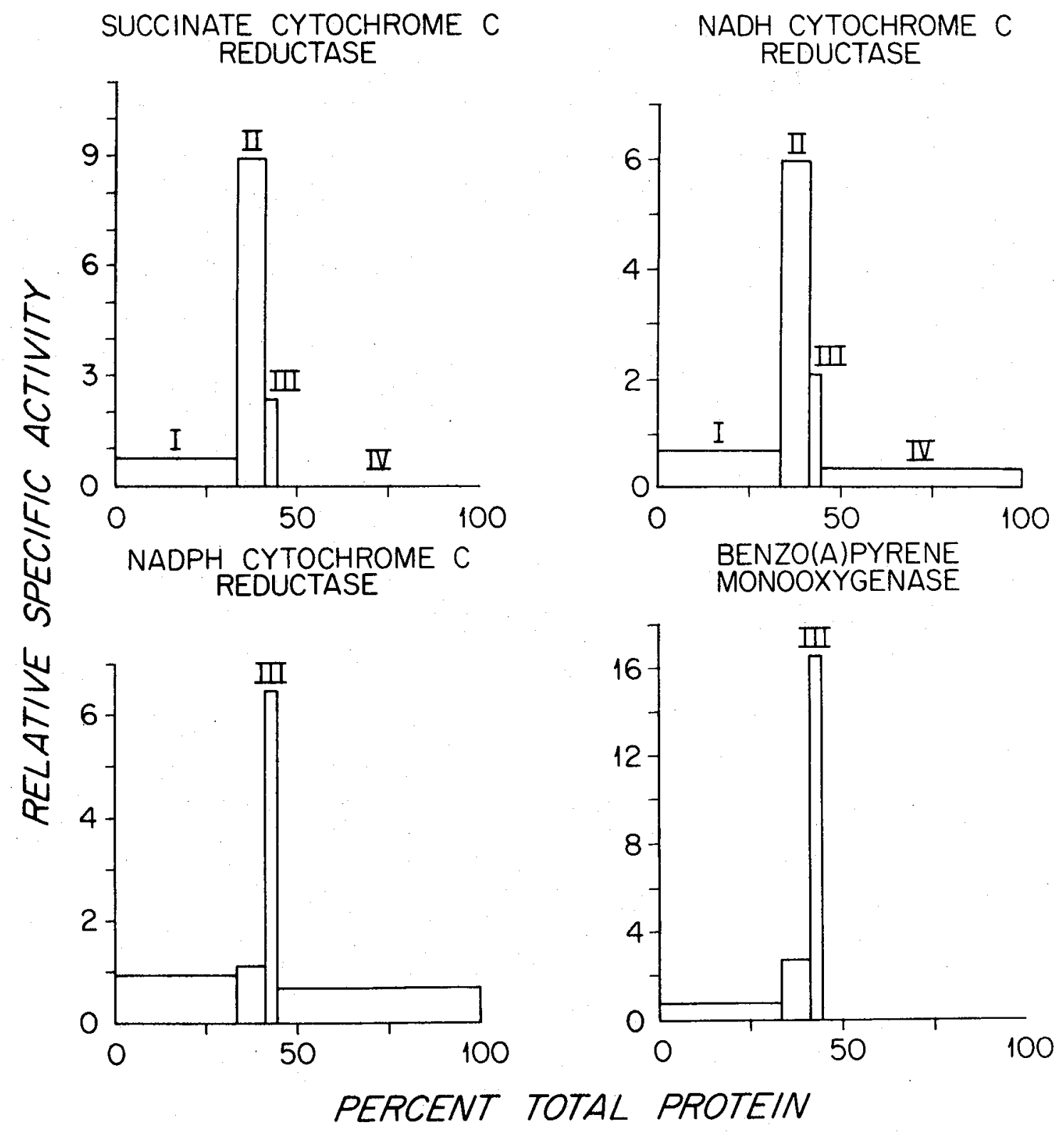


Page 98

$\mathrm{NADH}-\mathrm{cytoch}$ rome $\mathrm{c}$ reductase activity sedimented similarly to $\mathrm{SCR}$ activity except that activity was also present in the supernatant. The co-sedimentation of most of the NADH-cytochrome $c$ reductase activity with SCR activity suggests that the $\mathrm{NADH}-\mathrm{cyt}$ (och rome reductase activity is associated with the mitochondrial electron transport systems. The ratio of the relative specific activities of the NADH- and succinate-cytoch rome c reductases in the microsomal fraction is about $1: 3$ times greater than that in the mitochondrial fraction, suggesting that at least a portion of the NADH-cytoch rome $c$ reductase in the microsomes is derived from the endoplasmic reticulum and is not due to mitochondrial contamination.

Both the $10 \mathrm{~K}$ and $40 \mathrm{~K}$ fractions of whole embryos were examined by electron microscopy. The $10 \mathrm{~K}$ fraction was clearly enriched in mitochondria (not shown), and the $40 \mathrm{~K}$ fraction (Figure 3-2) was largely composed of membranous vesicles resembling liver microsomes (see: Fleischer and Kervina, 1974). The $40 \mathrm{~K}$ pellet also contained a large amount of nonvesicular cellular debris, the source of which is not apparent. Liver microsomes are much more homogenous than the "whole embryo microsomal fraction" prepared here, but this is not surprising considering the variety of tissues and structures likely to be contributing to this fraction. The low speed fraction of whole eleutheroembryos was examined by light microscopy and was found to be composed mostly of large debris, including sheets of unbroken cells, pieces of capillaries, and red blood cells. The low speed pellet is fibrous and brown in color, the $10 \mathrm{~K}$ pellet is granular and black, and the microsomal pellet is gelatinous, and pale brown to yellowish in color. 
Figure 3-2. Electron micrograph of a $40 \mathrm{~K}$ or microsomal pellet prepared from a homogenate of whole Fundulus embryos (stages 33-34). Original magnification was $20,000 \mathrm{X}$ and the scale bar equals $1 \mu \mathrm{M}$. 


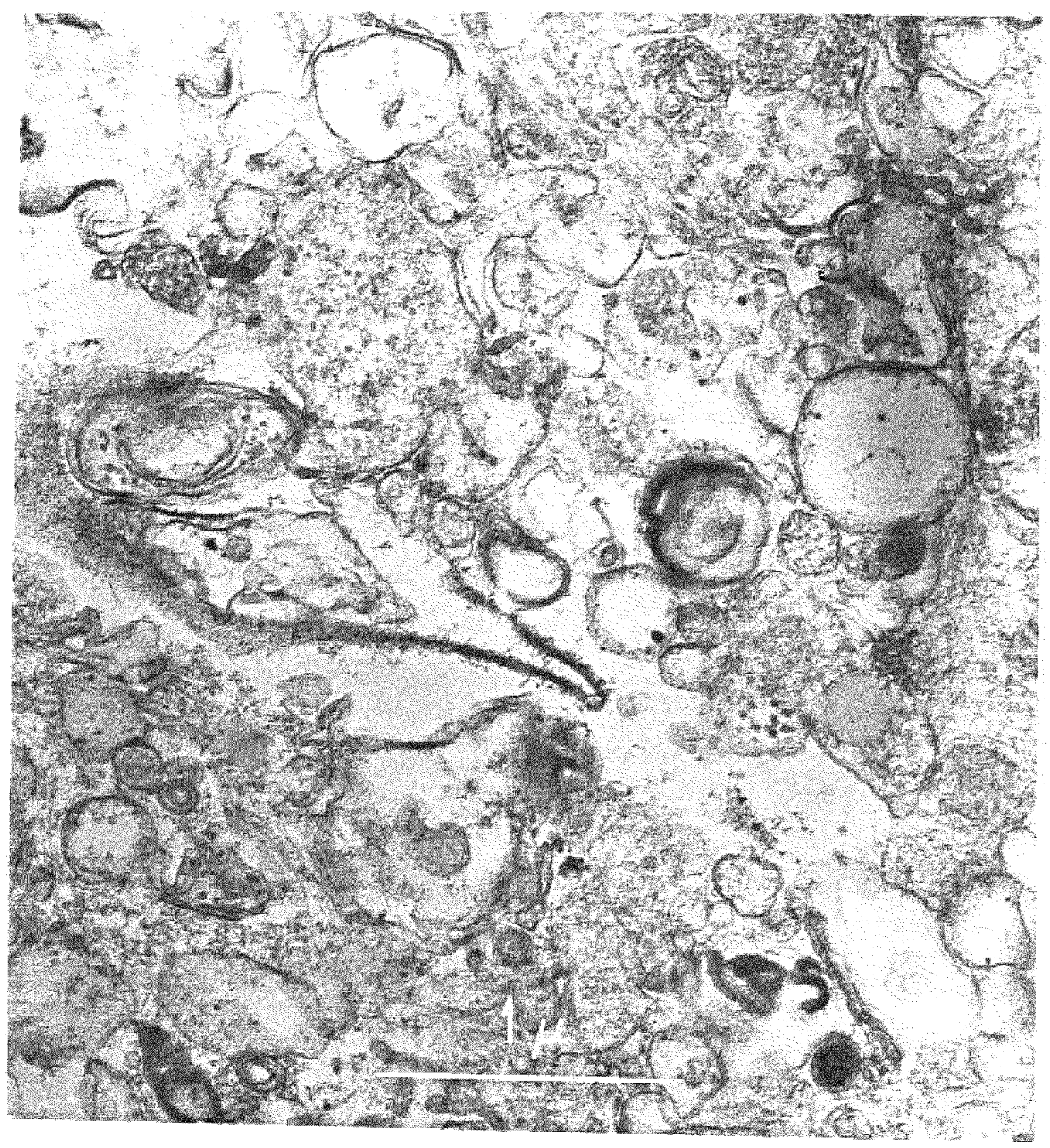


Detection of BPM activity in untreated embryos before hatching:

When fractions were prepared from embryos as described in Materials and Methods, BPM activity was reproducibly detectable at every prehatching stage examined. The procedure used involves removing the chorions from embryos with microsurgical scissors, then mechanically rupturing yolk sacs and washing embryos free of a substantial quantity of the yolk. Dechorionation prior to homogenization was found essential for the detection of BPM activity in untreated Fundulus embryos. When embryos were prepared for fractionation in this way, BPM activity was generally only detectable in the microsomal or $40 \mathrm{~K}$ fraction, consistent with the primary localization of this activity in eleutheroembryos. Thus no change in the distribution of activity in untreated embryos before and after hatching was observed.

In the experiments described in the previous chapter, BPM activity was not detectable in centrifugal fractions of untreated embryos, and in inducer exposed embryos activity was largely associated with the $10 \mathrm{~K}$ fraction. These embryos were homogenized with their chorions or shells intact. After hatching a much larger portion of the monooxygenase activity was associated with the $40 \mathrm{~K}$ fraction. The distribution of $\mathrm{BPM}$ activity in centrifugal fractions observed in these early experiments was due in part to over sedimentation of the mitochondrial fraction, as sedimentation times were not corrected when tubes contained less than full volumes. However, sedimentation conditions were not responsible for the change in distribution of activity after hatching. The mitochondrial fractions of eleutheroembryos were actually sedimented more intensely 
than those of embryos. Apparently the presence of the chorion or perivitelline fluid during homogenization was responsible for the sedimentation of induced monooxygenase activity in the $10 \mathrm{~K}$ fraction. This effect may be due to an aggregation of microsomes by some factor in the extraembryonic fluid; (e.g., microsomes can be aggregated by divalent cations, Kamath et al., 1971). Aggregation of microsomes may also be responsible for the lack of detectable activity in untreated embryos homogenized with their chorions intact.

Ontogeny of microsomal enzyme activities:

The developmental patterns of BPM and NADPH- and NADH-cytochrome $c$ reductase activities in microsomes prepared from whole embryos and eleutheroembryos are shown in Figure 3-3. The data presented are compiled results from assays on 7 different groups of embryos; data points for each group are indicated by distinct symbols.

A striking developmental pattern is seen for BPM activity, with low specific activities in microsomes prepared from embryos, and about a 10-fold higher specific activity in microsomes prepared from eleutheroembryos. The earliest embryos examined were 4 days from fertilization in stages 25-26. The increase in monooxygenase activity in eleutheroembryos was not programmed to occur at a given age but rather required hatching, as indicated by the data points at 19 days of age. BPM specific activity was 17-fold higher in microsomes from 19-day old eleutheroembry os compared to microsomes from 19-day old embryos from the same group (additional data on this group of embryos will be presented in a later section). 
Figure 3-3. Ontogeny of BPM activity and NADPH- and NADH-cytochrome c reductase activities in microsomes prepared from whole Fundulus embryos and eleutheroembryos. Embryos and eleutheroembryos were fractionated and assayed as described in Materials and Methods. Microsomes were prepared from 50-500 embryos or eleutheroembryos. The data are compiled from assays on a total of 3400 embryos and eleutheroembryos from 7 different pools of eggs; stripped from a total of 78 females. Each data point is the mean of 3 to 4 replicate determinations on an individual microsomal preparation; distinct symbols are used to indicate data from different embryo cohorts. 


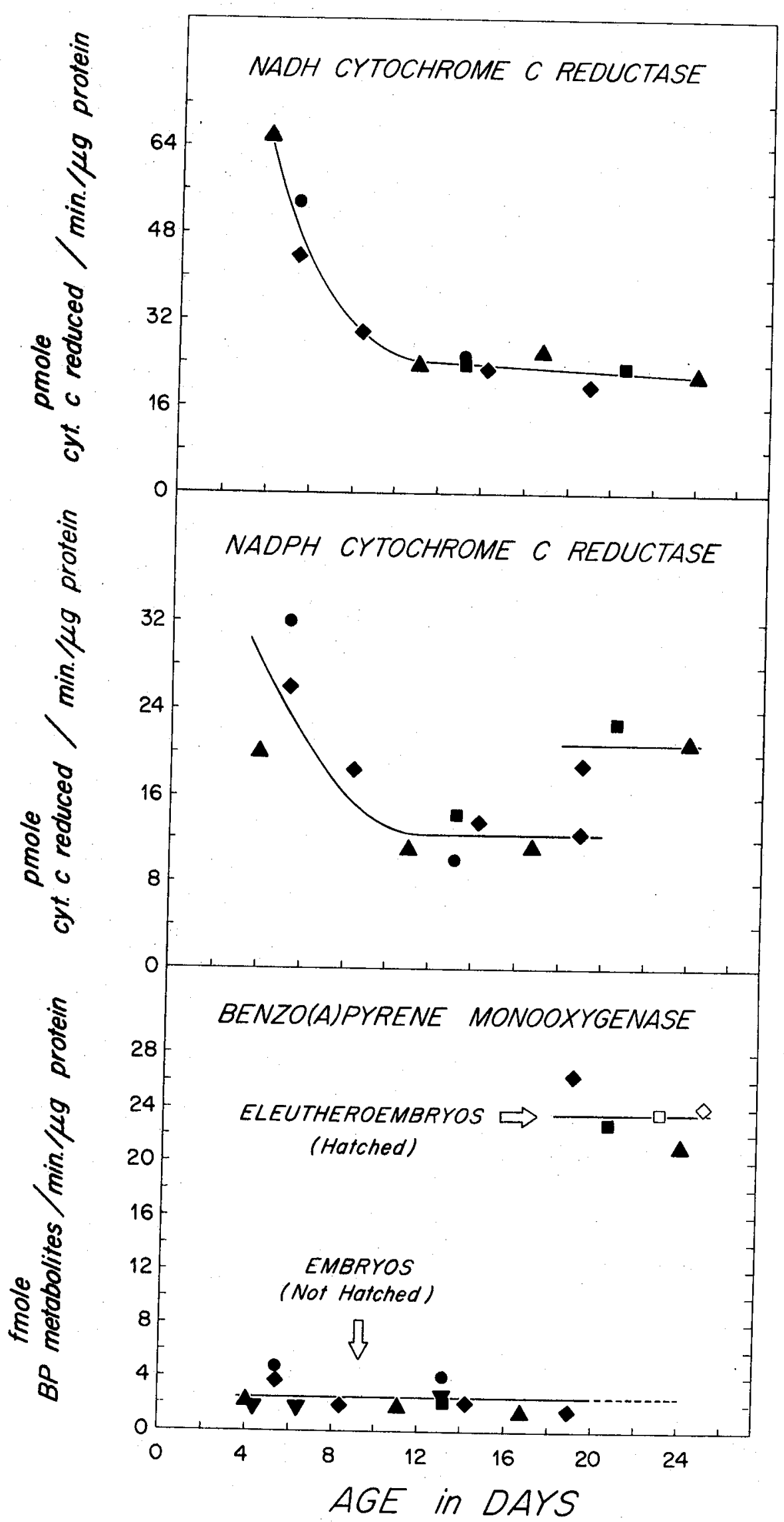


Each of the eleutheroembryo data points in Figure 3-3 were obtained with individuals that had hatched over a period of 1-4 days before the time of assay. The post-hatching increase in specific activity occurs over a shorter interval, and these data do not provide information on the time course of the change. This topic will be treated in a later section. Whole embryo weight, yield of microsomal protein, and level of BPM activity at different developmental stages of Fundulus are shown in Table 3-II. These data were obtained with a single pool of embryos from 8 females. The weights are of whole embryos, which consist of the embryo body and yolk. In Fundulus whole embryo weight does not change very much over the course of development. However, around the time of hatching a weight loss has consistently been observed, which apparently is due to a loss of fluid from the embryo. In stages 33-34 the urinary bladder and pericardial and peritoneal cavities contain substantial fluid. Around the time of hatching (stages 35-36) this fluid is released, and the yolk is pulled up into the peritoneal cavity, making the embryo more compact. Although whole embryo weight changes relatively little with development, there is a continuous increase in the mass of the embryonic body at the expense of yolk. Thus, as seen in Table 3-II, there is a steady increase in the yield of microsomal protein per embryo.

The developmental pattern of BPM specific activity seen in Table 3-II is like the overall pattern in Figure $3-3^{6}$. In the case of these particular embryos there was about a $30 \%$ decline in BPM specific 


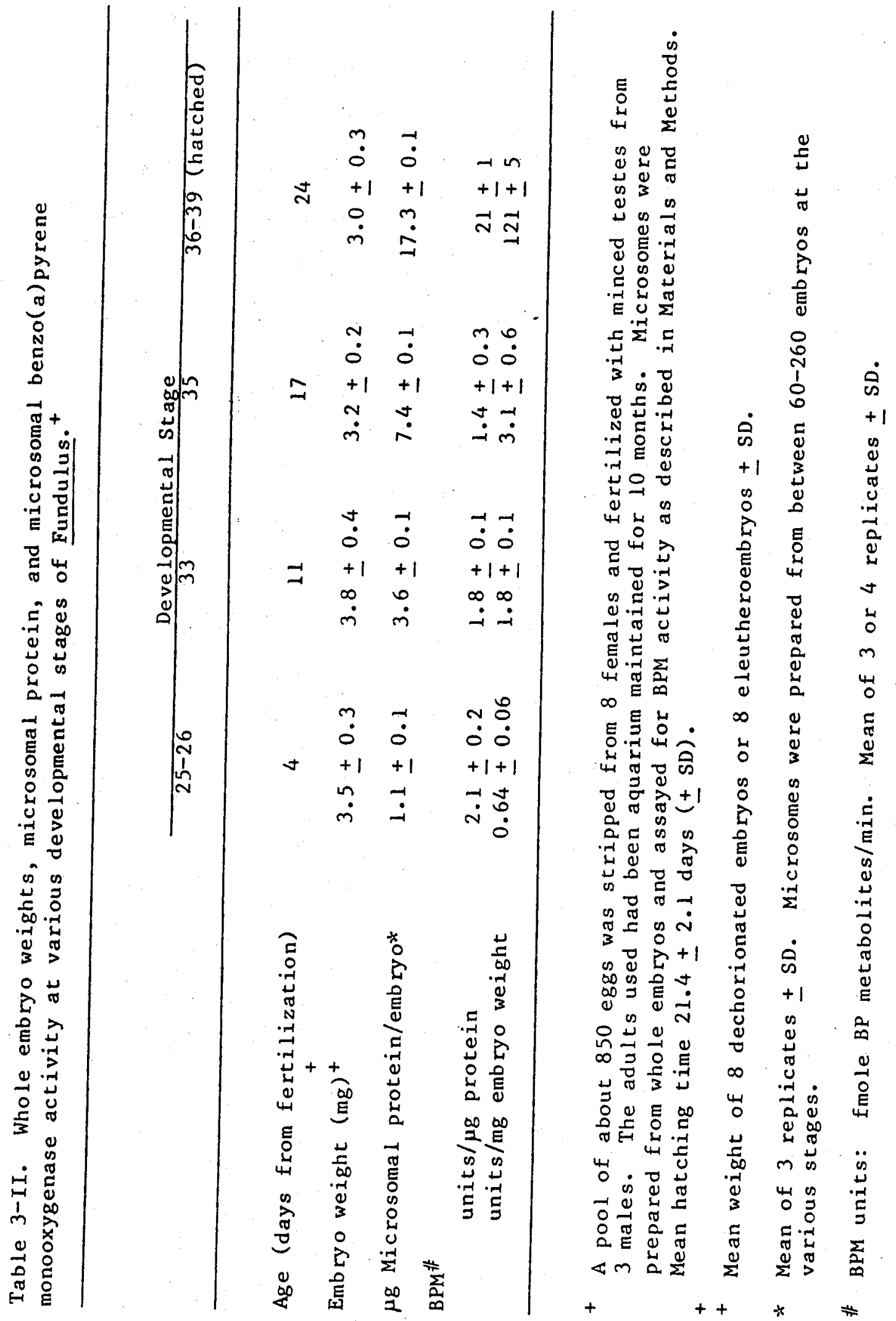


activity from days 4 to 17 of development; this was followed by a 15-fold increase in activity after hatching. The changes in specific activity do not closely reflect changes in the total capacity of the embryos to metabolize benzo(a)pyrene. Although BPM specific activity decreased from day 4 to 17 , the total activity normalized to weight rose about 5 -fold over this period due to the increase in microsomal protein with growth. For the same reason, the increase in total activity per unit weight after hatching was more than twice the increase in specific activity. Thus, from the earliest embryonic stages of Fundulus examined there is a continuous increase in the total capacity to metabolize benzo(a)pyrene with development.

The developmental pattern of whole embryo microsomal NADPH-cytoch rome c reductase activity was distinct from that of BPM activity. The highest specific activities in whole embryo microsomes were measured around 5 days of development (stage 28). The specific activity decreased roughly 2 to 4-fold by day 13 (stages 33-34), then remained fairly constant up to the time of hatching (stage 35), and then showed a modest increase of about 1.6-fold in stages assayed after hatching (stages 36-39). Prior to hatching, the developmental pattern of $\mathrm{NADH}-c y t o c h$ rome $\mathrm{c}$ reductase closely resembled that of $\mathrm{NADPH}-\mathrm{cytoch}$ rome $\mathrm{c}$ reductase; however, NADH reductase activity did not increase after hatching. The specific activity of $\mathrm{NADH}$ cytoch rome $c$ reductase was greater than that of NADPH-cytochrome $c$ reductase at all of the pre-hatching stages; but after hatching, the activities of the two reductases were about the same. 
Test for the presence of endogenous inhibitors before hatching:

One possible explanation for the consistently lower BPM activity measured in microsomes prepared from embryos, as compared to those prepared from eleutheroembryos, is the presence of an endogenous inhibitor or inactivator. A likely candidate is the hatching enzyme which is released in large quantities from glands within the mouth of the embryo at the time of hatching (Armstrong, 1936). This protease (Kaighn, 1964) digests the inner layers of the chorion, then hatching occurs when movements of the embryo rupture the thin envelope which remains. Substantial amounts of hatching enzyme must be present in embryos approaching hatching. Release of this protease upon homogenization of embryos could conceivably inactivate the microsomal monooxygenase system.

To test for the presence of endogenous inhibitors or inactivators released upon homogenization of the embryos, microsomes were prepared from homogenates of dechorionated embryos, eleutheroembryos, and a mixture of the two homogenized together. Both the embryos and eleutheroembryos were from the same pool of eggs and were 24 days old. The results of BPM assays are shown in Table 3-III. Consistent with the previous results, the microsomes prepared from eleutheroembryos were much more active in metabolizing BP than those from the embryos ${ }^{7}$. The microsomes prepared from the mixed homogenate had an activity that was the exact numerical average of the activities measured in embryo and

7 Note, the activities in Table 3-III are normalized per embryo. These data were not plotted in Figures 3-3 because sufficient material for protein determinations was not available, thus specific activity could not be calculated. 
Table 3-III. BP monooxygenase activity in microsomes prepared from whole embryos, eleutheroembryos, and a mixture of the two homogenized together.

\begin{tabular}{lcc}
\hline Material Homogenized & & \multicolumn{1}{c}{ BP Monooxygenase } \\
& Measured & Expected \\
& $37 \pm 4$ & - \\
Embryos & $357 \pm 7$ & 197 \\
Embryos + Eleutheroembryos $(1: 1)$ & $197 \pm 5$ & \\
\hline
\end{tabular}

+ The embryos and eleutheroembryos used were from the same pool of eggs and were 24 days old. Eleutheroembryos had hatched at various times over the preceding 5 days and were in stages 36-39; embryos were in stages 35 or 36 . Microsomes were prepared from homogenates of 60 dechorionated embryos, 60 eleutheroembryos, and a mixture of 30 dechorionated embryos and 30 eleutheroembryos. Fractionation and assay procedures were as described in Materials and Methods.

* Activity is expressed as fmole/min/embryo. Data are the mean of 3 replicates $\pm S . D$. 
eleutheroembryo microsomes. This result shows quite clearly that the activities were additive, and that there were no factors released from embryos upon homogenization capable of inactivating the eleutheroembryo monooxygenase system. The data also indicate that the paucity of activity in embryos is not due to the absence of some soluble activator which appears after hatching, such as a metal ion or cofactor, since in that case greater than additive results would probably have been seen. Apparent ly the observed increase in monooxygenase activity after hatching is not artifactual, but is a measure of a real change in the capacity of embryos to metabolize xenobiotics.

Time-dependent changes in BPM and NADPH-cytochrome $c$ reductase activities after hatching:

The data of Figure 3-3 show that there is greater than an order of magnitude increase in BPM specific activity, and about a 1.6-fold increase in NADPH-cytochrome $c$ reductase specific activity in whole Fundulus embryo microsomes after hatching. Since pools of eleutheroembryos that had hatched over a number of days were assayed, the time courses of these increases in activity are not apparent from these data. The ideal way to determine the time courses of increase would be to follow these activities in a group of eleutheroembryos that hatched within a short interval of time. The problem is that hatching times are distributed over a period of about a week, and a very large pool of embryos would be required to provide an adequate number of eleutheroembryos hatching over a short interval. A different approach 
was taken. A pool of eleutheroembryos was divided into groups that had hatched during sequential intervals before a single point in time when they were all fractionated. In other words, all the eleutheroembryos were the same age at the time of assay, but eleutheroembryos in different groups had been hatched for various lengths of time. Data collected in this way will not show a strict time course, but still will give an indication of how much time is required after hatching for the changes in activity to occur.

The results of this experiment are illustrated in Figure $3-4$; the details of the experimental protocol are described in the figure legend. A group of embryos of the same age were also assayed for comparison to the eleutheroembryos. There was a continuous increase in BPM specific activity with the length of time that eleutheroembryos had been hatched. Microsomes from eleutheroembryos that hatched just prior to fractionation ( 0.2 to 2.5 hours) were only modestly ( 1.4 times) more active in metabolizing BP than those from embryos. The largest single increment in activity was in the group that had hatched 12 to 24 hours before fractionation. Microsomes from that group were 11 times more active in metabolizing BP than those from the embryos. The BPM specific activity in microsomes from the eleutheroembryos that hatched 24 to 60 hours before fractionation was $26 \mathrm{fmole} / \mathrm{min} / \mu \mathrm{g}, 17$ times greater than the activity in the preparation from the embryos. Based on data obtained from other eleutheroembryos that had hatched from 1 to 4 days before 
Figure 3-4. Levels of BPM activity and NADPH cytochrome c reductase activity in microsomes prepared from 19 day old eleutheroembryos that hatched during various intervals prior to fractionation, and in a group of dechorionated embry os of the same age. Embryos and eleutheroembryos were from a pool of 4300 eggs stripped from 15 females and fertilized with minced testis from 5 males. Zero time is the moment at which all dishes of eleutheroembryos were placed on ice. They were subsequently homogenized and fractionated as described in Materials and Methods. Each group consisted of about 80 individuals except the 24-60 hour group which had 68 e leutheroembryos. The eleutheroembryos in the various hatching groups were in different developmental stages. The staging was as follows: not hatched, stages $35-36 ; 0.2-2.5 \mathrm{hr}$. and $2.5-12 \mathrm{hr}$, stages $36-37 ; 12-24 \mathrm{hr}$., stage $37 ; 24-60 \mathrm{hr}$., stages $37-38$. The mean hatching time for the entire pool of embryos was $20.9 \pm 1.7$ days. The data are the mean of 3 replicate determinations; error bars are the standard deviation. Where error bars are not indicated the coefficients of variation (S.D./mean) were less than 0.05 . 


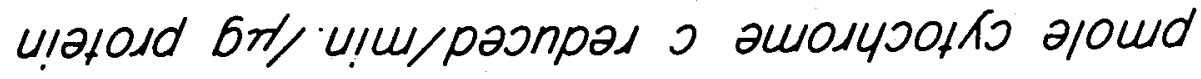

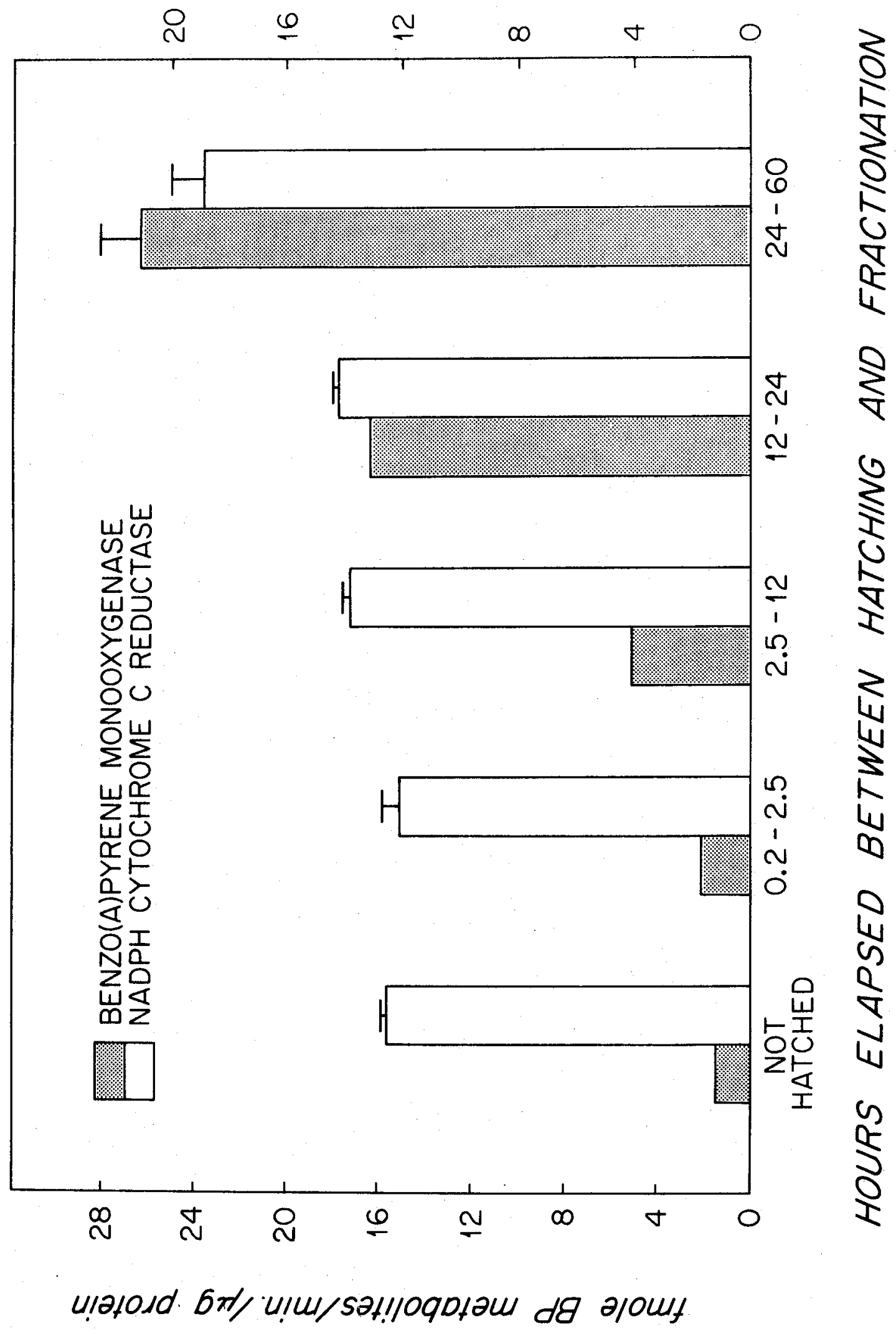


fractionation (Figure $3-3$ and Table $3-I I)^{8}$, further increases in specific activity in whole eleutheroembryo microsomes would not be expected with additional time from hatching. Thus, the maximal level of BPM activity appears to be reached in eleutheroembryos somewhat after 24 hours from hatching. Again, these data clearly show that the increase in BPM specific activity observed in post-hatching stages is not simply age-dependent. Furthermore, the data indicate that the trigger for increase occurs proximate to the event of hatching.

The increase in $\mathrm{NADPH}-\mathrm{cy}$ toch rome $c$ reductase specific activity after hatching did not closely follow the increase in BPM activity (Fig. 3-4). The specific activity of NADPH-cytochrome $c$ reductase in the microsomes prepared from eleutheroembryos 12 to 24 hours after hatching was only 1.1 times greater than that in the microsomes from embryos, while there was an eleven-fold difference in the capacity of these two preparations to metabolize BP. The largest increment in NADPH-cytochrome $c$ reductase was in the 24-60 hour group, whose activity was 1.5 times higher than that of the dechorionated embryos. The time course of the increase in NADPH-cytochrome c reductase activity after hatching is apparently distinct from that of BPM activity. NADH-cytochrome c reductase activity was also measured in each of the groups in this experiment. As before (Fig. 3-3), hatching had no effect on this activity. Activities were essentially identical in all preparations (mean value: $20.5 \pm 0.7$ pmole cytochrome c reduced $/ \mathrm{min} / \mu \mathrm{g}$ protein).

${ }^{8}$ The data from the dechorionated and 24-60 hr groups in this experiment are the points plotted in Figure 3-3 at 19 days of age. Earlier stages from the same pool of embryos are also plotted in the figure indicated by diamond-shaped symbols. 
Requirements for BPM activity in microsomes:

In Table 3-IV the microsoma 1 BP monooxygenases of whole Fundulus embryos and eleutheroembryos, and adult liver are compared with regard to requirements for activity and sensitivity to inhibitors. The adult liver and eleutheroembryo activities are seen to require native enzyme, oxygen and NADPH, and are much less effectively supported when NADH is substituted for NADPH. An absolute oxygen dependence was not demonstrated, but the simple gassing procedures used here would not be expected to produce truly anoxic conditions. In all cases BPM activity was substantially inhibited by carbon monoxide, evidence that cytochrome P-450 mediates this activity. Furthermore, in all cases, $100 \mu \mathrm{M}$ cytochrome $c$ effectively abolished BPM activity. In incubations with cytoch rome $c$, the concentration of $\mathrm{NADPH}$ was increased to $1.6 \mathrm{mM}$, a level far in excess of that which could be oxidized by the NADPH-cytochrome c reductase present in any of the preparations. The inhibition of BPM activity by cytoch rome $c$ in the presence of excess NADPH suggests that cytochrome $c$ interferes with the flow of electrons from NADPH to the oxygenase, rather than just depleting NADPH. Cytochrome c inhibition of microsomal monooxygenase activity provided the first evidence that the physiological role of microsomal NADPH-cytochrome $c$ reductase is the transfer of electrons from NADPH to cytochrome P-450 (Phillips and Langdon, 1962). The properties of the BPM activity measured in the Fundulus preparations are typical of cytochrome $\mathrm{P}-450$ dependent reactions. The data presented in Table 3-IV strongly suggest that the BPM activities of adult Fundulus hepatic microsomes, and whole embryo and eleutheroembryo microsomes are catalyzed by cytochrome $\mathrm{P}-450$ systems. 


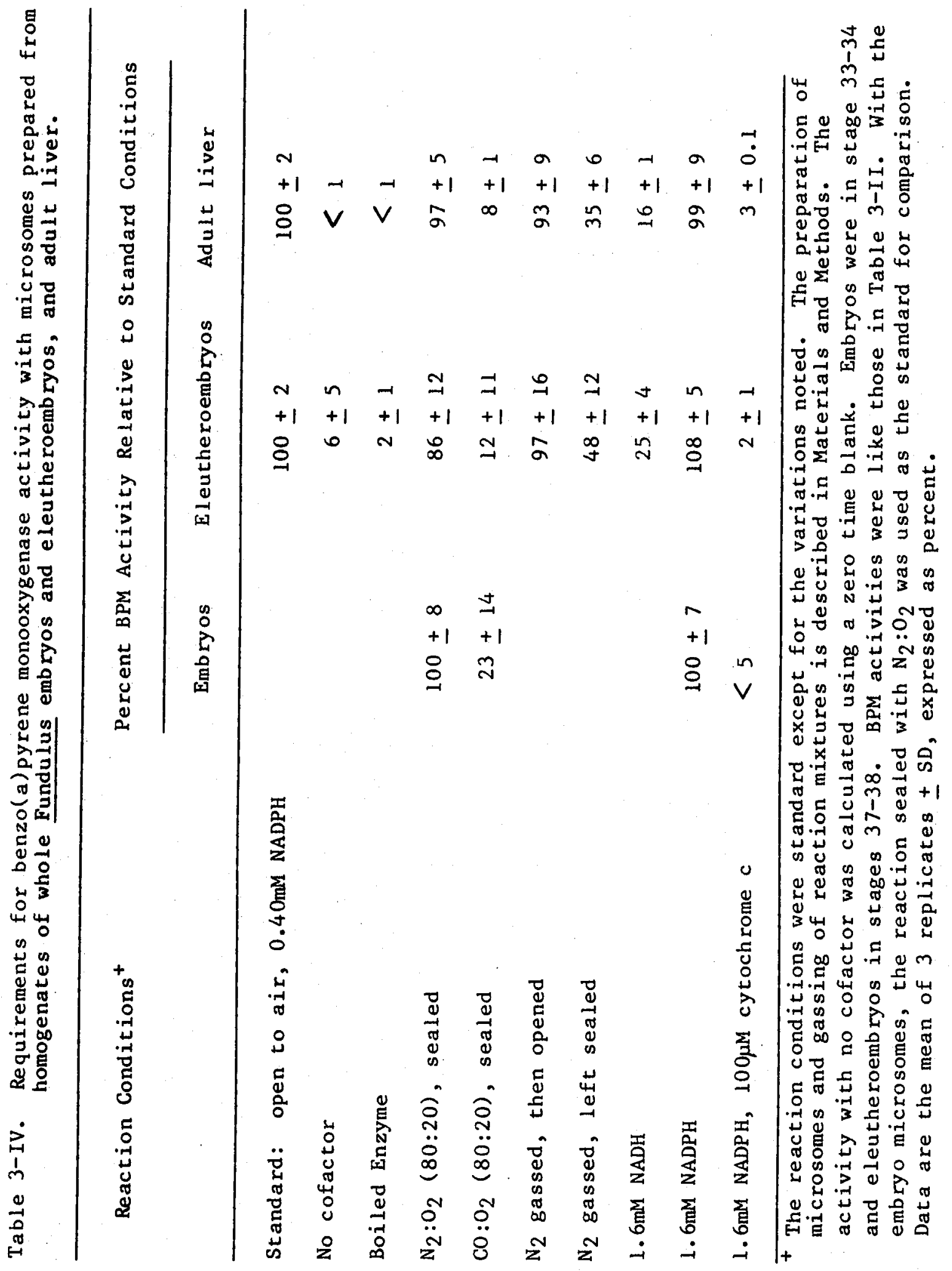


Analysis of eleutheroembryo fractions by difference spectroscopy:

Microsomes prepared from whole eleutheroembryos were analyzed by difference spectroscopy in an effort to detect and quantify cytochromes $\mathrm{P}-450$ and $\mathrm{b}_{5}$. Only a limited number of analyses were possible, because the spectral techniques are not very sensitive and require material from a large number of eleutheroembryos. To avoid interference from any hemoglobin present, CO reduced/CO oxidized difference spectra were recorded (Matsubara et al., 1974). Such spectra obtained with Fundulus adult liver microsomes, and the microsomal and $10 \mathrm{~K}$ fraction of eleutheroembryos are shown in Figure 3-5. Curve $A$ is the spectrum of adult hepatic microsomes. The peak at $450 \mathrm{~nm}$ is due to cytochrome $\mathrm{P}-450$ and the shoulder around $430 \mathrm{~nm}$ is due to cytochrome $b_{5}$ which absorbs at $424 \mathrm{~nm}$ in the reduced state. Curves $B$ and $C$ were obtained with whole eleutheroembryo microsomes. These spectra closely resemble the cytochrome P-450 spectrum, except for peaks at $430 \mathrm{~nm}$, and, in the case of curve $C$, the increased depth of the trough at $410 \mathrm{~nm}$. Generally the CO reduced/Co oxidized difference spectrum of eleutheroembryo microsomes consisted of peaks at $450 \mathrm{~nm}$ and $430 \mathrm{~nm}$ and a trough at $410 \mathrm{~nm}$. Often the peak at $430 \mathrm{~nm}$ was much larger than that at $450 \mathrm{~nm}$, and in some cases only a shoulder was seen around $450 \mathrm{~nm}$. The peak at $430 \mathrm{~nm}$ was not due to cytoch rome $b_{5}$, as the addition of NADH to both the sample and reference cuvettes had no noticeable effects on this signal. The reduction of cytochrome $b_{5}$ by $\mathrm{NADH}$ would eliminate its contribution to the reduced versus oxidized difference spectrum. 
Figure 3-5. Difference spectra obtained with whole Fundulus eleutheroembryo fractions and adult liver microsomes. Fractions were prepared and analyzed as described in Materials and Methods. Curves A through $D$ are $C O-d i t h i o n i t e$ reduced versus $C O$ oxidized difference spectra, which were redrawn from the original tracings. Spectrum A: cuvettes contained adult liver microsomes from a pool of livers from 3 male and 3 female fish, at $0.67 \mathrm{mg}$ protein/ml. Spectrum B: microsomes from a pool of 240 stage 37-39 whole eleutheroembryos at $0.30 \mathrm{mg}$ protein/ml. In an effort to reduce mitochondrial contamination of the microsomal fraction, the $10 \mathrm{~K}$ or "mitochondrial" fraction of these eleutheroembryos was sedimented 3 times longer than usual. Spectrum c: microsomes from a pool of 190 stage 38-39 whole eleutheroembryos at $0.46 \mathrm{mg}$ protein $/ \mathrm{ml}$. Spectrum $\mathrm{D}$ : the $10 \mathrm{~K}$ fraction from the spectrum $\mathrm{C}$ eleutheroembryos at $0.64 \mathrm{mg}$ protein $/ \mathrm{ml}$. For spectra $A$ and $D$ each division on the absorbance scale is equal to an optical density of 0.01 , while for spectra $B$ and $C$, each division equals an optical density of 0.001 . The eleutheroembryo microsomes were analyzed fresh, the other fractions were stored in liquid nitrogen before analysis. 

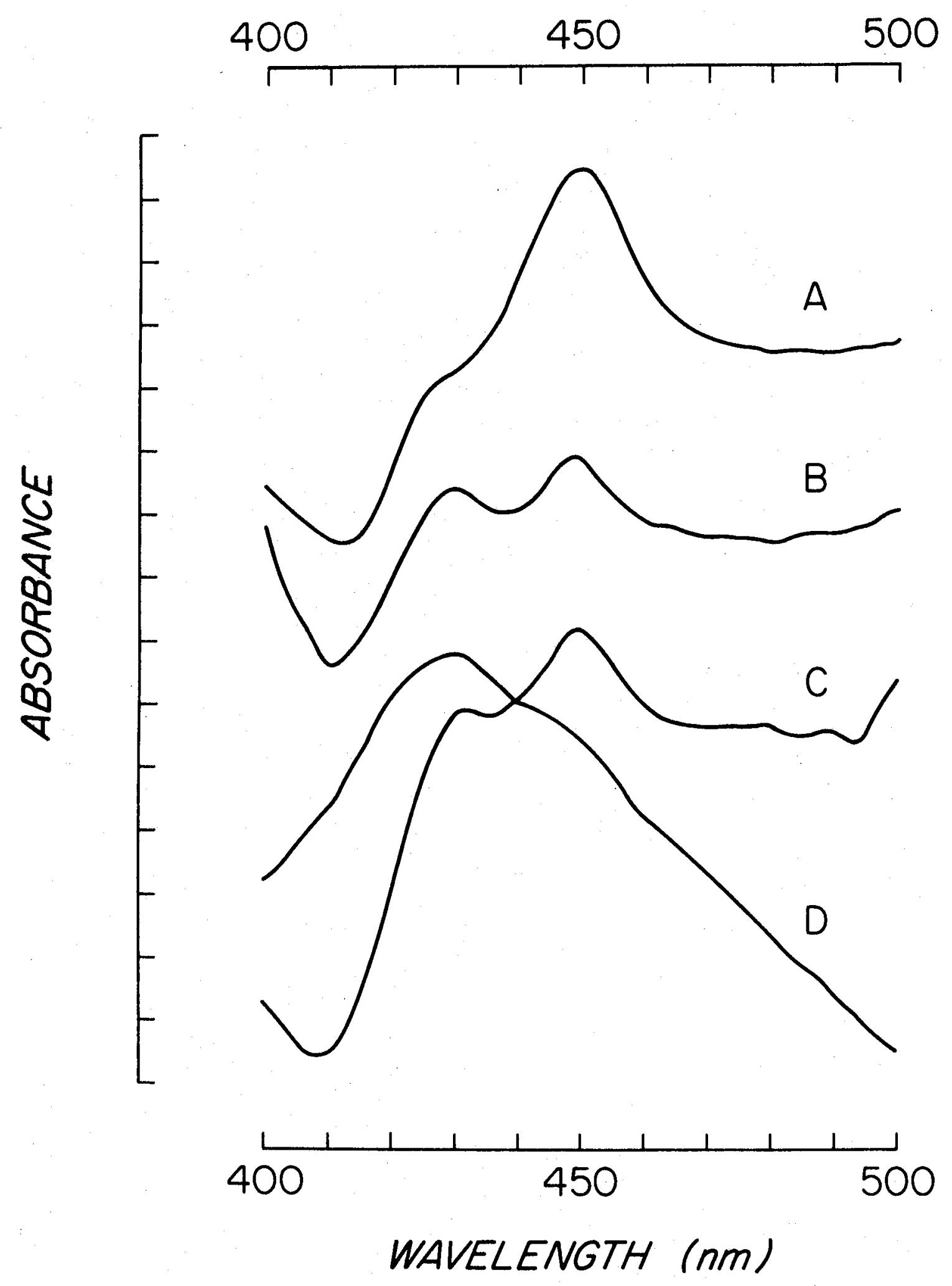
Curve $D$ is the spectrum of the $10 \mathrm{~K}$ fraction of the eleutheroembryos from which the microsomes of curve $C$ were prepared. As discussed earlier the majority of the mitochondria sediment in this centrifugal fraction of eleutheroembryos. Mitochondrial cytochrome $a_{3}$ in the reduced state forms a complex with $c 0$ which has an absorbance of $430 \mathrm{~nm}$, and is probably responsible for the peak at $430 \mathrm{~nm}$ in the difference spectrum of the 10K fraction (curve D). Since whole eleutheroembryo microsomes are contaminated with mitochondria, as indicated by the presence of succinate cytochrome $c$ reductase activity, it would seem likely that this contamination is responsible for the signal at $430 \mathrm{~nm}$ in the microsomal difference spectrum. The spectra obtained with the $10 \mathrm{~K}$ and microsomal fractions of whole eleutheroembryos are clearly distinct. The peak at $450 \mathrm{~nm}$ appears only in the microsomal spectrum, and is very likely to be due to cytochrome $\mathrm{P}-450$. This conclusion is supported by the catalytic data (Table 3-IV) which indicate that cytochrome $P-450$ is present in eleuthe roembryo microsomes.

Figure 3-6 shows NADH reduced versus oxidized difference spectra obtained with microsomes from whole eleutheroembryos (A) and adult liver (B). The liver microsomal difference spectrum is characteristic of cytochrome $b_{5}$, with a trough around $410 \mathrm{~nm}$ and a peak near $424 \mathrm{~nm}$ (Omura and Sato, 1964). The difference spectrum of eleutheroembryo microsomes was similar to that of liver microsomes, while the $10 \mathrm{~K}$ fraction of whole eleutheroembryos did not give a difference spectrum when an NADH-reduced sample was compared to an oxidized reference. Thus, the peak in the eleutheroembryo microsomal difference spectrum is likely to be due to cytochrome $b_{5}$ rather than mitochondrial contamination. 
Figure 3-6. Cytochrome $b_{5}$ difference spectra obtained with whole Fundulus eleutheroembryo microsomes and adult liver microsomes. Fractions were prepared and analyzed as described in Materials and Methods. NADH reduced versus oxidized difference spectra were recorded. Spectrum A: cuvettes contained eleutheroembryo microsomes at $0.57 \mathrm{mg}$ protein $/ \mathrm{ml}$. These microsomes were prepared from a homogenate of $880 \mathrm{stage}$ 38-39 eleutheroembryos, with the 10K fraction sedimented for 3 times as long as standard. Spectrum B: adult liver $\mathrm{microsomes}$ at $0.84 \mathrm{mg}$ protein $/ \mathrm{ml}$, from a pool of livers from 3 males and 3 females. Both spectra were redrawn from the original tracings, and spectrum $A$ was corrected for baseline absorbance. 
Page 122

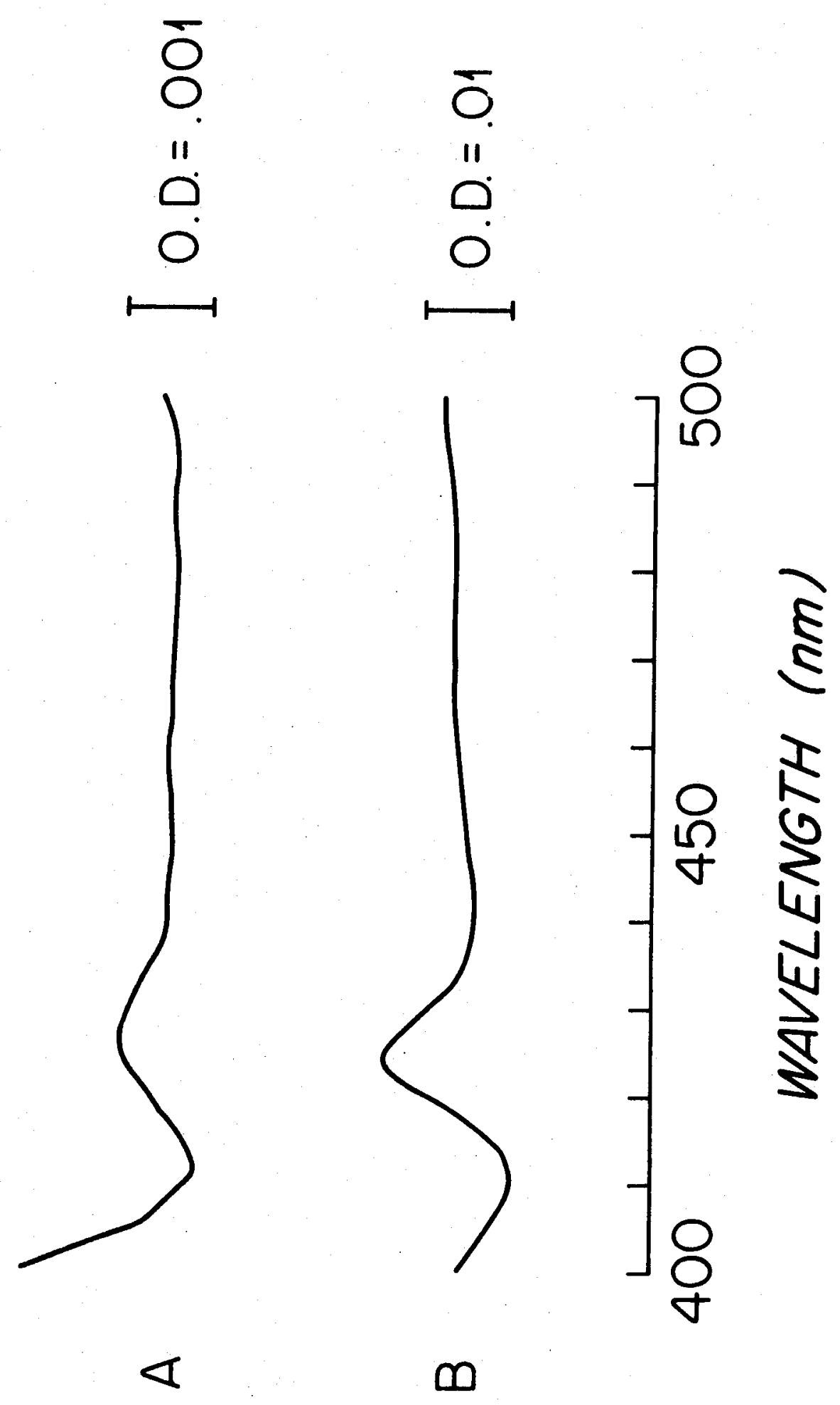


Page 123

Compilation of data on the monooxygenase system in microsomes prepared from whole eleuthe roemb ryos:

Shown in Table $3-V$ is a compilation of the data on the levels of monooxygenase activities and the components of microsomal electron transport in whole eleutheroembryo microsomes. In addition to BPM activity, another monooxygenase activity, aminopyrine $\mathrm{N}$-demethylase (ADP) was measurable in whole eleutheroembryo microsomes. The ontogeny of ADP was not examined. The specific contents of cytochrome $P-450$ and cytoch rome $b_{5}$ were estimated from difference spectra like those in Figures 3-5 and 3-6. As a point of reference, the level of cytochrome P-450 in eleutheroembryo microsomes is about $1 / 40$ of the level in adult Fundulus hepatic microsomes.

BPM activity in livers of Fundulus eleutheroembryos, larvae and adults:

The use of microsomal preparations from whole embryos has proven valuable for answering basic questions concerning the ontogeny of the microsomal monooxygenase system in Fundulus. However, it is desirable to know how xenobiotic monooxygenase activities change during the course of development of individual organs and tissues. The liver is of particular interest because in adult vertebrates it is the primary site of xenobiotic metabolism, and generally has the highest levels of microsomal monooxygenase activities. Results presented in Chapter 2 (Table 2-II) demonstrated that BPM activity can be detected in the livers of untreated eleutheroembryos. Additional determinations of BPM activity in eleutheroembryo livers were made, and hepatic BPM activity was also 
Table 3-V. Monooxygenase activities, NADPH- and NADH-cytochrome c reductase activities and content of cytochromes $\mathrm{P}-450$ and $\mathrm{b}_{5}$ in microsomes prepared from whole Fundulus eleuthe roembryos.

\begin{tabular}{|c|c|}
\hline 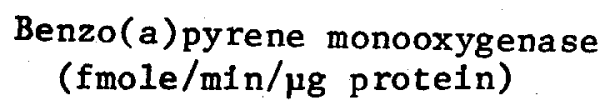 & $23 \pm 3$ \\
\hline 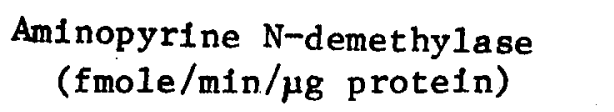 & $89 \pm 14$ \\
\hline $\begin{array}{l}\text { NADPH-cytochrome c reductase } \\
(\mathrm{pmole} / \mathrm{min} / \mu \mathrm{g} \text { proteln) }\end{array}$ & $21 \pm 2$ \\
\hline $\begin{array}{l}\text { NADH-cytochrome c reductase } \\
(\text { pmole/m } 1 \mathrm{n} / \mu \mathrm{g} \text { proteln) }\end{array}$ & $22 \pm 2$ \\
\hline $\begin{array}{l}\text { Cytochrome } \mathrm{P}-450 \\
\quad(\text { fmole/ } / \mathrm{g} \text { proteln) }\end{array}$ & $8 \pm 1$ \\
\hline $\begin{array}{l}\text { Cytochrome } b_{5} \\
\text { (fmole/ } \mu g \text { protein) }\end{array}$ & $9 \pm$ \\
\hline
\end{tabular}

Microsomes were prepared from pools of whole eleutheroembryos which were 19-24 days old (stages 36-39). Al1 data are the mean of assays on 3 pools $\pm S D$, except the cytochrome $b_{5}$ data which is the mean of 2 determinations \pm range. All pools of eleuthe roembryos contalned at least 60 individuals, and were obtained from several different females. The BPM and reductase data were plotted in Figure 3-2 (diamond, square and upright triangular symbols). 
measured during the early larval period. Whole homogenates of liver were assayed rather than microsomes, because only about 40 to $60 \%$ of the total activity is usually recovered in liver microsomal fractions. Considering the extremely small amount of tissue available from eleutheroembryos (about $1 \mu \mathrm{g}$ protein/liver), it was necessary to maximize the amount of product produced in the assay reaction mixtures.

A comparison of body weight, liver protein to body weight and hepatic BPM activity in Fundulus eleutheroembryos, larvae and adults is shown in Table 3-VI. The liver protein to body weight ratio is used here rather then the standard liver weight to body weight ratio as an indicator of the amount of liver tissue per unit body weight, because wet weights could not be obtained for the very small livers of eleutheroembryos and larvae. Growth is very rapid in Fundulus once feeding begins; over an interval of about 5 days from the late embryonic period to the early larval period body weight more than doubled. It should be noted that the body weight shown for eleutheroembryos includes the weight of yolk. Yolk was about $35 \%$ of the total weight in the stage 36-38 eleutheroembryos examined. As Asociated with the transition from the embryonic to larval periods of development and the onset of feeding, is a large increase in the amount of liver protein per unit body weight. This parameter increased by a factor of 3.5 from the late embryonic to larval periods. Part of the increase was due to yolk absorption, but even when corrected for yolk, the larvae had more than twice the relative amount of liver protein as eleutheroembryos. The yield of liver protein per unit body weight varied considerably between different groups of larvae, although 


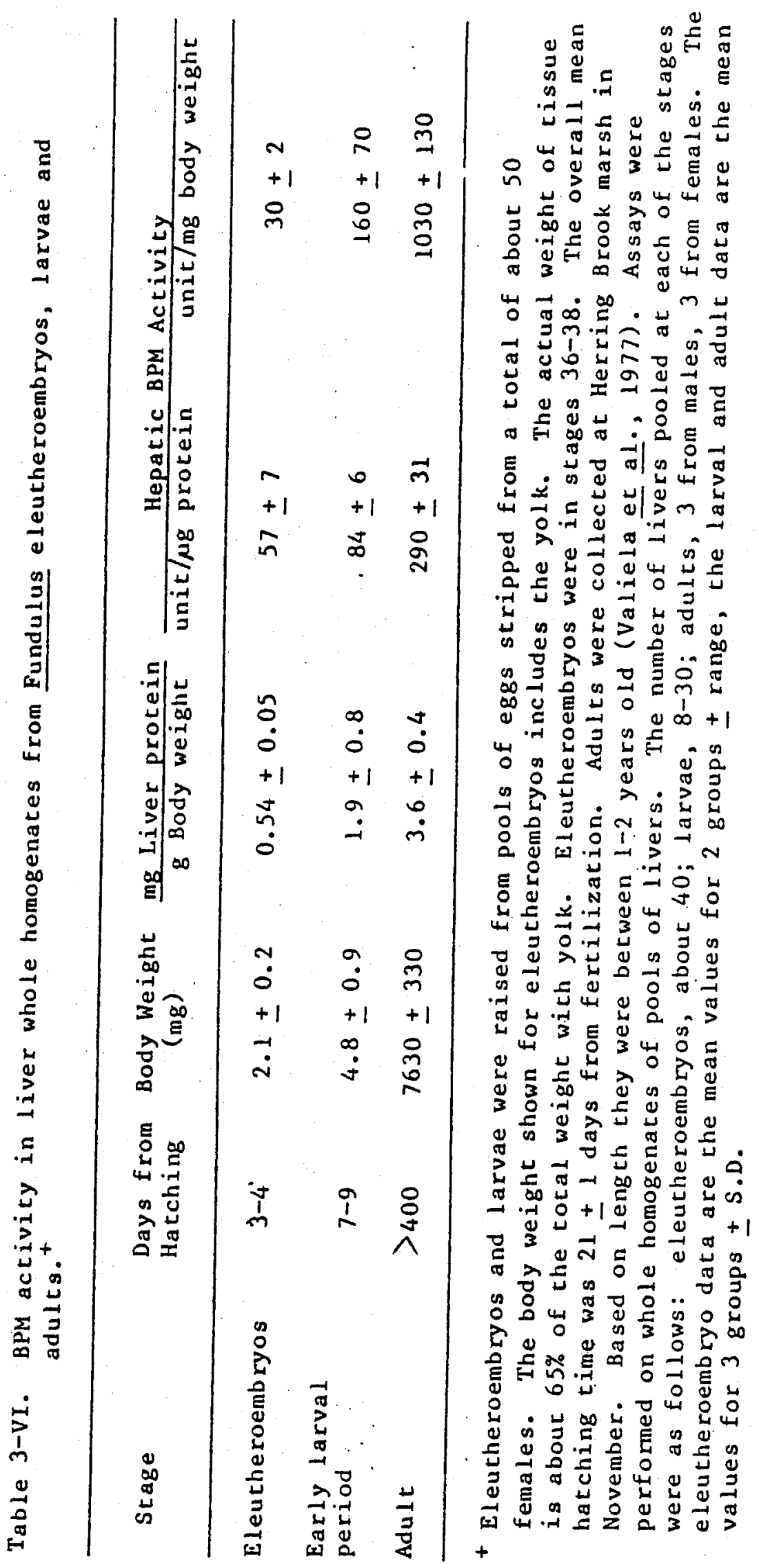


they were raised under similar conditions. On the average the adults had more than twice as much liver protein per unit body weight as the larvae, but for one group of larvae the value of this parameter was $75 \%$ of the adult value.

BPM specific activities in the livers of eleutheroembryos and larvae were similar, and were about $20 \%$ and $30 \%$ of the activity measured in adults, respectively. Because of increase in the relative amount of liver protein, total hepatic BPM activity per unit body weight was more than 5-times higher in larvae than in eleutheroembryos. Even though hepatic BPM specific activity changes little from the late embryonic to early larval periods there is a substantial increase in the relative hepatic capacity to metabolize BP over this interval of development. On the average, the adults assayed had about 6 times as much hepatic BPM activity per unit body weight as the larvae.

Localization of BP monooxygenase activity in the microsomal fraction of Fundulus larval liver, and a comparison of enzymatic activities and cytoch rome content of larval, juvenile and adult hepatic microsomes

Since the total hepatic capacity to metabolize BP measured at the beginning of the larval period was only a fraction of the adult capacity, it was of interest to see how the level of this activity and associated components of the monooxygenase system changed during larval and early juvenile development. Since BPM activity was readily detectable in the larval liver, it was desirable to prepare microsomal fractions rather 
than assay whole homogenates. Microsomes offer the advantage that they can be frozen in liquid nitrogen with little loss of activity, and they afford the possibility of the measurement of cytochromes P-450 and $b_{5}$ without interference from mitochondrial cytochromes and hemoglobin.

Since only a limited amount of larval and juvenile liver was available, a centrifugation procedure was empirically established for the preparation of hepatic microsomes from small volumes of homogenates. Using the microprocedure, microsomes can be prepared from as little as 100 ul of liver homogenate. A comparison of adult liver microsomes prepared by this microprocedure and the standard fractionation procedure is shown in Table 3-VII. For each of the enzymatic activities examined, the percent of the total activity sedimenting in the microsomal fraction was quite similar for the two procedures. The yield of protein per gram liver was somewhat higher in the microsomes prepared by the microprocedure, and the specific activities of the two reductases and BPM were 85 to $87 \%$ as great as those in the microsomes prepared by the standard procedure. A similar level of mitochondrial contamination was present in the fraction prepared by both procedures as indicated by the levels of succinate-cytoch rome $c$ reductase activity.

Data on the distribution of BPM activity in centrifugal fractions of Fundulus larval liver prepared using the microprocedure are shown in Table 3-VIII. The localization of BPM activity in the microsomal fraction is apparent, as the microsomal specific activity is 5 times that in the combined nuclear-mitochondrial fraction. of the total activity measured in the whole homogenate, $93 \%$ was recovered in these two fractions; the supernatant fraction was not assayed. 


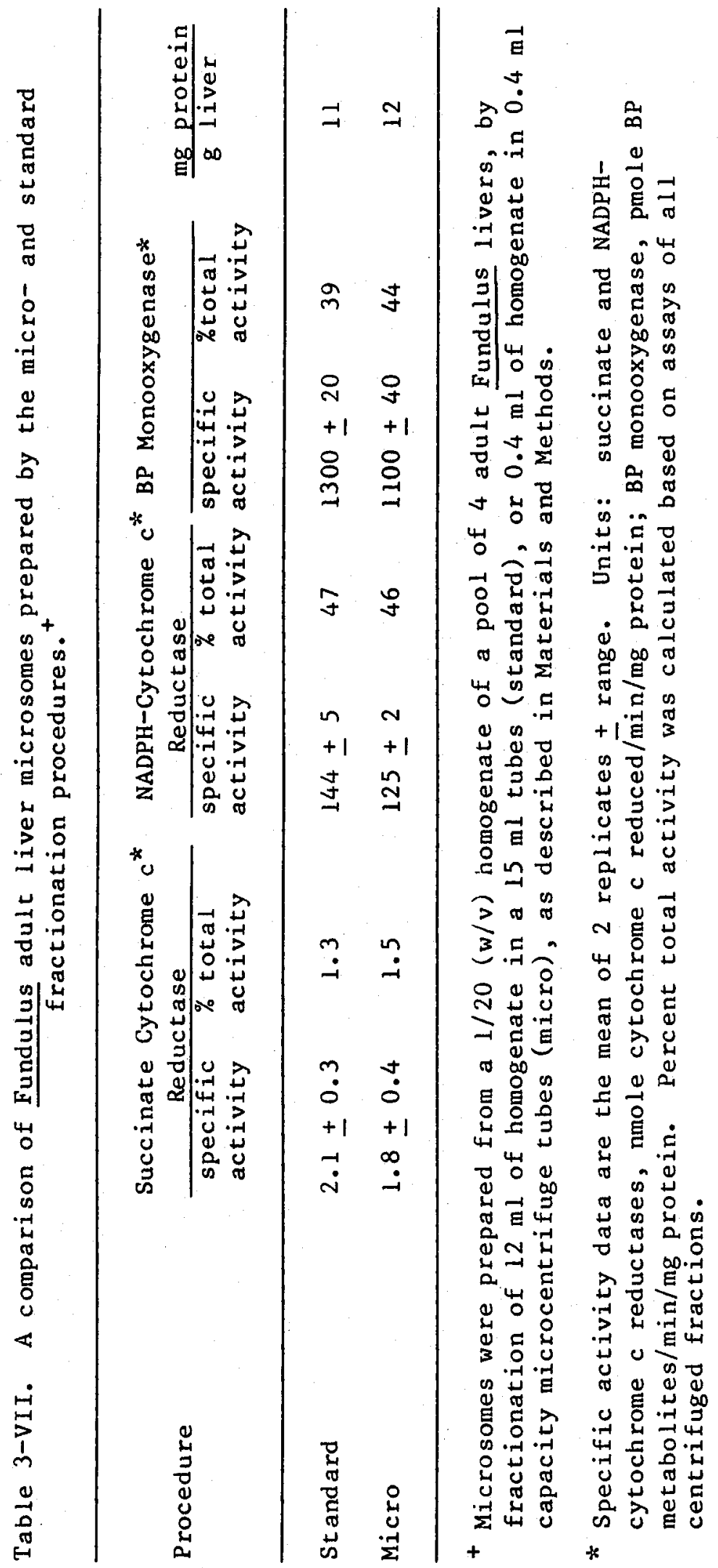


Table 3-VIII. BP monoxygenase activity in centrifugal fractions of Fundulus larval liver.

\begin{tabular}{|c|c|c|}
\hline \multirow{2}{*}{ Fraction } & \multicolumn{2}{|c|}{ BP Monooxygenase Activity } \\
\hline & fmole/min/ $/ \mathrm{g}$ protein & Percent total \\
\hline Whole homogenate & $127 \pm 14$ & 100 \\
\hline Nuclear-mitochondrial & $88 \pm 7$ & 35 \\
\hline Microsomal & $453+8$ & 58 \\
\hline
\end{tabular}

+ Larvae were 41 days from fertilization and had hatched about 20 days prior to assay. A pool of 23 livers were homogenized and fractionated as described in Materials and Methods. Specific activity data are the mean of 3 replicates $\pm S D$. 
Shown in Table 3-IX are data on the levels of monooxygenase activities, $\mathrm{NADPH}-$ and $\mathrm{NADH}-\mathrm{cytoch}$ rome $\mathrm{c}$ reductase activities, and cytochrome content in microsomes prepared from Fundulus larvae, juvenile, and adult livers. All of the larvae and juveniles were raised from a single pool of embryos. As noted above growth is rapid after the onset of feeding; from 9 to 48 days after hatching body weight increased 26-fold. Over this interval the ratio of total liver protein to body weight showed little change, but the yield of microsomal protein was lower in the juveniles than in the larvae. Apparently the most dramatic change in the relative amounts of liver protein occurs during the transition from the embryonic to larval periods of development (Table 3-VI).

BPM specific activity increased 2.5 -fold from 9 to 48 days after hatching. Total hepatic microsomal BPM activity normalized to body weight increased about 1.3-fold from the early to mid-larval period, but then, due to the decline in microsomal protein, remained essentially unchanged at the later stages assayed. Thus, while BPM specific activity continually increased over the interval of development examined, there was little change in the total hepatic capacity to metabolize BP per unit weight.

The data on adult hepatic microsomes in Table 3-IX were obtained with the same pools of livers used for the whole homogenate data in Table 3-VI. Consistent with this whole homogenate data, hepatic microsomal BPM specific activity in the early larval period was about $25 \%$ of the adult value. In the oldest juveniles examined, the microsomal BPM specific activity was $63 \%$ of the adult value. 
Page 132

Table 3-IX. A comparison of heparic microsomal enzyme activities and cytochrome content in fractions prepared from Fundulus larvae, juveniles and adults.

\begin{tabular}{|c|c|c|c|c|c|}
\hline Character & --C---Larv & ae & --Juveniles & $s^{-\cdots+}+$ & Adults \\
\hline Days frow hatching & +9 & +15 & +30 & +48 & $>400$ \\
\hline Body weight (mg) & $5.35 \pm 0.39$ & $12.4 \pm 1.9$ & $50.6 \pm 12.4$ & $140 \pm 27$ & $7360 \pm 330$ \\
\hline $\begin{array}{l}\text { Ug Liver procein } \\
\text { mg Body weight }\end{array}$ & 2.7 & 2.7 & 3.0 & 2.7 & $3.56 \pm 0.36$ \\
\hline$\frac{\text { 48 Microsomal procein }}{\text { ug Liver protein }}$ & 0.16 & 0.17 & 0.087 & 0.088 & $0.121 \pm 0.003$ \\
\hline $\begin{array}{l}\text { Benzo(a) pyrene Monooxygenase } \\
\text { (unit/pg microsomal protein) } \\
\text { (unie/pg body weight) }\end{array}$ & $\begin{array}{l}334 \pm 41 \\
145 \pm 10\end{array}$ & $\begin{array}{l}430 \pm 44 \\
192 \pm 3\end{array}$ & $\begin{array}{l}692 \pm 30 \\
180 \pm 6\end{array}$ & $\begin{array}{l}853 \pm 87 \\
204 \pm 5\end{array}$ & $\begin{aligned} 1360 & \pm 218 \\
587 & \pm 70\end{aligned}$ \\
\hline $\begin{array}{l}\text { Aminopyrine Demethylase } \\
\text { (unic/pg microsomal protein) }\end{array}$ & & & $\cdot$ & $1940 \pm 350$ & $2730 \pm 300$ \\
\hline $\begin{array}{l}\text { NADPH Cyrochrome c Reductase } \\
\text { (unit/pg microsomal protein) }\end{array}$ & & $101 \pm 12$ & $160 \pm 6$ & $162 \pm 45$ & $112 \pm 9$ \\
\hline $\begin{array}{l}\text { NaDH Cytochrome c Reductase } \\
\text { (unic/ng microsomal protein) }\end{array}$ & & $148 \pm 19$ & $299 \pm 16$ & $229 \pm 26$ & $221 \pm 14$ \\
\hline $\begin{array}{l}\text { Cycochrome } P-450 \\
\text { (nmole/ug wicrosomal protein) } \\
\text { Cycochrome b5 } \\
\text { (nmole/ug microsomal protein) }\end{array}$ & & & & 0.354 & $0.305 \pm 0.069$ \\
\hline $\begin{array}{l}\text { (nmole/ug microsomal protein) } \\
\text { Larvae and juveniles were rais } \\
\text { fertilized with minced cestis } \\
\text { individuals. A sample of } 10 \\
\text { livers were pooled from } 13-16 \\
\text { Larval and juvenile body weigh } \\
\text { mean of } 3 \text { replicates } \pm \text { SD. Al } \\
\text { were described in Table } 3-v I I \\
\text { CH2O/min; reductases, pmole cy }\end{array}$ & $\begin{array}{l}\text { sed froma s } \\
\text { from } 3 \text { males } \\
\text { individuals } \\
\text { individuals, } \\
\text { hts are the } \\
\text { Il adult data } \\
\text { I. Enzyme ur } \\
\text { ytoch rome c }\end{array}$ & $\begin{array}{l}\text { gle pool of } \\
\text { For larval } \\
\text { s weighed in } \\
\text { each of whic } \\
\text { an of indivi } \\
\text { are the mean } \\
\text { ts: BPM, fm } \\
\text { duced/min. }\end{array}$ & $\begin{array}{l}\text { ggs stripped } \\
\text { stages, liver: } \\
\text { act before di } \\
\text { was weighed } \\
\text { lual values } \pm \\
\text { values of } 3 \text { pc } \\
\text { le metabolites }\end{array}$ & $\begin{array}{l}\frac{0.102}{\text { from } 9 \text { fema }} \\
\text { s were pool } \\
\text { ssection. } \\
\text { intact befo } \\
\text { SD. Enzyme } \\
\text { ools } \pm \text { SD. } \\
\text { s/min; APD }\end{array}$ & $\begin{array}{l}\frac{0.121+0.002}{\text { les and }} \\
\text { ed from about } 30 \\
\text { For juveniles, } \\
\text { re dissection. } \\
\text { assays are the } \\
\text { The adult pools } \\
\text { fmole }\end{array}$ \\
\hline
\end{tabular}


The specific activity of microsomal $\mathrm{NADPH}-\mathrm{cyt}$ och rome c reductase measured in larvae was about the same as that in adults. In the juvenile stages examined, this activity was somewhat higher than the level in adults. It thus appears that this reductase is not limiting monooxygenase activity in juvenile and larval hepatic microsomes, which further suggests that the level of BPM activity may be determined by the amount, or form of cytochrome $\mathrm{P}-450$ present at these stages of development. Cytoch rome $\mathrm{P}-450$ and cytoch rome $\mathrm{b}_{5}$ were readily measurable in the liver microsomes prepared from the Fundulus juveniles 48 days from hatching. (Sufficient material for analysis was not available from the earlier stages.) The spectra are shown in Figure 3-7, and the specific contents are listed in Table 3-IX. The spectra are essentially the same as those of the adult cytochromes (Figures 3-5 and 3-6). The peak of absorbance for the juvenile cytochrome $P-450$ was about $449 \mathrm{~nm}$, while for the three pools of adult livers examined, the peaks were at $449-450 \mathrm{~nm}$. The specific content of cytochrome $\mathrm{P}-450$ in the juvenile microsomal sample was about the same as that in the adult microsomes, which is interesting since the juvenile BPM activity was about $60 \%$ of the adult level. This suggests that the adult cytochrome may be more efficient in catalyzing BP metabolism than the juvenile cytochrome, supporting the idea that the forms of cytochrome P-450 present in these adults and juveniles were different. However, the ratios of aminopyrine demethylase activity to BPM activity in the juvenile and adult hepatic microsomes were similar (Table 3-IX), indicating the similar substrate specificities of the adult and juvenile cytoch romes. 
Figure 3-7. Difference spectra obtained with hepatic microsomes from Fundulus juveniles 48 days from hatching. Microsomes were prepared from a pool of 13 juvenile livers and analyzed as described in Materials and Methods. The concentration of microsomal protein in the cuvettes was $0.25 \mathrm{mg} / \mathrm{ml}$. The upper curve is an $\mathrm{NADH}$ reduced versus oxidized difference spectrum, which is characteristic of cytochrome $\mathrm{b}_{5}$. The lower curve is a $\mathrm{CO}$, dithionite reduced versus $\mathrm{CO}$ difference spectrum on the same sample, with NADH balanced. This spectrum is characteristic of cytochrome $\mathrm{P}-450$. Quantitative data on the specific contents of cytoch romes $\mathrm{P}-450$ and $\mathrm{b}_{5}$ in these microsomes (+48) are given in Table 3-IX. 

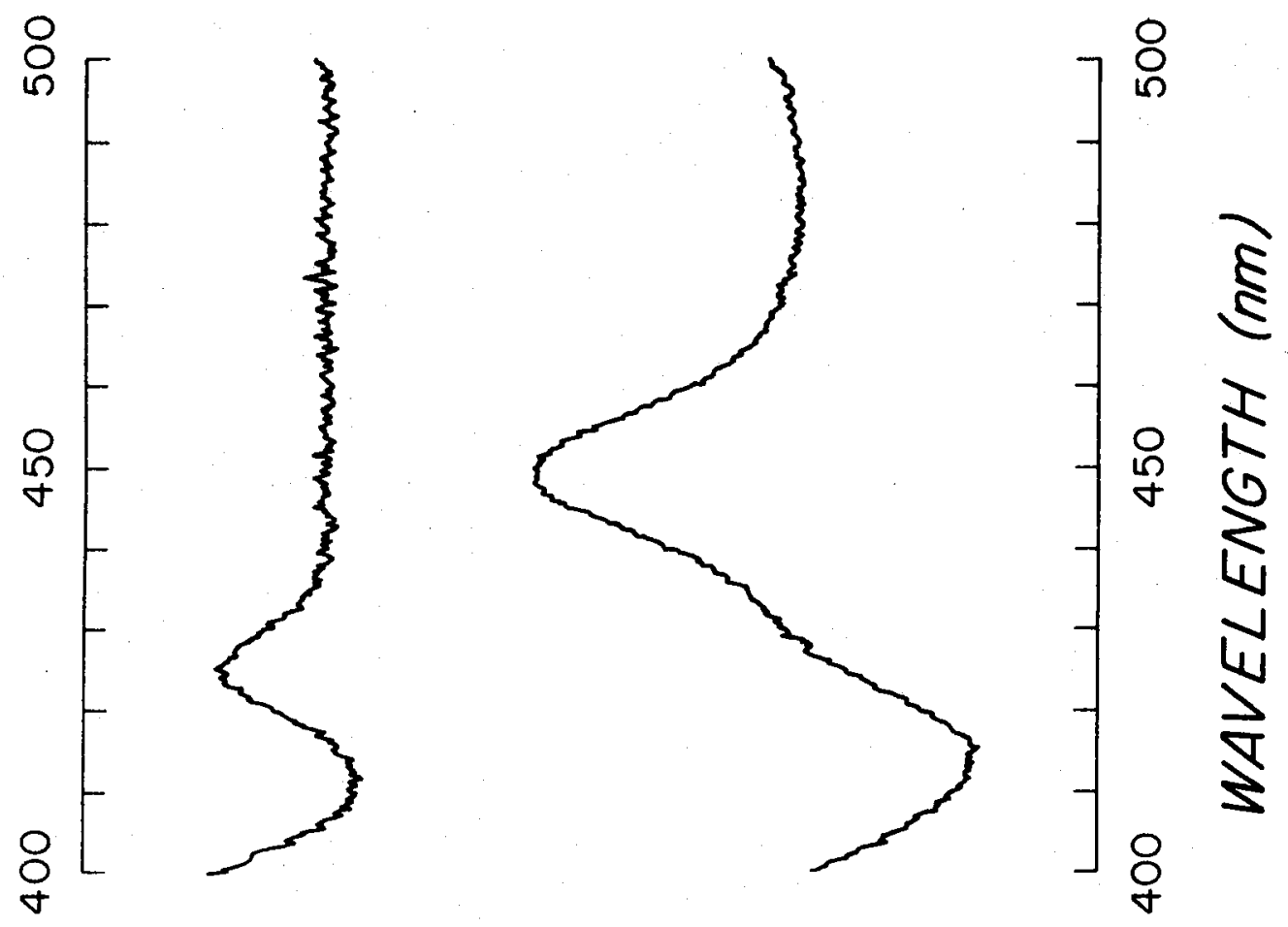

\section{(40!s!1!p/t!un G2000) \\ $\exists \supset N \forall \theta 40 S g \forall$}


Page 136

It is important to note that the value for juvenile cytochrome $\mathrm{P}-450$ in Table 3-IX is from a single determination; such limited data should not be overinterpreted. Also, cytoch rome $P-450$ was assayed in the presence of $\mathrm{NADH}$, which was necessary for the prior assay of cytoch rome $b_{5}$. Assays were performed in this way because of the limited amount of juvenile hepatic microsomes available for spectrophotometric analysis. Levels of adult cytochrome $\mathrm{P}-450$ measured in the absence of NADH were on the average $40 \%$ higher than in its presence. Whether the level of cytochrome $\mathrm{P}-450$ determined in juveniles was similarly affected by NADH is not known.

To further examine the possibility that different isozymes of cytochrome $\mathrm{P}-450$ are present in hepatic microsomes from Fundulus larvae, juveniles and adults, the sensitivity of BPM activity in these preparations to inhibitors of cytochrome $P-450$ was examined. The two inhibitors used were $\alpha$-napthoflavone (ANF) and SKF-525A. The microsomal preparations used were the same as in Table 3-IX, except that the younger larvae and juveniles were not examined. The data are shown in Table 3-X. Results with the microsomes prepared from three pools of adult livers are shown separately. Each of the stages showed a very similar sensitivity to the two inhibitors, and the inhibition produced by ANF and SKF-525A was quite similar. On the basis of the sensitivity of BPM activity to these inhibitors, the larval, juvenile and adult hepatic cytochromes $\mathrm{P}-450$ ap pear quite similar. 
Table 3-X Intibition of Fundulus larval, juvenile and adult hepatic microsomal BPM activity by $\alpha$-napthoflavone and and SKF-525A $\mathrm{A}^{+}$.

\begin{tabular}{|c|c|c|c|c|c|}
\hline \multirow{3}{*}{ Inhibitor } & \multicolumn{5}{|c|}{ Percent BPM activity remaining } \\
\hline & \multirow{2}{*}{$\begin{array}{l}\text { Larvae } \\
(+150) \\
\end{array}$} & \multirow{2}{*}{$\begin{array}{c}\text { Juveniles } \\
(+48 d)\end{array}$} & \multicolumn{3}{|c|}{ Adults } \\
\hline & & & Poo1 1 & Pool2 & Poo13 \\
\hline \multicolumn{6}{|c|}{$\alpha$-napthoflavone } \\
\hline $1 \mu \mathrm{M}$ & $86 \pm 4$ & $91 \pm 5$ & $93 \pm 7$ & $95 \pm 1$ & $91 \pm 2$ \\
\hline $10 \mu \mathrm{M}$ & $67 \pm 1$ & $65 \mp 3$ & $70 \mp 4$ & $68 \mp 2$ & $66 \mp 2$ \\
\hline $100 \mu \mathrm{M}$ & $50 \mp 2$ & $43 \pm 4$ & $44 \pm 2$ & $44 \pm 1$ & $43 \pm 2$ \\
\hline \multicolumn{6}{|l|}{$S K F-525 \mathrm{~A}$} \\
\hline $1 \mu M$ & $79 \pm 5$ & $86+7$ & $97+4$ & $94 \pm 2$ & $97+2$ \\
\hline $10 \mu / 1$ & $74 \pm 7$ & $72 \mp 2$ & $80 \mp 4$ & $75 \pm 3$ & $79 \pm 5$ \\
\hline $100 \mu \mathrm{M}$ & $47 \mp 7$ & $45 \pm 5$ & $53 \pm 4$ & $51 \pm 1$ & $54 \mp 1$ \\
\hline
\end{tabular}

+ Microsomal preparations were the same as in Table 3-X. Assays were performed as described in Materials and Methods. All data are che mean of 3 replicates $\pm S D$. 
DISCUSSION

Monooxygenase activity and components of the monooxygenase system in Fundulus embryos and eleutheroembryos:

The data presented here clearly show that preparations from untreated Fundulus embryos have the capacity to metabolize benzo(a)pyrene in vitro. Presumably this in vitro activity reflects an in vivo capacity to metabolize BP and other xenobiotics. Generally, with untreated embryos BPM activity was only detectable in the microsomal or $40 \mathrm{~K}$ fraction of homogenates, and removal of the chorion prior to homogenization was found essential for detection of this activity. In contrast to embryos, BPM activity was measurable in all of the particulate fractions of eleutheroembryos, but this activity was clearly localized in the microsomes (Figure 3-1). Thus, when fractions are prepared from whole embryos or eleutheroembryos as described in Materials and Methods, there is no change in the distribution of BPM activity after hatching. The results presented in Chapter 2 , in which petroleum and $\mathrm{PCB}$-induced BPM activity were localized in the 10K fraction of embryos, apparently were artifacts of homogenization of embryos with their chorions intact.

The $40 \mathrm{~K}$ fraction of homogenates of whole eleutheroembryos was shown to correspond to a microsomal fraction, since it is a post-mitochondrial particulate fraction and both $\mathrm{NADPH}-\mathrm{cyt}$ och rome $c$ reductase activity and BPM activity sediment with it. Furthermore, when a whole embryo $40 \mathrm{~K}$ 
Page 139.

pellet was examined by electron microscopy (Figure 3-2), it was seen to contain much vesicular material resembling adult liver microsomes. NADH-cytochrome $c$ reductase activity was primarily localized in the $10 \mathrm{~K}$ or "mitochondrial" fraction, but activity was also present in all other fractions. A substantial portion of the $\mathrm{NADH}$-cytochrome c reductase activity in eleutheroembryonic microsomes may be associated with mitochondrial fragments. The presence of cytochrome $b_{5}$ in whole eleutheroembryo microsomes (Figure 3-6), and the fact that NADH does support BPM activity (Table 3-IV), provides evidence that some of the $\mathrm{NADH}-\mathrm{cyt}$ toch rome $\mathrm{c}$ reductase in the $40 \mathrm{~K}$ fraction is derived from the endoplasmic reticulum, and is not associated with the respiratory, mitochondrial electron transport system.

The BPM activity in microsomes prepared from whole Fundulus eleutheroembryos, has properties of a typical cytochrome P-450 dependent monooxygenase activity. This activity requires native enzyme, oxygen and NADPH, and is inhibited by carbon monooxide and cytochrome $c$ (Table 3-IV). NADPH was much more effective in supporting this activity than NADH. The BPM activity in adult Fundulus hepatic microsomes has similar sensitivities and requirements. The activity in microsomes from whole Fundulus embryos also appears to be cytochrome $\mathrm{P}-450$ dependent, as it is inhibited by both $\mathrm{CO}$ and cytoch rome $c$. This activity was not characterized as completely as the others, because of the limited amount of embryonic material available. Additional evidence indicating that the BPM activity in Fundulus embryos and eleutheroembryos is cytoch rome P-450 dependent is the fact that it is induced by the known inducer of cytochrome P-450, Aroclor 1254 (Alvares, 197.7). 
Page 140.

Microsomes prepared from whole eleutheroembryos we re analyzed spectrally for cytoch rome $\mathrm{P}-450$ and cytoch rome $\mathrm{b}_{5}$. The spectrophotometric assays for these cytochromes are not very sensitive, so a relatively large amount of material was required for the assays, and only a limited number of assays could be performed. For measuring cytoch rome $\mathrm{P}-450$ the reduced $\mathrm{CO} / \mathrm{CO}$ oxidized method of recording difference spectra was used to eliminate effects from contaminating hemoglobin, and allow quantitation of cytochrome $\mathrm{P}-450$ in the presence of mitochondrial contamination. With microsomes prepared from whole eleutheroembryos a signal was consistent ly observed at $450 \mathrm{~nm}$, but there always was interference at $430 \mathrm{~nm}$ (Figure $3-5$ ). The peak at $430 \mathrm{~nm}$ was not due to cytochrome $b_{5}$, since the addition of NADH to sample and reference cuvettes had no effect on the difference spectrum. Whole eleutheroembryo microsomes are contaminated with mitochondria as indicated by the presence of succinate-cytochrome $c$ reductase activity (Fig. 3-1); this contamination is the likely source of the peak at 430 nm. Much evidence indicates that the signal at $450 \mathrm{~nm}$ is due to cytochrome $\mathrm{P}-450$. First of all, the catalytic data described above strongly suggest that the BPM activity measured in whole eleutheroembryo microsomes is cytochrome $\mathrm{P}-450$ dependent (Table 3-IV). Additionally the peak of $450 \mathrm{~nm}$ was only present in the microsomal difference spectrum and not in the difference spectrum of the $10 \mathrm{~K}$ fraction, which is consistent with the localization of BPM activity.

A turnover number can be estimated for benzo(a)pyrene from the data in Table $3-V$. The turnover number is calculated by dividing the average 
BPM specific activity by the average specific content of cytochrome $\mathrm{P}-450$, and is a measure of the catalytic efficiency of the cytochrome. A value of 2.9 fmole BP metabolites/min/fmole of cytochrome $\mathrm{P}-450$ is obtained for the eleutheroembryo cytoch rome P-450. A similar calculation for the Fundulus adult hepatic microsomes described in Table 3-IX gives a value of 3.2 (calculated for the levels of cytochrome $\mathrm{P}-450$ measured without prior reduction with $\mathrm{NADH}$ ). The very good agreement of these two numbers supports the contention that the peak at $450 \mathrm{~nm}$ in the $C O$ reduced/co oxidized difference spectrum of eleutheroembryo microsomes is due largely to cytoch rome $\mathrm{P}-450$, and apparently the content of cytoch rome P-450 can be reasonably estimated from these spectra.

It is not surprising that a clean cytoch rome $\mathrm{P}-450$ spectrum could not be obtained with eleutheroembryo microsomes, considering that the microsomes were prepared from homogenates of whole eleutheroembryos. This is equivalent to trying to measure the cytochrome $\mathrm{P}-450$ content of a fish by preparing microsomes from a homogenate of the whole animal. This approach is certainly not ideal, since the majority of tissue homogenized are likely to have low levels of cytochrome $\mathrm{P}-450$, and are also likely to contribute factors to the microsomal fraction which may interfere with the difference spectrum of this cytochrome.

Cytochrome $b_{5}$ is usually measured in microsomes by recording an $\mathrm{NADH}$ reduced versus oxidized difference spectrum (Omura and Sato, 1964). Under such conditions whole eleutheroembryo microsomes gave a spectrum similar to that of cytochrome $b_{5}$ (Figure 3-6); while whole e leutheroembryo $10 \mathrm{~K}$ fractions did not give difference spectra. Thus, the 
spectrum recorded with microsomes is not likely to be due to contamination from mitochondrial cytoch romes. The fact that NADH supports BPM activity in whole eleutheroembryo microsomes is further evidence for the presence of cytochrome $b_{5} \cdot$ The levels of cytochrome $b_{5}$ measured in whole eleutheroembryo microsomes were similar to those of cytoch rome $\mathrm{P}-450$.

Because the spectrophotometric assays of cytochrome $\mathrm{P}-450$ and cytochrome $b_{5}$ were near the limits of detection with samples from eleutheroembryos, no attempts were made to measure these cytochromes in whole embryo microsomes. Based on the levels of BPM activity, dechorionation of an adequate number of embryos for a single cytochrome P-450 determination would require about 20 hours of dissection. A reasonable way to demonstrate cytoch rome P-450 in Fundulus embryos would be immunochemically, with antibodies to purified adult forms of cytochrome P-450. Unfortunately, the adult cytochromes have yet to be purified.

\section{Ontogeny of microsomal enzyme activities:}

A striking developmental pattern was observed for BPM specific activity in whole embryo microsomes. BPM activity was uniformly low at all stages assayed before hatching, then within 24 hours after hatching activity increased 10-fold (Figures 3-2, 3-3). This increase in BPM activity after hatching was shown not to be age-dependent, but rather to require hatching, as activity increased with time from hatching among a group of eleutheroembryos of the same age (Fig. 3-4). The possibility 
Page 143.

that the low BPM activity in microsomes prepared from whole embryos is due to an endogenous inhibitor, such as the hatching protease, was ruled out by a mixing experiment (Table 3-III). A lack of a role for the hatching protease in inactivating the embryonic monooxygenase system is also indicated by the fact that the activity measured in newly hatched eleutheroembryos is only slightly higher than in embryos of the same age (Fig. 3-4). Furthermore, high levels of activity can be induced in embryos by PCBs (Chapters 2 and 4 ). This indicates that the low constitutive activity is a real measure of the capacity of embryos to metabolize $B P$, rather than the result of inactivation by an endogenous factor.

The ontogenic pattern of total BPM activity per unit weight was somewhat different than that of BPM specific activity. Activity per unit embryo weight continually increased from the earliest stages examined as a result of the increase in the mass of tissue and yield of microsomal protein with growth (Table 3-II). However, there was a dramatic 39-fold jump in total BPM activity per unit weight after hatching as a result of the increase in BPM specific activity.

BPM activity was measurable in whole embryo microsomes at the earliest stages assayed (stages 25-26), which is shortly after the onset of circulation (Fig. 3-3, Tables 3-I and 3-II). Light microscopic examination of thin sections of embryos indicates that the liver rudiment does not appear until stages 28-29. The presence of BPM activity in whole embryo microsomes prior to the appearance of the liver rudiment points to the significance of the extrahepatic tissues in xenobiotic 
metabolism in Fundulus embryos. While it would be of interest to determine which embryonic tissues are active in xenobiotic metabolism, the small size of Fundulus embryos made assays of individual tissues impractical with the techniques at hand. Monooxygenase activities occur widely in the extrahepatic tissues of adult fish, but with most substrates the highest activities are found in the kidney (Bend et al., 1973; Buhler and Rasmusson, 1968; James et al,. 1979; Payne and Penrose, 1975; Pederson et al., 1974; Stegeman et al., 1979). In Fundulus embryos the kidney differentiates fairly early, and is active in excreting dyes by stage 27, at about 5 days of development (Armstrong, 1932; Armstrong and Child, 1965). Possibly the kidney is a major site of xenobiotic metabolism in Fundulus embryos, although practically all of the embryonic tissues may have some capacity to metabolize xenobiotics.

It is somewhat surprising that BPM activity in whole embryo microsomes changes little from stages 25-26 until after hatching, because this period is characterized by active organogenesis (Armstrong and Child, 1965). However, assays on whole embryo microsomes are not likely to be sensitive to changes in individual tissues. It should be emphasized that whole embryo microsomal preparations have proven extremely valuable for examining gross changes in the total capacity of embryos to metabolize xenobiotics and to respond to inducers.

In addition to metabolizing benzo(a)pyrene, microsomes prepared from eleutheroembryos were also shown to be active in catalyzing the oxidative $\mathrm{N}$-demethylation of aminopyrine (Table $3-\mathrm{V})$. A point worth noting is that a hallmark of the microsomal monooxygenase system is its versatility. 
The fact that BPM activity has been demonstrated in Fundulus embryos, indicates that they probably have the capacity to metabolize a great variety of lipophilic foreign compounds, including many environmentally relevant substances.

The developmental pattern of $\mathrm{NADPH}-\mathrm{cytoch}$ rome reductase activity was distinct from that of BPM activity (Fig. 3-3). While BPM activity changed little before hatching, the highest specific activities of NADPH-cytochrome $c$ reductase were measured in the earliest stages examined, then dropped off sharply to a plateau in stages prior to hatching. The specific activity of $\mathrm{NADPH}-\mathrm{cyt}$ tochrome $c$ reductase did increase after hatching, but the increase was modest compared to that of BPM activity (Figure 3-3). Also the time course of the increase in reductase activity after hatching was slower than the increase in monooxygenase activity (Figure $3-4$ ). The different developmental patterns for BPM activity and NADPH-cytochrome c reductase activity suggest that these two activities are independently controlled. Although there is a lack of correlation between the levels of NADPH-cytochrome c reductase activity and monooxygenase activity, the cytochrome $c$ inhibition data (Table $3-I V$ ) indicate that the reductase plays a functional role in NADPH-dependent monooxygenase activity.

The high levels of reductase activity in the microsomes of early embryos, and the large increase in BPM activity shortly after hatching, without concommitant changes in reductase activity, suggest that the level of reductase activity is not limiting monooxygenase activity in embryos. In fact the ratio of $\mathrm{NADPH}-\mathrm{cytoch}$ rome $c$ reductase activity to 
Page 146.

BPM activity in embryo microsomes is 10-fold higher than that in adult liver microsomes (compare data in Table 3-IX and figure 3-3). These data suggest that changes in the cytochrome components of the system are likely to be associated with the large posthatching increases in monooxygenase activity. A similar conclusion was mentioned above concerning developmental changes in BPM activity in larval liver. However, such interpretations must be made with caution. First of all, in the present case there is no direct evidence indicating that changes in the levels of cytochrome $\mathrm{P}-450$ are associated with the posthatching increase in monooxygenase activity. Another possibility is that changes in the functional association of cytochrome $\mathrm{P}-450$ and its reductase are responsible for the increased BPM activity after hatching. As discussed in the introduction, in the livers of chickens there is about a 3-fold increase in certain microsomal monooxygenase activities within 24 hours of hatching, but little change in the content of cytochrome $\mathrm{P}-450$ or the level of NADPH-cytochrome $c$ reductase activity (Powis et al., 1976). However, the increase in monooxygenase activity is correlated with an increase in NADPH-cytochrome $\mathrm{P}-450$ reductase activity. Whether this is the case in Fundulus is not known. A point worth emphasizing is that BPM and reductase activities were measured in microsomes prepared from whole Fundulus embryos and eleutheroembryos. The activities measured are more or less an average of those in many different tissues. It is possible that in certain tissues the levels of reductase activity are actually limiting monooxygenase activity, and that high reductase activities occur in some tissues without associated monooxygenase activity. 
Prior to hatching the developmental pattern of NADH-cytochrome c reductase was very similar to that of $\mathrm{NADPH}-\mathrm{cyt}$ toch rome $c$ reductase (Figure 3-3). However, the level of microsomal NADH-cytochrome c reductase did not change after hatching. As already mentioned, much of the NADH cytochrome $c$ reductase measured in whole embryo microsomes may be due to mitochondrial contamination. Developmental changes in the activity associated with the endoplasmic reticulum may be masked by the large amount of the mitochondrial form of this activity present in the microsomal fraction:

It is interesting that the highest specific activities of NADPH-cytochrome $c$ reductase in whole embryo microsomes were observed at the earliest stages examined, although BPM specific activity was consistently low at all stages prior to hatching (Figure 3-3). The physiological function of this activity is obscure. Possibly monooxygenase activity with certain endogenous substrates is elevated at these early developmental stages. Another possibility is that a portion of the microsomal $\mathrm{NADPH}-\mathrm{cyt}$ toch rome $\mathrm{c}$ reductase activity measured in fish embryos is not associated with the flavoprotein reductase of cytochrome $\mathrm{P}-450$. The specific activity of microsomal $\mathrm{NADH}$-cytochrome $\mathrm{c}$ reductase activity is also highest in the earlier embryonic stages. Possibly both $\mathrm{NADH}$-and $\mathrm{NADPH}-\mathrm{cytoch} r o m e$ ceductase activities are involved in fatty acid desaturation and the processing of yolk lipid. 
Page 148 .

Hepatic monooxygenase activities:

BPM activity was measured in preparations of livers from Fundulus eleutheroembryos, larvae, juveniles and adults. Assays with livers from eleutheroembryos and young larvae were performed on liver whole homogenates (Table 3-VI). Using a microfractionation procedure the Larval hepatic BPM activity was shown to be localized in the microsomal fraction (Table 3-VIII). The levels of hepatic microsomal BPM activity were followed from the early larval period into the juvenile period (Table 3-IX). The overall pattern observed indicates that hepatic BPM specific activity increases steadily from the late embryonic to the juvenile periods of development. The total increase in specific activity over this interval (combining whole homogenate and microsomal data) was about 4-fold.

Over the period of development examined, the greatest increase in the relative hepatic capacity to metabolize $B P$ was during the transition between the late embryonic and early larval periods. With the onset of feeding, total liver protein per unit body weight rises rapidly. This increase in relative liver protein coupled with an increase in BPM specific activity, results in about a 5-fold higher level of BPM activity per unit body weight in young larvae compared to eleutheroembryos (Table 3-VI). In the group of larvae and juveniles from which liver microsomes were prepared, there was little change in total liver protein per unit body weight with development, and the yield of microsomal protein per unit body weight actually declined with age (Table 3-IX). So while BPM specific activity continually increased during larval and juvenile 
development, there was little change in BPM activity per unit weight. Further work is necessary to determine whether this is a general feature of the development of the liver in Fundulus, since the data in Table 3-IX were obtained with larvae and juveniles raised from a single pool of eggs. Considerable variation was observed in the yield of total liver protein among different groups of larvae.

In the Results section, hepatic BPM activities measured at various developmental stages were compared to results obtained with adult preparations (Tables $3-V I$ and $3-I X)$. In adult Fundulus, hepatic BPM specific activity and total activity vary to some extent with season (Stegeman, 1981a). Activities are generally highest in the fall and lowest in midsummer; the variation may be as great as 2 -fold. The adult data in Tables 3-VI and 3-IX were from fish collected in November, and are therefore at the upper range of adult activity. Considering this, hepatic BPM specific activity in eleutheroembryos and young larvae are about $25 \%$ and $40 \%$ of the average adult levels respectively. On the basis. of total hepatic BPM activity normalized to body weight, the differential between adults and the early developmental stages is even greater. Total hepatic BPM activity per unit body in eleutheroembryos and young larvae is about $4 \%$ and $20-30 \%$ of the average adult level, respectively. The specific activity of BPM activity in hepatic microsomes from the oldest juveniles examined is within the range that occurs in adults. However the activity per unit body measured is still only about $40 \%$ of the average adult level. 
Page 150.

On the basis of the specific activities of BPM, aminopyrine demethylase, NADPH- and NADH-cytochrome $c$ reductases, and the specific contents of cytochromes $\mathrm{P}-450$ and $\mathrm{b}_{5}$, the hepatic microsomal monooxygenase systems of Fundulus juveniles and adults appear quite similar (Table 3-IX). Additionally, larval, juvanile and adult hepatic BPM activity show similar sensitivities to the cytochrome P-450 inhibitors, $\alpha$-naphthoflavone and SKF-525A. In mammals these compounds differentially inhibit the monooxygenase activities induced by 3-MC and PB, respectively ( $L u$ et al., 1972; Thorgeirsson et al., 1979; Goujon et al., 1972; Wiebel et al., 1971). These inhibition data indicate that the Larval, juvenile and adult hepatic cytochromes $\mathrm{P}-450$ are catalytically similar.

Comparative aspects of the deve lopment of the monooxygenase system, and a rationale for the developmental pattern in Fundulus:

The increase in BPM activity in whole Fundulus embryo microsomes after hatching resembles the postnatal increases in hepatic monooxygenase activity seen in mammalian species (e.g. Cresteil et al., 1979; Dallner et al., 1966; Gielen et al., 1972; Lucier et al., 1975; Manchester and Neims, 1977; Rane et a1., 1973). Increases in hepatic monooxygenase activities shortly after hatching also occur in chickens (Powis et al., 1976). The Fundulus data are not directly comparable to the mammalian or avian liver data, since preparations from whole embryos were used. It is not known which tissues are responsible for the posthatching surge in BPM activity in Fundulus. Premature delivery experiments with rats and 
guinea pigs have demonstrated that some physiological change associated with birth triggers the postnatal increases in cytochrome $\mathrm{P}-450$ and associated monooxygenase activities (Leakey and Fouts, 1979; Manchester and Neims, 1977). Data presented here indicate that in Fundulus hatching is required for the increase in BPM activity which occurs during later embryonic development, and that this increase in activity is not programmed to occur at a certain age (Figure $3-3$ ). The factors regulating the postnatal increases in the components of the monooxygenase system in mammals have not been clearly established. During perinatal development in mammals changes in the levels of a number of enzymes have been shown to be under hormonal control (Greengard, 1971; Oliver, 1974). Glucocorticoids apparently play a role in the postnatal increases in hepatic monooxygenase activities in rats, and the analogous posthatching increases in chickens (Leakey et al., 1979; Leakey and Dutton, 1975; Leakey and Fouts, 1979; Leakey and Wishart, 1976; Mukhtar et al., 1974). It seems reasonable to speculate that hormonal factors are responsible for the posthatching surge in BPM activity in Fundulus embryos. Other factors which may be responsible for the posthatching increase in monooxygenase activity will be discussed in Chapter 4.

The events of birth in placental mammals and hatching in oviparous fish are physiologically quite distinct. Birth represents a physiological crisis for the developing mammal (Greengard, 1971). The continuous supply of glucose from the maternal circulation is cut off, and within 24 hours of parturition there is an almost total depletion of liver glycogen. The neonatal liver must be able to metabolize the lipids 
and aminoacids from mother's milk and maintain serum glucose levels. The neonate must tolerate an environment rich in oxygen, regulate its own temperature, and can no longer depend on its mother's circulation to remove nitrogenous wastes and bilirubin (a breakdown product of hemoglobin). To meet this physiological challenge, changes occur at the level of a number of enzymes during the perinatal period. The urea cycle enzymes appear in the liver in late fetal life, as does UDP-glucuronyl transferase, which is involved in bilirubin excretion. Phosphorylase, responsible for glycogen breakdown emerges in the late fetal period, and the enzymes of gluconeogenesis rise rapidly after birth. Presumably the postnatal increases in monooxygenase activities meet the increased need for xenobiotic metabolism, as the neonate can no longer depend on maternal tissues to shield it from the chemical environment. While the neonate will depend solely on mother's milk for nutrition, this does not guarantee a supply of food free of xenobiotics. Lipophilic xenobiotics such as PCBs are excreted in mother's milk (Alvares and Kappas, 1975).

In contrast to birth in mammals, hatching in fish does not represent such a physiological crisis. After hatching endogenous yolk reserves provide a continuous supply of nutrients, and there is no change in environmental temperature. Histochemical examination of embryonic rainbow trout livers indicate that stores of glycogen are not affected by hatching (Vernier and Sire, 1976). Clearly though, hatching does represent an environmental change for the developing embryo, since the chorion is at least a partial barrier to the chemical environment. In PCB uptake studies preliminary to the experiments described in Chapter 4 , 
Page 153.

Fundulus embryos and eleutheroembryos were incubated in PCB coated petri dishes. The rate of uptake of PCBs into eleutheroembryos was 13-times higher than into embryos (data not shown). These results indicate that the chorion in Fundulus does serve to some extent as a barrier to the uptake of lipophilic xenobiotics. Other factors besides the absence of the chorion may lead to an increased exposure to xenobiotics after hatching. Within a few days of hatching in Fundulus the yolk is almost completely absorbed, and the developing eleutheroembryo will have to be able to handle the load of lipophilic xenobiotics which may reside there. Also once feeding begins the young fish is likely to be exposed to a complex assortment of non-nutritive lipophilic compounds, whose elimination may require metabolism by the cytochrome $\mathrm{P}-450$ system. Clearly, the potential exposure of developing Fundulus to xenobiotics greatly increases after hatching, and in that sense hatching and birth are analogous.

It seems desirable for Fundulus embryos to have relatively low capacity to metabolize xenobiotics during the period of active organogenesis prior to hatching. Damage from activated metabolites during this sensitive phase of development could lead to malformations severely reducing the viability of the developing organism. After hatching increased levels of monooxygenase activity may be required for the elimination of lipophilic foreign compounds, which might otherwise accumulate to toxic levels. Within a few days of hatching in Fundulus total BPM activity per unit weight increases 39 -fold (Table 3-II), then after the onset of feeding, total hepatic BPM activity per unit weight 
increases by an additional factor of 5 (Table 3-VI). Thus over a period of about 7 days after hatching, there is a great increase in the capacity of developing Fundulus to metabolize foreign compounds. 


\section{CHAPTER 4}

THE RESPONSES OF THE MONOOXYGENASE SYSTEMS OF FUNDULUS EMBRYOS AND ELEUTHEROEMBRYOS TO AROCLOR 1254

In the previous chapter aspects of the development of the xenobiotic monooxygenase system in untreated early developmental stages of Fundulus were examined. A striking developmental pattern was observed for benzo(a)pyrene monooxygenase activity with low, fairly uniform specific activities in whole embryo microsomes, followed by a ten-fold increase in specific activity within one day of hatching. In Chapter 2 it was demonstrated that BPM activity is inducible in Fundulus embryos and eleutheroembryos by PCBs and No. 2 fuel oil. In those early experiments the uptake of inducers was not quantitated, thus the actual tissue levels of inducers necessary to produce a response were not known. The experiments presented in this chapter were designed to further characterize the induction of monooxygenase activity in Fundulus embryos and eleutheroembryos by Aroclor 1254. The questions approached include whether environmentally realistic levels of $\mathrm{PCBs}$ can induce monooxygenase activity in Fundulus embryos, and whether there is a change in the relative sensitivity to PCBs as inducers of BPM activity after hatching, considering the large change in constitutive activity associated with this process. The relative capacity of early developmental stages to respond to $\mathrm{PCB}$ induction of $B P M$ activity was examined, and the the spectrum of BP metabolites produced by eleutheroembryo microsomes was analyzed by high performance liquid chromatography (HPLC). 


\section{MATERIALS AND METHODS}

\section{Chemicals and Supplies:}

Chemicals were as described in Chapter 3 with the following additions. Aroclor 1254 was lot AA-1 from Monsanto Co., St. Louis, Mo. Protosol and a uniformly $\left[{ }^{14} \mathrm{C}\right]$-labelled PCB isomeric mixture (96 $\mu(1 / \mathrm{mg})$, approximately $54 \%$ chlorine by weight, were purchased from New England Nuclear, Boston, MA. According to the manufacturer, the isomeric composition of this PCB mixture (1ot 872-193) determined by gas chromatography was essentially the same as Aroclor 1254. Samples of authentic BP metabolite standards were obtained from the IIT Research Institute, Chicago, IL. Acetonitrile, ethylacetate and methanol were purchased from Burdlck and Jackson Laboratorles, Muskegon, MI, and trichloropropylene oxide (TCPO) from Aldrich Chemical Co., Milwaukee, WI. Nalgene filmware tubes for liquid scintillation counting were purchased from Nalge Co., Rochester, NY, and Nucleopore filters from Nucleopore Corp., Heasanton, CA.

Embryos: PCB Exposure and Quantitation of PCB Uptake:

Embryos were obtained from adult Fundulus heteroclitus collected at Herring Brook, North Falmouth, MA during 1979 and 1980. Methods of obtaining and handling embryos and conditions of embryo maintenance were as described in Chapter 3. Embryos were exposed to Aroclor 1254 by incubation in $100 \mathrm{~mm}$ glass petri dishes coated with films of this PCB 
mixture. To coat a petri dish with Aroclor $1254,0.3 \mathrm{~m} 1$ of a methanolic solution was added to the dish and swirled to cover the entire surface, then allowed to air dry. Examination of dish surfaces with a stereomicroscope indicated that they were covered with a fairly uniform distribution of micro-PCB droplets. Once all the solvent had evaporated, filtered seawater and embryos were added to dishes, and incubation was as described in Chapter 3. For control dishes $0.3 \mathrm{ml}$ of methanol was added and allowed to evaporate. The rate of uptake of PCBs into embryos was found to vary with the surface density of PCBs (weight/unit area) coating a dish, and this quantity was varied to achieve desired rates of uptake. The details of exposure protocols are described in the figure legends. This method is simple and results in uniform levels of PCBs in embryos incubated within the same dish, and additionally has the great advantage that embryos are exposed only to PCBs. Thus any effects observed can be attributed solely to the $\mathrm{PCB}$ mixture and no synergisms are possible. To allow quantitation of PCB uptake, varying amounts of the $\left[{ }^{14} \mathrm{C}\right]-\mathrm{PCB}$ described above were mixed with the Aroclor 1254. The specific activities used ranged from $1-30 \mathrm{nCi} / \mu \mathrm{g}$ depending on the levels of PCBs to be reached in embryos. To prepare a labelled PCB mixture, a hexane solution of Aroclor 1254 was mixed with a volume of the $\left[{ }^{14} \mathrm{C}\right]-\mathrm{PCBs}$ to approximately the desired specific activity. The actual specific activity was determined by drying aliquots of this mixture on tared aluminum microbalance pans, weighing, then quantitating the radioactivity by liquid scintillation counting (LSC). The PCB mixture was then dried under nitrogen and redissolved in methanol to the desired concent ration. 
To quantitate the levels of PCBs in embryos due to exposure, embryos were washed 3 times with filtered seawater $(25 \%)$, dechorionated with microsurgical scissors, transferred with a pipette to tared pieces of $8 \mu$ polycarbonate Nucleopore filters, blotted on filter paper and welghed. Embryos and filters were solubilized in Protosol overnight at room temperature in sealed Nalgene filmware tubes, then counted in $3 \mathrm{ml}$ of Aquasol acidified with an excess of HC1. Levels of PCBs in eleutheroembryos were simflarly quantitated, except they were immobilized by washing in ice cold seawater. The counting efficiency was determined by internal standardization using $\left[{ }^{14} \mathrm{C}\right]$-toluene. The Nucleopore filter material served as an excellent support for the fragile embryos during blotting and weighing; without such support wet weights could not be obtained on dechorionated embryos, as direct blotting of embryos results in rupture of the yolk sac. Because of the hydrophobic nature of the polycarbonate filters, a negligible weight of water is retained after blotting, and conveniently filters are completely solubilized by Protosol. Levels of PCBs in eleuthe roembryos were similarly determined. In some cases the distribution of PCBs between the yolk and the tissue was examined by dissecting embryos or eleutheroembryos free of yolk. The remaining bodies were weighed and solubilized like whole embryos. Before hatching, if great care was exercised, yolk with surrounding membrane could be removed from the embryo intact but was too fragile to weigh. In these cases yolks were transferred directly to filmware tubes with a Pasteur pipette, then solubilized and counted. After hatching when the yolk is reduced in size 
and more viscous, weights were readily measured with yolks supported on pieces of filter; the filter and yolk were then solubilized and counted.

\section{Fractionation of Embryos and Enzyme Assays:}

Embryo fractionation and enzyme and protein assays were exactly as described in Chapter 3. All benzo[a]pyrene monooxygenase assays were performed on fresh material; NADPH- and NADH-cytochrome c reductase and aminopyrine demethylase assays were performed on fractions frozen in liquid nitrogen.

HPLC:

The spectrum of BP metaholites produced by microsomes from untreated and $\mathrm{PCB}$-exposed eleutheroembryos were analyzed by high performance liquid chromatography (HPLC). Microsomes were prepared from 1200 untreated stage 37-38 eleutheroembryos, which were from a pool of eggs stripped from 25 females. Metabolites were prepared from these microsomes by combining $1.1 \mathrm{mg}$ of microsomal protein with $0.430 \mu \mathrm{mole}$ of NADPH, 49 pmole Tris-HCl, $\mathrm{pH} 7.2$, and $0.060 \mu$ mole of $\left[{ }^{3} \mathrm{H}\right]-\mathrm{BP}$ (390 $\mu \mathrm{Ci} /$ umole) added in $20 \mu \mathrm{l}$ of acetone, in a final volume of $1 \mathrm{ml}$. Immediately after the addition of the $\left[{ }^{3} \mathrm{H}\right]-\mathrm{BP}$, half of the reaction volume was removed and combined with $0.5 \mathrm{ml}$ of acetone on ice; this served as the zero-time blank to correct for oxidation productions present in the $B P$. The remaining reaction volume was incubated for 25 minutes at $30^{\circ}$, then combined with $0.5 \mathrm{ml}$ of acetone as before. To examine the effects of TCPO (epoxide hydrolase inhibitor), TCPO was added to a similar reaction mixture to a: final concentration of $1 \mathrm{mM}$. BP 
metabolites were similarly prepared using adult Fundulus hepatic microsomes.

When metabolites were prepared with microsomes from PCB exposed eleutheroembryos, the reaction volume was reduced to $0.20 \mathrm{ml}$ to reduce the background from oxidized products of $\left[{ }^{3} \mathrm{H}\right]-\mathrm{BP}$. The enzyme used was $0.30 \mathrm{mg}$ of a pool of approximately equal amounts of microsomal protein from groups 7 and 8 of Experiment 1 (described in Results). Immediately after addition of the $\left[{ }^{3} \mathrm{H}\right]-\mathrm{BP}$, half of the reaction volume was removed and combined with $0.9 \mathrm{ml}$ of $\mathrm{H}_{2} \mathrm{O}$ and $1 \mathrm{ml}$ of acetone; this served as the zero-time blank. The remaining reaction volume was incubated as before then combined with $0.9 \mathrm{ml}$ of $\mathrm{H}_{2} \mathrm{O}$ and $1 \mathrm{ml}$ of acetone. Water was added simply to increase the working volume.

Metabolites were extracted according to Selkirk (1976) and were finally dissolved in acetonitrile. Resolution of metabolites was accomplished using a Dupont LC850 chromatograph with a $10 \mu 1$ injection loop, a $0.46 \times 25 \mathrm{~cm}$ ODS column, and a UV detector operating at $254 \mathrm{~nm}$. Metabolites were eluted with a $40-100 \%$ gradient of acetonitrile in water at a flow rate of $2 \mathrm{ml} / \mathrm{mln}$ and were identified by coelution of peaks of radioactivity with the UV absorbance of coinjected authentic standards. Radioactive peaks were quantitated by liquid scintillation counting of fractions collected during the course of elution. The $\left[{ }^{3} \mathrm{H}\right]-\mathrm{BP}$ used was purtfled as described in Chapter 3, and all procedures were done under red light. 


\section{Statistics:}

The statistical significance of differences between sample means was evaluated by the Student $t$-test on pooled estimates of variance (Winer, 1971).

\section{RESULTS}

\section{Experiment 1}

Responses of the monooxygenase systems of embryos and eleutheroembryos to Aroclor 1254:

An experimental protocol was designed to examine the levels of Aroclor 1254 necessary to induce BPM activity in.embryos and eleutheroembryos, and to compare the relative sensitivities of the induction responses during these phases of development. A pool of embryos was divided into groups that were exposed to Aroclor 1254 over two different intervals of development (Figure 4-1). Groups 1-4 were loaded with varying amounts of PCBs beginning one day after fertilization and were fractionated at 13 days of development. Groups 5-8 were loaded with PCBs beginning 8 days after fertilization, and were fractionated at 20 days of development. These groups will be referred to as eleutheroembryo exposure groups. Embryos and eleutheroembryos were exposed to PCBs for the same total length of time (12 days), since the length of exposure could affect the extent of induction. This experiment was designed to compare the intrinsic capacity of embryos and. eleutheroembryos to respond to PCBs as monooxygenase inducers. 
Figure 4-1. Levels of PCBs in whole embryos during the course of Experiment 1. Ten groups of 150 embryos were selected from a large pool of eggs stripped from 18 females and fertilized with minced testis from 5 males. Eight of the groups were exposed to varying levels of a mixture of Aroclor 1254 and $\left[{ }^{4} \mathrm{C}\right]-\mathrm{PCBS}(4 \mu \mathrm{Ci} / \mathrm{ug})$, while the other 2 groups served as controls. Embryos were exposed to PCBs by incubation for 2 days in $10 \mathrm{~cm}$ glass petri dishes coated with PCB films of varying surface density, then were transferred to freshly coated dishes for an additional 2 days, then were finally transferred to clean dishes. The intervals of exposure in coated dishes are indicated in the figure by the darkened portions of the abscissa. Control groups were similarly treated with transfers between clean dishes. The exposure of groups $1-4$ began 1 day after fertilization, while groups 5-8 were exposed beginning at 8 days of age. The embryos in all groups were assayed for various enzymatic activities 12 days after the initiation of exposure.

Dishes were coated with PCBs as described in Materials and Methods. The amounts of PCBs added per dish for groups $1-4$ were $426,145,48$ and $16 \mu \mathrm{g} ' \mathrm{~s}$, respectively, and for groups 6-9: $200,80,30$, and $10 \mathrm{\mu g}$ 's respectively. Incubation conditions and analysis of PCB levels were as described in Materials and Methods. Each data point represents the mean $P C B$ leve $1 s$ in from 3-6 whole embryos calculated on a wet weight basis. The mean coefficient of variation (S.D./mean) was about $10 \%$. Embryos analyzed before hatching were dechorionated, so the data before and after hatching are comparable. 


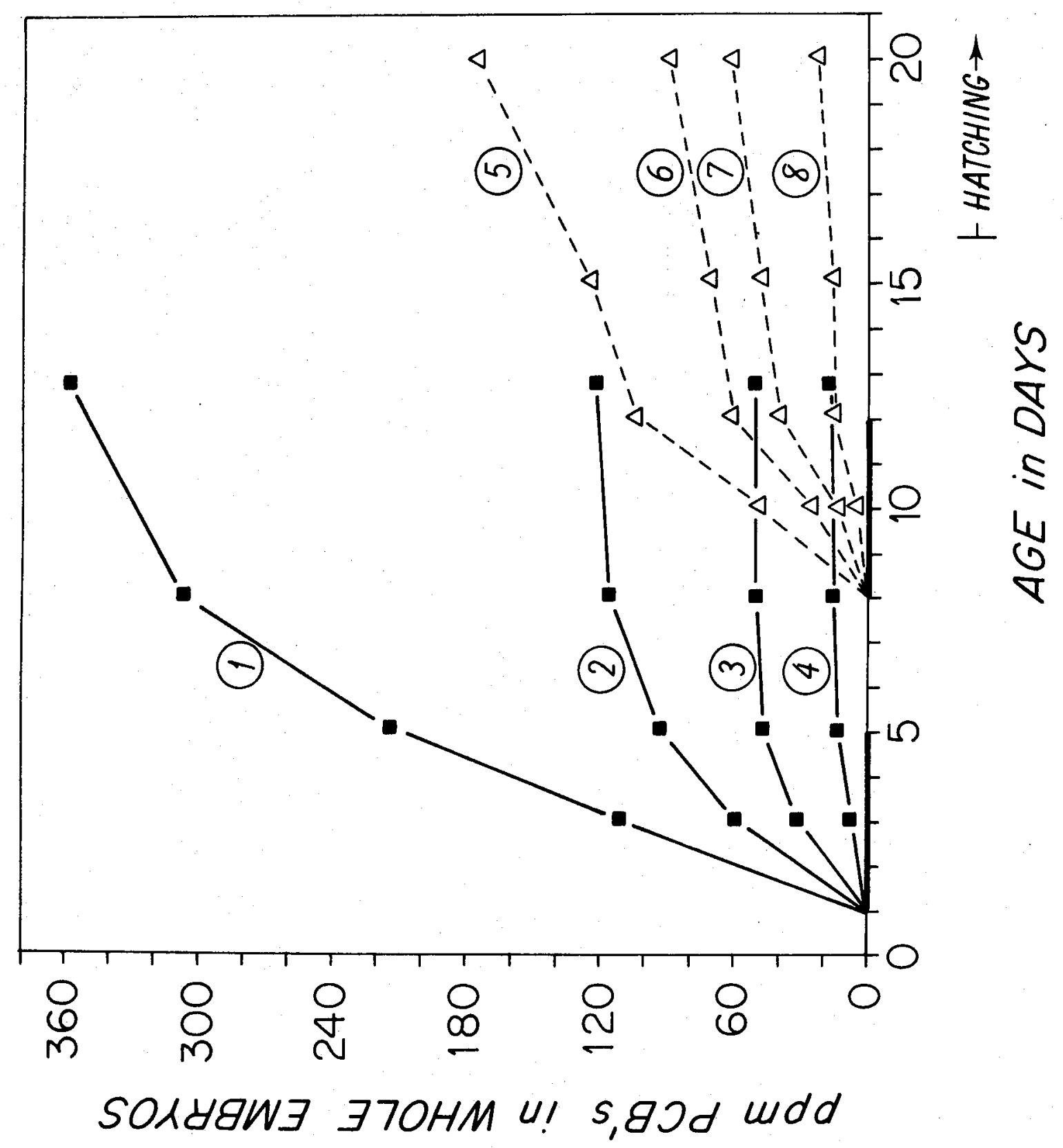


in glass Petri dishes coated with PCB films of varying surface densities for four days then transferring to clean dishes. The exposure conditions were selected based on a preliminary embryo dose response experiment and preliminary uptake experiments (data not shown). The levels of PCBs in whole embryos eleutheroembryos during the course of exposure are plotted in Figure 4-I, and the details of the exposure-method are described in the legend to this figure. The chorions of group 1 embryos, which were exposed to the highest levels of PCBs, became covered with PCB droplets visible with a dissecting microscope. These chorion-associated PCBs were responsible for the continued high rate of uptake of PCBs into group 1 embryos, after they were removed from direct contact with the PCB film (the periods in contact with PCB films are indicated by the darkened portions of the x-axis of Fig. 4-1.) A similar effect occurred in the other groups, but to a lesser extent. The increase in whole embryo PCB concentration in groups 5-8 after hatching is due to a decrease in the whole embryo weight; between days 15 and 20 of age there was little change in the total PCB content in embryos, but there was a mean decrease of $26 \%$ in whole embryo weight. The decrease in embryo weight around the time of hatching, due to loss of fluid, was described in Chapter 3 .

For interpretation of induction results it is important to know the tissue levels of PCBs, thus the distribution of PCBs within embryos and eleutheroembryos near the times of assay was determined. The tissues were dissected free of yolk and these two portions of the embryo and eleutheroembryos were separately analyzed for PCB content. "Only the levels of PCBs due to the exposure were neasured, the background levels 
of PCBs were not determined. Table 4-I shows levels of PCBs in intact embryos and eleutheroembryos as well as. tissue levels for each of the individual exposure groups shortly before they were fractionated and assayed. Table 4-II shows various compiled statistics on the embryo and eleutheroembryo exposure groups. It can be seen that levels of PCBs measured in intact embryos and eleutheroembryos were 3-4 times higher than the respective tissue levels (Table 4-I). This was due to the fact that in both embryos and eleutheroembryos the majority of PCBs was associated with yolk (Table 4-II). For the eleutheroembryo exposure groups 5-8, $P C B$ concentrations in the yolk were 8-9 times higher than the tissue levels. The yolk concentrations of PCBs could not be calculated for the embryo exposure groups, because their yolks were too fragile to weigh. For comparison of the sensitivity of the induction responses in embryos and eleutheroembryos, knowledge of the tissue levels of PCBs necessary to produce a response is essential. For comparison of results to environmental data, the levels of PCBs in intact embryos and eleutheroembryos are most relevant.

As mentioned above there is a decrease in whole embryo weight after hatching. This is evident in Table 4-II, when the whole embryo weights of groups $1-4$ ( 12 days of age) are compared to those of groups 5-8 (20 days of age). Despite the decrease in whole embryo weight from 12 to 20 days of development, there was a $180 \%$ increase in body weight over this period as a result of growth. The yield of microsomal protein per mg of tissue weight was higher in the eleutheroembryos compared to 
Table 4-I. Levels of PCB's in Experiment 1 embryos and eleutheroembryos near the times of assay.

Exposure ${ }^{+}$

Group

\begin{tabular}{cc} 
PPm PCBs* & \\
\hline Tntact & Tissues
\end{tabular}

Emb ryos

$\begin{array}{lcc}1 & 360 \pm 52 & 100 \pm 30 \\ 2 & 140 \pm 26 & 35 \pm 3 \\ 3 & 58 \pm 1 & 14 \pm 2 \\ 4 & 16 \pm 3 & 5.5 \pm 0.8\end{array}$

Eleutheroembryos

$\begin{array}{llll}5 & 180 \pm 22 & 55 \pm 12 & 450 \pm 61 \\ 6 & 90 \pm 8 & 27 \pm 5 & 250 \pm 30 \\ 7 & 62 \pm 7 & 18 \pm 4 & 152 \pm 5 \\ 8 & 23 \pm 2 & 6.6 \pm 1.0 & 61 \pm 13\end{array}$

+ Exposure group refers to the designations in Figure 4-1.

* "Intact" refers to the whole embryo or eleutheroembryo (i.e. the yolk and tissues). "Tissues" refer to the remainder of the embryo or eleutheroembryo after the yolk has been removed, essentially the body. "Yolk" refers to the fluid yolk, lipid droplets and surrounding membrane dissected from the yolk sac. Prior to hatching, yolk and surrounding membrane were too fragile to weigh and concentrations of PCB's could not be calculated. The data for exposure groups $1-4$ were obtained at 12 days of age, 1 day before they were assayed. For these groups, whole embryo levels of $\mathrm{PCB}$ 's were also determined on the day of assay ( $p$ lotted in Figure 4-1). The data for exposure groups 5-8 were obtained on the day of assay, at 20 days of development. Levels of PCBs were quantitated as described in Materials and Methods. The values shown are the mean $\pm S . D$. for $4-6$ individuals. $\mathrm{ppm}=\mathrm{ng} / \mathrm{mg}$ wet weight. 
Table 4-II. Complled statistics for PCB-exposed Experfment 1 embryos and eleutheroembryos near the times of assay.

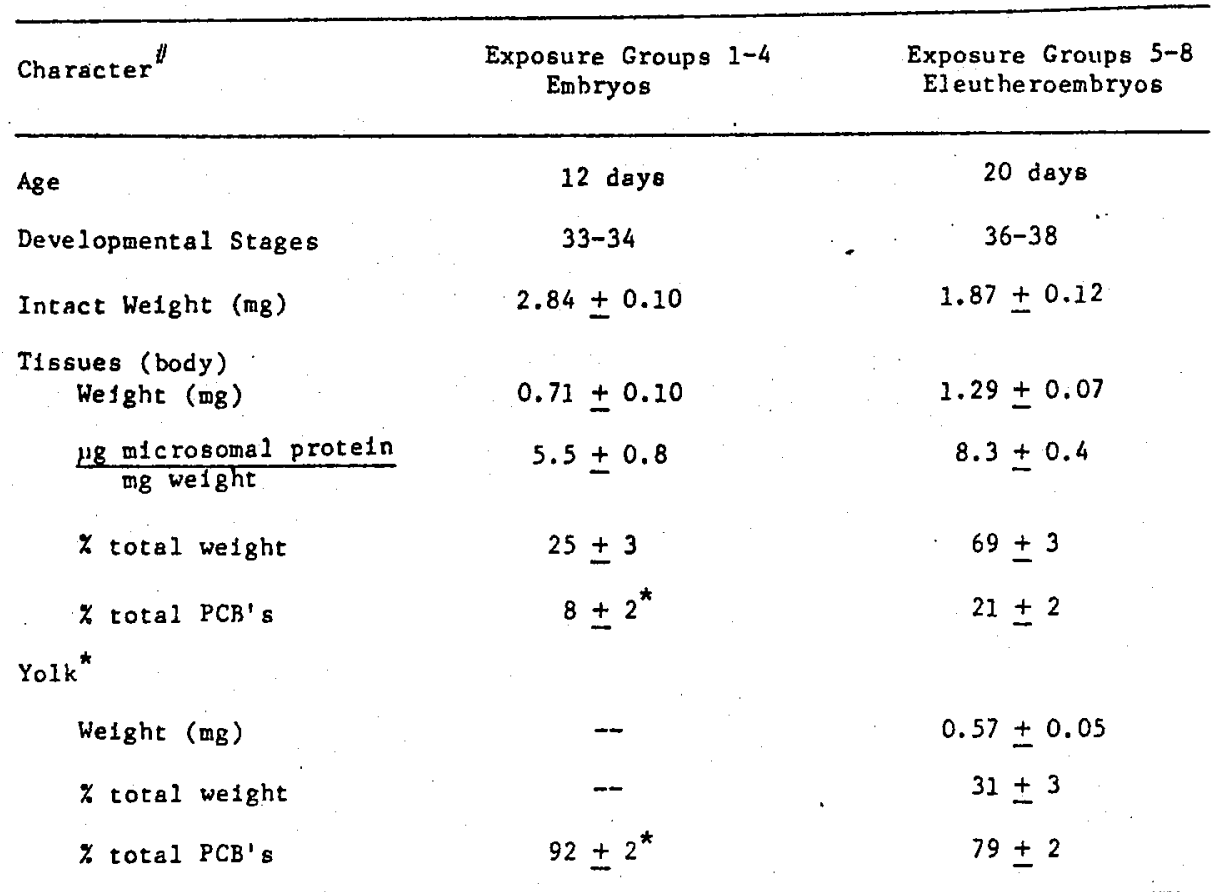

"The terms whole "1ntact", "tissues" and "yolk" are defined in Table 4-I.

+ Exposure groups refer to the designations in Figure 4-1 and Table 4-I. Group data were pooled as indicated and values are the mean of group data \pm S.D. Within each group measurements were made on at least 5 individuals.

Yolk and surrounding membrane were too fraglle to weigh before hatching. Substantial fluld is released from the perfcardial and peritoneal cavitles during dissection prior to hatching. Thus accurate yolk welghts can not be obtalned by subtraction of the embryo body weight from the intact embryo veight. 
embryos $^{1}$. This was not a specific effect, as the yield of protein per unit body weight was higher in all of the centrifugal fractions of the eleutheroembryos. No effect of PCB exposure on the yield of whole embryo or eleutheroembryo microsomal protein was apparent.

The exposure of embryos to PCBs had no apparent effect on the rate of development. At the times of observation, embryos in each of the groups were in the same development stages. Also the mean time to hatching and the percent hatching were not affected by exposure to PCBs at the levels used here. For groups 5-8 and their control the overall mean hatching time was $19.8 \pm 0.3$ days and the overall mean hatching success was $98 \pm 0.5 \%$ (both \pm standard deviation of the mean). The incldence of malformed embryos did not exceed $3.5 \%$ in any of the exposure groups, and only normal embryos were assayed. It should be noted that in the experiment described in Table 2-II, PCB exposure apparently slowed the development of embryos. In this experiment PCBs were added to the incubation water in DMSO. Possibly the effect on developmental rate was due to an interaction of the PCBs and DMSO.

The results of monooxygenase and $\mathrm{NADPH}-\mathrm{cytoch}$ rome $c$ reductase assays on the microsomal fraction of whole embryos and eleutheroembryos from the various exposure groups are shown in Figure 4-2. Embryos (groups 1-4 and control) were assayed at 13 days of age in devilopmental stages 33-34. Exposure to Aroclor 1254 produced a clear dose dependent

1 The yield of microsomal protein for whole eleuthe roembryos reported in Table 4-II is lower than that shown in Table 3-II. In the later case microsomes were prepared by sedimenting the low speed and 10K fractions in the same tube without decantation of supernatants. This leads to a higher yleld of microsomes. 
Figure 4-2. Microsomal BPM, APD and NADPH cytoch rome c reductase activities in fractions prepared from Experiment 1 embryos and eleutheroembryos. Enzyme specific activities are plotted versus the levels of PCBs in whole embryos or eleutheroembryos at the time of assay. The embryos were from exposure groups 1-4 (Figure 4-1) and their control group. Pools of 88 embryos from each of these groups were fractionated and prepared for assay at 13 days of age and stages 33-34. The eleutheroembryos were from exposure groups 5-8 (Figure 4-1) and their control group. Pools of 60 individuals from each of these groups were fractionated and prepared for assay at 20 days of age in developmental stages 36-38. The majority of eleutheroembryos had hatched more than 12 hours before they were fractionated. BPM data points are the mean of 4 replicates \pm S.D; NADPH-cytochrome c reductase data points are the mean of 3 replicates \pm S.D., and APD points are the mean of duplicate determinations \pm range. 


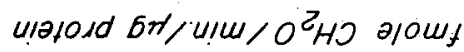

(०) $\exists S \forall 7 \wedge H \perp \exists W \exists O \quad \exists N I Y \Lambda D O N I W V$
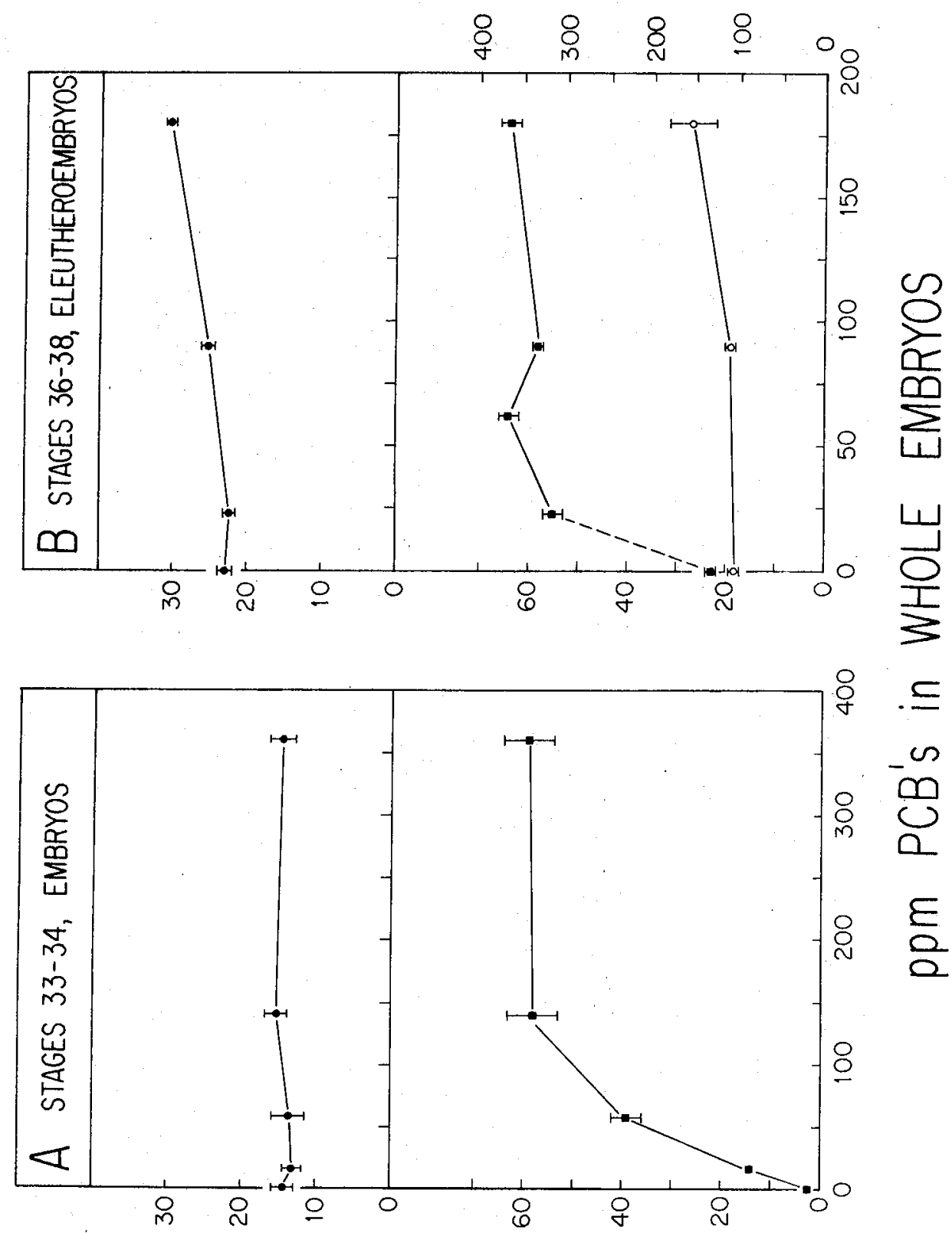

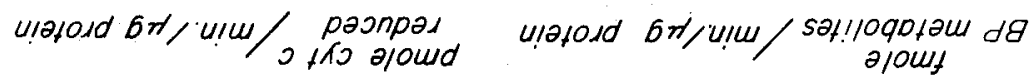

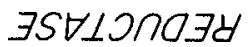

Э $3 W O U H O O \perp 10$ HdOVN (-) $35 V N \exists O \Lambda X O O N O W d \theta$ 
induction of embryonic microsomal BPM monooxygenase activity (Figure 4-2A). A near maximal induction of 27 -fold over the low constitutive activity of the control group was reached by a dose level of $140 \mathrm{ppm}$. At the lowest dose level of PCBs, $16 \mathrm{ppm}$ in the whole embryo, BPM activity was induced $6.3-$ fold. The dose response curve suggests that levels as low as $10 \mathrm{ppm}$ in whole Fundulus embryos can induce a greater than 4-fold Induction of $B P M$ activity. The $\mathrm{ED}_{50}$ for the induction of BPM activity in embryos by Aroclor 1254 was graphically estimated to be about $45 \mathrm{ppm}$ in the whole embryo ${ }^{2}$. Despite the almost 30-fold induction of embryonic BPM activity by PCBs, levels of NADPH-cytochrome c reductase activity were essentially unchanged by exposure of embryos to this PCB mixture. The levels of $\mathrm{NADH}$-cytochrome $c$ reductase activity were also measured, and showed a simflar lack of response to PCB exposure (data not shown). The mean $\mathrm{NADH}-\mathrm{cyt}$ (och rome c reductase activity was 25 pmole cytochrome $c$ reduced $/ \mathrm{mln} . / \mu \mathrm{g}$ protein, which was about 1.8 times higher than that of the $\mathrm{NADPH}-\mathrm{cyt}$ och rome $\mathrm{c}$ reductase.

Eleuthe roembryos (groups 5-8 and control) were assayed at 20 days of age in developmental stages 36-38. Consistent with previous observations, it can be seen that the basal BPM specific activity in the control eleutheroembryos was about 10-fold higher than that in the control embryos (compare 4-2A to 4-2B). In sharp contrast to the results with embryos, BPM activity was induced to a similar extent in eleuthe roembryos by all of the dose levels of PCBs examined. The induction ranged from 2.4 to 2.8 -fold, and no dose dependency is

$2 \mathrm{ED}_{50}$ is the dose necessary to produce a half-maximal response. 
apparent. (It should be noted that the PCB concentration scale in Figure $4-3 B$ is $1 / 2$ that in $4-3 A$ ). A near maximal induction was produced by only 23 ppm PCBs in whole eleuthe roembryos, while about $140 \mathrm{ppm}$ was requi red for maximal induction in the stage 33-34 embryos. Despite the large Increase in constitutive BPM specific activity associated with hatching, the maximal specific activity induced by PCB exposure, both before and after hatching, was about the same. With both embryos and eleutheroembryos the maximal BPM activity induced was about 60 fmole of metabolite/min/ $/ \mathrm{g}$ of microsomal protein. The lesser relative extent of induction after hatching is due to the rise in basal activity.

In certain of the eleutheroembryo exposure groups aminopyrine $\mathrm{N}$-demethylase activity was also assayed (Figure 4-2B). Although BPM activity was near maximally induced at $23 \mathrm{ppm}$ PCBs, APD activity was essentially unchanged at a leve1 of $90 \mathrm{ppm}$ PCBs in the whole eleutheroembryo. There is a suggestion of a modest increase in APD specific activity at $180 \mathrm{ppm}$ PCBs, but clearly over a range of PCB levels that produce a greater than 2.5-fold increase in BPM activity, APD activity changes very little.

Consistent with previous observations, it can be seen that the re was an increase in the specific activity of the NADPH-reductase after hatching. NADH-cytochrome c reductase activity was also measured in whole eleutheroembryos microsomes (data not shown). The constitutive activity of $\mathrm{NADH}$-cytochrome c reductase did not change after hatching, and the specific activities of the two reductases were essentially the same in the control eleutheroembryos. Both reductase activities were 
modestly Induced in eleutheroembryos by $\mathrm{PCB}$ exposure at the higher dose levels, although no induction was appazint in embryos even at about twice the highest level of PCBs in eleutheroembryos. At $180 \mathrm{ppm}$ PCBs in. whole eleutheroembryos, both the NADPH- and NADH-cytochrome c reductase activities were greater than 1.3 times the control activities; these increases in activity were statistically significant at the 0.001 and 0.01 levels, respectively (based on replicate determinations with Individual pools of microsomes). The dose response for induction of NADPH cytochrome $c$ reductase activity is apparently distinct from that of the induction of BP monooxygenase activity, as BPM activity was near maximally induced at 25 ppm PCBs in whole eleutheroembryos, while Induction of the reductase is only apparent at the highest dose levels. The data in Figure 4-2 indicate that BPM activity is maximally Induced in eleuthe roembryos (stages 36-38) at concentrations that are at least 6-fold lower than required for maximal induction in embryos (stages 33-34). This suggests that the induction response in eleutheroembryos is much more sensitive than in embryos. This is confirmed when the tissue levels of PCBs necessary to produce maximal responses in embryos and eleutheroembryos are compared. The BPM data presented in Figure 4-2 was replotted versus the levels of PCBs in embryo bodies (tissue levels) rather than the levels in intact embryos and eleutheroembryos, and the activities were normalized to embryo body (or tissue) weights. When the data are plotted in this way (Figure 4-3) a pattern similar to that seen before is apparent. In embryos the induction of BPM activity was dependent on the leve1 of PCBs within the embryo bodies, with a maximal 
Page 174

Figure 4-3. BPM activities for Experiment 1 embryos and eleutheroembryos normalized to embryo body weight, and plotted versus ppm PCBs in embryo bodies. Embryos ( $)$, eleutheroembryos $(\boldsymbol{a})$. 


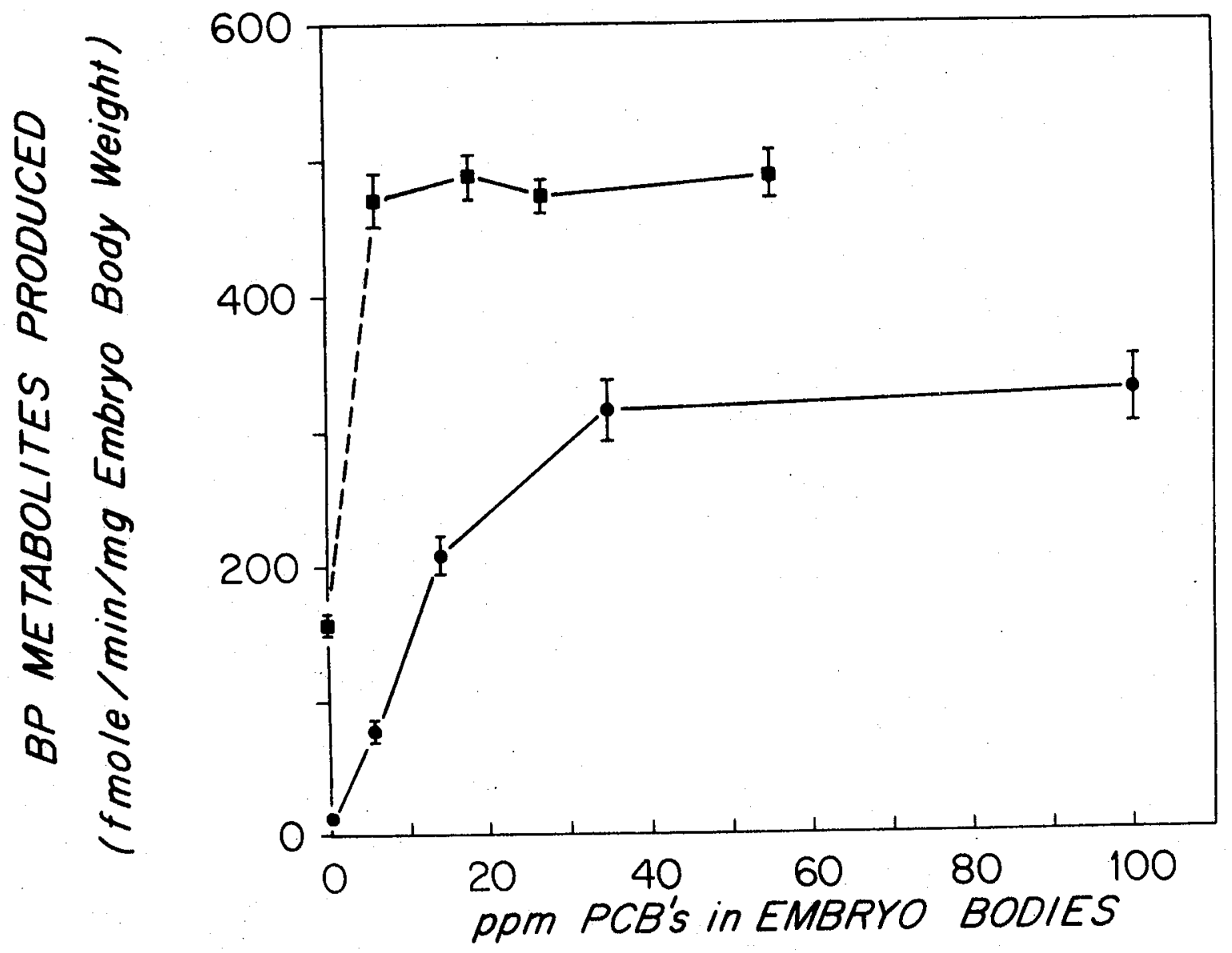


Induction of about 27-fold. The $\mathrm{ED}_{50}$ for induction, in terms of ppm of Aroclor 1254 in the embryo body, was graphically estimated to be $13 \mathrm{ppm}$. In the eleuthe roembryos each of the dose levels of PCBs produced an apparently maximal 3-fold induction of activity. While about 35 ppm PCBs within the embryo bodies was required for near maximal induction in the embryos, a near maximal induction was observed in eleutheroembryos at about $6.6 \mathrm{ppm}$. The data indicate that there is at least a 5-fold increase in the sensitivity of the induction response between stages 33-34 and stages 36-38. Since the dose response for induction of BPM activity in eleuthe roembryos was not defined, the actual increase in sensitivity may be even greater than 5-fold.

As al ready mentioned, the $\mathrm{PCB}$ exposure induced about the same maximal BPM specific activity in microsomes from the stage 33-34 embryos and the stage 36-38 eleutheroembryos (Fig. 4-2). However, as a result of the increased yield of microsomal protein in eleutheroembryos (Table 4-2), the maximal induced BPM activity normalized to body weight is about 1.5 times higher in eleutheroembryos than embryos. When the activities are normalized to whole embryo weight, the differential is even greater because of the growth of the embryo body with development (Table 4-2). The activities in maximally induced eleutheroembryos and embryos were about 320 and 86 fmole BP metabolites/min/mg whole embryo weight, respectively. Although similar maximal BPM specific activities can be induced in the microsomes of embryos and eleutheroembryos, the eleutheroembryos would have considerably more total capacity to metabolize benzo[a]pyrene, and would reach the maximally induced state at lower levels of the inducer. 
The data on BPM activities in the various exposure groups discussed so far were obtained by assaying the miscosomal fraction of whole embryos and eleutheroembryos. However, in Experiment 1 all of the centrifugal fractions were assayed for BPM activity immediately after preparation. A roughly parallel induction of activity was seen in the vartous particulate fractions, and activity was not detectable in the supernatant fractions (data not shown). Figure $4-4$ shows the distribution of BPM activity in the centrifugal fractions of $\mathrm{PCB}$ exposed embryos and eleutheroembryos. The data plotted are the mean results for the four exposure groups assayed before hatching and the four groups assayed after hatching. BPM activity was similarly distributed in the centrifugal fractions of the embryos and eleutheroembryos, and in both cases was primarily localized in the microsomal fraction. These results confirm the observations presented in Chapter 3 indicating that there is no change in the distribution of BPM activity after hatching.

\section{Experiment 2}

A comparison of the response of 4 and 13 day old embryos to PCB exposure:

To examine the relative capacity of 4 and 13 day old Fundulus embryos to respond to PCB induction of BPM activity, an experimental protocol similar to that of Experiment 1 was used. Two groups of embryos (I and II) were exposed to Aroclor 1254 for 95 hours before they were assayed for BPM activity at 4 and 13 days of development, respectively. The experimental procedure is described in detail in the legend to Figure 4-5. The levels of PCBs in the two groups of embryos during the course 
Figure 4-4. The distribution of BPM activity in centrifugal fractions of PCB exposed embryos and eleutheroembryos from Experiment 1. The designations I-IV refer to the low speed, $10 \mathrm{~K}$, microsomal and supernatant fractions, respectively. The embryo data are the mean results for exposure groups $1-4$, and the eleutheroembryo data - the mean results for exposure groups 5-8 (Figure 4-1). Relative specific activity is the percent total activity in a fraction divided by the percent total protein. 
Page 179
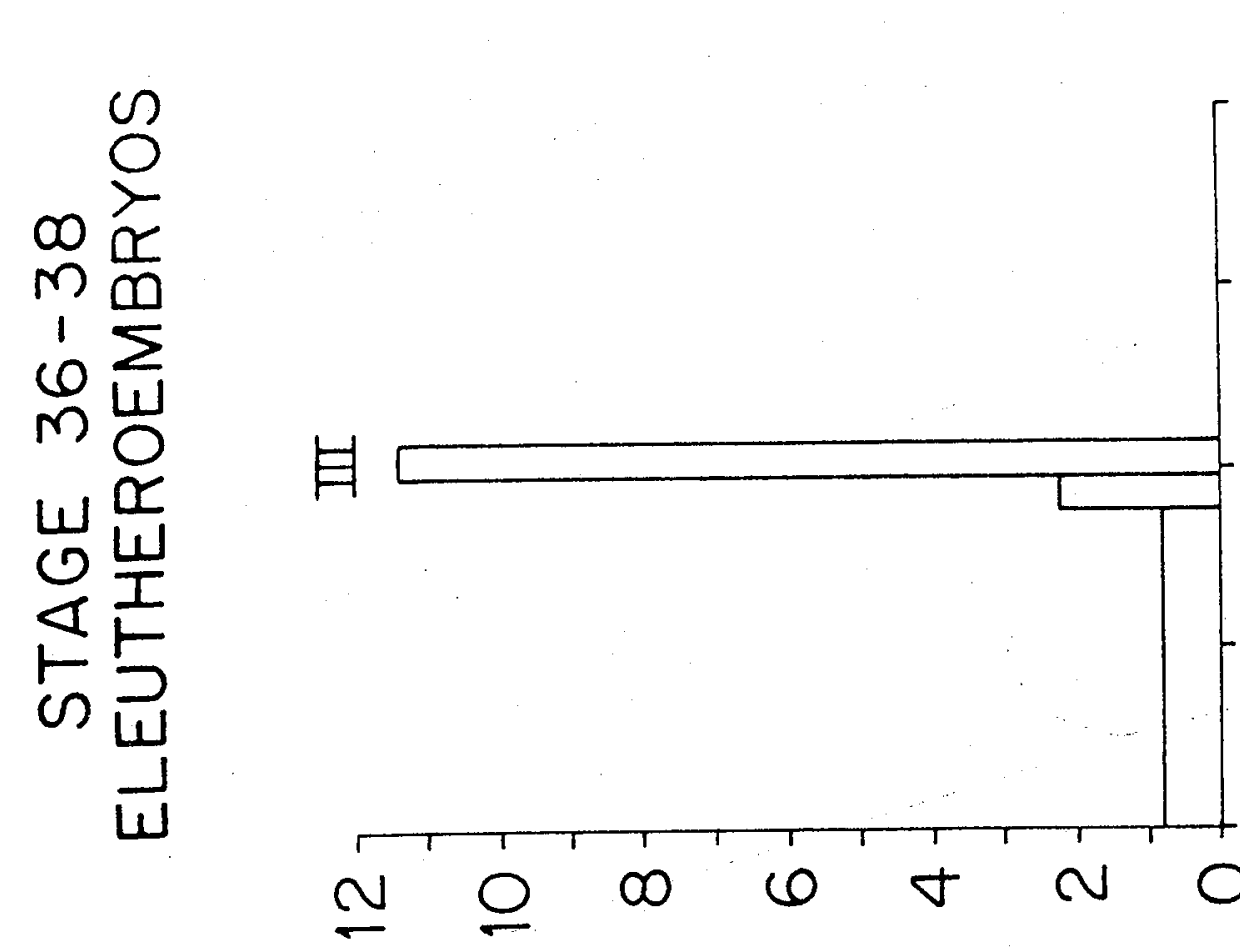

$\stackrel{0}{-}$
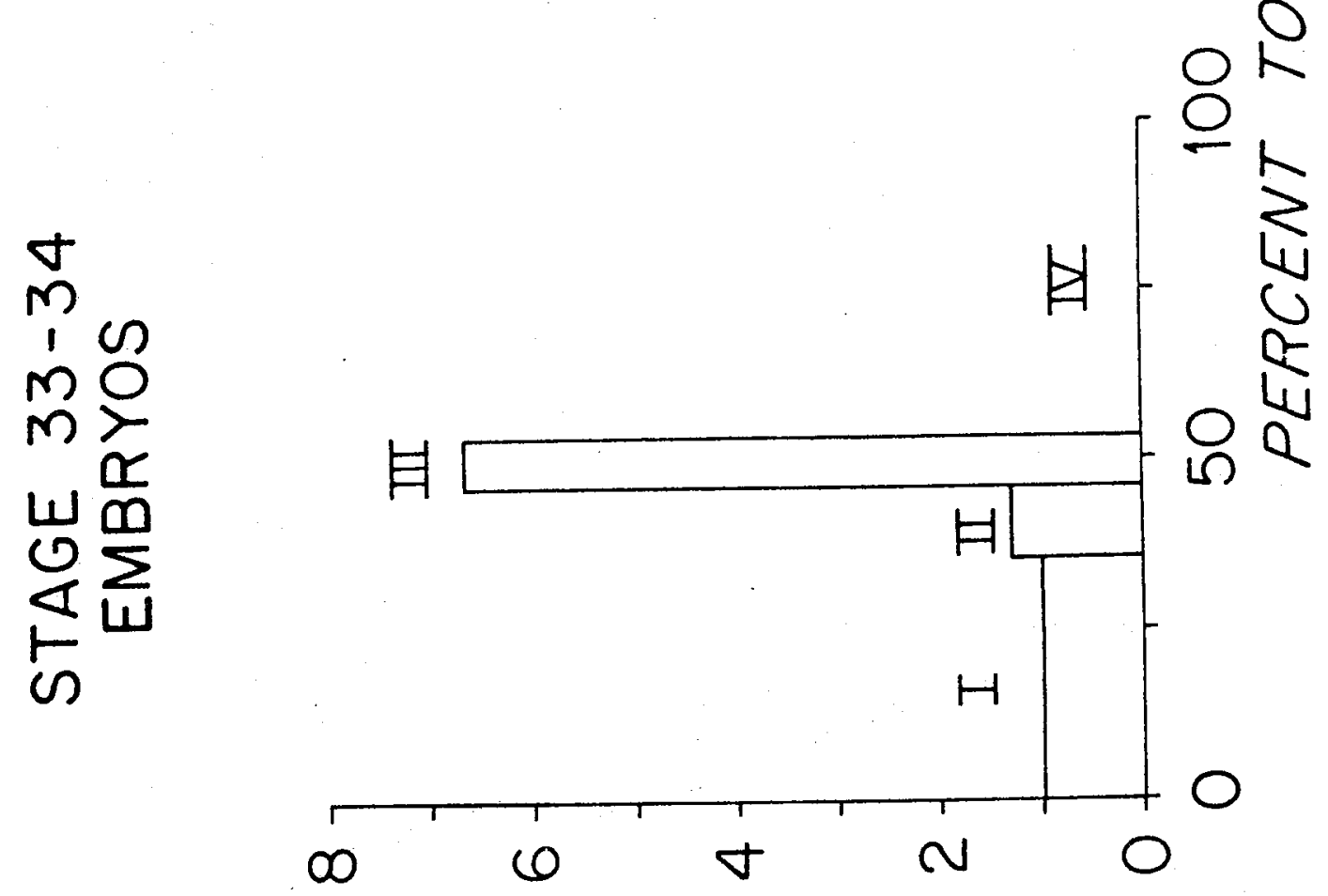

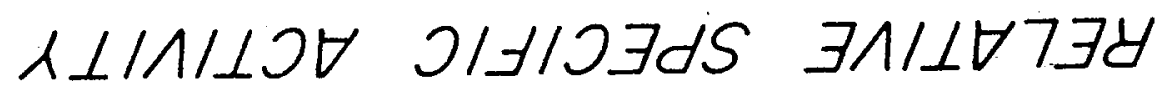 \\ $\exists S \forall N \exists D \Lambda X O O N O W d \theta$}


Figure 4-5. A) Levels of PCBs in Experiment 2 embryos during the course of exposure. B) BPM activity in fractions from control (CON) and PCB exposed embryos. Two groups of embryos were selected from a pool of eggs stripped from 13 females and fertilized with minced testis from 4 males. A portion of the embryos in each group was exposed to a mixture of Aroclor 1254 and $[14 \mathrm{C}]-\mathrm{PCBS}(1.0 \mathrm{nCi} / \mu \mathrm{g})$ for approximately 95 hours before they were fractionated and assayed; the remaining embryos served as controls. The exposure of group I was initiated $10 \mathrm{hrs.}$ after fertilization and that of group II, 9 days after fertilization. The exposure was accomplished by incubating approximately 100 embryos in 10 cm glass petri dishes coated with $600 \mu \mathrm{g}$ of the $\left[{ }^{14} \mathrm{C}\right]-\mathrm{PCB}$ mixture. Embryos were transferred to the $P C B$ coated dishes at the time of initiation of exposure, and were incubated in the same dish with daily water changes until they were fractionated. Control embryos were treated similarly with transfers between clean dishes.

The data in part A of the figure are the mean PCB levels in from 3-6 dechorionated embryos \pm S.D. For group $I$ about 200 control and exposed embryos were fractionated, while for group II about 100 control and exposed embryos were fractionated. Group I embryos were fractionated at 4.4 days of development in stages 26-27, while group I I embryos were fractionated at 13 days of development in stages 33-34. The BPM data shown in part $B$ are the mean of 4 replicates $\pm S . D$. The coefficients of variation for the control data were $5-10 \%$. 

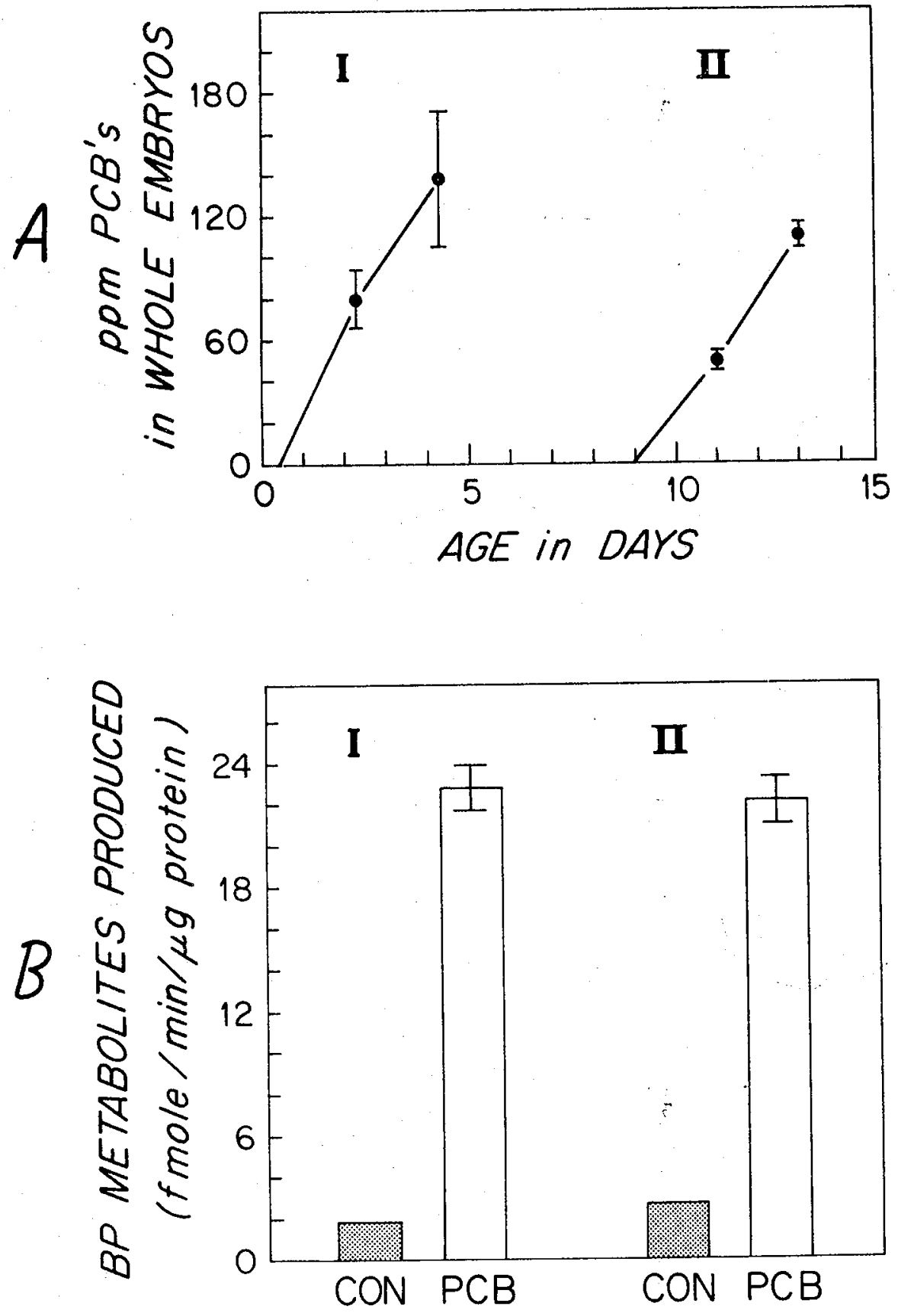
of exposure are shown in part $A$ of the figure. The rate of uptake of PCBs into group I embryos was somewhat faster than into group II. The final concentration of PCBs reached in whole embryos of groups I and II were $138 \pm 33$ and $110 \pm 6$ respectively. Microsomal BPM activity in fractions prepared from embryos of the two exposure groups are shown in part $B$ of Figure 4-5: A very similar response to the PCB exposure was seen in both groups. The activity in the exposed embryos of group I was 12-fold higher than that in the controls, while in group II there was an 8-fold induction. However, activity was induced to essentially the same absolute level in both groups, as the constitutive activity in group I was lower than that of group II. The data clearly show that as early as 4 days after fertilization (stages 26-27), Fundulus embryos are competent to respond to exposure to inducers with increased levels of monooxygenase activity, and that their capacity to respond is very similar to that of 13 day old embryos (stages 33-34).

In Experiment 1 embryos were also assayed at 13 days of development in stages 33-34, and a similar level of constitutive activity was observed. The levels of PCBs in group II embryos in this experiment were near the maximally inducing levels of Experiment 1. The maximal relative induction at 13 days of development in Experiment 1 was 27-fold, to a specific activity of $60 \mathrm{fmole} / \mathrm{min} / \mu \mathrm{g}$ protein, whereas here the relative induction was only 8 -fold to a specific activity of 22 . However, the total period of exposure here was one-third as long as in Experiment 1 and the levels of PCBs were increasing almost linearly throughout the course of exposure. The relative induction of monooxygenase activity is 
apparently a function of both the average levels of PCBs and the length of the exposure period.

\section{Experiment 3}

Additional Observations on the Induction of BPM Activity in

Eleutheroembryos:

To further characterize the sensitivity of the induction response after hatching, embryos were loaded with a range of $\mathrm{PCB}$ concentrations lower than those in Experiment 1. The levels of PCBs in whole embryos during the course of exposure are shown in Figure 4-6, and the detalls of the exposure protocol are described in the legend to this figure. All embryos exposed to PCBs were incubated together in a single coated dish; when a desired level of PCBs was reached a portion of the embryos was removed. In this way embryos were divided into 3 exposure groups, $A-C$. The exposure was inftiated at 2.8 days of development and eleutheroembryos were assayed 21 days later in stages 38-39. The levels of PCBs in whole eleuthe roembryos and eleutheroembryo tissues or bodies are shown in Table 4-III. The lowest levels of PCBs in intact eleuthe roembryosin this experiment were about $1 / 4$ those in Experiment 1 (Table 4-I). However the eleutheroembryos in this experiment were older than those of Experiment 1 (24 compared to 20 days) and had less yolk remaining. The tissues constituted $92 \%$ of the whole embryo weight, and contained on the average $51 \%$ of the total body burden of PCBs (compare to values in Table 4-II). For these eleutheroembryos (stages 38-39), the ratio of the percent total PCBs in the tissues to the percent total weight was 0.55 . For both the stage 33-34 embryos and stage 36-38 
Figure 4-6. Levels of PCBs in whole embryos during the course of Experiment 3. Eggs were stripped from 3 females and fertilized with minced testis from 1 male. Of a total of 230 eggs, 60 served as controls and the remainder were exposed to a mixture of Aroclor 1254 and $\left[{ }^{14} \mathrm{C}\right]-\mathrm{PCBs}(30 \mathrm{nCi} / \mu \mathrm{g})$. At 2.8 days of development those embryos that were to be exposed to PCBs were transferred to a $10 \mathrm{~cm}$ glass petri dish coated with $20 \mu \mathrm{g}$ of the PCB mixture. The uptake of PCBs into embryos was monitored in time; when a desired level was reached a portion of the embryos was transferred to a clean dish. Remaining embryos were transferred daily to a freshly coated dish. In this manner embryos were evenly divided into 3 exposure groups; group $C$ was removed from exposure to the PCB film after 10 hours, group B after 59 hours, and group $A$ after 148 hours. The incubation conditions and quantitation of PCB leve 1 s were as described in Materials and Methods. The data points represent the mean PCB levels in 4 embryos \pm S.D. 


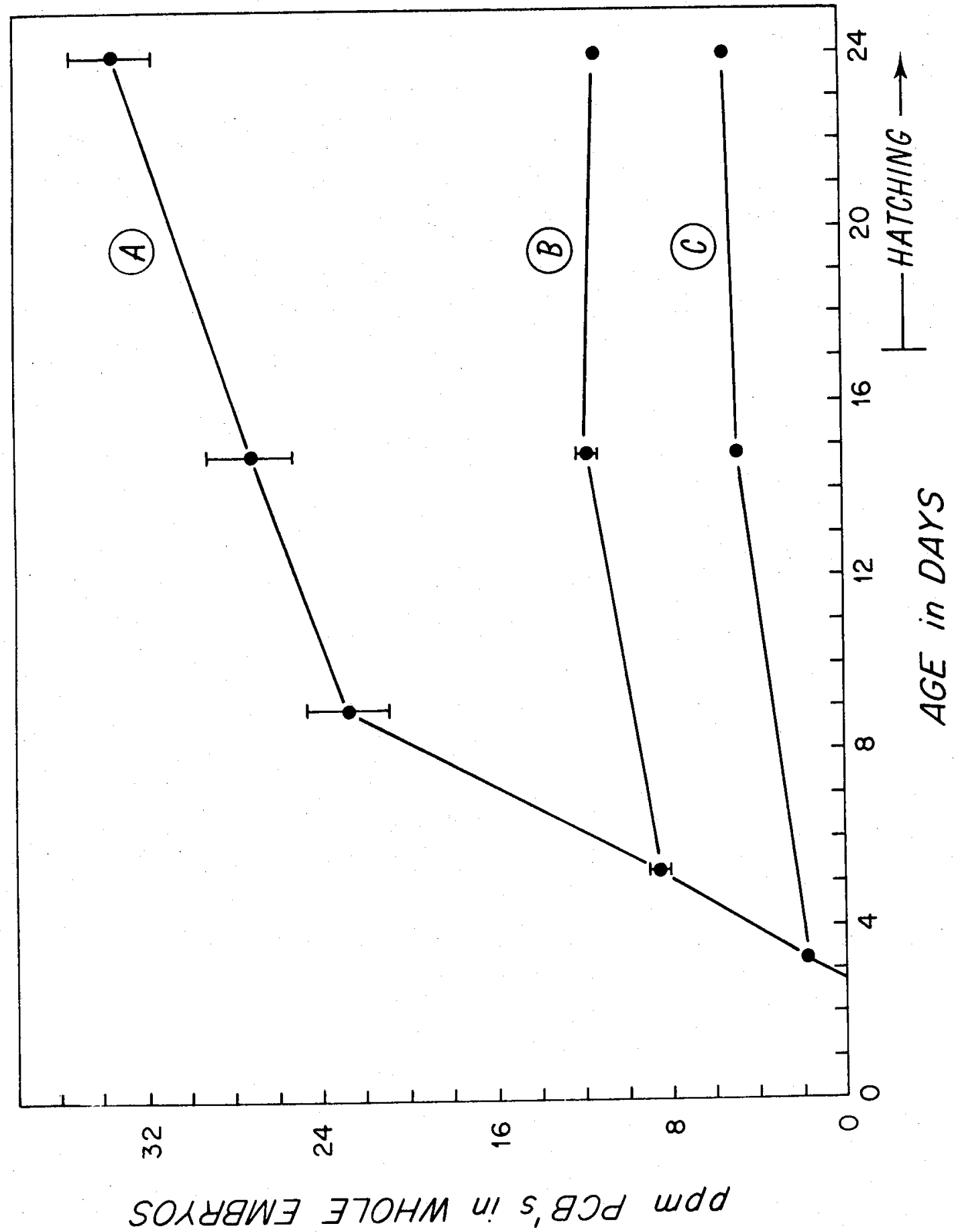


Table 4-III. Levels of PCBs in intact eleutheroembryos and eleutheroembryo tissues at the time of assay in Experiment $3 .^{+}$

\begin{tabular}{ccc}
\hline \multirow{2}{*}{ Exposure Group } & \multicolumn{2}{c}{$\mathrm{Ppm} \mathrm{PCBs}^{*}$} \\
\cline { 2 - 3 } & Intact & $\begin{array}{c}\text { Eleutheroembryo } \\
\text { Tissues }\end{array}$ \\
\hline B & $33.4 \pm 1.9$ & $13.8 \pm 1.5$ \\
C & $11.9 \pm 0.30$ & $7.6 \pm 1.8$ \\
& $5.3 \pm 0.4$ & $3.4 \pm 0.7$ \\
\hline
\end{tabular}

+ Exposure group refers to the designations in Fig. 4-6.

* Values are the mean of determination on 4 individuals $\pm S . D$. 
eleutheroembryos of Experiment 1, this parameter was 0.31 . This Indicates that towards the end of the imbryonic phase of development, when the yolk is almost completely absorbed, the release of PCBs 1nto the tissues is not matched by growth. Thus there apparent ly is a redistribution of PCBs from the yolk into the tissues as the end of the embryonic period of development is approached. For a given level of PCBs measured in intact embryos or eleutheroembryos, later stage eleuthe roembryos wi11 have higher levels of PCBs in the tissues.

The levels of microsomal BPM activity in the various exposure groups are plotted in figure 4-7. At each of the 3 dose levels of PCBs, BPM activity was induced about 5-fold over the constitutive activity of the control group. At the lowest dose level there were $5.3 \pm 0.4 \mathrm{ppm}$ PCBs in the whole embryo and $3.4 \pm 0.7 \mathrm{ppm}$ in the embryo body. The data show that this level of PCBs produced a maximal induction of BPM activity In the late embryonic period. Since a maximal induction was observed at all the doses an $E D_{50}$ cannot be estimated and the sensitivity of the induction response in these Fundulus eleuthe roembryos remains a question. Both the relative and absolute extent of maximal induction are higher in this experiment compared to Experiment 1. However, the exposure here was for 21 days rather than 12 days and the embryos were older and in later stages.

HPLC :

The resolution of $\mathrm{BP}$ metabolites produced by microsomes from whole PCB exposed eleutheroembryos, is shown in Figure 4-8. The relative 
Figure 4-7. Experiment 3 results; microsomal BPM activity in fractions prepared from whole eleutheroembryos exposed to varying levels of PCBs (exposure to PCBs shown in Figure 4-6). The activity is plotted versus the levels of PCBs in the whole eleutheroembryos at the time of assay. The point at zero ppm PCBs corresponds to the control group which was not exposed; the background levels of PCBs in embryos was not determined. A total of 15 embryos from each of the exposure groups was assayed at 24 days of age in stages 38-39. The mean hatching time for all groups was 22 days. The data plotted are the mean of 3 replicates $\pm S . D$. 


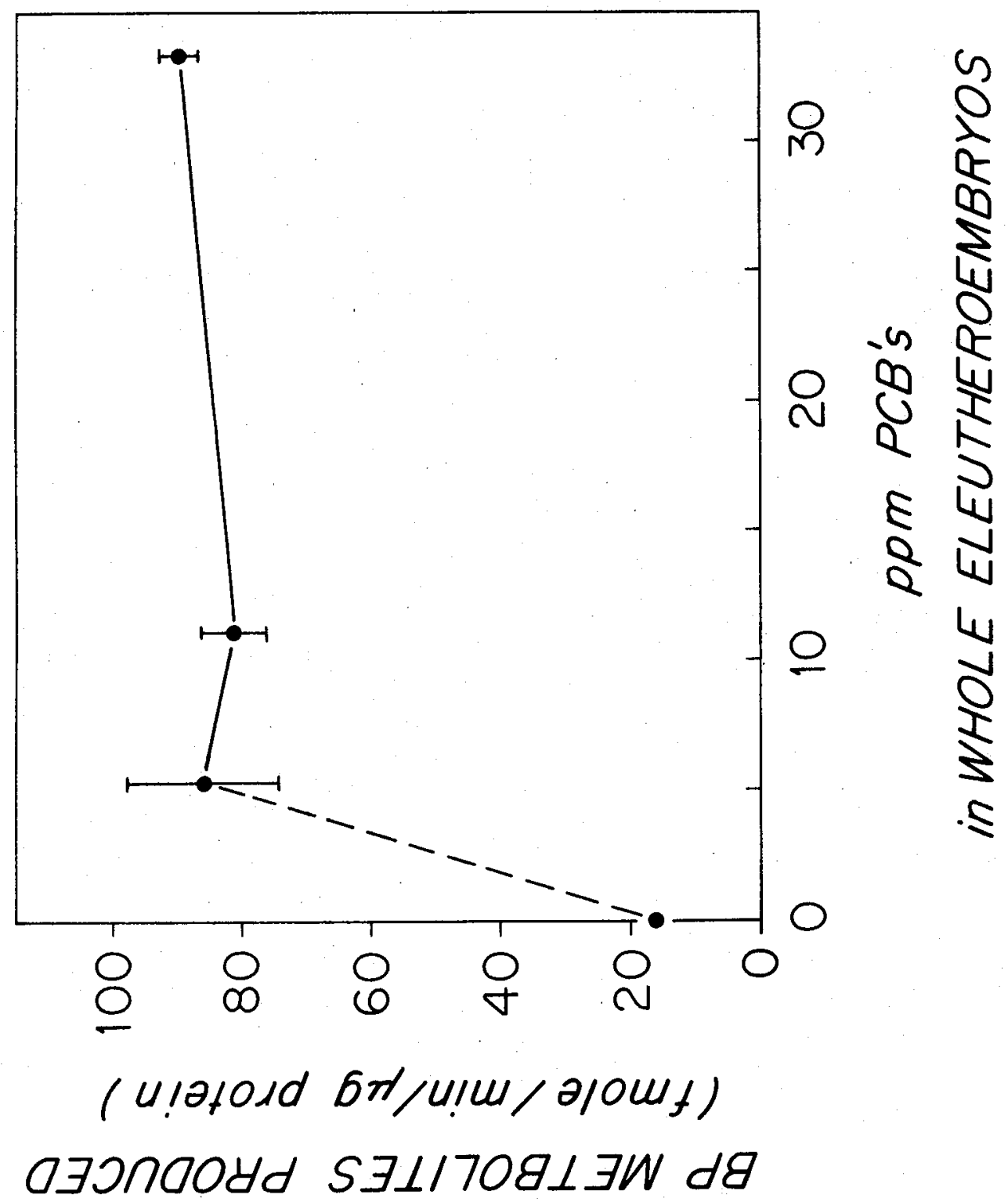


Figure 4-8. HPLC elution profile of benzo(a)pyrene metabolites produced by microsomes from PCB treated Fundulus eleutheroembryos. The procedure is described in Materials and Methods; the microsomes used were a mixture of the preparations from exposure groups 7 and 8 described in Figure 4-1. The data were corrected for background oxidation products present in the substrate by subtraction of the radioactivity in the analysis of a ze ro time blank. A total of about 50 pmole of metabolites were injected. The BP peak was at $550 \times 10^{3} \mathrm{dpm} / \mathrm{m} 1$, and less than $4 \%$ of the $B P$ in the reaction mixture was metabolized. The abbreviations are diol= dihydrodiol, $Q=$ quinone, and $\mathrm{OH}=$ hyd roxy. 


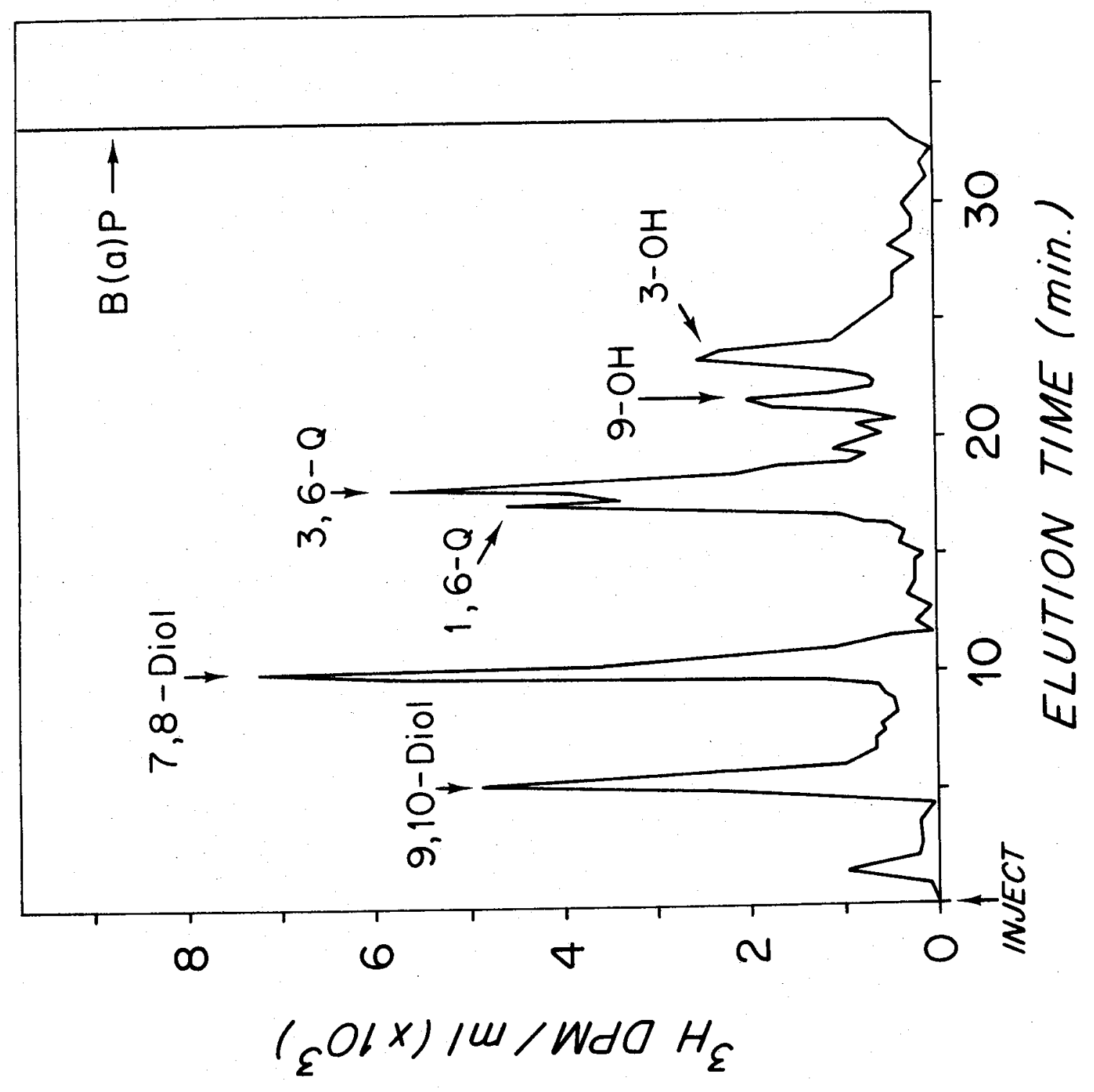


amounts of the various metabolites are shown in Table 4-IV, along with comparative data on the proportion of metabolites produced by adult Fundulus hepatic microsomes. The principal metabolites produced by eleuthe roembryo microsomes were dihydrodiols and quinones; peaks coeluting with 9- and 3-hydroxy-BP standards were also present. The benzo-ring dihydroxy metabolites, trans-7,8- and trans-9,10-dihydrodiol-BP, comprised more than $40 \%$ of the total metabolites, and no trans-4,5-dihydrod101-BP was detectable. The Identity of the hydroxy metabolites is not certain as phenols other than the standards used elute in this region (Tjessum and Stegeman, 1979). The small peak eluting before the diols may correspond to mult 1-hydroxylated metabolites, based on preliminary mass spectral analysis of adult fish metabolites eluting in this region (Stegeman, 1981a).

Metabolites produced by microsomes from untreated eleutheroembryos were also analyzed by HPLC, but in these first attempts with preparations of low activity, the resolution was not as good as seen in Figure 4-8, because of high background counts (data not shown). The microsomes from untreated eleutheroembryos did produce a spectrum of metabolites similar to that produced by the preparation from PCB treated eleutheroembryos, with a high proportion of dihydrodiol metabolites and lesser amounts of quinones and phenols. Whether the microsomes from untreated eleutheroembryos produced any trans-4,5-dihydrodiol could not be determined from the chromatogram obtalned. The production of dihydrodiol metabolites by microsomes from both untreated and PCB-exposed 
Table 4-IV. Relative amounts of benzo(a)pyrene metabolites produced by microsomes prepared from adult Fundulus liver and whole PCB exposed eleutheroembryos.

\begin{tabular}{lcc}
\hline & Percent of Total* \\
& & \\
\cline { 2 - 3 } Metabolite & Eleutheroembryos & Adult Liver \\
\hline 9,10 Dihydrodiol & 21 & 19 \\
4,5 Dihydrodiol & N.D. ${ }^{+}$ & N.D. \\
7,8 Dihydrodiol & 24 & 20 \\
1,6 Quinone & 11 & 12 \\
3,6 Quinone & 23 & 15 \\
$9-$ Hydroxy & 7 & 5 \\
$3-$ Hydroxy & 14 & 29 \\
\hline
\end{tabular}

* Calculated as the percent of the total radioactivity eluting in these peaks. The eleutheroembryo data are from the chromatogram shown in Fig. 4-8. The overall rates of production of metabolites for the eleutheroembryo and adult liver microsomes were 53 and 314 $\mathrm{pmole} / \mathrm{min} / \mathrm{mg}$ protein, respectively. These values were calculated based on an estimated extraction efficiency of $50 \%$.

+ N.D. = not detectable. 
eleutheroembryos indicates that the enzyme epoxide hydrolase is present in these preparations ( $Y a n g$ et al., 197.8). This was confirmed by including the epoxide hydrolase inhibitor trichloropropylene oxide (TCPO) (Selki.rk et al., 1974) in a BP metabolite reaction mixture. TCPO abolished the diol peaks produced by microsomes from untreated eleutheroembryos (data not shown). From Table:4-IV it can be seen that the spectrum of BP metabolites produced by adult hepatic microsomes is very simflar to that produced by the microsomes from PCB exposed eleutheroembryos. The adults produced somewhat more material eluting with the 3-hydroxy standard and less of the 3,6-quinone. These results indicate the catalytic similarity of the forms of cytochrome $P-450$ responsible for BP metabolism in Fundulus adults and eleutheroembryos.

\section{DISCUSSION}

The data presented in this chapter clearly show that BPM activity in Fundulus eleutheroembryos is maximally induced at lower doses of PCBs than those required for maximal induction in embryos (Figures 4-2, 4-3 and 4-7). When embryos and eleutheroembryos were similarly exposed to Aroclor 1254 for 12 days, a dose-dependent induction of BPM activity was observed in microsomes prepared from whole embryos (stages 33-34), but $B P M$ activity was near maximally induced $(2.7 x)$ at all dose levels in the preparations from eleutheroembryos (Figures 4-2 and 4-3). Maximal induction of BPM activity in eleutheroembryos occurred at lower tissue (body) levels of PCBs than required in embryos (Fig. 4-3). Thus the 
difference in the response of embryos and eleutheroembryos was not simply due to a change in the distribution of PCBs with yolk absorption. Although the dose-dependency for the induction of BPM activity in eleutheroembryos must be established before the real sensitivity is known, the data obtained indicate that eleutheroembryos in stages 36-38 are at least 5-times more sensitive to PCBs than embryos in stages $33-34$. Although constitutive BPM activity was low before hatching, the maximal extent of induction was 27-fold, and the maximal induced specific activity was the same in microsomes prepared from both embryos and eleutheroembryos (Fig. 4-3). Thus the low activities measured in embryos are not due to a lack of capacity to respond to induction. These results also indicate that endogenous inhibitors of the monooxygenase activity are not present in embryos, consistent with the data from the mixing experiment described in Chapter 3 (Table 3-III). The results obtained here also confirm that there is no difference in the distribution of BPM activity in the centrifugal fractions of embryos and eleutheroembryos (Fig. 4-4).

Several factors could be responsible for the increase in to higher sensitivity of the induction response after hatching. One possibility is that the most active inducers are metabolites of the PCBs, and that the increased constitutive monooxygenase activity after hatching leads concentrations of these particularly active inducers within responsive tissues. However, there is no evidence that PCBs require metabolism for activity as inducers, and some of the most active inducers are likely to be metabolized very slowly (Goldstein et al., 1977; Parkinson et al., 
1980; Poland and Glover, 1977). Another possibllity is suggested by the results of Guenthner and Mannering (19/7a and 1977b). They reported evidence that in rats a repressor of maternal origin blocks the response of fetal liver to phenobarbital. Shortly after parturition the neonatal liver is normally responsive to $\mathrm{PB}$. Perhaps an endogenous repressor produces a similar effect on the response of Fundulus embryos to PCBs prior to hatching.

Another interesting difference between the response of embryos and eleuthe roembryos to Aroclor 1254, is that neither NADPH- or NADH-cytochrome c reductase activities were induced in embryos, but both of these activities were Induced in eleutheroembryos (Fig. 4-2 and text). The dose response for induction of NADPH-cytochrome $c$ reductase activity in eleutheroembryo microsomes was clearly distinct from that of BPM activity (Fig. 4-2). The induction of the reductase activity was dose dependent, while BPM activity was maximally induced at all dose levels of Aroclor 1254. These results indicate that the reductase and BPM activity are under independent control. This conclusion is also supported by the fact that the time courses for the increases in BPM activity and $\mathrm{NADPH}-\mathrm{cytoch}$ rome $\mathrm{c}$ reductase activity are distinct in unt reated animals after hatching (Fig. 3-4). In Chapter 3 it was pointed out that the increase in monooxygenase activity in untreated Fundulus embryos after hatching was like that seen postnatally in mammalian species, although hatching and birth are physiologically quite different. It is interesting to note that in rabbits, rats and guinea pigs, NADPH-cytochrome c reductase activity is either not inducible in 
fetal liver by $P B$ or inducible only shortly before birth, but $P B$ readily induces this activity in the livers of neonates and adults (Cresteil et a1., 1979; Guenthner and Mannering, 1977a; Kuenzig et al., 1974; Rane et al., 1973). These results further suggest the similarity of the effects of birth in mammals and hatching in Fundulus on the regulation of the monooxygenase system.

The fact that BPM activity was induced almost 30 -fold in whole embryo microsomes with no change in NADPH-cytochrome c reductase activity indicates that the levels of NADPH-cytochrome $c$ reductase are not limiting monooxygenase activity in these preparations (Fig. 4-2). In further support of this conclusion, the ratio of NADPH-cytochrome $c$ reductase activity to $B P M$ activity in maximally induced whole embryo microsomes is still 3-fold higher than in adult liver microsomes (compare Fig. 4-2 and Table 3-IX). Also, maximal induction of BPM activity in eleutheroembryo microsomes occurs at levels of PCBs that do not induce detectable increases in NADPH-cytochrome $c$ reductase activity. It is worth noting again that, although the levels of NADPH-cytochrome $c$ reductase activity generally have not correlated with the levels of $B P M$ activity, the inhibition by cytochrome c (Table 3-IV) quite clearly indicates a functional role for this reductase in supporting monooxygenase activity. Substantial induction of monooxygenase activity with little change in $\mathrm{NADPH}$-cytochrome $c$ reductase activity is not unusual, and in fact is typical of the response to 3-MC type inducers in mamals. In mammals induced monooxygenase activity is due to the induction of specific forms of cytochrome P-450. The induction of BPM 
activity in Fundulus embryos and eleutheroembryos is also likely to be assoclated with an Induction of form(s) cytochrome P-450. This conclusion is supported by the fact that BPM activity was maximally induced by levels of PCBs that had little or no effect on aminopyrine demethylase activity (Fig- 4-2B). These data suggest that the increased BPM activity is associated with an induction of a form or forms of cytochrome $\mathrm{P}-450$ active in aromatic hydroxylation, while those forms responsible for aminopyrine $\mathrm{N}$-demethylation remain unchanged.

Several species of fish apparently can not respond to $\mathrm{PB}-t y p e$ Inducers, and it may be the case that fish in general lack competence to respond to this class of inducers (Add1son et a1., 1977; Balk et al., 1980; Bend et al., 1973; Forlin, 1980; Elcombe and Lech, 1979; Hanson et a1., 1980; James and Bend, 1978). Aroclor 1254 is a mixed inducer in rats about equipotent as $\mathrm{a} P B$ and 3-MC type inducer (Goldstein et al., 1977). The lack of any substantial induction of APD activity in Fundulus eleutheroembryos by Aroclor is consistent with a lack of PB-type response, since $\mathrm{APD}$ and other activities are characteristically induced in mammalian liver by PB (Conney, 1967; Lu et al., 1976; Alvares and Kappas, 1977). NADPH-cytochrome c reductase activity is also characteristically induced by $P B$ in mammalian 1iver, and little affected by 3-MC type inducers (Alvares and Kappas, 1977). However, as noted in the introduction, 3-MC type compounds induce NADPH-cytochrome c reductase activity in some species of fish including Fundulus (Stegeman, 1979). In spite of the above, there was a suggestion of an induction of 
APD activity in eleutheroembryo microsomes at the highest levels of PCBs used (Fig. 4-2B). Perhaps Fundulus are capable of responding to PCB isomers that are $\mathrm{PB}$ type inducers, but only at very high doses. Another possibility is that a minor component of Aroclor 1254 is capable of inducing APD activity in Fundulus eleutheroembryos, and this substance may or may not be a PB type inducer in mamals: Along these lines, James and Bend (1978) made the very interesting observation that $3,3^{\prime}, 4^{\prime}, 4^{\prime}, 5,5^{\prime}$-hexachlorobiphen 1 (HCB) nominally a 3-MC-type inducer, produced an induction response in sheepshead that was very different from the response produced by $3-M C$. Administration of $3-M C$ to sheepshead did not affect benzphetamine $N$-demethylase (BeND) activity, and induced BPM activity that was inhibited by $\alpha$-napthoflavone (ANF). Aroclor 1254 produced a response similar to $3-\mathrm{MC}$. In contrast, $3,3^{\prime}, 4^{\prime}, 4^{\prime}, 5^{\prime}, 5^{\prime}-\mathrm{HCB}$ induced hepatic BeND and NADPH-cytochrome $c$ reductase activities, as well as BPM activity that was not inhibited by ANF. This type of response is generally associated with the PB class of inducers. However, $2,2^{\prime}, 4,4^{\prime}, 5,5^{\prime}$-hexabromobiphenyl had no effect on any of these activities, even though it is a $\mathrm{PB}$-type inducer in rats. It should be noted that $3,3^{\prime}, 4,4^{\prime}, 5,5^{\prime}-\mathrm{HCB}$ apparently has not been detected in Aroclor 1254 or similar European PCB mixtures, and the related congener $3,3^{\prime}, 4^{\prime} 4^{\prime}$-tetrachlorobiphenyl is a minor component of commercial PCBs (Jensen and Sundstrom, 1974; Sissons and Welti, 1971). Some fish may have an induction response that resembles the $P B-t y p e$, but that is not elicited by $\mathrm{PB}$-type compounds. It will be of great interest to examine the response of Fundulus eleutheroembryos to $3,3^{\prime}, 4^{\prime}, 4^{\prime}, 5,5^{\prime}-\mathrm{HCB}$ and to 
determine whether higher doses of Aroclor 1254 do in fact Induce APD activity.

Induction competence in embryos prior to the appearance of the 11ver rudiment :

The data of Experiment 2, presented in Figure 4-5, clearly show that embryos as early as 4.4 days from fertilization (stages 26-27) are competent to respond to Aroclor 1254 exposure with increased leve1s of BPM activity. The response of the stage 26-27 embryos was very much like that of simarly exposed stage 33-34 embryos (13 days old), which suggests that all competent stages prior to hatching are similarly sensitive to PCBs. Comparison of the response of the stage 33-34 embryos of Experiments 1 and 2 (Figures 4-2 and 4-5) 1ndicate that the level of induced BPM activity depends on the length of exposure as well as the average concentration of PCBs in the embryos.

Examination of thin sections of Fundulus embryos by light microscopy revealed that the liver rudiment appears between stages 28 to 29. The refore, the induction response in stage 26-27 embryos is due solely to the extrahepatic tissues. This may be the earliest point during the development of a vertebrate species in which induction of monooxygenase activity has been directly demonstrated. Apparently, there are no reports in the literature of the induction of monooxygenase activity in embryos before the appearance of the liver rudiment. However, Galloway et al. (1980) reported indirect evidence that mouse embryos as early as day $71 / 2$ of gestation can respond to 3-MC-type 
Inducers. Briefly, they observed an increased Incidence of sister chromatic exchanges (SCE) in embryos of responsive strains of mice cultured in the presence of BP, but not in embryos of strains genetically nonresponsive to 3-MC-type inducers. These results were interpreted as indicating that the responsive strain embryos have the capacity to activate $\mathrm{BP}$, and that this capacity is induced. (These experiments are described in more detail in Chapter 1, p. 53) A direct comparison of the development of Fundulus and mice is difficult with the data available, but the day $71 / 2$ of gestation in mice is about equivalent to the 3 rd day of development in Fundulus.

Quite possibly Fundulus embryos are competent to respond to monooxygenase inducers earlier than stages 26-27. BPM activity was detectable in untreated embryos at stages 25-26 (Table 3-II). It seems likely that these stages will also be found to be competent. Examination of induction competence in earlier stages will require a different approach than that taken in Experiment 2. There are limits to how quickly embryos can be loaded with PCBs by exposure after fertilization. To examine Induction competence in earlier stages, eggs will have to be loaded with inducer in the ovary by maternal exposure. This approach was attempted. Female Fundulus, naturally in spawning condition were stripped of eggs, then intraperitoneally injected with about $180 \mathrm{mg} / \mathrm{kg}$ $\left[{ }^{14} \mathrm{C}\right]-1 \mathrm{abelled} \mathrm{PCBs}$. The fish were maintained under conditions to promote further egg production, and eggs were obtained from some fish with about $100 \mathrm{ppm}$ PCBs. However, the $\mathrm{f}$. $\mathrm{sh}$ produced an inadequate number of eggs to examine the question of when induction competence appears. 
Yet this approach should be useful for future studies of induction competence in early embryos.

Factors affecting the induction of BPM activity in embryos and eleutheroembryos:

To further compare the response of pre-hátching and post-hatching stages to Aroclor 1254, data from Experiment 1 embryos (stages 33-34) and Experiment 3 eleutheroembryos (stages 38-39) were compiled in Table 4-V. The exposures were not equivalent since the embryos were exposed to PCBs for 12 days (Fig. 4-1) and the eleutheroembryos were exposed for 21 days (Fig. 4-6). However, this is more like the situation encountered under "natural" conditions, when eggs are spawned from PCB contaminated fish. In contaminated environments, embryos are likely to contain substantial levels of PCBs continuously over the course of development.

In Experiment 3 a maximal induction of BPM activity in eleutheroembryo microsomes was observed at the lowest dose. level of PCBs used (Fig. 4-7), thus the actual sensitivity of the eleutheroembryos to PCBs was not established. From the data in Table 4-V, it is seen that the stage 38-39 eleutheroembryos were maximally induced by levels of PCBs in the tissues that were $1 / 10$ as great as necessary for maximal induction in the stage 33-34 embryos. In terms of the levels of PCBs calculated for intact embryos and eleutheroembryos, the eleutheroembryos were maximally induced by $P C B$ concentrations not more than $1 / 26$ those required for maximal induction in embryos. The difference in the relative sensitivity indicated by these two measures of $\mathrm{PCB}$ content is due to the 
Table 4-V. A compilation of data on the sensitivity of Fundulus embryos and eleutheroembryos to Aroclor 1254 as an inducer of BPM activity.*

\begin{tabular}{|c|c|c|}
\hline & $\begin{array}{c}\text { Embryos } \\
\text { (stages 33-34) }\end{array}$ & $\begin{array}{l}\text { Eleuthe roembryos } \\
\text { (stages 38-39) }\end{array}$ \\
\hline $\mathrm{ED}_{50}$ in ppm Aroclor 1254 & & \\
\hline Int act & 45 & -- \\
\hline Tissues & 13 & -- \\
\hline $\begin{array}{l}\text { Lowest dose at which } \\
\text { maximal induction observed } \\
\text { (ppm Aroclor 1254) }\end{array}$ & & \\
\hline Int act & 140 & 5.3 \\
\hline Tissues & 35 & 3.5 \\
\hline
\end{tabular}

* Data are from Experiments 1 and 3. The terms "intact" and "tissues" are defined in Table 4-I. The values for eleutheroembryos were the lowest levels of Aroclor 1254 used; these stages may be even more sensitive. The concentrations of Aroclor 1254 are on a wet weight basis, and background levels of PCBs in embryos and eleutheroembryos were not measured. 
fact that in eleutheroembryos proportionately more of the total burden of PCBs was located in the tissues, compared to the distribution in the embryos (compare Tables 4-I, 4-II, 4-III and Results text, Experiment 3). Thus in addition to the increased sensitivity of the induction response after hatching, pharmacokinetic effects will favor a response at lower total burdens of PCBs in later stage eleutheroembryos than in embryos.

There are at least four factors which will affect the level of Induced BPM activity in Fundulus embryos and eleutheroembryos exposed to PCBs. These are the total burden of PCBs, the length of exposure, the developmental stage (pre- or post-hatching) and the distribution of PCBs between the yolk and tissues. Under conditions of continuous exposure, these factors will result in an increase in the level of induced activity as development proceeds. When the concentrations of PCBs present are adequate to produce only a slight induction before hatching, the greatest change in induced activity will occur after hatching, when the sensitivity of the induction response greatly increases.

Comparison of the induction response to other species:

The available data on the sensitivity of Fundulus early developmental stages in summarized in Table 4-V. In chickens, the only other spectes examined at embryonic stages, Aroclor 1254 is not a very potent inducer of hepatic BPM activity. The $E D_{50}$ for the whole chicken embryo with yolk is about $130 \mathrm{ppm}$, or about 3-times higher than in Fundulus embryos (Poland and Glover, 1977). 
Apparently rainbow trout is the only species of fish in which dose response data for the PCB induction of henzo(a)pyrene metabolism have been reported. Elcombe and Lech (1978) examined the response of hepatic BPM activity to int raperitoneal doses of Aroclor 1242. This PCB mixture contains $42 \%$ chlorine by weight and is of simflar potency as Aroclor 1254 as an inducer of monooxygenase activities in rats (Ecobichon and Comeau, 1974). In adult trout the level of induced BPM activity increased fairly steadily up to $275 \mathrm{mg} / \mathrm{kg}$, which was the highest dose examined. The lowest dose used, $32 \mathrm{mg} / \mathrm{kg}$, produced a clear induction of BPM activity. If these doses were uniformly distributed in the treated animals, which is not at all $11 \mathrm{kely}, 1 \mathrm{mg} / \mathrm{kg}$ would be equivalent to $1 \mathrm{ppm}$ in the whole body. Comparison of the data of Elcombe and Lech to that obtained with Fundulus (Table $4-\mathrm{V}$ ), suggest that Fundulus eleutheroembryos are much more sensitive to PCBs as inducers than adult trout. Maximal induction of BPM activity was produced by $3.4 \mathrm{ppm}$ Aroclor 1254 in the eleutheroembryo body. However, a number of factors make direct comparison of these data difficult. First of all, different PCB mixtures were used (Aroclors 1242 and 1254). The tissue distribution of PCBs administered by $1 . p$. injection may be very different from that resulting from uptake during the course of development. Final1y, microsomes were prepared from whole eleutheroembryos compared to hepatic microsomes from the trout.

Egaas and Varanasi (1980) examined the effect of preexposure of rainbow trout to Aroclor 1254, on the in vitro binding of BP to DNA catalyzed by liver enzyme preparations. Feeding trout a dose of $10 \mathrm{mg} / \mathrm{kg}$ 
Aroclor 1254 resulted in a 20-fold increase in DNA binding, and higher doses did not produce a further increase. A dose of $1 \mathrm{mg} / \mathrm{kg}$ did not significantly affect the level of DNA binding. Apparently the BPM activity responsible for the binding of BP to DNA was maximally induced by $10 \mathrm{mg} / \mathrm{kg}$ Aroclor 1254 . This result suggests that trout are sensitive to fairly low levels of PCBs. The different roites of administration used by Elcombe and Lech (1978) and Egaas and Varanasi (1980) (oral versus $i \cdot p \cdot)$ are likely to be partially responsible for the great differences in the response to PCBs observed in these studies. Possibly the sensitivity of rainbow trout to Aroclor 1254 as an inducer of BPM activity is of the same order of magnitude as that of Fundulus eleutheroembryos. However, Fundulus eleutheroembryos may yet prove to be much more sensitive to PCBs, once the dose dependency is established.

\section{Envi ronmental levels of PCBs:}

PCBs are ubiquitous contaminants of the global environment (Risebrough et al.,1972; Nisbet and Sarofim, 1972; Wassermann et al., 1979). In the past commercial PCB mixtures were widely used for a number of applications in industry such as dielectric fluids in capacitors, heat exchange fluids and plasticlzers. The U.S. production between 1957 and 1975 was about 400,000 tons (Iloyd et al., 1976). During the early 1970 's about 18,000 tons per year were produced in the U.S. of which 4,500 tons per year are estimated to have been released into the environment (Maugh, 1975). Production in the United states was stopped in 1977. PCBs are very stable and thus persistent in the environment, 
and because they are lipophilic they are readily accumulated by organisms. The higher chlorinated iscaars are only very slowly metabolized and eliminated (Bickel and Muehlebach, 1980).

Table 4-VI shows levels of PCBs in fish collected at different locations. The data were selected to give an idea of the range of concentrations encountered. Generally, fish from lakes and rivers in industrlalized a reas are most heavily contaminated, but PCBs are detected in fish remote from human activities, such as in the deep sea. In composite samples of fish collected from major freshwater systems in the U.S., PCBs were detectable in $93 \%$ of the samples, and $53 \%$ of the samples were in excess of $5 \mathrm{ppm}$ (Veith et al., 1979). As part of a National Pesticide Monitoring Program composite samples of juvenile estuarine fish of mixed spectes were analyzed for $\mathrm{PCB}$ content (Butler and Schutzmann, 1978). The data were reported as state-wide averages. For east coast states, the values ranged from $0.083 \mathrm{ppm}$ (F1orida) to $0.780 \mathrm{ppm}$ (Delaware), and the overall mean was $0.343 \mathrm{ppm}$. These values are expressed on a wet weight basis for whole fish using Aroclors 1242, 1254, and 1260 as standards.

Fundulus heteroclitus occur in estuarine envi ronments from Florida to Maine (Bigelow and Schroeder, 1953), and thus are found in areas remote from contamination as well as in areas heavily affected by urban and Industrial pollution. The $E_{50}$ for induction of $B P M$ activity in stage 33-34 Fundulus embryos is about 45 ppm Aroclor 1254 in the whole embryo (Table 4-V). From the dose response curve in Fig. 4-2A, it can be estimated that concentrations of $\mathrm{PCBs}$ as $1 \mathrm{ow}$ as $10 \mathrm{ppm}$ in the whole 


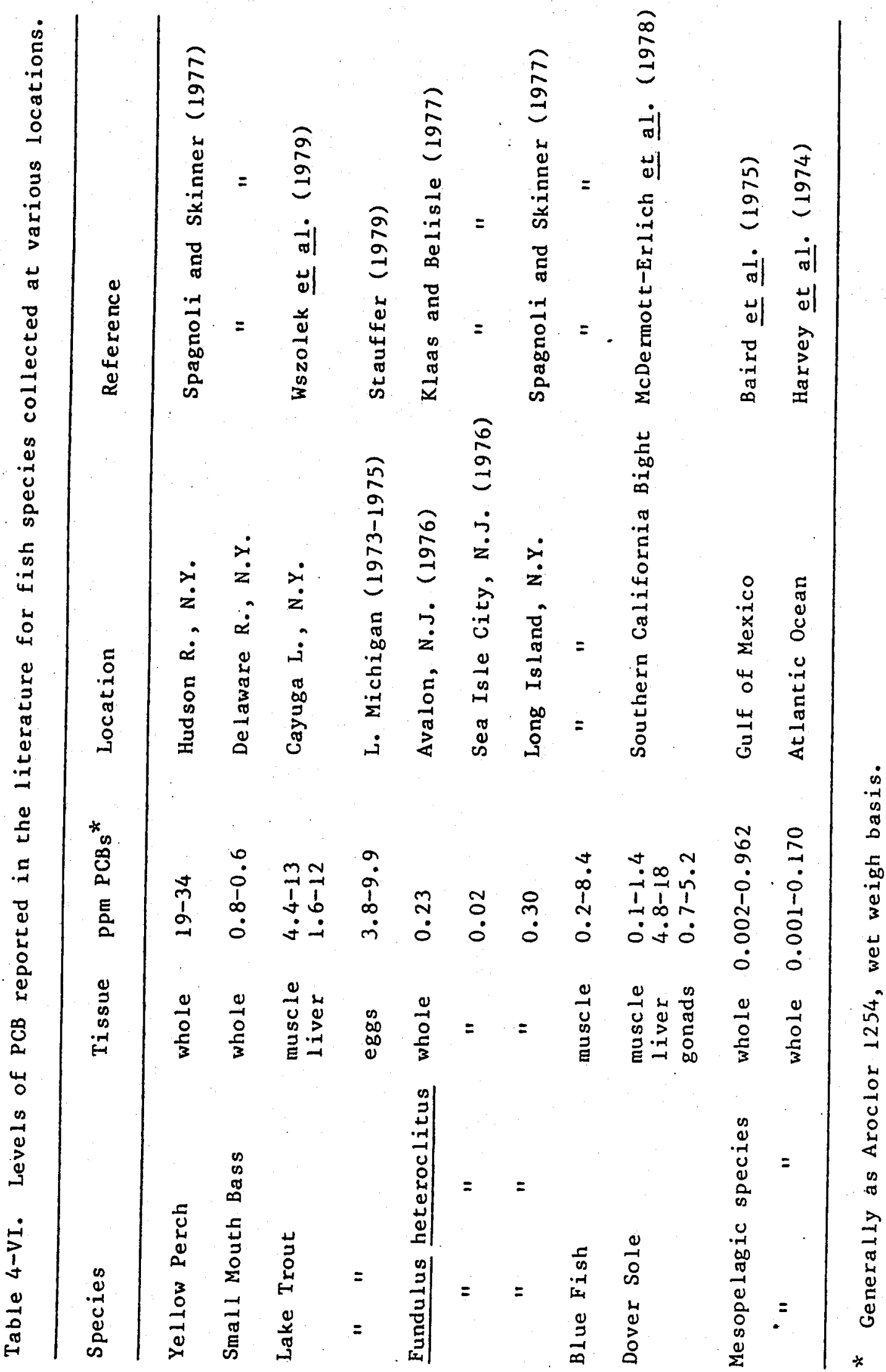


embryo will produce about a 4-fold induction of BPM activity. It should also be remembered that No. 2 fuel oi: was shown to induce BPM activity in Fundulus embryos (Table 2-I). In contaminated envi ronments a number of different substances could potentlally contribute to an induction of monooxygenase activity. Values for PCB levels in Fundulus eggs are not yet avallable, and the relationship between the levels in spawned eggs and whole adult fish is not known. But the average PCB levels in estuarine fish mentioned above, and values appearing in Table 4-VI give an Indication of the concentrations of $\mathrm{PCBs}$ found in environmental samples.

Considering the relative insensitivity of Fundulus embryos to PCBs, and probably other monooxygenase inducers, substantial inductions in embryos are likely to occur only at particularly polluted sites. Based on the observation of maximal induction at about 5 ppm Aroclor 1254 in whole eleutheroembryos, and about $3.4 \mathrm{ppm}$ in the tissues (Table $4-\mathrm{V}$ and Fig. 4-7), it seems reasonable to assume that levels of PCBs less than 1 ppm in whole eleutheroembryos and approaching $0.5 \mathrm{ppm}$ in the tissues would produce a detectable induction of BPM activity. Thus, in heavily contaminated environments Fundulus eleutheroembryos are 1ikely to have maximally induced monooxygenase systems, and some degree of induction is likely at levels of moderate contamination at many locations. An important question is just how sensitive are Fundulus eleutheroembryos to the inducing properties of PCBs. In Chapter 1 data was described which suggests that individuals of some species of fish, and perhaps all members of certain other species of $f i s h$, have monooxygenase systems that 
are partially induced. Considering the results obtained with Fundulus, this may well be the case.

In microsomes prepared from untreated Fundulus embryos a greater than 10-fold increase in BPM activity is observed shortly after hatching (F1g. 3-4). It is interesting that this increase in constitutive activity correlates with the large increase in sensitivity of the Induction response after hatching. As noted in Chapter 3, it seems reasonable to hypothesize that the levels of constitutive monooxygenase activity around the time of hatching are under hormonal control. However, it is also possible that the background levels of PCBs or other xenobiotics in untreated embryos, which do not have much effect on the relatively insensitive stages prior to hatching, are responsible for the post-hatching increase in BPM activity. This possibility can not be ruled out since the dose-dependency of the post-hatching induction response was not established, and the background levels of PCBs and other xenoblotics in embryos were not determined. However, the post-hatching changes in the monooxygenase system of untreated embryos and the PCB induced changes are somewhat different. In untreated embryos both BPM activity and NADPH-cytochrome c reductase activity increase after hatching, while $\mathrm{NADH}-\mathrm{cyt}$ och rome $\mathrm{c}$ reductase activity remains unchanged (Figures 3-3 and 3-4). In $\mathrm{PCB}$ exposed embryos, both $\mathrm{NADH}-$ and NADPH-cytochrome $c$ reductases are induced to the same extent, but only at concentrations of PCBs much greater than required to maximally induce BPM activity (Fig. 4-2 and text). Under conditions in which BPM activity is submaximally induced, the re probably would be no change in either 
reductase activity. These results suggest that the post-hatching changes in the monooxygenase system of untreatea embryos are not due solely to a xenobiotic-type induction.

The levels of BPM activity, measured in microsomes prepared from untreated eleutheroembryos from several different pools of eggs, were quite similar (Figure 3-3). These pools of eggs were obtained from fish collected during two different spawning seasons, at different sites in Herring Brook marsh, and in one case eggs were obtained from fish which had been aquarium maintained for more than 10 months (Table 3-2). If the post-hatching increases in BPM activity were due to xenobiotic-type Induction, one would expect graded responses depending on the levels of inducers present, since the activities measured clearly were not at the maximally induced level. It seems unlikely that long term aquarium maintalned fish produced eggs with essentially the same levels of xenoblotic 1nducers as the f1sh collected in the field. Thus it seems unlikely that xenobiotics present in the embryos are responsible for the majority of the post-hatching increase in BPM activity. To determine if there is a contribution from xenobiotic-type induction to the post-hatching increase in BPM activity, the sensitivity of the induction response in eleutheroembryos must be established in conjunction with measurements of residues of selected xenobiotics. Also, following the post-hatching development of aminopyrine $\mathrm{N}$-demethylase activity, which is not Induced by moderate levels of PCBs, would be valuable. Large post-hatching increases in APD activity would be strong evidence that xenobiotics are not involved in the increases in monooxygenase activity after the hatching in untreated embryos. 
Possible significance of the presence and inducibility of xenobiotic monooxygenase activity in Fundulus embryos and eleutheroembryos:

The spectra of BP metabolites produced by microsomes prepared from untreated and $P C B$ exposed eleutheroembryos and adult Fundulus 1iver (Fig. 4-8, Table 4-III, and text) are typical for marine teleost fish with a high proportion of benzo-ring metabolites (Stegeman, 1981b). This type of metabolite spectrum resembles those produced by 3 -MC induced mammals (Thorgiersson and Nebert, 1977). The production of diol metabolites by eleutheroembryo microsomes was shown to depend on the enzyme epoxide hydrolase (EH), as the EH inhibitor TCPO abolished these peaks. The fact that microsomes prepared from Fundulus eleutheroembryos are active in metabolizing the benzo-ring of benzo(a)pyrene and have epoxide hydrolase activity, suggests that they are capable of activating $B P$ to the highly mutagenic 7,8-dihydrodiol-9,10-epoxides, which are likely to be the ultimate carcinogenic forms of BP. Populations of Fundulus in contaminated enviromments might be at risk of initiation of.cancer from $B P$ and related polycyclic aromatic hydrocarbons ( $P A H$ ) during the sensitive embryonic stages.

BPM activity was detectable in untreated Fundulus embryos as early as stages 25-26, at about 4 days from fertilization (Table 3-III), and Fundulus embryos were shown to be competent to respond to PCB induction of BPM activity at stages 26-27 (Fig. 4-5). Circulation of blood begins in stage 25 , and subsequent stages are characterized by active organogenesis. Organs and structures which have yet to appear at stages 25-26 include the liver, gall bladder, swim bladder, gills and jaws. $B P$ 
and certain other PAH's are not only carcinogens but also teratogens (Lambert and Nebert, 1977; Shum et a1., 1979). Production of activated metabolites from BP or other xenobiotics during the period of active organogenesis could lead to malformations. Induction of monooxygenase activity by PCBs or other inducers might increase the risk of teratogenes1s. Shum et al. (1979) have demonstrated that when pregnant mice are dosed with $\mathrm{BP}$, the genetic capacity of fetuses to respond to 3-MC-type inducers is associated with increased in utero toxicity and malformations. Considering the potential deleterious effects of Induction of monooxygenase activity during organogenesis, the relative insensitivity of Fundulus embryos to monooxygenase inducers seems to be very adaptive. During the most critical stages of development, prior to hatching, very high levels of inducer are necessary to produce a response (Fig. 4-2A). After hatching when the potential exposure to xenoblotics 1s considerably greater (discussed in Chapter 3 ), and the need to metabolize and eliminate xenobiotics is likely to be more important, monooxygenase activity is stimulated by much lower levels of inducer. This regulatory system may have evolved to protect developing Fundulus from the toxicity of naturally occurring xenobiotics. 
CHAPTER 5

HEPATIC BENZO(A) PYRENE MONOOXYGENASE ACTIVITY IN BROOK TROUT (SALVELINUS FONTINALIS) EMBRYOS: CONSTITUTIVE LEVELS AND INDUCTION BY PCBs

In the previous three chapters various aspects of the ontogeny of the xenobiotic monooxygenase system in the killifish Fundulus heteroclitus were examined. Using microsomes prepared from whole embryos, BPM activity was shown to be present fairly early during embryonic development and was found to increase sharply within 24 hours of hatching. This activity was inducible both before and after hatching, and the induction after hatching was shown to occur in both the liver and extrahepatic tissues. The sensitivity of the induction response was shown to be much greater in eleutheroembryos than embryos.

A basic question which arises from these observations is whether embryos of other species of $f$ ish have the capacity to metabolize xenobiotics and to respond to inducers of cytochrome $\mathrm{P}-450$. In this chapter work addressing this question is presented. The capacity of untreated and PCB exposed brook trout embryos to metabolize benzo(a)pyrene is examined, and levels of activity are compared to those in yearling brook trout. The results obtained are contrasted to the observations on Fundulus. 
MATERIALS AND METHODS

\section{Chemicals and Supplies:}

All chemicals and supplies were as described in the previous chapters.

Anima ls:

Brook trout (Salvelinus fontinalis) embryos were obtained by standard techniques at the Sandwich Fish Hatchery, Massachusetts Division of Fisheries and Game, during the natural spawning season in November, 1979. The embryos were from two different pools of eggs. Pool I was a very large pool of eggs stripped from about 30 females and fertilized with milt from about 10 males; most of these were used to replenish the hatchery stock. Pool II, obtained two weeks later, was stripped from 4 females and fertilized with milt from 4 males. Embryos were maintained at the hatchery in flowing spring water at $10^{\circ}$ for varying periods, then brought back to the laboratory and incubated in the same water in glass dishes at $10^{\circ}$. In the laboratory, water was changed daily and any dead embryos were removed at frequent intervals. Embryos were not treated with any of the antimicrobial agents normally used at the hatchery. Brook trout yearlings were obtained from the hatchery at the same time as the embryos. Hepatic microsomes from these fish were used to establish the BPM assay conditions. Yearlings, which had been raised at the hatchery from the pool I eggs, were obtained in March, 1981. Liver whole homogenates from these fish were used for comparison with embryo preparations. 
Page 216.

Exposure of Embryos to PCBs and Quantitation of PCB Levels Within Embryos:

Brook trout embryos were exposed to Aroclor 1254 spiked with a $\left[{ }^{14} \mathrm{C}\right]$-polychlorinated biphenyl isomeric mixture of similar composition (the same lots used in Chapter 4), by addition of this material to the incubation water in DMSO. The details of the exposure are described in the legend to Figure 5-2. To quantitate $\left[{ }^{14} \mathrm{C}\right]-\mathrm{PCB}$ in brook trout embryos, embryos were removed from exposure dishes, washed twice with water, dechorionated, weighed, and then solubilized in $0.3 \mathrm{ml}$ of Protosol in glass vials for 2 days at $40^{\circ}$. Ten $\mathrm{ml}$ of Aquasol and $0.3 \mathrm{~mL}$ of $0.6 \mathrm{~N}$ $\mathrm{HCl}$ was added to each vial, and radioactivity was measured by liquid scintillation counting. Counting efficiency was determined as before. To check for loss of PCBs during solubilization, known amounts of $\left[{ }^{14} \mathrm{C}\right]-\mathrm{PCB}$ s were added to vials with embryos and Protosol, then treated as above; greater than $95 \%$ of the PCBs were accounted for.

Preparation of Materials for Assay:

Whole brook trout embryos were fractionated by a method similar to that used for Fundulus (Chapter 3). Embryos were dechorionated with microsurgical scissors, then yolk sacs were individually torn with forceps, releasing a substantial portion of the fluid yolk. Embryos were then washed in ice cold TES ${ }^{\perp}$ buffer, and homogenized like Fundulus

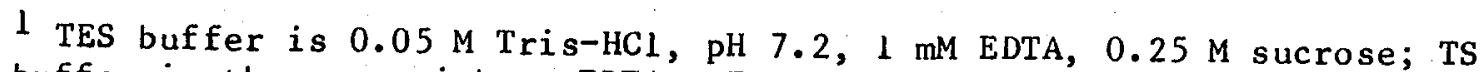
buffer is the same without EDTA. For brook trout all buffers were adjusted at $25^{\circ}$, the temperature of the BPM assay. 
embryos in $25 \mu 1$ TES buffer per embryo. Centrifugation conditions were identical to those described in Chapte. 3. The $10 \mathrm{~K}$ and $40 \mathrm{~K}$ pellets were resuspended in $0.05 \mathrm{M}$ Tris-HCl, $\mathrm{pH} 7.2$ ( $2 \mu \mathrm{l} / \mathrm{emb}$ ryo).

Livers were dissected from brook trout embryos and homogenized essentially as described for Fundulus embryos, except homogenization was in $3-5 \mu 1$ of TS buffer per liver. Whole homogenates were assayed immediately for BPM activity. In some cases the carcasses remaining after dissection were homogenized and fractionated by differential centrifugation like whole embryos. Prior to homogenization, the gut of each carcass was cut open and rinsed with TES buffer to remove the bile which accumulates there during development. Homogenization of carcasses was in $100 \mu 1$ of TES buffer/embryo. The $10 \mathrm{~K}$ and $40 \mathrm{~K}$ fractions were resuspended in $0.05 \mathrm{M} \mathrm{pH} 7.2 \mathrm{Tris}-\mathrm{HCl}(3-5 \mu \mathrm{l} / \mathrm{emb} r y \mathrm{O})$ and assayed immediately for BPM activity.

Liver homogenates and microsomes were prepared from brook trout yearlings as described for Fundulus adults. Whole homogenates were assayed for BPM activity immediately, while microsomal suspensions were stored in liquid nitrogen before use.

Benzo(a) pyrene Monooxyenase Activity:

BPM activity was assayed under the same conditions used for Fundulus (Chapter 3) except the incubation time was 20 minutes and the incubation temperature was $25^{\circ}$ and between 2-30 $\mu \mathrm{g}$ of liver protein was added per reaction mixture. The incubation temperature was determined to be optimal using yearling hepatic microsomes, and the reaction with yearling 
microsomes was linear with time for at least 20 minutes, and with liver homogenate protein up to $70 \mu \mathrm{g}$ per reaction mixture.

Activity was considered detectable when the complete reaction mixture differed from the blank at the 0.05 level of significance by the Student t-test. The limit of detection of activity for any given sample depends on the replicate variability and the amount of material added per reaction mixture. For the purposes of this study the limit of detection is defined as that amount of product necessary for the power of the t-test to be 0.95 with $P<0.05$. This was individually calculated for samples in which activity was not detectable using the pooled estimate of variance of the complete reaction mixture and blanks (Winer, 1971). Dividing the amount of product calculated by the incubation time and the number of embryos per reaction mixture gives a limit of detection in terms of BP metabolites/min/embryo.

RESULTS

Comparison of Fundulus and Brook Trout Embryonic Development:

The course of embryonic development in Fundulus and brook trout is quite similar (Armstrong and Child, 1965; Ballard, 1973). By the time of hatching in both species most of the major organs have formed. The most conspicuous differences between these two species is that the embryos of trout weigh about 15 times more than those of Fundulus, and since the environmental temperature during the trout spawning season is lower than during the Fundulus season, embryonic development is substantially 
s lower in trout. The standard temperatures for maintenance of trout and Fundulus embryos were $10^{\circ}$ and $20^{\circ}$, respectively. Hatching in Fundulus takes about 20 days, whereas for the two pools of trout embryos examined the mean hatching time was 46 days. Fundulus begin feeding about 4 or 5 days after hatching, and the yolk is completely depleted in about a week if feeding is not begun. Brook trout have relatively more yolk than Fundulus, and remain dependent on the yolk for more than a month after hatching. Thus, the embryonic period after hatching in brook trout is extended compared to that in Fundulus.

Hepatic BP Monooxygenase Activity in Brook Trout Embryos and

\section{Eleutheroembryos:}

BPM activity was readily measurable in the livers of brook trout embryos at the stages examined. Figure 5-1 shows the specific activity of BPM in whole homogenates of livers of brook trout embryos and eleutheroembryos. The data were obtained with embryos from the two pools of eggs described in Materials and Methods. There apparently is about a 3-fold increase in BPM specific activity in the embryonic liver after hatching. Because of chis increase in activity the data were plotted versus days from hatching rather than age (days from fertilization). This allows comparison of the data from the two groups of embryos which had mean hatching times 6 days apart. After the initial posthatching rise, there appears not to be much change in hepatic BPM specific activity over the period of development examined. There is a suggestion of an initial peak in activity after hatching, but further sampling is 
Figure 5-1. BP monooxygenase activity in whole homogenates of livers of brook trout embryos and eleutheroembryos. Embryos were from the two pools of eggs described in Materials and Methods ( $\Delta$, Pool I; $\bullet$, Pool II). The overall mean hatching time for these two pools of eggs was $46 \pm$ 3 days (t range). At each sampling livers from 5-30 individuals were pooled, homogenized, and immediately assayed for BPM activity. The data are the mean of 3 or 4 replicates and error bars indicate S.D. 


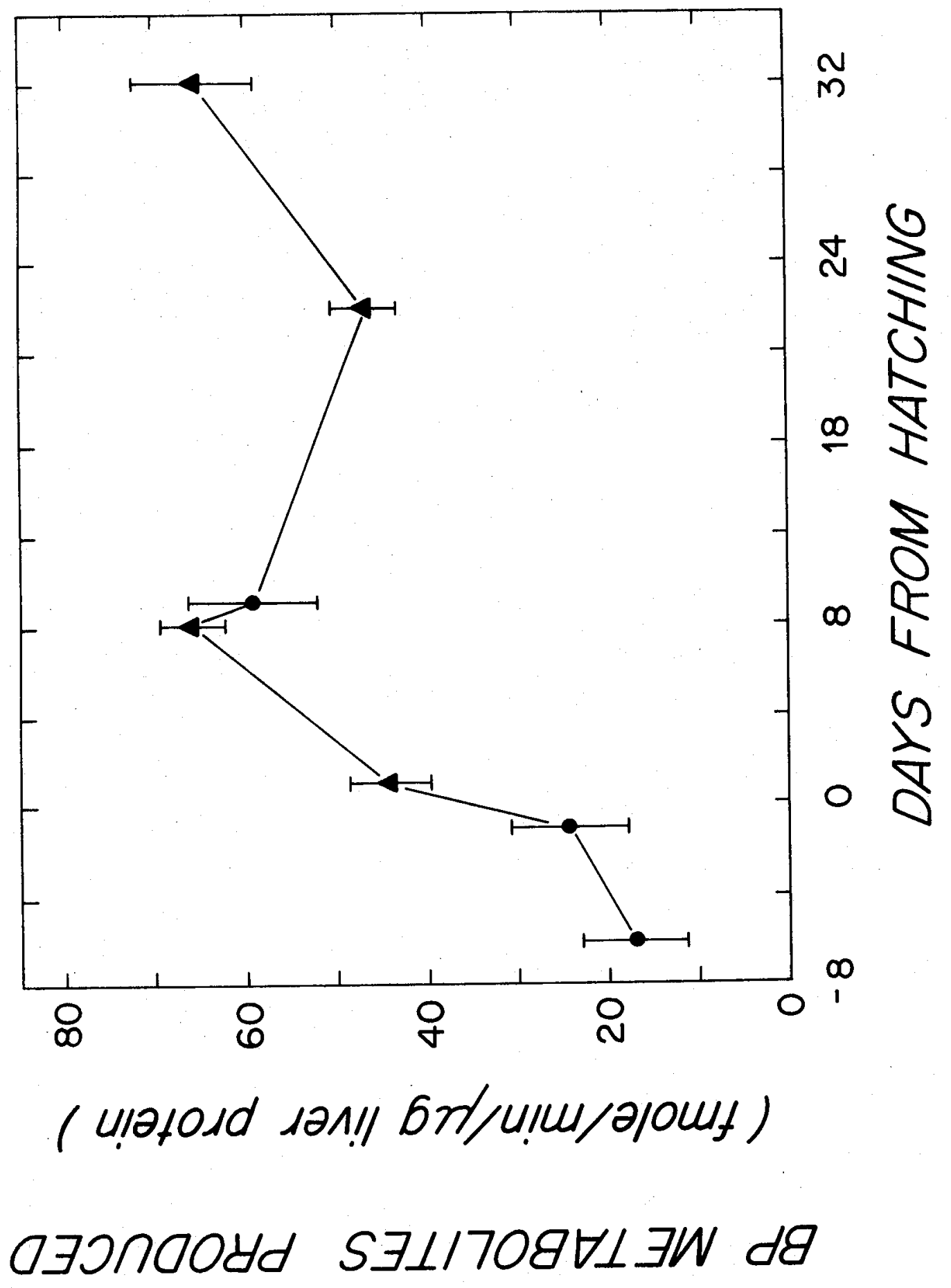


necessary to determine whether this is a general feature of the developmental pattern.

Additional data on the embryos described in Figure 5-1 is presented in. Table 5-I, along with comparative data on yearling brook trout. The data were pooled for the embryos at -6 and -1 days from hatching, 8 and 9 days from hatching, and 22 and 32 days from hatching. Over the course of embryonic development in brook trout, there is a continual increase in the mass of tissue at the expense of yolk. As can be seen in Table 5-I, near the time of hatching the embryo body accounted for only $14 \%$ of the total weight of the embryos examined, while 4 weeks after hatching the embryo body composed more than $50 \%$ of the whole embryo weight. Over this period of development, whole embryo weight was observed to change little (data not shown). Associated with the growth of the embryo body is an increase in total liver protein per embryo, but the ratio of liver protein to embryo body weight changed little over the interval of development examined. The mean value was $1.2 \mu \mathrm{g}$ liver protein/mg body weight, which is similar to the value of 1.7 obtained for yearlings.

The fact that hepatic BPM specific activity increased about 3-fold after hatching, then changed little in later embryonic stages is apparent from the pooled data shown in Table 5-I. However, as a result of growth, the total hepatic capacity to metabolize BP normalized to whole embryo weight steadily increased over this interval. Of interest is the fact that BPM specific activity was essentially the same in the livers of brook trout embryos and yearlings, and the activity in eleutheroembryos was about $2-5$ times higher than that in yearlings. The yearlings were 


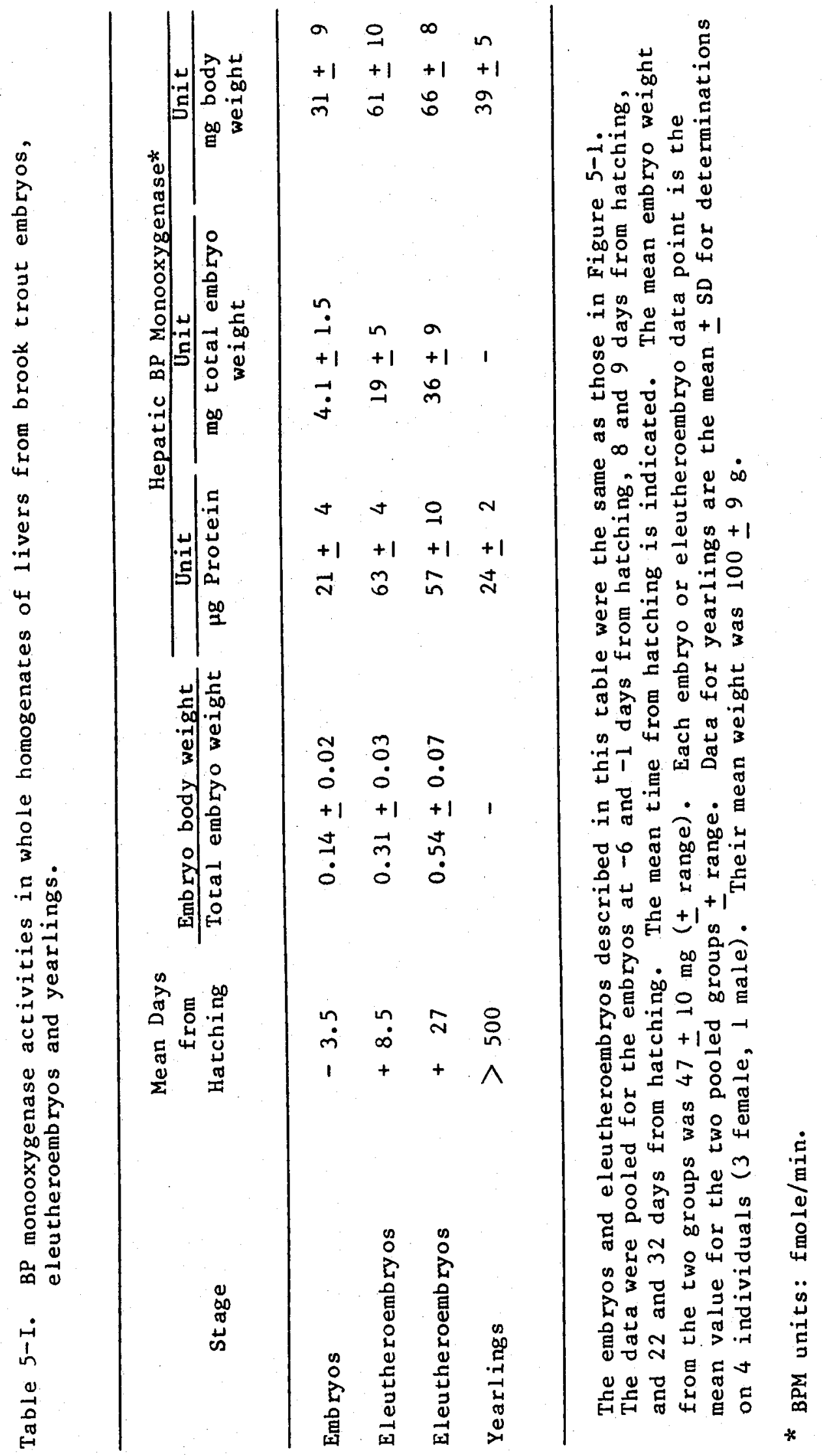


from one of the pools of eggs from which embryos were obtained, and were raised at the Sandwich fish hatchery as part of the regular stock. The levels of activity measured in yearlings are at least as high as in reproductively quiescent adults (Stegeman, 1981a). Thus in brook trout, the embryonic liver near the time of hatching is as active as adult liver in metabolizing BP, and after hatching is considerably more active than adult liver. However, because the embryonic body near hatching constitutes less than a fifth of the total embryo weight, embryos at this time have substantially less hepatic capacity to metabolize BP per unit total weight than yearlings or adults. The activity per unit weight rises sharply after hatching with the increase in specific activity and growth.

Lack of Detection of BPM Activity in Fractions of Whole Embryos and Embryo Carcasses:

Initially BPM assays were performed on $10 \mathrm{~K}$ and $40 \mathrm{~K}$ fractions of dechorionated brook trout embryos that were prepared for homogenization similarly to Fundulus embryos. There was no indication of activity in fractions prepared from embryos in stages $16-18$, and $21 \mathrm{~A}$ and $21 \mathrm{~B}^{2}$. The limits of detection for these assays calculated as described in Materials and Methods were around 30 fmole BP metabolites/min/embryo. Carcass

2 The liver rudiment is first apparent in sections of fixed embryos at stage 15, and is visible in the intact embryo by stage 17; circulation begins in stage 16 (Ballard, 1973). Stages 16-18 in brook trout are roughly equivalent to stages 25-29 in Fundulus, and stages $21 \mathrm{~A}$ and $B$ in brook trout are roughly equivalent to stage 33 in Fundulus (See Table 3-I). Brook Trout hatch in stage 23. 
fractions from the embryos assayed for hepatic BPM activity at -6 and +1 days from hatching (Figure 5-1), were iso assayed, and no activity was detectable. For the eleutheroembryos +1 day from hatching, the estimated limit of detection of activity for the $10 \mathrm{~K}$ and $40 \mathrm{~K}$ carcass fractions was about $100 \mathrm{fmole}$ BP metabolites/min/eleutheroembryo, whereas the hepatic activity that was measured was $357 \mathrm{fmole} / \mathrm{min} / \mathrm{eleutheroembryo.} \mathrm{The} \mathrm{fact}$ that the limit of detection in the carcass fractions is substantially lower than the activity in the liver, suggests that in brook trout embryos the liver plays the major role in xenobiotic metabolism.

Induction of BP Monooxygenase Activity in Brook Trout Embryonic Liver by Aroclor 1254:

In order to examine the competence of brook trout embryonic liver to respond to monooxygenase inducers, brook trout embryos were exposed to two dose levels of Aroclor 1254 for a period of 3 weeks. The levels of PCBs in the embryos during the course of the exposure are shown in Figure 5-2 and the details of the exposure protocol are described in the legend of this figure. The embryos were assayed approximately 5 days before hatching. The levels of BPM activity in whole homogenates of livers from control and exposed embryos are shown in Table 5-II. At both dose levels Aroclor 1254 induced hepatic BPM activity about 4-fold. Apparently this is the maximal extent of the response since no dose dependence was observed. The exposure produced no apparent change in total liver protein (data not shown). 
Figure 5-2. Levels of PCBs in dechorionated brook trout embryos during the course of exposure. Embryos were from Pool II described in Materials and Methods. For each treatment, 65 embryos were incubated in $10 \mathrm{~cm}$ glass petri dishes in $30 \mathrm{ml}$ of water at $10^{\circ}$. Embryos were exposed to 0.75 (ن) or 7.5 (A) ppm Anoclor 1254 spiked with $[14 \mathrm{C}]$-chlorinated biphenyls to a specific activity of $0.3 \mathrm{nCi} / \mu \mathrm{g}$. The PCBs were added in $15 \mu \mathrm{l}$ of DMSO; DMSO alone was added to control embryos. The exposure was initiated 23 days after fertilization (embryos were in stages 18 and 19) and water was changed and additional inducer added at 48 hour intervals for a total of 10 additions. Uptake of PCBs by embryos was quantitated as described in Materials and Methods. Each data point is the mean of determinations on 3 embryos; error bars indicate the standard deviation. Where error bars are not shown coefficients of variation (SD/mean) were less than $6 \%$. 


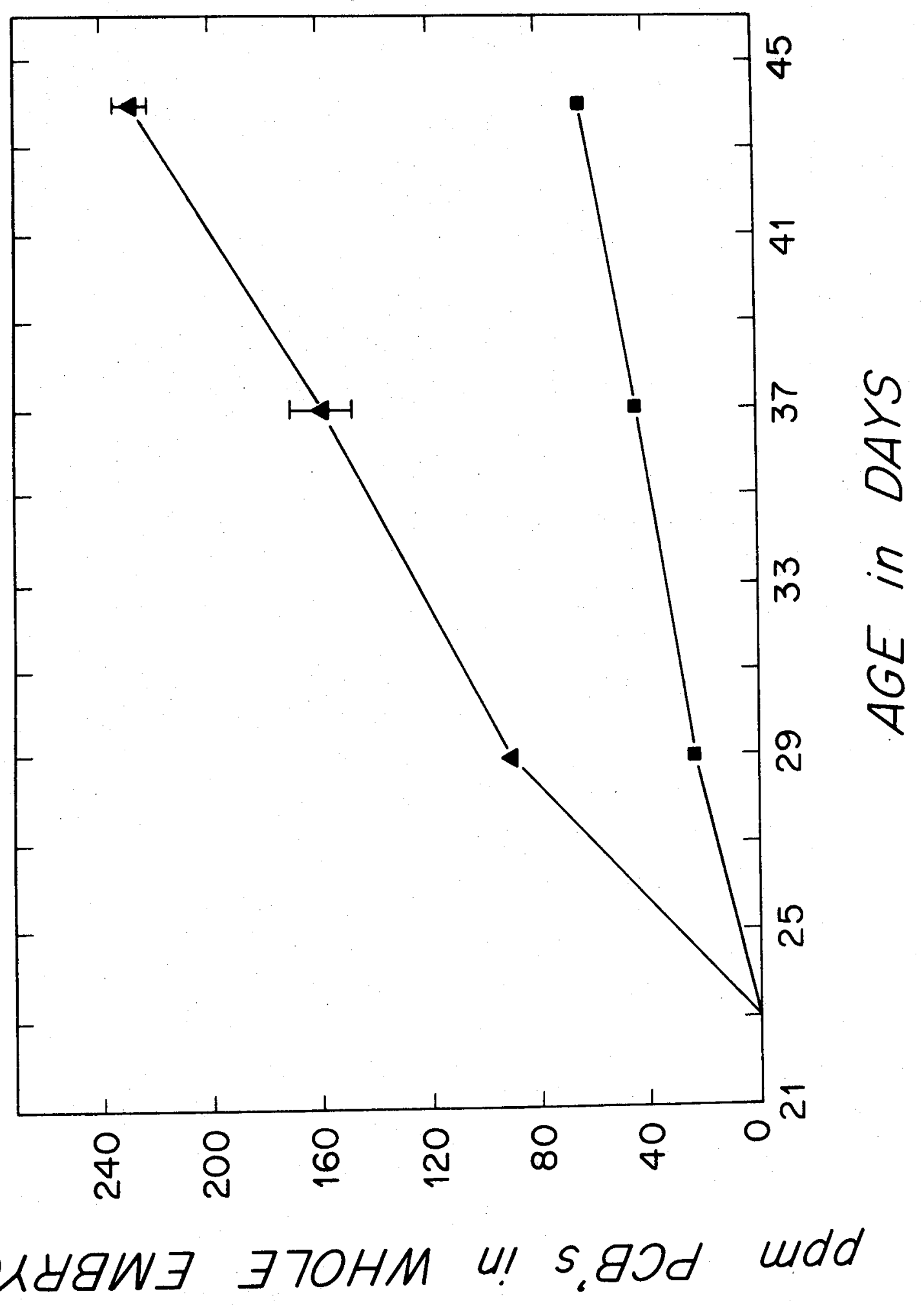


Table 5-II. BP monooxygenase activities in whole homogenates of livers from control and Aroclor 1254 exposed brook trout embryos ${ }^{+}$

\begin{tabular}{lcc}
\hline Group & $\begin{array}{c}\text { Ppm PCBs in } \\
\text { Whole Embryos } \\
\text { at Time of Assay }\end{array}$ & $\begin{array}{l}\text { BPM Activity* } \\
\text { (pmole/min/ }\end{array}$ \\
\hline Control & - & $17 \pm 6$ \\
$0.75 \mathrm{ppm}$ & $64 \pm 4$ & $71 \pm 7$ \\
$7.5 \mathrm{ppm}$ & $229 \pm 6$ & $68 \pm 15$ \\
\hline
\end{tabular}

+ Embryos were exposed to Aroclor 1254 as described in Figure 5-2, and were assayed at 44 days of development in stage $22 \mathrm{~B}$. The mean $+$ hatching time for this pool of embryos was $49 \pm 0.6$ days $( \pm$ SD).

+ Data are the mean of 3 replicates \pm SD.

* For each group, assays were performed on homogenates of pools of 16-20 livers. The data are the mean of 5 replicates $\pm S D$. Both treated groups are significantly different from the control group at $\mathrm{P}<0.001$. 
Page 229.

DISCUS SION

The data presented here clearly show that the livers of brook trout embryos are active in metabolizing BP (Fig. 5-1, Table 5-I). In fact, BPM specific activity in embryo liver homogenates was as high as that measured in preparations from yearling trout or sexually quiescent adults. Hepatic BPM activity was followed from about a week before hatching until about 4.5 weeks after. In stages assayed after hatching, BPM activity was 2- to 3-fold higher than in stages assayed before hatching. These data provide further evidence that hatching in fish and birth in mammals lead to similar changes in the monooxygenase system.

The average BPM specific activity measured in brook trout eleutheroembryo livers $(56 \pm 10 \mathrm{fmole} / \mathrm{min} / \mu \mathrm{g}$ protein) is essentially the same as the value measured for Fundulus eleutheroembryos $(57 \pm 9$ $\mathrm{fmole} / \mathrm{min} / \mu \mathrm{g}$ protein). However, the livers of Fundulus adults are more than ten times as active in metabolizing $B P$ as those of adult brook trout (compare Tables 5-I and 3-VII, also data in Stegeman, 1979; Stegeman and Chevion, 1980). The changes in BPM activity in Fundulus embryonic liver around the time of hatching are not known, but there is a continuous rise in specific activity from the late embryonic period into the juvenile period, by which time adult levels of activity are approached (Tables 3-VI, 3-IX and text Chapter 3). The total increase in BPM specific activity over this interval of development is about four-fold. In contrast, the increased hepatic BPM activity appearing after hatching in brook trout eleutheroembryos is about 2.5 times greater than that of 
Page 230.

adult trout (Table 5-I). The ontogeny of BPM activity in brook trout resembles that seen in chicken, where substantial monooxygenase activity is present before hatching, and within 1 day after hatching activity rises to about twice the adult level (Powis et al., 1976).

Unlike the results obtained with Fundulus, BPM activity was not detectable in fractions of homogenates of whole brook trout embryos. However, whole embryo fractions were assayed only at stages earlier than those in which liver BPM activity was measured. Carcasses remaining after livers were excised were also assayed and no BPM activity was detected. These results suggest that in brook trout embryos, the liver is the primary site of xenobiotic metabolism. It should be noted that endogenous inhibitors may have prevented the detection of activity in carcass or whole embryo fractions. No mixing experiments like that done with Fundulus embryos (Table 3-III) were performed to examine this question.

Aroclor 1254 was shown to induce BPM activity in livers of brook trout embryos (Table 5-II). Both dose levels used (64 and 229 ppm in the whole embryos) induced BPM activity four-fold, which apparently is the maximal extent of induction. Addison et al. (1979) have previously shown that Aroclor 1254 induces hepatic ethoxycoumarin 0-deethylase activity in the livers of adult brook trout. The results presented here clearly show that brook trout liver is competent to respond to monooxygenase inducers during early development.

In Fundulus about $140 \mathrm{ppm}$ PCBs in whole embryos was required for maximal induction of BPM activity (Fig. 4-2). It should be remembered 
that BPM activity in Fundulus embryos was measured in microsomes prepared from whole embryos. Comparison of the Fundulus and trout data suggest that brook trout embryos are more sensitive to PCBs than Fundulus embryos. However, a number of factors make comparison of liver and whole embryo data uncertain. For example, the details of how PCBs distribute within embryo bodies are not known - the liver may be a site of high concentration. Also the sensitivities of different tissues to induction may vary. Thus, with the data available it is not possible to say whether brook trout embryos are more sensitive to PCBs than those of Fundulus.

Levels of PCBs in the $\mathrm{ppm}$ range commonly occur in freshwater fish (Veith et al., 1979). Eggs of lake trout collected in Lake Michigan in 1973 had levels of PCBs as high as $9.90 \mathrm{ppm}$ on a wet weight basis (Stauffer, 1979). While a maximal induction of hepatic BPM activity in brook trout was observed at $64 \mathrm{ppm}$ PCB in the whole embryos, levels less than $10 \mathrm{ppm}$ are likely to produce some response, and they could be considerably more sensitive. In many freshwater systems, induction of monooxygenase activity during the embryonic development of fish seems likely. It is important to determine the dose-dependency of the induction of monooxygenase activity in the embryos of freshwater species.

The results of the following study are particularly relevant to the data presented here. Wales et a1. (1978) reported that when rainbow trout eggs were exposed to $0.5 \mathrm{ppm}$ aflatoxin $B_{1}$ for one hour, an incidence of liver tumors as high as $60 \%$ was observed in fish one year later. The incidence of tumors was relatively low when the eggs were 
exposed prior to the appearance of the liver rudiment, but rose sharply after it appeared. Aflatoxin $B_{1}$ is a procarcinogen that requires metabolic activation by the cytochrome P-450 monooxygenase system (Campbell and Hayes, 1976). Apparently the monooxygenase system is present in rainbow trout embryonic hepatocytes shortly after the appearance of the liver rudiment, although no measurements of aflatoxin metabolism were made for lack of an adequately sensitive assay. These findings point out the possible consequences of the metabolism of carcinogens by embryonic fish liver. 
CHAPTER 6 .

SUMMARY AND DISCUSSION

The most important original findings of the research described in this thesis are listed below.

1). Fish embryos and larvae have the capacity to metabolize xenobiotics.

2). Common envi ronmental contaminants, PCBs and petroleum hydrocarbon, can induce xenobiotic monooxygenase activity in fish embryos.

3). During embryonic development in Fundulus there is a large increase in the sensitivity of the induction response after hatching. This regulatory mechanism might serve to protect the most sensitive developmental stages from damage from activated metabolites.

4). Fundulus embryos are competent to respond to monooxygenase inducers as early as 4.5 days from fertilization, prior to the appearance of the liver rudiment. This may be the earliest stage in the development of a vertebrate species in which induction of monooxygenase activity has been directly demonstrated.

5). Environmentally realistic levels of $\mathrm{PCBs}$ are likely to induce monooxygenase activity during the embryonic period in sensitive species of fish.

Experimental results have been discussed in detail in Chapters 3-5. The following discussion will serve to highlight and summarize the findings and point out questions which remain.

The data presented in this thesis has clearly demonstrated that fish embryos and larvae have the capacity to metabolize foreign compounds. In microsomes prepared from Fundulus embryos, BPM activity was measurable as early as 4 days after fertilization (stages 25-26) (Table 3-II). This is shortly after the onset of circulation and near the beginning of the most 
Page 234.

active period of organogenesis. The liver rudiment has yet to appear at these stages which indicates that the extrahepatic tissues of Fundulus embryos may play an important role in xenobiotic metabolism. In livers of brook trout embryos, BPM activity was first measured 6 days before hatching, and surprisingly the embryonic liver was about as active as adult liver in metabolizing BP (Fig. 5-1, Table 5-I).

The commercial PCB mixture, Aroclor 1254, and No. 2 fuel oil were shown to induce BPM activity in fractions prepared from whole Fundulus embryos (Fig. 4-2, 4-5; Table 2-I). As noted above, embryos as early as 4.5 days from fertilization were competent to respond to induction (Fig. 4-5). In Fundulus eleutheroembryos Aroclor 1254 was shown to induce BPM activity in both the liver and extrahepatic tissues (Table 2-II). BPM activity was also inducible in brook trout embryonic liver (Table 5-II).

Evidence was obtained indicating that BPM activity in microsomes prepared from Fundulus embryos and eleutheroembryos is cytoch rome P-450-dependent (Table 3-IV). Direct spectral evidence for the presence of cytochrome $\mathrm{P}-450$ was obtained with microsomes from eleutheroembryos (Fig. 3-6). Cytoch rome $b_{5}$ is also present in eleutheroembryo microsomes (Fig. 3-7) and NADPH- and NADH-cytochrome c reductase activities were measurable in embryonic microsomes at all stages assayed (Fig. 3-3). Generally the levels of NADPH-cytochrome c reductase activity did not correlate with BPM activity, but a functional role for this reductase in monooxygenase activity was indicated by the sensitivity of BPM activity to cytochrome c (Table 3-IV). Although essentially all of the evidence for embryonic metabolism of foreign compounds has been obtained using benzo(a)pyrene as a substrate, the fact that this activity 
Page 235.

is catalyzed by cytochrome $\mathrm{P}-450$ indicates that embryos are likely to be active in metabolizing a great variety of foreign compounds, and probably will respond to a large number of different inducing substances. Results obtained with BP can be considered indicative of more general changes in the capacity to metabolize foreign compounds.

The overall developmental pattern of xenobiotic monooxygenase activity in Fundulus is characterized by low activity in all stages before hatching, and a large increase in activity during the period shortly after hatching (Fig, 3-3). The total capacity to metabolize xenobiotics increases sharply again after the onset of feeding, due to the rapid growth of the liver (Table $3-V I$ ).

Another developmental change in the monooxygenase system of potentially great significance is the fact that much higher tissue levels of PCBs are required to induce BPM activity in Fundulus embryos than are required in eleutheroembryos (Fig. 4-3). Apparently there is some fundamental change in the regulation of the monooxygenase system after hatching.

The developmental changes in the monooxygenase system of Fundulus can be rationalized as balancing the need to protect sensitive developmental stages from damage from activated metabolites, and the need to eliminate lipophilic xenobiotics. During the most sensitive phases of development prior to hatching, basal levels of monooxygenase activity are low, and high levels of inducer are necessary to produce a response. Since lipophilic xenobiotics will tend to concentrate in the yolk, it might actually serve a protective function, and prehatching stages may have little need to metabolize xenobiotics. After hatching, as discussed in 
Chapter 3 , the potential exposure to xenobiotics is much greater, and increased constitutive levels of monooxygenase activity and a more sensitive induction response are likely to be adaptive.

The ontogenic pattern of monooxygenase activity in brook trout liver contrasts to the results obtained with Fundulus. The levels of BPM activity in Fundulus embryonic liver are not known, but the BPM specific activity in eleuthe roembryo livers is about $1 / 4$ the adult level. Presumably in embryos the activity is much lower than in eleutheroembryos. Brook trout embryonic liver is about as active as adult liver in metabolizing BP, and after hatching BPM specific activity in the liver increases to a level 2.5 times that found in adults (Table 5-I). This increase in BPM activity after hatching can be rationalized by the arguments discussed above, but the function of the relatively high monooxygenase activity before hatching is uncertain. Data described in Chapter 5 suggests that the liver may play a more important role in xenobiotic metabolism in trout embryos than in Fundulus embryos, which might explain the high activity in trout embryonic liver.

While only 2 species of $\mathrm{fish}$ were examined in this study, it seems reasonable to assume that the early developmental stages of many species are likely to have the capacity to metabolize foreign compounds. Considering the differences between Fundulus and brook trout, it will be necessary to examine ontogenic patterns in several species before general patterns can be discerned. The data obtained with Fundulus and brook trout indicate that levels of PCBs which occur in the environment are likely to induce monooxygenase activity during the embryonic development of sensitive species. However, the actual sensitivities of Fundulus 
eleutheroembryos and brook trout embryos was not established, since maximal inductions were observed at all doses used (Fig. 4-2, 4-5; Table 5-II). It will be of great interest to determine the sensitivity of the induction responses during embryonic development in a number of different species of fish. This information is important to understanding the effects of low level contamination on early developmental stages. Also of great interest is whether other species besides Fundulus show a change in the sensitivity of the induction response with development; considering the apparent adaptive advantage this offers.

As noted above, monooxygenase activity was detectable in preparations from Fundulus embryos prior to the period of most active organogenesis. Fundulus embryos were also shown to be competent to respond to monooxygenase inducers during this sensitive period of development. The se results suggest that in contaminated environments $f$ ish embryos might be subject to teratogenic effects from activated metabolites generated by the monooxygenase system. Induction of higher levels of activity might potentiate such effects. The rapidly proliferating tissues of embryos may also be particularly sensitive to the initiation of carcinogenesis. HPLC analysis of BP metabolites produced by Fundulus eleutheroembryos (Fig. 4-8) suggest that they can activate BP to its ultimate carcinogenic form. Thus populations of $f$ ish in contaminated environments might be at risk of initiation of carcinogenesis during embryonic development.

While the work described here has answered certain basic and significant questions, many more have been generated. Among them are when does monooxygenase activity appear during the development of $\mathrm{fish}$, 
Page 238.

and when does induction competence appear? In Fundulus a further characterization of the changes associated with hatching is necessary. Is the increase in BPM activity after hatching associated with an increase in cytochrome $P-450$ ? Is de novo synthesis of cytochrome $P-450$ triggered by some process associated with hatching? More fundamental and difficult questions are what factors are responsible for the post-hatching increase in BPM activity in untreated embryos, and what controls the increase in induction sensitivity after hatching. A question of basic importance is what role does the metabolism of foreign compounds by fish embryos play in the initiation of cancer and the production of malformations. 
ADDISON R.F., ZINCK M.E. and WILLIS D.E. (1977) Mixed-function oxidase enzymes in trout (Salvelinus fontinalis) liver; absence of induction following feeding of $p, p^{-D} D T$ or $P, p^{-D D E}$. Comp. Biochem. Physiol 57C, 39.

ADDISON R.F., ZINCK M.E., WILLIS D.E. and DARROW D.C. (1979) Induction of hepatic mixed function oxidases in trout by polychlorinated biphenyls and butylated monochlorodiphenyl ethers. Toxicol. App 1. Pha rmacol. 49:245-248.

AHOKAS J.T., KARKI N.T., OIKARI A. and SOIVIO A. (1976) Mixed function monooxygenase of $\mathrm{fish}$ as an indicator of pollution of aquatic environment by industrial effluent. Bull. Environ. Contam. Toxicol. 16, 270 .

AHOKAS J., PAAKKONEN R., RONNHOLM R., RAUNIO V., KARKI N. and PELKONEN 0 . (1977) Oxidative metabolism of carcinogens by trout liver resulting in protein binding and mutagenicity In: "Microsomes and Drug Oxidations." (V. Ullrich, I. Roots, A. Hildebrandt, R.W. Estabrook and A.H. Conney, eds.), p. 435. Pergamon Press, Oxford.

AHOKAS J.T., PELKONEN O. AND KARKI N.T. (1975) Metabolism of polycyclic hydrocarbons by a highly active aryl hydrocarbon hydroxylase in the liver of a trout species. Biochem. Biophys. Res. Commun., 63, 635.

AHOKAS J.T., PELKONEN O. and KARKI N.T. (1976) Cytoch rome P-450 and drug induced spectral interactions in the hepatic microsomes of trout, Salmo trutta lacustris. Acta Pharmacol. Toxicol. 38, 440.

AHOKAS J.T., PELKONEN O. and KARKI N.T. (1977) Characterization of benzo(a) pyrene hydroxylase of trout liver. Cancer Res. 37, 3737.

AHOKAS J.T., SAARNI H., NEBERT D.W. and PELKONEN O. (1979) The in vitro metabolism and covalent binding of benzo(a)pyrene to DNA catalysed by trout liver microsomes. Chem.-Biol. Interactions 25 , 103.

ALVARES A.P., BICKERS D.R. and KAPPAS A. (1973) Polychlorinated biphenyls: a new type of inducer of cytochrome $P-448$ in the liver. Proc. Natl. Acad. Sci. 70:1321.

ALVARES A.P. and KAPPAS A. (1975) Induction of aryl hydrocarbon hydroxylase by polychlorinated biphenyls in the foeto-placental unit and neonatal livers during lactation. FEBS Letters 50:172.

ALVARES A.P. and KAPPAS. (1977) Heterogeneity of cytochrome P-450s induced by polychlorinated biphenyls. I. Biol. Chem. 252:6373. 
Page 240.

ALVARES A.P., SCHELLING G. and LEVIN W. (1970) Species differences in the induction of microsomal hemoproteins and 3,4-benzpyrene hydroxylase by phenobarbital and 3-methylcholanthrene. J. Pharmac. Exp. Ther. 175:4.

ALVARES A.P., SCHELLING G., LEVIN W. AND KUNTZMAN R. (1967) Studies on the induction of co-binding pigments in liver microsomes by phenobarbital and 3-methylcholanth rene. Bioch. Biophy. Res. Comm. $29: 521$.

ARMSTRONG P.B. (1932) The embryonic origin of function in the pronephros through differentiation and parenchyma-vascular association. Amer. J. Anat. 51:157.

ARMSTRONG P.B. (1936) Mechanism of hatching in Fundulus heteroclitus. Biol. Bull. $71: 407$.

ARMSTRONG P.B. and CHILD J.S. (1965) Stages in the normal development of Fundulus heteroclitus. Biol. Bull. $128: 143$.

ATLAS S.A., BOOBIS A.R., FELTON J.S., THORGEIRSSON S.S. and NEBERT D.W. (1977) Ontogenetic expression of polycyclic aromatic compound-inducible monooxygenase activities and forms of cytochrome $\mathrm{P}-450$ in the rabbit. Evidence for temporal control and organ specificity of two genetic regulatory systems. J. Biol. Chem. $252: 4712$.

BAIRD R.C., THOMPSON N.P., HOPKINS T.L. and WEISS W.R. (1975) Chlorinated hydrocarbons in mesopelagic fishes of the eastern Gulf of Mexico. Bull. Mar. Sci. 25:473.

BALK L., MEIJER J., SE IDEGARD J., MORGENSTEIN R. and DEPIERRE J.W. (1980) Initial characterization of drug-metabolizing systems in the liver of the northern pike, Esox lucius. Drug Metab. Disp. $8: 98$.

BALL L.M., ELMAMLOUK T.H. and BEND J.R. (1980) Metabolism of benzo(a)pyrene in little skate mixed-function oxidase systems. In: "Microsomes and Drug Oxidations and Chemical Carcinogenesis.", Vol. 2. (M.J. Coon, A.H. Conney, R.W. Estabrook, H.V. Gelboin, J.R. Gillette and P.J. O'Brien, eds.) p. 1203. Academic Press, New York.

BALLARD W.W. (1973) Normal embryonic stages for salmonid fishes, based on Salmo gairdneri Richardson and Salvelinus fontinalis (Mitchell). J. Exp. Zool. 184:7.

Balon E.K. (1975) Terminology of Intervals in Fish Developuent. J. Fish. Res. Bd. Can. 32:1663. 
BASU T.K., DICKERSON J.W.T. and PARKE D.V.W. (1971) Effect of development of microsomal drug-metabolizing enzymes in rat liver. Biochem. J. 124:19.

BEND J.R., BALL L.M., ELMAMLOUK T.H., JAMES M.O. AND PHILPOT R.M. (1979) Microsomal mixed-function oxidation in untreated and polycyclic aromatic hydrocarbon-treated fish. In: "Pesticide and Xenobiotic Metabolism in Aquatic Organisms." (M.A.Q. Kahn, J.J. Lech and J.J. Menn, eds.) p. 297. American Chem. Soc. Washington D.C.

BEND J.R., FOUREMAN G.L. and JAMES M.D. (1978) Partially induced hepatic mixed function oxidase in individual members of certain marine species from coastal Maine and Florida. In: "Aquatic Pollutants, Transformation and Biological Effects." (D. Hutzinger, I.H. VanLe lyveld, and B.D.J. Zoeteman, eds.). Pergamon Press, New York.

BEND J.R., HALL P. and FOUREMAN G.L. (1976) Comparison of benzo(a)pyrene hydroxylase (aryl hydrocarbon hydroxylase, AHH) activities in hepatic microsomes from untreated and $1,2,3,4-d$ ibenzanthracene (DBA)-induced male little skates (Raja erinacea). Bull. Mt. Desert Is. Biol. Lab. 16:3.

BEND J.R. and JAMES M.O. (1978) Xenobiotic metabolism in marine and freshwater species. In: "Biochemical and Biophysical Perspectives in Marine Biology." (D.C. Malins and J.R. Sargent, eds.). Vol. 4, p. 128. Academic Press, New York.

BEND J.R., JAMES M.O., and DANSETTE P.M. (1977) In vitro metabolism of xenobiotics in some marine animals. Ann. N.Y. Acad. Sci. 298, 505.

BEND J.R., POHL R.J., ARINO E. and PHILPOT R.M. (1977) Hepatic microsomal and solubilized mixed-function oxidase systems from the little skate, Raja erinacea, a marine elasmobranch. In:

"Microsomes and Drug Oxidations." (V. Ullrich, I, Roots, A. Hildebrand, R.W. Estabrook and A.H. Conney, eds.), p. 160. Pergammon Press, Oxford.

BEND J.R., POHL R.J. and FOUTS J.R. (1973) Further studies of the microsomal mixed-function oxidase system of the little skate, Raja erinacea, including its response to some xenobiotics. Bull. Mt. Desert Is. Biol. Lab. 13:9.

BERKY D.L., SLAGA T.J., WILSON N.M., ZACHARIAH P.K., NAMKUNG M.J., BRACKEN W.M. and JUCHAU M.T. (1977) Transplacental induction of mixed-function oxygenases in extrahepatic tissues by $2,3,7,8$-tetrachloro-p-dioxin. Biochem. Pharmacol. 26:1383. 
BICKEL M.H. and MUEHLEBACH S. (1980) Pharmacokinetics and ecodisposition of polyhalogenated hydrocarbons: aspects and concepts. Drug Metab. Rev. 11:149.

BICKERS D.R., HARBER L.C., KAPPAS A., ALVARES A.P. (1972) Polychlorinated biphenyls: comparative effects of high and low chlorine containing Aroclors on hepatic mixed-function oxidase. Res. Comm. Chem. Path. Pharm. 3:505.

BIGELOW H.B. and SCHROEDER W.C. (1953) Fishes of the Gulf of Maine. U.S. Government Printing Office, Washington, D.C.

BINDER R.L. and STEGEMAN J.J. (1980) Induction of aryl hydrocarbon hydroxylase activity in embryos of an estuarine fish. Biochem. Pharmacol. 29:949.

BOTELHO L.H., RYAN D.E. and LEVIN W. (1979) Amino acid compositions and partial amino acid sequences of three highly purified forms of liver microsomal cytochrome $\mathrm{P}-450$ from rats treated with polychlorinated biphenyls, phenobarbital, or 3-methylcholanthrene. J. Biol. Chem. 254:5635.

BOWES G.W., MULVIHILL M.J., SIMONETT B.R.T., BURLINGAME A.L. and RISEB ROUGH R.W. Identification of chlorinated dibenzofurans in American polychlorinated bipheny 1s. Nature 256:305.

BOYD J.F. and SIMMONDS R.C. (1974) Continuous Laboratory production of fertile Fundulus heteroclitus (Walbaum) eggs lacking chorionic fibrils. J. Fish Biol. $6: 389$.

B ROWN E. R. R., HAZDRA J.J., KEITH L., GREENSPAN I., KWAPINSKI J.B.G. and BEAMER P. (1973) Frequency of fish tumors found in a polluted watershed compared to nonpolluted Canadian waters. Cancer Res. $33: 189$.

BUHLER D.R. and RASMUSSON M.E. (1968) The oxidation of drugs by fishes. Comp. Biochem. Physiol. 25:223.

BURNS K.A. (1976) Microsomal mixed function oxidases in an estuarine $\mathrm{fish}$, Fundulus heteroclitus, and their induction as a result of envi ronmental contamination. Comp. Biochem. Physiol. 53B:443.

BUTLER P.A. and SCHUTZMANN R.L. (1978) Residues of pesticilles and PCBs in estuarine fish, 1972-76 - National Pesticide Monitoring Program. Pest. Monit. J. 12:51-59.

CAMPBELL T.C. and HAYES J.R. (1976) The role of aflatoxin nietabolism in its toxic lesion. Tox. Appl. Pharm. 35:199.

CARLSTEDT-DUKE J.M.B. (1979) Tissue distribution of the receptor for $2,3,7,8$-tetrachlorodibenzo-p-dioxin in the rat. Cancer Res. $39: 3127$. 
CARLSTEDT-DUKE J.M.B., ELFSTROM G., HOGBERG B. and GUSTAFSSON J. (1979) Ontogeny of the rat hepatic receptor for $2,3,7,8$-tetrachloro-dibenzo-p-dioxin and its endocrine independence. Cancer Res. 39:4653.

CARLSTEDT-DUKE J.M.B., GILLNER M., HANSSON L., TOFTGARD R., GUSTAFSSON S., HOGBE RG B. and GUSTAFSSON J. (1980) The molecular basis for induction of aryl hydrocarbon hydroxylase: characteristics of the receptor protein for $2,3,7,8$-tetrachlorodibenzo-p-dioxin (TCDD). In: "Biochemistry, Biophysics and Regulation of Cytochrome P-450." (J. Gustafs son, J. Carlstedt-Duke, A. Mode, J. Rafter, eds.). Elsevier/North Holland, New York.

CHAMBERS J.E. and YARBROUGH J.D. (1976) Xenobiotic biotransformation systems in fishes. Comp. Biochem. Physiol. 55C:77.

CHATTERJEE I.B., PRICE Z.H, and MCKEE R.W. (1965) Biosynthesis of L-ascorbic acid in different sub-cellular fractions of prenatal and postnatal rat livers. Nature 207:1168.

CHEDID A. and NAIR V. (1974) Ontogenesis of cytoplasmic organelles in rat hepatocytes and the effects of prenatal phenobarbital on endoplasmic reticulum development. Dev. Biol. 39:49.

CHEN T.S. and DuBOIS K.P. (1973) Studies on the enzyme inducing effect of polychlorinated biphenyls. Tox. Appl. Pharm. 26:504.

CHEVION M., STEGEMAN J.J., PEISACH J. and BLUMBERG W.E. (1977) Electron paramagnetic resonance studies on hepatic microsomal cytoch rome $\mathrm{P}-450$ from a marine teleost fish. Life Sci. 20:895.

CONNEY A.H. (1967) Phamacological implications of microsomal enzyme induction. Pharmacol. Rev. 19:317.

COON M.J. and VATSIS (1978) Biochemical studies on chemical carcinogenesis: role of multiple forms of liver microsomal cytoch rome $\mathrm{P}-450$ in the metabolism of benzo(a)pyrene and other foreign compounds. In: "Polycyclic Hydrocarbons and Cancer, Vol. 1: Environment, Chemistry and Metabolism." (H.V. Gelboin and P.O.P Ts'O, eds.). Academic Press, New York.

COOPER D.Y., LEVIN S., NARASIMHULU S., ROSENTHAL D. and ESTABROOK R.W. (1965) Photochemical action spectrum of the terminal oxidase of mixed function oxidase systems. Science 147:400.

CRESTEIL T., FLINOIS J.P., PFISTER A. and LEROUX J.P. (1979) Effect of microsomal preparations and induction on cytochrome $P-450$ dependent monooxygenases in fetal and neonatal rat liver. Biochem. Pharmacol. $28: 2057$. 
DALLNER G., SIEKEVITZ P. and PALADE G.E. (1966a) Biogenesis of endoplasmic reticulum membranes. I. Structural and chemical differentiation in developing rat hepatocytes. J. Cell Biol. 30:73.

DALLNER G., SIEKEVITZ P. and PALADE G.E. (1966b) Biogenesis of endoplasmic reticulum membranes. II. Synthesis of constitutive microsomal enzymes in developing rat hepatocyte. J. Cell Biol.
$30: 97$.

deBARROS A., KAPLAN J., DUVALDEST IN P. and BERTHELOT P. (1978) $\mathrm{PB}-$ induced increase of NADH-cytoch rome $\mathrm{b}_{5}$ reductase activity in rat liver microsomes. Biochem. Pharm. 27:367.

DePIERRE J.W. and DALLNER G. (1975) Structural a spects of the membrane of the endoplasmic reticulum. Biochem. Biophys. Acta
415:411.

DeWAIDE J.H. and HENDERSON P.T. (1968) Hepatic N-demethylation of aminopyrine in rat and trout. Biochem. Pharm. 17:1901.

DICKENS M., BRIDGES J.W., ELCOMBE C.R., and NETTER K.J. (1978) A novel haemoprotein induced by isosafrole pretreatment in the rat. Biochem. Biophys. Res. Comm. 80:89.

DRUMMOND A.H., MCCALL J.M. and JONDORF W.R. (1972) Some factors affecting liver microsomal drug metabolism in the chicken. Proceedings of the Biochemical Society, Biochem. J. 130:73.

DUCE R.A. and DUURSMA E.K. (1977) Inputs of organic matter to the ocean. Marine Chem. 5:319.

DUNN B.P. (1979) Polycyclic aromatic hydrocarbons in marine sediments, bivalves, and seaweeds:' Analysis by high-pressure liquid chromatography. In: "Polynuclear Aromatic Hydrocarbons: Fourth International Symposium on Analysis, Chemistry and Biology." (A. Bjorseth, ed.) p. 367. Battelle Press, Columbus,
Ohio.

DUS K. (1976) On the structure and function of cytochrome P-450. In: "The Enzymes of Biological Membranes Vol. 4, Electron Transport Systems and Receptors." (A. Martinosi, ed.). Plenum
Press, New York.

ECOBICHON D.J. and COMEAU A.M. (1974) Comparative effects of commercial Aroclors on rat liver enzyme activities. Chem.-Biol.
Int. $9: 341-350$.

ECOBICHON I.J., DYKEMAN R.W. and HANSELL M.M. (1978) The development of hepatic drug-metabolizing enzymes in prenatal guinea pigs: A biochemical and morphological study. Can. J. Biochem. 56:738. 
ELCOMBE C.R., FRANKLIN R.B. and LECH J.J. (1979) Induction of hepatic microsomal enzymes in rainbow trout. In: "Pesticide and Xenobiotic Metabolism in Aquatic Organisms." (M.A.Q. Kahn, J.J. Lech, and J.J. Menn eds.). p. 319. American Chemical Society, Washington D.C.

ELCOMBE C.R. and LECH J.J. (1979) Induction and characterization of hemoprotein(s) $\mathrm{P}-450$ and monooxygenation in rainbow trout (Salmo gairdneri). Toxicol. Appl. Pharmacol. 49:437.

ELCOMBE C.R. and LECH J.J. (1978) Induction of monooxygenation in rainbow trout by polybrominated biphenyls: a comparative study. Environ. Health Perspect. 23:309.

ELCOMBE C.R., VODICNIK M.J. and LECH J.J. (1980) Characterization of monooxygenase inducers in the rainbow trout. Toxicol. Appl. Pharmacol. (in press).

EGAAS E. and VARANSI U. (1980) Effect of preexposure of rainbow trout to polychlorinated biphenyls on binding of benzo(a)pyrene to DNA catalyzed by liver enzymes. Fed. Proc. 39:1013.

ESTABROOK R.W. (1971) A new spectral intermediate associated with cyrochrome $\mathrm{P}-450$ function in liver microsomes. Bioch. Biophy. Res. Comm. $42: 132$.

FANTEL A.G., GREENWAY J.C., JUCHAU M.R. and SHEPARD T.H. (1979) Teratogenic bioactivation of cyclophospamide. Life Sci. 25:67.

FEUER G. (1978) Role of phospholipids in the development of the hepatic endoplasmic reticulum associated with drug metabolism. Res. Commun. Chem. Path. Pharm. 22:549.

FLEISCHER S. and KERVINA M. (1974) Subcellular fractionation of rat liver. In "Methods in enzymology XXXI." (Ed. S. Fleischer and L. Parker). Academic Press, New York.

FORLIN L. (1980) Effects of Clophen A50, 3-methylcholanthrene, pregnenolone-16a-carbonitrile and phenobarbital on the hepatic microsomal cytochrome $\mathrm{P}-450$ dependent monooxygenase system in rainbow trout, Salmo gairdneri, of different age and sex. Toxicol. Appl. Pharmacol. 54:420.

FORLIN L. and LIDMAN V. (1978) Effects of Clophen A50, 4-, 2, 5, 2', $5^{\prime}$ tetra- and $2,4,5,2^{\prime}, 4^{\prime}, 5^{\prime}$-hexachlorobiphenyl on the mixed-function oxidase system of rainbow trout (Salmo gairdneri) liver. Comp. Biochem. Physio 1. 60C:193. 
Page 246.

FOUTS J.R. and DEVEREUX T.R. (1972) Developmental aspects of hepatic and extrahepatic drug metabolizing enzyme systems: microsomal enzyme components in rabbit liver and lung during the first month of life. J. Pharmacol. Exp. Therap. 183:458.

FUJITA S. and PEISACH J. (1977) Electron transfer between liver microsomal cytochrome b5 and cytochrome $\mathrm{P}-450$ in the azo reductase reaction. Biochem. Biophys. Res. Commun. 78:328.

GALLOWAY S.M., PERRY P.E., MENESES J., NEBERT D.W. and PEDERSEN R.A. (1980) Cultured mouse embryos metabolize benzo(a)pyrene during early gestation: Genetic differences detectable by sister chromatid exchange. Proc. Nat1. Acad. Sci. U.S. 77:3524.

GERHART E.H. and CARLSON R.M. (1978) Hepatic mixed-function oxidase activity in rainbow trout exposed to several polycyclic aromatic compounds. Env. Res. 17:284.

GIELEN J.E., GOUJON F.M. and NEBERT D.W. Genetic regulation of arylhydrocarbon induction. (1972) J. Biol. Chem. 247:1125.

GILLETTE J.R., BRODIE B.B. and LaDU B.N. (1957) The oxidation of drugs by liver microsomes: on the role of TPNH and oxygen. J. Pharmacol. Exp. Therap. 119:532.

GILLETTE J.R., DAVIS D.C. and SASAME H.A. (1972) Cytoch rome P-450 and its role in drug metabolism. Ann. Rev. Pharmacol. 12:57.

GILLETTE J.R., MITCHELL J.R. and BRODIE B.B. (1974) Biochemical mechanisms of drug toxicity. Ann. Rev. Pharmacol. 14:271.

GILLETTE J.R. and STRIPP B. (1975) Pre- and postnatal enzyme capacity for drug metabolite production. Fed. Proc. 34:172.

GOLDBERG E.D. (1976) "The health of the oceans." UNESCO Press, Paris.

GOLDSTEIN A., ARONOW L. and KALMAN S.M. (1974) "The Principles of Drug Action: The Basis of Pharmacology." J. Wiley and Sons, New
York.

GOLDSTEIN J.A., HASS J.R., LINKO P. and HARVAN D.J. (1978) $2,3,7,8$-tetrachlorodibenzofuran in a comercially available $99 \%$ pure polychlorinated biphenyl isomer identified as the inducer of hepatic cytochrome $\mathrm{P}-448$ and aryl hydrocarbon hydrolase in the rat. Drug Metal Disp. $6: 258$.

GOLDSTEIN J.A., HICKMAN P., BERGMAN H., MCKINNEY J.D. and WAL KER M.P. (1977) Separation of pure polychlorinated biphenyl isome $s$ into two types of inducers on the basis of induction of cytoch rome $p-450$ or P-448. Chem. Biol. Int. 17:69. 
Page 247.

GOUJON F.M., NEBERT D.W. and GIELEN J.E. (1972) Genetic expression of aryl hydrocarbon hydroxylase induction. Mol. Pharmacol. 8:667.

GRAM T.E., GUARINO A.M., SCHRODER D.H. and GILLETTE J.R. (1969)

Changes in certain kinetic properties of hepatic microsomal aniline hydroxylase and ethylmorphine demethylase associated with postnatal development and maturation in male rats. Biochem. J. 113:681.

GREEN D.E., MU G. and KOHOUT P.M. (1955) Studies on the terminal electron transport system. I. Succinate dehydrogenase. J. Biol. Chem. 217:551.

GREENGARD 0. (1971) Enzymic differentiation in mammalian tissues. Essays Bioch. $7: 159$.

GREENLEE W.F. and POLAND A. (1979) Nuclear uptake of $2,3,7,8$-tetrachlorodibenzo-p-dioxin in $\mathrm{C} 57 \mathrm{BL} / 6 \mathrm{~J}$ and $\mathrm{DBA} / 2 \mathrm{~J}$ mice. J. Biol. Chem. $254: 9814$.

GRIECO M.P., HENDRICKS J.D., SCANLON R.A., SINNHUBER R.O. and PIERCE D.A. (1978) Carcinogenicity and acute toxicity of

dimethylnitrosamine in rainbow trout (Salmo gairdneri). J. Natl. Cancer Inst. 60:1127.

GRUGER E.H.Jr., HRUBY. T. and KARRECH N.L. (1976) Sublethal effects of structuraliy related tetrachlor-, pentachlor-, and

hexach lorobiphenyl on juvenile coho salmon. Environ. Sci. Technol. $10: 1033$.

GUENTHNER T.M. and MANNERING G.J. (1977b) Induction of hepatic mono-oxygenase systems in fetal and neonatal rats with phenobarbital, polycyclic hydrocarbons and other xenobiotics. Biochem. Pharmacol. 26:567-575.

GUENTHNER T.M. and MANNERING G.J. (1977b) Induction of hepatic monooxygenase systems of pregnant rats with phenobarbital and 3-methy lcholanth rene. Biochem. Pharmacol. 26:577.

GUENTHNER T.M. and NEBERT D.W. (1978) Evidence in rat and mouse liver for temporal control of 2 forms of cytochrome $P-450$ inducible by $2,3,7,8$-tetrachlorodibenzo-p-dioxin. Eur. J. Biochem. 91:449.

HANSSON T., RAFTER J. and GUSTAFSSON J. (1979) A comparative study on the hepatic in vitro metabolism of 4-androstene-3, 17-dione in the hagfish, Myxine glutinosa, the dogfish, Squalus acanthias, and the rainbow trout, Salmo gairdnerii. Gen. Comp. Endocrin. 37:240.

HANSSON T., RAFTER J. and GUSTAFSSON J. (1980) Effects of some common inducers in the hepatic microsomal metabolism of androstenedione in rainbow trout with special reference to cytochrome $\mathrm{P}-450$ dependent enzymes. Bioch. Pharmacol. 29:583. 
HART S.G., ADAMSON R.H., DIXON R.L. and FOUTS J.R. (1962) Stimulation of hepatic microsomal drug metabolism in the newborn and fetal rabbit. J. Pharmacol. Exp. Therap. 137:103.

HARVEY G. R., MIKLAS H.P., BOWEN V.T. and STEINHAUER W.G. (1974) Observations on the distribution of chlorinated hydrocarbons in At lantic Ocean organisms. J. Mar. Res. 32:103.

HAUGEN D.A. and COON M.J. (1976) Properties of electrophoretically homogeneous phenobarbital inducible and -napthoflavone forms of Liver microsomal cytoch rome P-450. J. Biol. Chem. 251:7929.

HARBISON R. D. (1978) Chemical-biological reactions common to teratogenesis and mutagenesis. Environ. Health Persp. 24: 87.

HE IDELBERGER C. (1975) Chemical carcinogenesis. Ann. Rev. Biochem. $44: 79$.

HENDRICKS J.D., SCANLAN R.A., WILLIAMS J.L., SINNHUBER R.O. AND GRIECO M.P. (1980) Carcinogenicity of $N$-methyl-N'-nitrosoguanidine to livers and kidneys of rainbow trout ( $\mathrm{Sa}$ lmo gairdneri) exposed as embryos. J. Nat 1. Cancer Inst. $64: 1511$.

HILL D.W., HEJTMANICK E., and CAMP B.J. (1976) Induction of hepatic microsomal enzymes by Aroclor 1254 in Ictalurus punctatus (channel catfish). Bul1. Environ. Contam. Toxicol. 16:495-502.

HINTON D.E., KLAUNIG J.E., LIPSKY M.M., JACK R., KAHNG M., SANEFUJI H., JONES R.T. and TRUMP B.F. (1978) Chemical carcinogenes is in fish: Induction of hepatic drug metabolizing enzymes and bacterial mutagenesis with polycyclic aromatic hydrocarbons (PAH). In: "Polynuclear Aromatic Hydrocarbons in the Marine Environment." ( $N$. Richards, ed.). Proceedings of a Conference, Pensacola, Florida, August 1978, U.S. EPA. (In press).

HOLDER G., YAGI H., DANSETTE P., JERMA D.M., LEVIN W., LU A.Y.H. and CONNEY A.H. Effects of the inducers and epoxide hydrase on the metabolism of benzo(a)pyrene by live microsomes and a reconstituted system: analysis by high pressure liquid chromatography. (1974) Proc. Natl. Acad. Sci. U.S.A. 71:4356.

HOLTZMAN J.L., GRAM T.E., GIGON P.L. and GILLETTE J.R. (1968) The distribution of the components of the mixed-function oxidase between the rough and smooth endoplasmic reticulum of liver cells. Biochem. J. 110:407.

HRYCAY E.G. and PROUGH R. (1974) Reduced nicotinamide adenine dinucleotide-cytoch rome $b_{5}$ reductase and cytochrome $b_{5}$ as electron carriers in NADH-supported cytochrome $\mathrm{P}-450$ dependent enzyme activities in liver microsomes. Arch. Bioch. Biophy.
165:331. 
IMAI Y., HORIE S., YAMANO T. and IIZUKA T. (1978) Molecular Properties, Chapter 3. In: "Cytochrome P-450." (R. Sato and T. Omura, eds.). p. 37, Academic Press, New York.

INANO H., MORE K., TAMAOKI B. and GUSTAFSSON J.A. (1976) In vitro metabolism of testosterone in hepatic tissue of a hagfish, Eptatretus burgeri. Gen. Comp. Endocrin. 30:258.

JAKOBSSON S.V. and CINTI D.L. (1973) Studies on the cytochrome P-450 containing monooxygenase system in human kidney cortex microsomes. J. Pharmaco 1. Exp. Therap. 185:226.

JAMES M.O. and BEND J.R. (1978) Effect of polynuclear aromatic hydrocarbons and polyhalogenated biphenyls on hepatic mixed-function oxidase activity in marine fish. In: "Carcinogenic Polynuclear Aromatic Hydrocarbons in the Marine Environment." (N. Richards, ed.). Proceedings of Conference, Pensacola, Florida. August 1978, U.S. EPA (in press).

JAMES M.O. and BEND J.R. (1980) Polycyclic aromatic hydrocarbon induction of cytoch rome $P-450$ dependent mixed-function oxidases in marine fish. Toxicol. Appl. Pharmacol. 54:117.

JAMES M.O., KAHN M.A.Q. and BEND J.R. (1979) Hepatic microsomal mixed-function oxidase activities in several marine species common to coastal Florida. Comp. Biochem. Physiol. 62C:155.

JANSSON I. and SCHENKMAN J.B. (1973) Evidence against the participation of cytoch rome $b_{5}$ in the hepatic microsomal mixed-function oxidase reaction. Mol. Pharmacol. 9:840.

JENSEN S. and SUNDSTROM (1974) Structures and levels of most chlorobiphenyls in two technical $P C B$ products and in human adipose $t$ issue. Ambio $3: 70$.

JERINA D.M. and DALY J.W. (1974) Arene oxides: A new aspect of drug metabolism. Science 185:573.

JOHNSON E.F. (1979) Multiple forms of cytochrome P-450: Criteria and significance. Rev. Bioch. Toxicol. $1: 1$.

JUCHAU M.R., PEDERSEN M.G. and SYMMO K.G. (1972) Hydroxylation of 3,4-benzpyrene in human fetal tissue homogenates. Bioch. Pharmacol. $21: 2269$.

KAHL G.F., FRIEDERICI D.E., BIGELOW S.W., OKEY A.B. and NEBERT D.W. (1980) Ontogenetic expression of regulatory and structural gene products associated with the Ah locus. Dev. Pharmacol. Therap. 137. 
KAIGHN M.E. (1964) A biochemical study of the hatching process in Fundulus heteroclitus. Dev. Biol. 9:56.

KAMATH S.A., KUMMEROW F.A. and NARAYAN K.A. (1971) A simple procedure for the isolation of rat liver microsomes. FEBS Letters 17:90.

KAPITULNIK J., TSHERSHEDSKY M. and BARENHOLZ Y. (1979) Fluidity of the rat liver microsomal membrane: Increase at birth. Science $206: 843$.

KATO R. (1974) Drug Metabolism Review 3:1.

KING H.W.S., OSBORNE M.R., BELAND F.A., HARVEY R.G. and BROOKES P. (1976) ( \pm )-7,8-Dihydroxy-910-epoxy-7,8,9,10-tetrahydrobenzo(a)pyrene is an intermediate in the metabolism and binding to DNA of Benzo(a)pyrene. Proc. Natl. Acad. Sci. U.S. 73:2679.

KITCHIN K.T., SCHMID B.P. and SANYAL M.K. (1981) Teratogenicity of cyclophospamide in a coupled microsomal activating/embryo culture system. Biochem. Pharmacol. 30:59.

KLAAS E.E. and BELISLE A.A. (1977) Organochlorine pesticide and polychlorinated bipheny 1 residues in selected fauna from a New Jersey salt marsh - 1967 vs. 1973. Pesticide Monit. J. 10:149.

KRAMER R.E., GREINER J.W., RUMBAUGH R.C., SWEENEY T.D. and COLBY H.D. (1978) Relation of the gonadal hormones to growth hormone actions on hepatic drug metabolism in rats. J. Pharmacol. Exp. Therap. $204: 247$.

KUENZIG W., KAMM J.J., BOUBLIK M., JENKINS F. and BURNS J.J. (1974) Perinatal drug metabolism and morphological changes in the hepatocytes of normal and phenobarbital-treated guinea pigs. J. Pharmacol. Exp. Therap. 191:32.

KULKARNI A.P., SMITH E. and HODGSON E. (1976) Occurrence and characterization of microsomal cytochrome $P-450$ in several vertebrate and insect species. Comp. Biochem. Physiol. 54B:509.

KUNTZMAN R., LEVIN W., JACOBSON M. and CONNEY A.H. (1968) Studies on microsomal hydroxylation and the demonstration of a new carbon monoxide binding pigment in liver microsomes. Life Sci. 7:215.

KURELEC B., BRETVIC S., RIJAVEC M., MULLER W.E.G. and ZAHN R.K.

(1977) Benzo(a)pyrene monooxygenase induction in marine fish-molecular response to oil pollution. Mar. Biol. 44:211. 
KURELEC B., MATIJASEVIC Z., RIJAVEC M., ALACEVIC M., BRITVIC S., MULLER W.E.G. and ZAHN R.K. (1979) Induction of benzo(a)pyrene monooxygenase in fish and the Salmonella test as a tool for detecting mutagenic/carcinogenic xenobiotics in the aquatic environment. Bull. Environ. Contam. Foxicol. 21:799.

LaFLAMME and HITES (1978) The global distribution of polycyclic aromatic hydrocarbons in recent sediments. Geochim. Cosomochim. Acta $42: 289$.

LAMBERT G.H, and NEBERT D.W. (1977) Genetically mediated induction of drug-metabolizing enzymes associated with congenital defects in the mouse. Teratol. $16: 147-154$.

LEAKEY J. and DUTTON G.J. (1975) Precocious development in vivo of UDP-glucuronyltransferase and aniline hydroxylase by corticosteroids and ACTH, using a simple new "continuous flow" technique. Biochem. Biophys. Res. Commun. 66:250.

LEAKEY J.E.A. and FOUTS J.R. (1978) Effects of hormones on the development of enzymes associated with drug metabolism. Toxicol. Appl. Pharmacol. 45:362.

LEAKEY J.E.A. and FOUTS J.R. (1979) Precocious deve lopment of cytoch rome $P-450$ in neonatal rat liver after glucocorticoid treatment. Biochem. J. 182:233.

LEAKEY J.E.A. and WISHART G.J. (1976) Differential stimulation of monooxygenase and UDP glucuronosyl transferase EC-2,4,1, and 17 activities in chick liver during natural development and after treatment in ovo with corticosterone. Biochem. Soc. Trans. 4:1072.

LIDMAN U., FORLIN L., MOLANDER O, AND AXELSON G. (1976) Induction of the drug metabolizing system in rainbow trout (Salmo gairdnerii) liver by polychlorinated biphenyls (PCBs). Acta Pharmacol. Toxicol. 39:262.

LIPSKY M.M., KLAUNIG J.E. and HINTON D.E. (1978) Comparison of acute response to polychlorinated biphenyl in liver of rat and channel catfish: a biochemical and morphological study. J. Tox. Env. Health $4: 107$.

LLOYD J.W., MOORE R.M., WOOLF B.S, and STEIN H.P. (1976) Polychlorinated biphenyls. J. Occup. Med. 18:109.

LOWRY O.H., ROSEBROUGH N.J., FARR A.L. and RANDALL R.J. (1951) Protein measurement with the folin phenol reagent. J. Biol. Chem. 193:265. 
Page 252.

LU A.Y.H., KUNTZMAN R. and CONNEY A.H. (1976) The liver microsomal hydroxylation enzyme system. Induction and properties of the functional components. In: Frontiers of Gastrointestinal Research V.2 (L. van der Reis, ed.) S. Karger A.G., Basel.

LU A.Y.H. and LEVIN W. (1974a) The resolution and reconstitution of the liver microsomal hydroxylation system. Bioch. Biophy. Acta $344: 205$.

LU A.Y.H. and LEVIN W. (1974b) Liver microsomal electron transport systems III. The involvement of cytochrome b5 in the NADPH-supported cytochrome P-450 dependent hydroxylation of chlorobenzene. Bioch. Biophy. Res. Comm. $61: 1348$.

LU A.Y.H., SOMOGYI A., WEST S., KUNTZMAN R. and CONNEY A.H. Pregnenolone-16 $\alpha$-carbonitrile: A new type of inducer of drug-metabolizing enzymes. Arch. Biochem. Biophys. 152:457.

LU A.Y.H. and WEST S.B. (1972) Reconstituted liver microsomal enzyme system that hydroxylates drugs, other foreign compounds, and endogenous substrates. Mol. Pharmacol. 8:490-500.

LU A.Y.H. and WEST S.B. (1980) Multiplicity of mammalian microsomal cytoch romes P-450. Pharmacol. Rev. 31:277.

LU A.Y.H., WEST S.B., VORE M., RYAN D., and LEVIN W. (1974) Role of cytoch rome $b_{5}$ in hydroxylation by a reconstituted cytochrome P-450 containing system. J. Biol. Chem. 249:6701.

LUCIER G.W., SONAWANE B.R., MCDANIEL O.S. and HOOK G.E.R. (1975) Postnatal stimulation of hepatic microsomal enzymes following administration of TCDD to pregnant rats. Chem. Biol. Interactions $11: 15$.

MacLEOD S.M., RENTON K.W. and EADE N.R. (1972) Development of hepatic microsomal drug-oxidizing enzymes in immature male and female rats. J. Pharm. Exp. Therap. 183:489.

MANCHESTER D.K. and NEIMS A.H. (1977) The effect of birth on the maturation of hepatic cytoch rome(s) P-450 monooxygenase and tyrosine aminotransferase activities in the guinea pig. Biol. Neonate $31: 213$.

MARTZ F., FAILINGER C. and BLAKE D.A. (1977) Phenyltoin teratogenesis: correlation between embryopathic effect and covalent binding of putative arene oxide metabolite in gestational tissue. I. Pha rmacol. Exp. The rap. 203:231.

MATSUBARA T., PROUGH R.A., BURKE M.D. and ESTABROOK R.W. (1974) The preparation of microsomal fractions of rodent respiratory tract and their characterization. Cancer Res. 34:2196. 
MAUGH II T.H. (1975) Chemical pollutants: polychlorinated biphenyls still a threat. Science 190:1189.

MCCORMACK K.M., CAGEN S.Z., RICKERT D.E., GIBSON J.E. and DENT J.G. (1979) Stimulation of hepatic and renal mixed-function oxidase in developing rats by polybrominated biphenyls. Drug Metab. Disp. $7: 252$.

MCDERMOTT-ERLICH D., YOUNG D.R. and HEESEN T.C. (1978) DDT and PCB in flatfish around southern California municipal outfalls. Chemosphere 6:453-461.

McKIM J. M. (1977) Evaluation of tests with early life stages of fish for predicting long-term toxicity. J. Fish. Res. Bd. Can. $34: 1148$.

MILLER J.A. (1970) Carcinogenesis by chemicals: An overview-G.H.A. Clowes Memorial Lecture. Cancer Res. 30:559.

MUKHTAR H., SAHIB M.J. and KIDWAI J.R. (1974) Precocious induction of hepatic aniline hydroxylase and aminopyrine n-demethylase with hydrocortisone in neonatal rat. Biochem. Pharm. 23:345.

MURPHY S.D. (1966) Liver metabolism and toxicity of thiophosphate insecticides in mammalian, avian, and piscine species. Proc. Soc. Exp. Biol. Med. 123:392.

NARBONNE J.F. and GALLIS J.L. (1979) In vivo and in vitro effect of phenoclor DP6 on drug metabolizing activity in mullet liver. Bull. Environ. Contam. Toxicol. 23:338.

NAT IONAL ACADEMY OF SCIENCES (1975) "Petroleum in the Marine Envi ronment." Washington, D.C.

NEBERT D.W. and GELBOIN H.V. (1969) The in vivo and in vitro induction of aryl hydrocarbon hydroxylase in mamalian cells of different species, tissues, strains and developmental and hormonal states. Arch. Biochem. Biophys. 134:76.

NEBERT D.W. and JENSEN N.M. (1979) The Ah locus: Genetic regulation of the metabolism of carcinogens, drugs, and other environmental chemicals by cytoch rome P-450 mediated monooxygenases. CRC Crit. Rev. Bioch. 6:401.

NEBERT D.W., ROBINSON J.R., NIWA A., KUMAKI K. and POLAND A.P. (1975) Genetic expression of aryl hydrocarbon hydroxylase activity in the mouse. J. Cell. Physiol. 85:393.

NEFF J.M. (1979) Polycyclic aromatic hydrocarbons in the aquatic environment. Sources, fates and biological effects. Applied Science Publishers, London. 
NEGISHI M. and KREIBICH G. (1978) Coordinated polypeptide synthesis and insertion of protoheme in cytochrome $\mathrm{P}-450$ during development of endoplasmic reticulum membranes. J. Biol. Chem. 13:4791.

NEIMS A.H., WARNER M., LOUGHNAN P.M. and J.V. ARANDA (1976)

Developmental aspects of the hepatic cytoch rome P-450 monooxygenase system. Ann. Rev. Pharm. Tox. 16:427.

NEWBOLD, R.F. and BROOKES P. (1976) Exceptional mutagenicity of benzo(a)pyrene diol epoxide in cultured mamalian cells. Nature $261: 52$.

NISBET I.C.T. and SAROFIN A.F. (1972) Rates and routes of transport of PCB's in the environment. Environ. Health Perspect. 1:21.

NORMAN R.L., JOHNSON E.F. and MULLER-EBERHARD U. (1978) Identification of the major cytochrome $\mathrm{P}-450$ form transplacentally induced in neonatal rabbits by

2,3,7,8-tetrachlorodibenzo-p-dioxin. J. Biol. Chem. 253:8640.

OKEY A.B., BONDY G.P., MASON M.E., KAHL G.F., EISEN H.J., GUENTHNER T.M. and NEBERT D.W. (1979) Regulatory gene product of the Ah locus. Characterization of the cytosolic inducer receptor complex and evidence for its nuclear translocation. J. Biol. Chem. $254: 11636$.

OLIVER I.T. (1974) Developmental enzymology. In: "Concepts of Development." (J. Lash and J.R. Whittaker, eds.) Sinauer Associates, Stamford, Conn.

OMURA T. and SATO R. (1964) The carbon monooxide-binding pigment of liver microsomes. I. Evidence for its hemoprotein nature. J. Biol. Chem. 239:2370.

OPPENHEIMER J.M. (1937) The normal stages of Fundulus heteroclitus. Anatom. Rec. $68: 1$.

ORRENIUS S., ERICSSON J.L.E. and ERNSTER L. (1965) Phenobarbital-induced synthesis of the drug metabolizing enzyme system and its relationship to the proliferation of endoplasmic membranes: A morphological and biochemical study. J. Cell Biol. $25: 627$.

PANCIROV R.J. and BROWN R.A. (1977) Polynuclear aromatic hydrocarbons in marine tissues. Env. Sci. Tech. 11:989.

PARKINSON A., COCKERLINE R. and SAFE S. (1980a) Polychlorinated bipheny $l$ isomers and congeners as inducers of both 3-methyl-cholanthrene and phenobarbitone-type microsomal enzyme activity. Chem.-Biol. Inter. 29:277. 
PARKINSON A., ROBERTSON L, SAFE L and SAFE S. (1980b) Polychlorinated biphenyls as inducers of hepatic microsomal enzymes: structure-activity rules. Chem.-Biol. Inter. 30:271.

PAYNE J.F. (1976) Field evaluation of penzopyrene hydroxylase induction as a monitor for marine pollution by petroleum. Science $191: 945$.

PAYNE J.F., MARTINS I. and RAHIMTULA A. (1979) Crankcase oils: are they a major mutagenic burden in the aquatic environment? Science $200: 329$.

PAYNE J.F. and PENROSE W.R. (1975) Induction of aryl hydrocarbon (benzo(a)pyrene) hydroxylase in fish by petroleum. Bull. Envir. Contam. Tox. 14:112.

PEDERSON M.G., HERSHBERGER W.K. and JUCHAU M.R. (1974) Metabolism of 3,4-benzola]pyrene in rainbow trout (Salmo gairdnerii). Bull. Environ. Contam. Tox. 12:481.

PEDERSON M.G., HERSHBERGER W.K., ZACHARIAH P.K. and JUCHAU M.R. (1976) Hepatic biotransformation of environmental xenobiotics in six strains of rainbow trout (Salmo gairdneri). J. Fish. Res. Board Can. 33:666.

PEZZUTO J.M., YANG C.S., YANG S.K., MCCOURT D.W. and GELBOIN H.V. (1978) Metabolism of benzo(a)pyrene and (-)-trans-7,8-dihydroxy-7,8-dihydrobenzo(a)pyrene by rat liver nuclei and microsomes. Cancer Res. $38: 1241$.

PHILLIPS A.H. and LANGDON R.G. (1962) Hepatic triphosphopyridine nucleotide-cytoch rome c reductase: Isolation, characterization, and kinetic studies. J. Biol. Chem. 237:2652.

PHILPOT R.M. AND ARINC E. (1975) Solubilization, separation and partial purification of cytoch rome $P-450$ and cytochrome b5 from hepatic microsomes of the little skate Raja erinacea. Bull. Mt. Desert Is. Biol. Lab. 15:62.

PLISS G.B. and KHUDOLEY V.V. (1975) Tumor induction by carcinogenic agents in aquarium fish. J. Nat 1. Cancer Inst. 55:129.

POHL R.J., FOUTS J.R. and BEND J.R. (1975) Responses of microsomal mixed-function oxidases in the little skate, Raja erinacea, and the winter flounder, Psuedopleuronectes americanus, to pretreatment with $\operatorname{TCDD}(2,3,7,8$-tetrachlorodibenzo-p-dioxin) or DBA $(1,2,3,4-$ dibenzanth racene $)$. Bull. Mt. Desert Is. Biol. Lab. 15:64. 
POLAND A. and GLOVER E. (1974) Comparison of $2,3,7,8$-tetrachlorodibenzo-p-dioxin, a potent inducer of ary 1 hydrocarbon hydroxylase with 3-methycholanthrene. Mol. Pharmacol. $10: 349$.

POLAND A. and GLOVER E. (1975) Genetic expression of aryl hydrocarbon hydroxylase by $2,3,4,7$-tetrachlorodibenzo-p-dioxin: Evidence for a receptor mutation in genetically nonresponsive mice. Mol. Pharmaco1. 11:389.

POLAND A. and GLOVER E. (1977) Chlorinated biphenyl induction of aryl hydrocarbon hydroxylase: A study of the structure activity relationship. Mol. Pharmacol. 13:924.

POLAND A., GLOVER E. and KENDE A.S. (1976) Stereospecific high affinity binding of $2,3,7,8$-tetrachlorodibenzo-p-dioxin by hepatic cytosol: Evidence that the binding species is receptor for induction of aryl hydrocarbon hydroxylase. J. Biol. Chem. 251:4936.

POLAND A.P. and NEBERT D.W. (1973) A sensitive radiometric assay of aminopyrine n-demethylation. J. Pharm. Exp. Therap. 184:269.

POWIS G., DRUMMOND A.H., MacINTYRE D.E. and JONDORF W.R. (1976) Development of liver microsomal oxidations in the chick. Xenobiotica $6: 69$.

RANE A., BERGGREN M., YAFFE S. and ERICSSON J.L.E. (1973) Oxidative drug metabolism in the perinatal rabbit liver and placenta. Xenobiotica $3: 37$.

RASMUSSEN R.E. and WANG I.Y. (1974) Dependence of specific metabolism of benzo(a)pyrene on the inducer of hydroxylase activity. Cancer Res. 34:2290.

RIFKIND A.B., GILLETTE P.N., CHULL S.S. and KAPPAS A. (1973) Drug stimulation of $\mathcal{S}$-aminolevulinic acid synthetase and cytochrome P-450 in vivo in chick embryo liver. J. Pharmacol. Exp. Therap. $185: 214$.

RIFKIND A.B., TROEGER M. and PETSCHKE T. (1979) Equality of the rates of mixed-function oxidation in livers of male and female chick embryos. Biochem. Pharmacol. 28:1681.

RIFKIND A.B., TSENG L., HERSCH M.B. and LAUERSEN N.H. (1978) Aryl hydrocarbon hydroxylase activity and microsomal cytoch rome content of human fetal tissues. Cancer Res. 38:1572.

RISEBROUGH R.W. and DeLAPPE B. (1972) Accumulation of polychlorinated biphenyls in ecosystems. Environ. Health Perspect. No. 139. 
ROSE K.J. (1980) Children of Poseidon. Omni, July.

ROSENTHAL H. and ALDERDICE D.F. (1976) Sublethal effects of environmental stressors, natural and pollutional on marine fish eggs and Larvae. J. Fish. Res. Bd. Can. 33: 2 vi47.

RUGH R. (1964) "Vertebrate Embryology" Chapter 6, p. 237. Harcourt, Brace and World, Inc., New York.

RYAN D.E., THOMAS P.E., KORZENIOWSKI D. and LEVIN W. (1979) Separation and characterization of highly purified forms of liver microsomal cytochrome $\mathrm{P}-450$ from rats treated with polychlorinated bipheny 1s, phenobarbital and 3-methylcholanthrene. J. Biol. Chem. $254: 1365$.

SATO R. and OMURA T. (1978) "Cytochrome P-450." Academic Press, New York.

SCHENKMAN J.B., JANSSON I. and ROBIE-SUH K.M. (1976) The many roles of cytochrome by in hepatic microsomes. Life Sci. 19:611.

SCHOENTAL R. (1974) Carcinogenicity as related to age. Ann. Rev. Pharm. Tox. $14: 185$.

SCHWAB G.E., NORMAN R.L., MULLER-EBERHARD U. and JOHNSON E.F. (1980) Identification of the form of cytochrome $P-450$ induced in neonatal rabbit liver microsomes by phenobarbital. Mol. Pharm. 17:218.

SELKIRK J.K., CROY R.G., ROLLER P.P. and GELBOIN H.V. (1974) High-pressure liquid chromatographic analys is of benzola]pyrene metabolism and covalent binding and the mechanism of action of 7,8-benzoflavone and 1,2-epoxy-3,3,3-trichloropropane. Cancer Res. $34: 3474$.

SELKIRK J.K., CROY R.G. and GELBOIN H.V. (1976) High pressure liquid chromatographic separation of 10 benzo[a]pyrene phenols and the identification of 1 -phenol and 7-phenol as new metabolites. Cancer Res. 36:922.

SHORT C.R. and DAVIS L.E. (1970) Perinatal development of drug-metabolizing enzyme activity in swine. J. Pharmacol. Exp. Therap. 174:185.

SHORT C.R., KINDEN D.A. and STITH R. (1976) Fetal and neonatal development of the microsomal monooxygenase system. Drug Metab. Rev. $5: 1$.

SHORT C.R. and STITH R. (1973) Perinatal development of hepatic microsomal mixed function oxidase activity in swine. Bioch. Pharm. 22:1309. 
SHUM S., JENSEN N.M. and NEBERT D.W. (1979) The murine Ah locus: In utero toxicity and teratogenesis associated with genetic differences in benzo(a)pyrene metabolism. Teratology 20:365.

SINNHUBER R.O., WALES J.H., AYRES J.L., ENGEBRECHT R.H. and AMEND D.L. (1968) Dietary factors and hepatoma in rainbow trout (Salmo gairdneri). I. Aflatoxins in vegetable protein feedstuffs. J. Nat 1. Cancer Inst. 41:711.

SISSONS D. and WELTI D. (1971) Structural identification of polychlorinated biphenyls in commercial mixtures by gas-liquid ch romatography, nuclear magnetic resonance and mass spectrometry. J. Chromatogr. $60: 15$.

SMITH S. (1957) Early development and hatching. In: The physiology of fishes, ed. by M.E. Brown, Vol. 1. 323-359. Academic Press, New York.

SPAGNOLI J.J. and SKINNER L.C. (1977). PCB's in fish from selected waters of New York State. Pesticide Monit. J. 11:69.

STAUFFER T.M. (1979) Effects of DDT and PCBs on survival of lake trout eggs and fry in a hatchery and in Lake Michigan, 1973-1976. Trans. Am. Fish. 108:178-186.

STATHAM C.N., SZYJKA S.P., MENAHAN L.A. and LECH J.J. (1977) Fractionation and subcellular localization of marker enzymes in rainbow trout liver. Biochem. Pharmacol. 26:1395.

STEGEMAN J.J. (1978) Influence of environmental contamination on cytoch rome $P-450$ mixed-function oxygenases in fish: implications for recovery in the Wild Harbor Marsh. J. Fish. Res. Bd. Can. $35: 668$.

STEGEMAN J.J. (1979) Temperature influence on basal activity and induction of mixed function oxygenase activity in Fundulus heteroclitus. J. Fish. Res. Board Can. 36:1400.

STEGEMAN J.J. (1980) Cytoch rome P-450 and benzo(a)pyrene metabolism in cardiac tissue of the marine fish Stenotomus versicolor. Pharmacologist 20:248.

STEGEMAN J.J. (1981a) Unpublished data - personal communication.

STEGEMAN J.J. (1981b) Polynuclear aromatic hydrocarbons and their metabolism in the marine environment. In: "Polycyclic Aromatic Hydrocarbons and Cancer." (H.V. Gelboin and P.O.P. Ts'o, eds.). Academic Press, New York. 
STEGEMAN J.J. AND BINDER R.L. (1979) High benzo(a)pyrene hydroxylase activity in the marine teleost $\mathrm{f}$ ish Stenotomus versicolor. Biochem. Pharmacol. $28: 1686$.

STEGEMAN J.J., BINDER R.L. and ORREN A. (1979) Hepatic and extrahepatic microsomal electron transport components and mixed-function oxygenases in the marine fish Stenotomus versicolor. Biochem. Pharmacol. 28:3431.

STEGEMAN J.J. and CHEVION M. (1980) Sex differences in cytoch rome $\mathrm{p}-450$ and mixed-function oxygenase activity in gonadally mature trout. Biochem. Pharmacol. 28:553.

STEGEMAN J.J., SKOPEK T.R. and THILLY W.G. (1978) Bioactivation of polynuclear aromatic hydrocarbons to cytotoxic and mutagenic products by marine fish. In: "Carcinogenic Polynuclear Aromatic Hydrocarbons in the Marine Environment." (N. Richards, ed.). Proceedings of Conference, Pensacola, Florida, August 1978, U.S. EPA (in press).

STEGEMAN J.J. and WOODIN B.R. (1980) Patterns of benzo(a)pyrene metabolism in liver of the marine fish Stenotomus versicolor. Fed. Proc. 39:1752.

SUGIYAMA, T., MIKI N. and YAMANO T. (1979) The obligatory requirement of cytoch rome $b_{5}$ in the $p$-nitroanisole o-demethylation reaction catalyzed by cytoch rome $\mathrm{P}-450$ with a high affinity for cytochrome b5. Biochem. Biophys. Res. Commun. 90:715.

THO RGEIRSSON S.S., ATLAS S.A., BOOBIS A.R. and FELTON J.S. (1979) Species differences in the substrate specificity of hepatic cytoch rome $\mathrm{P}-448$ from polycyclic hydrocarbon-treated animals. Biochem. Pharmaco 1. 28:217.

THO RGEIRSSON S.S. and NEBERT D.W. (1977) The Ah locus and the metabolism of chemical carcinogens and other foreign compounds. Adv. Cancer Res. 24:149.

TJESSUM K. and STEGEMAN J.J. (1979) Improvement of reverse-phase high pressure liquid chromatographic resolution of benzola]pyrene metabolites using organic amines: application to metabolites produced by fish. Ana l. Biochem. 99:129-135.

TREDGER J.M. and CHHABRA R.S. (1980) Factors affecting the properties of mixed function oxidases in the liver and small intestine of neo-natal rabbits. Drug Metab. Disp. 8:16.

TRINKAUS, J.P. (1967) Fundulus. In: "Methods in Developmental Biology." (F.H. Wilt and N.K. Wessells) Thomas Crowell, New York. 
VAINIO H. (1974) Enhancement of microsomal drug oxidation and glucuronidation in rat liver by an environmental chemical polychlorinated biphenyl. Chem. Biol. Int. 9:379.

VanCANFORT J., DeGRAEVE J. and GIELEN J.E. (1977) Radioactive assay for aryl hydrocarbon hydroxylase. Improved method and biological import ance. Biochem. Biophys. Res. Commun. 79:505.

VALIELA I., WRIGHT J.E., TEAL J.M. and VOLKMANN S.B. (1977) Growth, production and energy transformation in the salt marsh killifish Fundulus heteroclitus. Mar. Biol. 40:135.

VARANASI U. and GMUR D.J. (1980) Metabolic activation and covalent binding of benzo(a)pyrene to deoxyribonucleic acid catalyzed by liver emzymes of marine fish. Biochem. Pharmacol. 29:753.

VARANASI U., GMUR D.J. and KRAHN M.M. (1980) Metabolism and subsequent binding of benzo(a)pyrene to DNA in pleuronectid and salmonid fish. In: Polynuclear Aromatic Hydrocarbons: Fourth International Symposium on Analysis, Chemistry and Biology." (A. Bjorseth, ed.). p. 455. Battelle Press, Colombus, Ohio.

VEITH G.D., KUEHL D.W., LEONARD E.N.; PUGLISI F.A. and LEMKE A.E. (1979) Polychlorinated biphenyls and other organic chemical residues in fish from major watersheds of the United States, 1976. Pesticide Monit. J. 13:1.

VERNIER J. and SIRE M. (1976) Evolution of the glycogen content and of glucose-6-phosphatase activity in the liver of Salmo gairdneri during development. Tiss. Ce11 3:531-546.

VOS,J.G., KOEMAN J.H. and van der MAAS M.C. (1970) Identification and toxicological evaluation of chlorinated dibenzofuran and chlorinated napthalene in two commercial polychlorinated biphenyls. Fd. Cosmet. Tox. 8:625.

WALES J.H., SINNHUBER R.O., HENDRICKS J.D., NIXON J.E. and EISELE T.A. (1978) Alfatoxin $B_{1}$ induction of hepatocellular carcinoma in the embryos of rainbow trout (Salmo gairdneri). J. Nat1. Cancer Inst. $60: 1133-1139$

WALTON D.G., PENROSE W.R. and GREEN J.M. (1978) The petroleum inducible mixed-function oxidase of cunner: some characteristics relevant to hydrocarbon monitoring. J. Fish. Res. Board Can. $35: 1547$.

WASSERMANN M., WASSERMANN D., CUCOS S. and MILLER H.J. (1979) WorId PCBs map: Storage and effects in man and his biologic environment in the 1970's. Ann. N.Y. Acad. Sci. 320:69. 
WEBB R.G. and MCCALL A.C. (1972) Identities of polychlorinated biphenyl isomers in Aroclors. J. Ass. Off. Anal. Chem. 55:746.

WE INSTE IN I.B., JEFFREY A.M., JENNETTE K.W., BLOBSTEIN S.H., HARVEY R.G., HARRIS C., AUTRUP H., KASAI H. and NAKANISHI K. (1976) Benzo(a)pyrene diol epoxides as intermediates in nucleic acid binding in vitro and in vivo. Science 193:592.

WE ISBURGER E.K. (1978) Mechanisms of chemical carcinogenesis. Ann. Rev. Pharm. Tox. $18: 395$.

WELCH R.M., GOMMI B., ALVARES A. and CONNEY A.H. (1972) Effect of enzyme induction on the metabolism of benzo(a)pyrene and $3^{\prime}$-methy 1-4-monomethy laminoazobenzene in the pregnant and fetal rat. Cancer Res. 32:973.

WEST S.B. and LU A.Y.H. (1977) Liver microsomal electron transport systems: Properties of a reconstituted, NADH-mediated benzo(a) pyrene hydroxylation system. Arch. Bioch. Biophy. 182:369.

WIEBEL F.J., LEUTZ J.C., DIAMOND L. and GELBOIN H.V. (1971) Hydrocarbon benzo(a) pyrene hydroxylase in microsomes from rat tissues: differential inhibition and stimulation by benzoflavones and organic solvents. Arch. Biochem. Biophys. 144:76.

WILSON J.T. (1970) Alteration of normal development of drug metabolism by injection of growth hormone. Nature 225:861.

WILSON J.T. and FROHMAN L.A. (1974) Concomitant association between high plasma levels of growth hormone and low hepatic mixed-function oxidase activity in the young rat. I. Pharmacol. Exp. Therap. $189: 255$.

WINER B.J. (1971) "Statistical Principles in Experimental Design." Pp. 26-37. McGraw-Hill, New York.

WISHART G.J. and DUTTON G.J. (1975) Precocious development of glucuronidating and hydroxylating enzymes in chick embryos treated with pituitary grafts. Biochem. J. 152:325.

WISLOCKI P.G., WOOD A.W., CHANG R.L., LEVIN W., YAGI H., HERNANDEZ 0., JERINA D.M. and CONNEY A.H. High mutagenicity and toxicity of a diol epoxide derived from benzo(a)pyrene. Biochem. Biophys. Res. Commun. 68:1006.

WSZOLEK P.C. and LISK D.J. Persistence of polychlorinated biphenyls and 1,1 -dichloro-2,2-bis ( $p$-chloropehyl)ethylene ( $\left.p, p^{\prime}-D D E\right)$ with age in lake trout after 8 years. Environ. Sci. Technol. 13:1269-1271. 
YANG S.K., DEUTSCH J. and GELBOIN H.V. (1978) Benzo(a)pyrene metabolism: activation and detoxification. In: "Polycyclic Hydrocarbons and Cancer, Vol. 1, Environment, Chemistry, and Metabolism." (H.V. Gelboin and P.O.P. Ts'O, eds.). Academic Press, N.Y.

YANG S.K., SELKIRK J.K., PLOTKIN E.V. and GELBOIN H.V. (1975) Kinetic analysis of the metabolism of benzo(a)pyrene to phenols, dihydrodiols, and quinones by high pressure liquid chromatography compared to analysis of AHH assay, and the effect of enzyme induction. Cancer Res. 35:3642.

YARBROUGH J.D. and CHAMBERS J.E. (1977) Crude oil effects on microsomal mixed-function oxidase system components in the striped mullet (Mugil cephalus). Life Sci. 21:1095. 


\section{BIOGRAPHT TAL NOTE}

I was born in Brooklyn, N.Y. in 1950 and grew up in Huntington, N.Y. I graduated from Walt Whitman H.S., Huntington in 1968. Senior year in high school I was awarded the Bausch and Lomb Science Medal. I was an honors major in biochemistry at the University of Pennsylvania, and graduated cum laude with a bachelors degree in 1972. After graduation I worked as a research laboratory technician at the Penn Medical School for three years. I was employed by ULf Nilsson in the Dept. of Medicine, Allergy-Immunology Section, and later by Leonard Warren in the Department of Therapeutic Research. During 1974, I spent a summer working at the Marine Biological Laboratory in Woods Hole with Leonard Warren. I entered the Joint Program in 1975 and took the core curriculum in toxicology in the Department of Food and Nutrition at MIT.

\section{Publications :}

BINDER R.L. and STEGEMAN J.J. (1980) Induction of aryl hydrocarbon hydroxylase in embryos of an estuarine $f$ ish. Biochem. Pharmacol. $29: 949$.

STEGEMAN J.J., BINDER R.L. and ORREN A. (1979) Hepatic and extrahepatic microsomal electron transport components and mixed function oxygenases in the marine fish Stenotomus versicolor. Biochem. Pharmacol. 28:3431.

STEGEMAN J.J. and BINDER R.L. (1979) High benzo(a)pyrene hydroxylase activity in the marine fish Stenotomus versicolor. Biochem. Pharmacol. $28: 1686$.

JAIN R.S., BINDER R.L., LEVY-BENSHIMAL A., BUCK C.A. and WARREN L. (1977) Purification of $\alpha$-L-fucosidase from various sources by affinity ch romatography. J. Chromatog. 139:283.

JAIN R.S., BINDER R.L., WALZ C., BUCK C.A. and WARREN L. (1977)

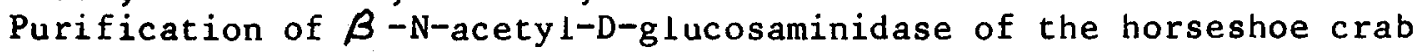
by affinity chromatography. J. Chromatog. 136:14l. 